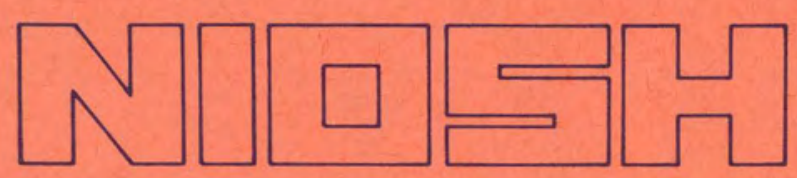

TECHNICAL REPORT

\title{
Respiratory and Immunologic Evaluation of Isocyanate \\ Exposure in a New Manufacturing Plant
}

U.S. DEPARTMENT OF HEALTH AND HUMAN SERVICES

Public Health Service

Centers for Disease Control

National Institute for Occupational Safety and Health 
Respiratory and Immunologic Evaluation of Isocyanate Exposure in a New

Manufacturing Plant

\author{
Hans Weill, M.D. \\ Brian Butcher, Ph.D. \\ Venkatram Dharmarajan, Ph.D. \\ Henry Glindmeyer, D.Eng. \\ Robert Jones, M.D. \\ Jean Carr, M.S.H. \\ Carol O'Neil, M.S. \\ John Salvaggio, M.D. \\ Tulane University School of Medicine \\ New Orleans, Louisiana
}

NIOSH Contract No. 210-75-0006
U. S DEPARTMENT OF HEALTH AND HUMAN SERVICES
Public Health Service
Centers for Disease Control
Nationa1 Institute for Occupational Safety and Health
Division of Respiratory Disease Studies
Morgantown, West Virginia

June 1981

For nale by the Superintendent of Documents, U.S, Government

Printing Office, Washington, D.C. 20402 


\section{DISCLAIME R}

Mention of company names or products does not constitute endorsement by the National Institute for Occupational Safety and Health。

NIOSH Project Officer: James A. Merchant, M.D., Dr. P.H.
Principal Investigator: Hans Weili, M.D.

DHHS (NIOSH) Publication No. 81-125 


\section{ABSTRACT}

In April, 1973, pre-exposure (baseline) information was obtained on 168 workers who were to begin manufacturing toluene dilsocyanate (TDI) in four months. None of these workers had prior exposure to TDI. Subsequent follow-up in this longitudinal investigation was five and one-half years in length, during which time eight additional visits were made to the manufacturing site. At each of visits 2, 3, 4 and 5, approximately 25 participants were added to the study population, bringing the total size of the study population to 277. The added participants had no more than 11 months of TDI exposure prior to inclusion in the study.

Exposure to TDI vapor was determined by personal monitors utilizing the paper tape stain method for continuous 8-hour measurement. The approximately 2,000 personal samples collected had median 8-hour time-weighted averages of $.002 \mathrm{ppm}$. The $25 \mathrm{th}$ and $75 \mathrm{th}$ percentiles were .0011 and .0036 respectively. Percentage of time above $.02 \mathrm{ppm}$, the current threshold limit value, averaged $3 \%$ in these personal samples. All members of the study population had some degree of TDI exposure, which depended on both job and location. No systematic trends in exposure were observed over the course of the study.

Detailed job histories allowed for the construction of cumulative exposure as a product of concentration and time. Cumulative exposure was used to define two exposure categories (division point $=.0682 \mathrm{ppm}$-months) with the low category chosen to represent the exposure received by a worker who spent the full follow-up period in a group of jobs (median 8-hour timeweighted average $=.0011 \mathrm{ppm}$ ) with the lowest TDI concentration.

Pulmonary function annual changes for spirometric measurements, lung volumes and diffusing capacities were computed for each participant as the slope of the least squares straight line using time as the independent variable.

The average annual decline of $\mathrm{FEV}_{1}$ was $24 \mathrm{ml}$ per year, comparable to that expected on the basis of cross sectional studies of "normal" populations. Average annual declines of $\mathrm{FEF}_{25-75}$ and $\mathrm{FEF}_{50}$ were 93 and $110 \mathrm{ml}$, larger than expected on the basis of cross sectional data. Average annual declines for single breath carbon monoxide diffusing capacity and the diffusion constant (K) were also larger than expected on the basis of cross sectional results.

After controlling for pack years of smoking and atopic status, $\mathrm{FEV}_{1}$, FEV\% and $\mathrm{FEF}_{25-75}$ annual declines were significantly related to the TDI exposure categories. Lung volume and diffusing capacity annual change was not related to TDI exposure. 
The effect of TDI exposure on $\mathrm{FEV}_{1}$ annual change was manifest primarily in those who never smoked cigarettes; its effect in smokers may be masked by smoking. In the never smokers, there was a $38 \mathrm{ml}$ per year $(\mathrm{p}=.001)$ difference between the low and high exposure categories. Among current smokers there was no observed effect of TDI. In the low exposure category, there was a $27 \mathrm{ml}$ per year $(\mathrm{p}=.004)$ difference between never and current cigarette smokers. This difference is comparable to the effect of TDI in the never smokers. Current smokers averaged 18 pack years of smoking. Never smokers in the low exposure group had an average annual increase in $\mathrm{FEV}_{1}$ of $1 \mathrm{ml}$ per year.

TDI exposure as determined by cumulative dose and peak exposure as measured by time spent above $0.02 \mathrm{ppm}$ correlated equally well with annual change in pulmonary function.

Clinically important bronchial hypersensitivity to TDI developed in $4.3 \%$ of the study population. A number of these workers were shown to develop bronchoconstriction in the laboratory following inhalation challenge using a maximum concentration of $0.02 \mathrm{ppm}$ TDI. Half of the TDI reactors had been exposed to high levels during a spill or equipment malfunction. $75 \%$ of the reactors became symptomatic within seven months of first exposure to TDI. Some TDI reactors have failed to attain pre-exposure or pre-sensitization values of $\mathrm{FEV}_{1}$ or $\mathrm{FEF}_{25-75}$ despite transfer to other areas of the chemical complex. Neither atopy nor smoking served to identify persons at higher risk of developing TDI reactivity.

TDI at certain concentrations acts as a partial agonist on 1ymphocytes to stimulate cyclic adenosine monophosphate (AMP) levels. At lower concentrations, it can block cyclic AMP stimulation by isoproterenol and prostaglandin $\mathrm{E}_{1}$ but not histamine. Lymphocytes of TDI sensitive individuals have decreased ability to respond to cyclic AMP stimuli such as beta agonists, isoproterenol, prostaglandin $\mathrm{E}_{1}$ and TDI.

RAST with p-toly1 isocyanate conjugated to human serum albumin only detects tolyl specific IgE antibodies in the serum of $15-18 \%$ of subjects proven by provocative inhalation challenge to be TDI reactive. This demonstrates that the presence of tolyl specific serum IgE antibodies cannot be used to diagnose clinical sensitivity to TDI.

All other humoral or cellular indicators of immunologic sensitization were non-revealing. 


\section{TABLE OF CONTENTS}

I. Introduction

II. Study Design and Protocols 3

III. TDI Exposure Indices 8

A. Cumulative Exposures 9

B. Time Above .02 PPM 11

C. Assignment of Exposure Indices for 11 Correlation Studies

IV. Longitudinal Results and Analysis 12

A. Introduction 12

B. Spirometry Results 15

C. Diffusion and Long Volume 20

D. Respiratory Symptoms 20

E. Immunology 23

F. Detailed Analysis of $\mathrm{FEV}_{1}$ Slope 23

V. TDI Reactors 29

A. Clinical and Epidemiologic Features 29

B. Immunologic Findings 30

C. Provocative Inhalation Challenge with TDI 31

D. Challenge Testing with Methacholine Chloride 31 (Mecholy1)

E. Study of the Effect of Pretreatment with 32 Disodium Cromoglycate

F. Lymphocyte Transformation and Leukocyte 32 Histamine Release

G. Lymphocyte cAMP Dose Response Studies 


\section{TABLE OF CONTENTS \\ (Continued)}

Page Number

V. H. Plasma Histamine Levels 33

I. Determination of Serum Complement and 33

Split Products of Complement

J. Loss of TDI and Methacholine Reactivity 34

after Removal from Isocyanate Exposure

Isocyanate Reactivity

L. Toly1-specific IgE Antibodies in Serum

of TDI Reactive Individuals

VI. Conclusions

Appendix 1 - Environmental Characterization

Appendix 2 - Statistical Considerations 48

Appendix 3 - Interview Forms, Symptom Criteria 59 and Edtorial Programs

References

Tables

Figures

Reprints 


\section{INTRODUCTION}

The construction of a new plant in Southwestern Louisiana for production of toluene difsocyanate (TDI) with start of operation late in 1973 led to a proposal by the National Institute of Occupational Safety and Health (NIOSH) to the investigators for a longitudinal study of respiratory health of the workers who would be exposed to TDI. The ability to begin the study prior to the start of TDI production presented the unique opportunity of obtaining pre-exposure biologic data on the study population. The proposed investigation had the full agreement and cooperation of the major chemical company operating this plant and its labor representatives.

It has been known for two decades that reversible afrways obstruction develops in a small proportion of workers exposed to isocyanate vapors, either during manufacture or application processes. In addition to the recognition of the risk for developing this form of occupational asthma, there had been a suggestion that chronic progressive fixed alrways obstruction was detected in an exposed population and was not related to "sensitiv1ty", but rather was a general effect of TDI exposure.

This multi-disciplinary investigation addressed the following scientific questions:

(1) What are the characteristics of plant airborne TDI concentrations, particularly in terms of average exposures, as well as variation in short term concentrations (peaks)? This was first assessed by area monitoring using a physico-chemical method for continuous monitoring developed In the United Kingdom and Introduced Into this Investigation by the princlpal investigator resulting in its first research or other application in the United States. During the course of the contract, personal sampling for continuous airborne concentrations of TDI vapor was similarly initlated and formed the basts for the comprehensive personal exposure profiles in these manufacturing workers detailed in this report.

(2) What proportion of exposed workers become reactive to TDI vapor following exposure, what are the temporal relationships between inftial exposure and such reactivity, and what are the clinical manifestations in the reactive group?

(3) Are there host factors which w111 serve to 1dentify those individuals who are susceptible to TDI exposure and develop the clinical plcture of occupational asthma as the result of such exposure? 
(4) Can the physiologic consequences (bronchoconstriction) of exposure in susceptible workers be reproduced in the laboratory by bronchoprovocation; and what are the physlologic, immunologic and exposure characteristics of such a reproduced bronchoconstrictor response?

(5) What is the mechanism of TDI induced asthma? Is it immunologic or non-immunologic?

(6) Is there a generalized adverse effect on respiratory function in the exposed working population, and if so, what are its determinants (e.g., host factors, level of exposure)?

(7) Is the airways obstruction which results from development of TDI reactivity reversible in all instances, or are there permanent residual effects which are measurable by follow-up serial ventilatory function studies? If permanent changes occur in some reactive Individuals, what are the determinants of such irreversibility?

(8) Does development of TDI reactivity lead to a general (nonspecific) bronchial hyperresponsiveness?

(9) What are the dose-response relationships of any acute or chronic respiratory effects identified in this exposed population as determined either by the longitudinal fleld survey or bronchoprovocation testing?

(10) Are there levels of exposure which are not associated with any acute or chronic adverse respiratory health effects?

(11) Are there measurements, either physiologic, immunologic or other which are likely to be useful in identifying workers who may have a high risk of developing TDI reactivity prior to or during the course of their exposure?

(12) What is the course of spectfic and non-spectfic bronchial hyperresponsiveness following removal of the susceptible worker from exposure?

As the reader of this report will appreclate, considerable information impacting on the above questions has been obtained in this five-year investigation. However, our knowledge concerning TDI-Induced respiratory health effects is by no means complete and several issues require additional scientific inquiry for their resolution. 


\section{STUDY DESIGN AND PROTOCOLS}

As originally conceived, the study design sought to compare three TDI exposure categories with respect to the longitudinal course of respiratory symptoms, spirometric measurements, lung volumes and diffusing capacity. Initial measurements were made prior to TDI production (and exposure) enab1ing an individual to serve as $\mathrm{his} / \mathrm{her}$ own control. The three exposure categories were (1) TDI production workers in daily contact with the chemical, (2) workers (primarily maintenance personne1) with intermittent TDI contact, and (3) controls employed outside the TDI production area. In April of 1973, prior to the beginning of TDI production, 168 workers were administered a modified British Medical Research Council questionnaire. It was used to gather smoking histories and to determine presence or absence of (1) upper respiratory symptoms, (2) lower respiratory symptoms, and (3) bronchitis (see longltudinal symptom analysis section for definitions). In addition, the 168 individuals underwent spirometric testing and determination of lung volumes and diffusing capacities.

of the original 168 participants, 49 had left the plant (two died and 47 either were fired or laid off, retired, quit, or transferred away from the plant) by the last visit in October of 1978. This corresponds to a dropout rate of $4.22 \%$ per visit. In addition to the 49 participants of the original 168 who had left the plant by the last visit, 19 refused to perform forced expirations at the last vistt. The decrease from 168 to 100 participants at the final visit corresponds to a dropout rate of $6.28 \%$ per visit.

The manufacturing site was visited a second time in November, 1973, at which time pre- and post-shift spirometric testing was performed. No relationship between pre- and post-shift decline and TDI exposure was observed. Subsequent visits have totaled 7: September, 1974 (spirometry, lung volumes, and diffusion); March, 1975 (spirometry); October, 1975 (spirometry, 1ung volumes, and diffusion); March, 1976 (spirometry); November, 1976, December, 1977 (spirometry, lung volumes, and diffusion); and October, 1978 (spirometry and lung volumes). A respiratory health questionnaire was administered at each of the follow-up visits. Change in symptom status was assessed by comparing the initial visit status with that on the last avallable questionnaire provided it was administered at one of the last three visits.

As the follow-up period lengthened, the original exposure categories lost their integrity due to job changing by participants. Concurrently, detailed exposure information based on personal monitors became available allowing the orlginal exposure categories to be replaced by cumulative exposure in ppm-months. (See the environmental section below.) 
At each of visits two through five approximately 25 participants were added to the study population. At their entry point, the interview used at the initial April, 1973, visit was administered. The additions brought the total size of the study population to 277 . In contrast to the original 168 participants who had no prior TDI exposure, the added participants had been exposed to TDI for a short period of time prior to their entry into the study. All had prior exposure less than 11 months.

Table I presents summary data, by visit, on spirometry participation for the 277 participants in the data file. Completing the interview seems better accepted by the workers than spirometric testing, and there are individuals with completed interviews who refused to perform forced expirations. Thus, Table I underestimates interview participation.

In the Fall of 1976, due to the continuing erosion of the study population because of workers leaving the plant, it was decided to follow up those who had left in order to see if their health had changed since leaving the plant. There were 42 people who had left the plant at that time and of those, 17 were successfully tested. The remainder were either fmpossible to locate or unwlling to be tested. The results of this follow-up were reported in the annual report of 1977 ,

All participants were tested with a subset of 16 common inhalant allergens*. The presence of two or more positive prick tests (wheal diameter $1 \mathrm{~mm}$ greater than contro1) was used to define atopy.

A copy of the initial and follow-up interviews together with the criteria used to define respiratory symptom categories can be found in Appendix 3. Also presented is a listing of the computer programs used to edit the interviews. Each coded interview has been machine edited to check for missing data and logical inconsistencies. When possible, errors were corrected. This procedure resulted in complete interview information for 98.5 percent of the 277 initial interviews.

There are several factors which impact on accuracy and rellability of pulmonary function measurements. They are instrumentation, calculation, data reduction methods, instrument calibration, test procedures and technician variability. These factors are now discussed in turn.

Pulmonary function tests were conducted in a mobile laboratory on a Cardio-Pulmonary instrument (Model 5000) Pulmolab. This unit is capable of measuring expiratory flows and volumes, lung volumes, and single breath diffusing capacity. It is equipped with an electronic dry rolling-seal splrometer which provides BTPS outputs of all volumes and flows. During a

*Allergens used were those known to be of local clinical relevance and Included Aspergillus sp., Homodendrum sp., Fusarium sp., Bermuda grass, Johnson grass, Helminthosporium sp., Alternarea sp., white oak, glant ragweed $\mathrm{mix}, \mathrm{elm}$, pecan, house dust, marsh elder, cat dander, dog dander, and plantain. 
maximum forced expiration, the output is fed into an XYT recorder in order to obtain plots of flow vs volume or volume vs time. The parameters calculated from the forced expiration include the forced vital capacity (FVC),

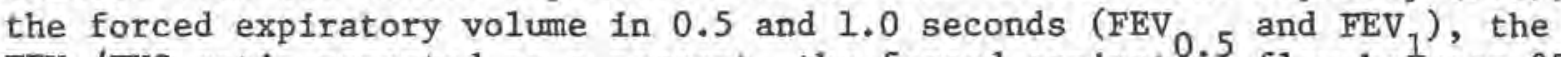
FEV /FVC ratio reported as a percent, the forced expiratory flow between 25 and $75 \%$ of the FVC $\left(\mathrm{FEF}_{25-75}\right), \mathrm{FEF}_{50}$ and $\mathrm{FEF}_{25}$. All these parameters were measured for each individual who was avallable at the time of testing. However, only satisfactory data were used in the analysis. For spirometry to be satisfactory for an individual, the two largest FVC maneuvers must be within $3 \%$ of one another. In addition, these curves must have a sharp initial flow with a smooth continuous effort extending until either flow plateaus to 0.0 liters per second, or seven seconds have elapsed. Therefore, the FVC could be termed an $\mathrm{FEV}_{7}$. When there are more than two satisfactory curves, all data from the two maneuvers with the highest combined percent of predicted for FEV ${ }_{5}$ and $\mathrm{FEF}_{25}-75$ were stored for analysis and averaged. These two parametèrs should provide data with the largest initial effort indicated by the high FEV ${ }_{5}$ and a good sustained effort, indicated by the large $\mathrm{FEF}_{25}-75^{\text {. }}$ The only change in calculation procedures occurred in 1975 when backward extrapolation was introduced to determine zero time for the beginning of timed volume (FEV $5, \mathrm{FEV}_{1}$ ). At that time, all data previously calculated were recalculated using this procedure and the data file was updated so that all data for the entire course of the study was standardized with a backward extrapolation start of time.

The measurement of lung volumes included the slow vital capacity maneuver (VC) and the residual volume (RV) measured by the nitrogen washout technique. In addition, the alveolar volume (AV) is taken as the sum of inspired volume from the diffusion test and residual volume. The total lung capacity (TLC) is calculated as the sum of RV and the larger of VC or FVC. The diffusing capacity for carbon monoxide in units of milliliters per minute per millimeter of mercury was measured by the single breath methot $\left(\mathrm{DLCO}_{\mathrm{SB}}\right)$. The diffusion constant $\mathrm{K}$ equals $\mathrm{DLCO}_{\mathrm{SB}} / \mathrm{AV}$ in units of $\mathrm{min}^{-1} \mathrm{mmHg}^{-1}$. For measurements of residual volume and dfffusing capacity only satisfactory data were analyzed. For satisfactory data, the residual volume from two tests had to be within $10 \%$ of each other, or $200 \mathrm{cc}$, whichever is larger. The smallest RV was used in the analysis. The diffusing capacity is reported from two DLCO measurements within $10 \%$ of each other in which the alveolar volume is at least $85 \%$ of the total lung capactiy and the time for the test is within ten to fourteen seconds.

In 1978, a computerized data reduction system was connected on Iine to the Pulmolab. The output from the Pulmolab is instantaneously fed by means of a ten b1t A/D converter to a Datapoint 1100 computer processor with three diskette drives. Data resolution of the computer are $10 \mathrm{ml}$ for volume and $20 \mathrm{ml} / \mathrm{sec}$ for flow. The computer calculates the parameters listed previously and uses the method of backward extrapolation in determining the FEV 5 and

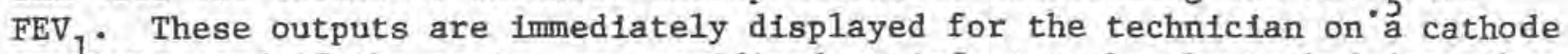
ray tube, and if the tests are considered satisfactory by the technician, the 
data are reduced in the same method previously employed when data were calculated by hand. The reduced data is stored magnetically on diskettes. In order to insure that this computerized system did not systematically affect data collection, spirometry obtained on 100 individuals was calculated by hand and compared to that measured by the computerized system. The mean difference between hand and computer calculated values were within $1 \%$ and $2 \%$ of the observed volumes and flows, respectively.

In addition to measuring spirometric parameters, the computer also determines residual volumes and diffusion capacity. These data were calculated and reduced with the same methods previously employed. In addition, when values obtained by computer were compared to those obtained by previous methods, identical data were produced.

The volume accuracy of the spirometer is calibrated with a $1,000 \mathrm{~m} 1$ syringe, and time calibrated with a stop watch. Setting the test gas cylinders at constant pressure would produce a constant flow into the spirometer. This will produce a linear plot of volume versus time, and repeating the maneuver glves a flow versus volume plot. If flow is accurately measured, its amplitude would equal the slope of the volume time plot (volume and time having been previously calibrated). The calibration for volume, time and flow was conducted twice daily and adjustments made if the volume inaccuracy exceeded $10 \mathrm{ml}$, flow inaccuracy exceeded $50 \mathrm{ml}$ per second, or the time inaccuracy exceeded $1 \%$.

The accuracy of the gas analyzers for measuring $\mathrm{DLCO}_{\mathrm{SB}}$ was assessed with a gas mixing pump which precisely mixed measured gas volumes to $\pm .06 \%$ accuracy. Simple combinations of test gases and room air provided by this gas mixing pump were used to assess accuracy and linearity of the analyzers. If linearity changed more than $1 \%$, new linearity curves were employed. Though this measurement was conducted monthly, changes in linearity occurred no more than once per year. Accuracy and span for the gas analyzers were conducted twice daily. This was done to determine the instrument's ability to measure $0 \%$ gas, and $100 \%$ gas for a diffusion mixture consisting of . $3 \%$ co and $10 \%$ helium in air. (Note: $100 \% \mathrm{CO}$ gas would be. $3 \% \mathrm{CO}$ ). These were adjusted twice daily if the concentrations varied by more than $1 \%$. In addition, the techniclans conducting the tests were tested weekly to insure repeatability of the diffusion measurements. In no case did the week to week variation differ by more than $2 \%$. In addition, following the technicians over a long term, that is, more than one year, never produced variations greater than $3 \%$ in single breath diffusing capacity.

The nitrogen analyzer used in the measurement of residual volume by the multibreath washout method was checked for 0 , span, and linearity at least twice daily. This was conducted by injecting $100 \%$ oxygen across the system, $80 \%$ nitrogen, or by washing out a canister of room air and displaying 
a semi log plot of nitrogen versus volume. A linear decline of this plot implies that there was no leak in the overall circuitry and plumbing of the system, and that the analyzer produced a linear response throughout the span of 0 to $80 \%$ nitrogen. This test was conducted twice daily and adjustments were made if the volume inaccuracy from the washout was greater than $20 \mathrm{ml}$, or if the 0 or span inaccuracy was greater than $1 \%$. If there was a problem in linearity it was always corrected before testing was conducted.

Test procedures remained the same for the duration of the study. All subjects were tested for spirometry in the standing position. Nose clips were used for all tests. The closed circuit procedure was used for spirometry, that is, the subject inspired from the spirometer and then expired the maximum forced vital capacity into the spirometer. In this way, the inspiration preceding the forced vital capacity could be monitored in order to assess the subject's ability to reach total lung capacity. At least four forced vital capacity measurements were conducted on each subject. At least two were displayed as volume/time curves and two as flow/volume loops. The lung volume and the diffusing capacity tests were always conducted in the seated position. Again, nose clips were always used, and at least two measures of residual volume were conducted which had to be within $10 \%$ or $200 \mathrm{~m} 1$, whichever is larger. The smallest residual volume measurement was used in analyses. At least three single breath diffusing capacity tests were conducted on each subject and of those, the two chosen for analyses had to be within $10 \%$ of one another. If more than two were within $10 \%$, the two with the largest alveolar volume, alveolar volume being the sum of inspired volume plus residual volume; were used in analyses. In addition, the time duration for diffusing capacity had to be within 10 to 14 seconds, and the alveolar volume had to be at least $85 \%$ of the total lung capacity.

Technician variability was held to a minimum by always having two technicians conduct the tests. The technicians used in the field always had at least two years of in-house pulmonary function testing in our laboratories. In addition, each technician was supervised for at least four on site field studies by a bioengineer (HWG) before being allowed to conduct independent testing.

As a final precaution, once data was entered into the computer for analysis, a sample of that data was printed to insure that the correct information was coded with the correct individual and stored for analysis in the appropriate format for the data base. In this way, the raw data and the reduced data were checked for agreement prior to analysis.

In summary, pulmonary function measurements were conducted throughout the study using the same equipment and test procedures. The method of backward extrapolation was implemented after the initiation of the study, but past data were recalculated and the analysis updated. In addition, the implementation of a computerized data reduction system was carefully analyzed 
and proved comparable to prevtous methods of data reduction and calculation. Therefore, for the duration of the study, data collection was standardized to reduce variability. Every precaution possible was taken to insure that the changes seen in this population during the duration of the study were influenced as ilttle as possible by the random and systematic variability which often affects measurements of pulmonary function.

The complete data file from all nine visits contains information on 277 participants. Four of these are female and have been deleted from all analyses. Table 2 presents descriptive statistics on the 274 males in the study, $85 \%$ of them are white, $73.7 \%$ are current $(51.1 \%)$ or ex $(22.6 \%)$ cigarette smokers, and $20.1 \%$ reacted positively to two or more skin tests. They have a mean age of 35.9 years, a mean height of 69.9 inches, and averaged 14.4 pack-years of clgarette smoking. All pulmonary function percent predicteds were near $100 \%$ with the exception of $\mathrm{FEF}_{25-75}(91.0 \%)$.

Each subject's chect x-rays held by the plant medical department were reviewed by a physician (RNJ) in 1974. The purpose was to detect potentially confounding disorders (e.g., tuberculosis, fibrosis) and to be certain that these were neither unusually prevalent nor unevenly distributed among groups of participants, Only a few subjects had films suspicious for inactive granulomatous infection; only one subject had diffuse linear shadows suggesting interstitial fibrosis, and the abnormality was stable, and long antedated TDI exposure. After this systematic review, an Individual's later films were examined only if the Investigators learned that he or she was having persistent or recurrent symptoms, or requested review of the films. No abnormal films were detected by individual case review. Review of reasons for absence due to illness in a 12-month perfod falled to detect cases of recurrent pneumonia, but recorded diagnostic information was often incomplete. In the entire study period we detected no case with clinical or radiographic evidence suggesting hypersensitivity pneumonia.

\section{TDI EXPOSURE INDICES}

Two thousand and ninety three personal samples on 143 workers were collected using MCM type 4000 tape samplers and 4100 MCM integrating Reader Recorder System, both manufactured by Universal Environmental Instruments and supplied by MDA. Sclentific Incorporated of Park Ridge, IIlinois. SampIing was done in a relatively uniform manner with respect to time from June, 1975, through October, 1978, Al1 job categories in the TDI manufacturing area are represented in the 143 people monitored.

Appendix 1 details the technical aspects of the TDI monitoring program and Appendix 2 treats the statistical methodology used to define exposure categories. In this section, the environmental data are sumarized and the two exposure indices developed for each particlpant are described. 


\section{A. Cumulative Exposure}

One hundred and forty four of the 2,093 personal samples were taken by maintenance workers during a single one-month period in 1975 (called turnaround time) of concentrated maintenance activity. Since these maintenance workers were not a representative collection of maintenance workers and since no sampling was done during subsequent turnaround times (the wearing of monitors was an impediment to work performance), these 144 samples were not used to determine cumulative exposure categories.

Since the frequency distribution of the 8-hour time-weighted averages of the remaining 1,949 samples, representing 42 job titles, was markedly skewed to the right, they were transformed using logarithms to the base 10 . The frequency distribution of the transformed 8-hour time-weighted averages 
was approximately symmetrical and the following categories were defined on the log scale:

\begin{tabular}{ccccc} 
Category & \multicolumn{2}{c}{ TWA $^{1}$} & \multicolumn{2}{c}{ LOG (TWA) } \\
& lower 11mit & upper 11mit & lower 1imit & upper limit \\
1 & 0 & .00025 & -4.00 & -3.60 \\
2 & .00025 & .0005 & -3.60 & -3.30 \\
3 & .0005 & .001 & -3.30 & -3.00 \\
4 & .001 & .002 & -3.00 & -2.70 \\
5 & .002 & .004 & -2.70 & -2.40 \\
6 & .004 & .008 & -2.40 & -2.10 \\
7 & .008 & .016 & -2.10 & -1.80 \\
8 & .016 & .032 & -1.80 & -1.50
\end{tabular}

(If LOG (TWA) coincided with a category boundary, it was placed in the lower category.)

Figure 1 contains histograms of the 1949 8-hour time-weighted averages used to develop exposure categories and of the 144 "turnaround time" 8-hour time-weighted averages. Table 3 contains descriptive statistics for the same two sets of 8 -hour time-weighted averages.

Using clustering techniques described in Appendix 2, the 42 job titles as described by 1949 8-hour time-welghted averages were divided into three categories: HIGH, MODERATE, and LOW. The jobs which make up each category are listed in Table 4 . The jobs cluster by exposure as follows:

(1) TDI C-Operators and Druming E-Operators in the HIGH GROUP

(2) TDI Foreman, TDI B-Operators, TDI maintenance personne1, and the TDI Laboratory Samplers in the MODERATE GROUP, and

(3) Primarily non-TDI area located jobs in the LOW GROUP.

Histograms on the LOG (TWA) scale and descriptive statistics in ppm for each of three exposure categories are presented in Figure 2 and Table 5 respectively. The histograms provide graphic verification of the separation between the HIGH and LOW GROUPS ( $80 \%$ of the samples in the LOW GROUP fall in LOG (TWA) category 4 or lower whereas $80 \%$ of the samples in the HIGH GROUP fall in LOG (TWA) category 5 or higher.) with the MODERATE GROUP 1ying in an intermediate position. The descriptive statistics in ppm show that the 25th percentile, the median, the geometric mean, the mean, and the 75 th percentile

\footnotetext{
$1_{\text {TWA }}$ - 8-hour time-weighted average
} 
all increase approximately by multiples of two from the LOW to HIGH CATEGORY, thus establishing a definite exposure gradient.

Job histories collected from personnel records and interviews were used to determine the number of months a participant spent in each of the three exposure categories. Cumulative exposure in ppm-months was computed by multiplying the time in an exposure category by a representative measure of concentration for that category and then summing the three obtained products. The representative measure of concentration was taken to be the geometric mean of the observed 8 hour time weighted averages for the category. The geometric mean instead of arithmetic mean was used as a measure of central tendency since it is more representative of the central portion of the distribution when, as is the case here, positive skewness is removed by taken logarithms,

\section{B. Time Above $.02 \mathrm{ppm}$}

In addition to calculating the 8-hour time-weighted average from each personal sample, the length of time the concentration was above each of the levels .005, .01, .02, .04, .06, and .08 ppm was recorded. This information on the 2,093 samples representing 50 job titles was used to develop "peak exposure" categories as described in Appendix 2. The Job titles for each of the resulting categories are listed in Table 6 . The proportion of time spent above each level is presented in Table 7 by category.

Using individual job histories, the time spent above a particular concentration level was calculated as the sum over peak exposure categories of the product of time spent in the category and proportion of time spent above the level for that category. This quantity whose units is months was used in seeklng assoctations between health effects and peak exposure. This index is not equal to the actual time above a particular level but is only proportional to it. The constant of proportionality (approximately .25) adjusts for the fact that in a 30 day or 720 hour month, approximately 168 hours are spent in the workplace.

Although six indices of peak exposure, one for each concentration level, were calculated, they were so highly correlated (the smallest correlation coefficient was .96) that we have used only the time above $.02 \mathrm{ppm}$ in the health effects correlation analyses. Because of its high correlation with the other five indices, no new information would be obtained by substituting the other indices for time above $.02 \mathrm{ppm}$.

\section{Assignment of Exposure Indices for Correlation Studies}

Four different sets of statistical analyses, one each for spirometry, lung volumes, diffusion, and resplratory symptoms are presented in the 
following sections. Since the visits for which usable data is available is different for each four analyses, exposure indices have been computed separately for each. Thus, for example, the cumulative exposure and time above .02 ppm indices for spirometry were computed from time of initial exposure at the manufacturing site through the date of the last visit for which usable spirometric data on the participant is available. In a similar manner, the two exposure indices were computed for each participant for each of the three other analyses.

In addition to treating cumulative exposure and time above $.02 \mathrm{ppm}$ as continuous variables as defined above, cumulative exposure and time above $.02 \mathrm{ppm}$ categories were also developed for use in relating a health effect to exposure. One of these categorizations dichotomized the continuous exposure index and the other created three subgroups as described below.

For cumulative exposure GROUP I consists of those participants whose cumulative exposure (for a particular analysis) was less than or equal to .0682 ppm-months and GROUP II those participants with more than .0682 ppm-months of exposure. To create three cumulative exposure categories, GROUP II was further dichotomized into GROUP IIA AND GROUP IIB using a division point of 0.1 ppm-months. $0.0682 \mathrm{ppm}$-months $=(0.0011 \mathrm{ppm})$ $X$ (62 months) was chosen as the first division point because it corresponds to the exposure accumulated by a participant who spent 62 months, the time from initial TDI production to the end of the study, in the lowest concentration exposure category which has a geometric mean of $0.0011 \mathrm{ppm}$. This placed approximately two-thirds of the population into GROUP I. The division point to dichotomize GROUP II into GROUP IIA and IIB was chosen so as to result in approximately equal numbers in these two subgroups.

For time above 0.02 Ppm GROUP I consists of those participants who spent no longer than 0.19 months above $0.02 \mathrm{ppm}$ and GROUP II those participants with exposure longer than 0.19 months above $.02 \mathrm{ppm}$. This division point corresponds to the time spent above $0.02 \mathrm{ppm}$ for a participant who spent the full period of 62 months in the lowest peak exposure category. GROUP I determined in this way contained approximately two-thirds of the study population. To create three peak exposure categories, GROUP II was further subdivided into GROUP IIA and GROUP IIB of approximately equal numbers using a division point of one month.

\section{LONGITUDINAL RESULTS AND ANALYSIS}

\section{A. Introduction}

The overall objective of this longitudinal study has been to relate change in variables representative of health status to host factors 
and variables reflecting exposure to TDI. The health status variables considered in the longitudinal analysis are spirometric measurements: $\mathrm{FEV}_{1}$, FVC, $\mathrm{FEV} \%, \mathrm{FEF}_{25}-75, \mathrm{FEF}_{50}$; diffusion capacity $\mathrm{DL}_{\mathrm{CO}}$ and $\mathrm{K}$; lung volumes: RV, TLC, and (RV/TLC) X 100; and respiratory symptoms: upper respiratory symptoms, lower resplratory symptoms; bronchitis and dyspnea. The host factors considered are cigarette smoking as measured by pack-years and atopic status as defined in the section on study design and protocols. TDI exposure indices as defined in the section on environmental characterization have been based on cumulative exposure and time above $.02 \mathrm{ppm}$.

Each of the health status variables with the exception of respiratory symptoms are quantitative in nature and annual change for them has been computed as the slope of the least squares straight line using time since initial visit as the independent variable. Usable data from three or more visits was sufficient to include a participant in the analysis. The slopes or annual changes were regressed using the technique described in Appendix 2 on independent variables representing TDI exposure, atopic status, and cigarette smoking. For each of the pulmonary function measurements six regressions were performed. In each regression pack years of cigarette smoking and atopic status as represented by a dummy variable equal to 1 if the participant was atopic and 0 otherwise, were included in the independent variables. The coefficient of the variable representing atopic status is an estimate of the mean annual change in atopics minus the mean annual change in non-atopics after controlling for the other variables. The variables representing exposure to TDI in the six regressions are as follows:

Regression 1 Cumulative exposure in ppm-months.

Regression 2 A dummy variable called cumulative exposure category II which is 1 if cumulative exposure is greater than .0682 ppm-months (See the Environmental Characterization for the rationale behind choosing this division point.) and 0 otherwise. Thus, the coefficient of this variable estimates the mean annual change of the cumulative exposure GROUP II participants minus the mean annual change of the cumulative exposure GROUP I participants (See the Environmental Characterization Section for GROUP I and GROUP II definitions) after controlling for the other variables.

Regression 3 In this regression TDI exposure is represented by 2 dummy variables:

(1) Cumulative exposure category IIA which is 1 if cumulative exposure is greater than .0682 ppm-months and 0 otherwise, and

(2) Cumulative exposure category IIB which is 1 if cumulative exposure is greater than $11 \mathrm{ppm}$-months and 0 otherwise. 
Regression 4 Time above $.02 \mathrm{ppm}$ in months.

Regression 5 A dummy variable called peak exposure category II indicating that a participant belongs to time above $.02 \mathrm{ppm}$ GROUP II (See the Environmental Characterization Section for definitions of GROUP I and II). The coefficient of this variable has been an interpretation analogous to that of the coefficient of cumulative exposure category II in Regression 2.

Regression 6 Two dumy variables called peak exposure category IIA and peak exposure category IIB which indicate respectively membership in time above .02 ppm GROUPS II and IIB. The coefficients of these variables have interpretations analogous to those of cumulative exposure category IIA and cumulative exposure category IIB of Regression 3.

Tables 8 through 13 present the results of these regressions. The numbers in parentheses in these tables are the regression coefficients divided by their standard errors and should be compared to percentiles of the normal distribution for tests of significance. Thus, a regression coefficient is significantly different from 0 at the $\alpha=.05$ level if it divided by its standard error exceeds 1.96 in absolute value.

Each observed annual change is the sum of the unobserved true annual change and an estimation error term. It is the variability of the true annual changes which we are trying to explain by the independent variables in the regression equations. The last column headed "\% variability explained" in Tables 8 through 13 is the percent of true annual change variance explained by independent variables in the regression equations. Estimates of the true annual change standard deviation for each pulmonary function considered are given in Table 14.

The estimation error term is the result of the variation in individual pulmonary function determinations about a participants regression on time. The differences between individual determinations and the fitted regression on time are called residuals. The variation in these residuals depends on, among other things, technical measurement error, seasonal variability in pulmonary function, technician effects if they exist, and daily variability in pulmonary function not affecting physlologic state. The residual error standard deviation for each pulmonary function considered is given in Table 14. 
Estimated mean annual changes and their standard errors are presented in Table 14. The remaining columns of Table 14 are more fully discussed in Appendix 2. Here we only note that for each pulmonary function approximately $50 \%$ of the observed annual change variability in a participant studied at all nine visits is true annual change variability and hence 1 s available for explanation by host factors and exposure to TDI.

With the possible exceptions of $\mathrm{FEF}_{25-75}$ and $\mathrm{FEF}_{50}$ the spirometric mean annual changes found in this longitudinal study are not markedly different from cross-sectional studies. The $\mathrm{FEF}_{50}$ longitudinal mean annual change is 3.5 to 7.5 times that expected from cross-sectional results, depending on which prediction equations are used.

Estimates of the mean annual changes in the study for DLCO $(-.716 \mathrm{ml} / \mathrm{min}$-mmHg-year), $\mathrm{K}(-.0947 \mathrm{~min}-\mathrm{mmHg}$-year) and TLC (.32 ml/year) differ from Cotes' (1) cross-sectional age coefficients. Mean annual changes for DLCO and $\mathrm{K}$ are larger by factors of 3.6 and 2.4 respectively. The TLC annual change is statistically significantly positive whereas Cotes' cross-sectional age coefficient is 0 .

Longitudinal RV and (RV/TLC) X 100 annual changes, although larger, are not markedly different from that expected from cross-sectional studies.

\section{B. Spirometry Results}

Two hundred and twenty-six participants had complete spirometry from three or more visits. Table 15 presents summary statistics on these 226 participants and the 48 who did not have complete data for the required number of visits. There were no important differences between the two groups.

The increased prevalence of atopy (23\% vs $6.3 \%$ ) in the group with three or more good spirometry visits is possibly counterintuitive, i.e,, long exposure to TDI which is implied by having large number of visits should result in an increased risk of being atopic. A more plausible explanation lies in the manner in which the skin testing was distributed over the nine visits of the study. Of the 48 participants with two or fewer complete spirometry visits, $31(64.6 \%)$ were not tested with seven or more of the possible 16 allergens, whereas only $30(13.3 \%)$ of the 226 with three or more complete visits had this characteristic. This "differential exposure to skin testing" makes it more difficult for the small number of visits group to be classified atopic, thus explaining the differential rates of atopy in the two groups. The differential exposure to skin testing is a consequence of the skin testing protocol whereby such testing was spread out over the nine visits with not all of the allergens used at each visit.

Three participants of the 226 lacked data on at least one of the explanatory variables and consequently have been deleted from the analysis. 
In each of the six regressions, both FEV 1 and FVC annual declines were significantly positively related to pack-years of smoking with each pack-year contributing $.6 \mathrm{ml} / \mathrm{yr}$ to $\mathrm{FEV}_{1}$ annual decline and $.7 \mathrm{ml} / \mathrm{yr}$ to the FVC annual decline. Neither FEV nor FVC annual decline were significantly related to atopic status. Neither $\mathrm{FEV} \%, \mathrm{FEF} 25-75$, nor $\mathrm{FEF}_{50}$ annual decline were assoclated with pack-years of cigarette smoking, Atoplcs showed consistently smaller $\mathrm{FEF}_{25-75}$ and $\mathrm{FEF}_{50}$ annual declines than non-atopics at p-values ranging from .12 $25-75$.

No spirometric measurement was significantly associated with cumulative exposure treated as a continuous variable. However, with the exception of FVC all annual declines became greater with increasing cumulative exposure.

Using one-tailed tests of significance $\mathrm{FEV}_{1}(\mathrm{p}=.034), \mathrm{FEV} \%(\mathrm{p}=.014)$, and $\mathrm{FEF}_{25-75}(\mathrm{p}=.004)$ estimated mean annual declines (after controlling for atopy and pack years of smoking) were significantly greater $\left(12 \mathrm{ml} / \mathrm{yr}, .20(\mathrm{yr})^{-1}\right.$, and $41 \mathrm{ml} / \mathrm{sec}-y x$ respectively) in cumulative exposure GROUP II (1.e., those participants with cumulative exposure greater than .0682 ppm-months) than in GROUP I. At 14 pack years of cigarette smoking, the mean number of pack years for the group of the 223 particlpants used in this analysis, the estimated mean annual declines (See Table 16) for non-atopics in GROUP I are $20 \mathrm{ml} /$ year, $.28 \mathrm{yr}^{-1}$, and $84 \mathrm{ml} / \mathrm{sec}-\mathrm{yr}$ respectively. Thus, even though there is a doserelated effect for $\mathrm{FEV}$, and $\mathrm{FEV} \%$ annual decline, the absolute level of the mean annual declines in the higher exposure group are approximately the same as expected from cross-sectlonal studies. However, the GROUP I and GROUP II FEF
estimated mean annual declines of $80 \mathrm{ml} / \mathrm{sec}-\mathrm{yr}$ and $121 \mathrm{ml} / \mathrm{sec}-\mathrm{yr}$ for non-atop with 0 pack years of cigarette smoking are significantly greater than the crosssectional annual decline of $31 \mathrm{ml} /$ year reported by Knudson, et al (2) for male "never-smokers" over age 25. The GROUP I estimated mean annual FEF ${ }_{50}$ decline of $103 \mathrm{ml} / \mathrm{sec}-\mathrm{yr}$ for non-atopics at 0 pack-years is also significantly greater than cross-sectional annual decline of $15 \mathrm{ml} / \mathrm{sec}-\mathrm{yr}$ reported by Knudson, et al (2). The biological significance of the discrepancy between FEF $25-75$ and FEF 50 annual changes as computed from longltudinal data and that expected based on crosssectional studies is not known. It could mean elther that the population under study had abnormally large declines in these flow rates, indicating a deleterlous effect on respiratory health, or that it is inappropriate to compare flow rate annual changes from these two types of studies. The magnitude of the differences between GROUP I and GROUP II ( $-41 \mathrm{ml} / \mathrm{sec}-\mathrm{yr}$ for $\mathrm{FEF}_{25}-75$ and -29 $\mathrm{m} 1 / \mathrm{sec}-\mathrm{yr}$ for $\mathrm{FEF}_{50}$ ) reflecting a relationship to TDI exposure Eogether with large annual declines for these pulmonary functions is suggestive of a hazardous local environment with TDI exposure 1ncreasing the risk. In any event, independent of the level of annual change, there is an exposure related effect for $\mathrm{FEV}_{1}, \mathrm{FEV} \%$, and $\mathrm{FEF}_{25-75}$ annual decline.

Table 16A presents descriptive statistics at the time of entry into the study for each of the two cumulative exposure categories, GROUP I was older and contained more participants with respiratory symptoms than did GROUP II. Thus, the potential blas is toward underestimating the excess decline in GROUP II. 
When GROUP II is dichotomized into GROUP IIA and GROUP IIB using a division point of .1 ppm-months, a larger mean decline 1 s to be expected in GROUP IIB than in GROUP IIA if there is a dose-response relationship. For $\mathrm{FEV}_{1}$, FEV\%, and $\mathrm{FEF}$ 25-75 annual declines, which showed an assoctation with the cumulative exposure dichotomized at .0682 ppm-months, this was not found. Although the declines were smaller in Group IIB than IIA, statistical significance (two-talled p-values $=.19, .68$, and .50 respectively) did not obtain. Estimated mean annual changes for these pulmonary function measurements are presented in Table 17 by exposure group for non-atopics with 14 pack years of smoking. Since large cumulative exposures are associated with participation from the beginning of the study to the later visits, the highest exposure group is possibly a survivor population. Such a selection could explain the non-significant decreases in annual declines from GROUP IIA to GROUP IIB.

With the exception of FVC annual decline, all spirometric annual declines increased with increasing time above $.02 \mathrm{ppm}$ treated as a continuous 
variable. Using one-tailed tests of signiffcance, p-values for the relationship between $\mathrm{FEV}_{1}, \mathrm{FEV}_{\%}, \mathrm{FEF}_{25-75}$ and $\mathrm{FEF}_{50}$ annual changes after controlling for atonic status and pack years of smoking were $.15, .027, .034$, and .32 respectively.

Again, using one-talled tests of significance $\mathrm{FEV}_{1}(\mathrm{p}=.05)$, FEV\% $(p=.05), \mathrm{FEF}_{25-75}(\mathrm{p}=.023)$, and $\mathrm{FEF}_{50}(\mathrm{p}=.038)$ estimated mean annual declines after controlling for atopy and pack years of smoking were significantly greater ( $11 \mathrm{ml} /$ year, $.15(\mathrm{yr})-1,32 \mathrm{ml} / \mathrm{sec}-\mathrm{yr}$, and $40 \mathrm{ml} / \mathrm{sec}-\mathrm{yr}$ ) in time above $.02 \mathrm{ppm}$ GROUP II (1.e., those participants with time above .02 greater than .19 months) than in GROUP I. At 14 pack-years of cigarette smoking estimated mean annual declines (See Table 18) for non-atopics in GROUP I are $21 \mathrm{ml} /$ year, $.31(\mathrm{yr})^{-1}, 88 \mathrm{ml} / \mathrm{sec}$-year, and $106 \mathrm{ml} / \mathrm{sec}$-year respectively. Thus, as in the dichotomized cumulative exposure regression, FEV $_{1}$ and FEV\% annual declines are approximately the same as those expected from crosssectional results whereas $\mathrm{FEF}_{25}=75$ and $\mathrm{FEF}_{50}$ declines are greater than expected.

When the time above .02 pPm GROUP II is dichotomized into GROUP IIA and GROUP IIB using a division point of 1 month, annual declines were smaller in GROUP IIB than in GROUP IIA for FEV 1 and $F E F_{50}$ and larger for FEV\% and FEF 25-75. In no case was the GROUP IIB decline significantly different at the .05 level from GROUP IIA. Estimated mean annual changes for these pulmonary function measurements are presented in Table 19 by exposure group for non-atopics with 14 pack years of smoking.

Previous authors, notably Fletcher, et al (3), Berry (4), and Berry, et al (5), have noted that observed annual change for FEV $_{1}$ is the sum of two components: true annual change and estimation error. The magnitude of the estimation error is determined primarily by length of follow-up, the variability of an individual $\mathrm{FEV}_{1}$ determination about the true value, and to a lesser extent by the distribution of visits between end points. Fletcher et al (3) estimate the standard deviation of an individual FEV $_{1}$ determination about its true values as $160 \mathrm{ml}$. Berry's (4) estimate, derived from several studies, is $120 \mathrm{ml}$. Our estimate of $133 \mathrm{ml}$ is comparable to these two,

We have estimated in our 5.5 year study that approximately $50 \%$ of the total variability (1,e, variability between observed $\mathrm{FEV}_{1}$ annual changes) is real variability (1.e., variability between true annual changes) and not due to estimation error. Berry, et al (5) and Fletcher et al (3) also estimate this percentage at $50 \%$ for studies 2.5 and 9 years in length, respectively. We expected that Berry's estimate of this percentage would be less than ours because his follow-up was shorter and that Fletcher's would be larger because his follow-up time was longer. This expectation is not realized because the three total variances differ. 
Berry's total variance is larger than would be expected from the increase in estimation error caused by the comparatively short follow-up period. Thus, although Berry's real variance as percentage of total variance is the same as in this study, his absolute real variance is larger. This may be due to the cotton dust exposure of his population producing abnormally

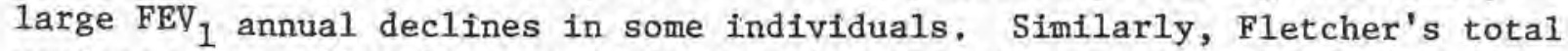
variance is smaller than would be expected from the decrease in estimation error caused by the comparatively long length of his follow-up period. This results in a smaller real variance possibly reflecting the relative homogeneity of his population with regard to $\mathrm{FEV}_{1}$ annual change. In addition, the statistical methodology employed by Fletcher assigns more of the total variance to estimation error than does our methodology. This would tend to decrease real variability as a percentage of true variability.

Our conclusion is that these three studies for which length of follow-up and variability among true annual changes were quite different, nevertheless, exhibited remarkedly comparable standard deviations of a single $\mathrm{FEV}_{1}$ determination about its true value and that the unexpected comparability of real variance as a percentage of total variance is explained by the differing population characteristics and statistical methodology. In short, the three studies produce no conflicting results.

In a previous annual report dated March 15, 1976, and in Butcher, et al (6), we reported an annual increase in $\mathrm{FEV}_{1}$ of approximately $55 \mathrm{ml} /$ year. This increase, based on the first five visits, was recognized as being abnormally high but was reported because extensive checking at the time revealed no reason to doubt its validity.

Before proceeding with the analysis reported here, we examined $\mathrm{FEV}_{1}$ for the 33 participants with complete spirometry at all nine visits in order to determine if there might have been a systematic bias at any of the visits. A graph of the mean $\mathrm{FEV}_{1}$ 's by visit for these 33 participants is presented in Figure 3 together with a least squares straight line fit to the means. This straight line gives an $\mathrm{FEV}_{1}$ annual change of $-21 \mathrm{ml} /$ year. There is an evident peak in mean $\mathrm{FEV}_{1}$ at the October, 1975, or 5th visit. A linear model as in Fletcher, et al (3), containing a secular bias term for each visit resulted in a significant $(\mathrm{p}<.001)$ bias term of $134 \mathrm{ml}$ at visit 5.1 No other visit exhibited a secular bias. A straight line fit to the $\mathrm{FEV}_{1}$ means for the first five visits results in an annual change of $+37 \mathrm{ml} /$ year which together with the now known positive bias at visit 5 suggests that the $\mathrm{FEV}_{1}$ annual increase reported earlier was due to the systematically high $\mathrm{FEV}_{1}$ 's at visit 5 .

We considered not using the visit 5 data in the current analysis but decided against that course for three reasons;

1 Both FVC and FEF $25-75$ a1so exhibited signiffcant biases at visit 5. 
(1) After extensive searching, we have found no explanation for the visit 5 bias; (2) because visit 5 is approximately midway in the follow-up period, it has 1 ittle effect on an individual participant's FEV 1 slope provided the participant has at least one data point avallable on either side of visit 5; (3) when those participants with visit 5 as either their first or last usable visit were not used in the $\mathrm{FEV}_{1}$ analysis, the results were similar.

\section{Diffusion and Lung Volume}

One hundred and sixty-five participants had diffusing capacity determinations from three or more vistts, and 183 participants had complete lung volume determinations from three or more visits. Tables 20 and 21 present summary statistics on those participants with and without three or more complete determinations for these two sets of pulmonary functions. No important differences between the two sub-groups of participants were revealed.

of the 165 participants with diffusing capacity determinations, one lacked data on at least one of the explanatory variables and was deleted from the analysis. Similarly, three participants have been deleted from the lung volume longitudinal analysis.

In each of the six regressions RV and (RV/TLC) X 100 annual increase was significantly correlated with pack-years of smoking adding $1 \mathrm{ml} /$ year to the RV annual increase and .01 ( $\mathrm{yr})^{-1}$ to the (RV) RC) X 100 annual increase. None of the other pulmonary functions ( $\mathrm{DL}_{\mathrm{CO}}, \mathrm{K}$, or TLC) considered were related to pack-years of smoking.

of the five pulmonary functions consldered, only $\mathrm{DL}_{\mathrm{CO}}$ was significantly $(\mathrm{p}<.05)$ related to atopic status. This relationship was evident $1 \mathrm{n}$ each of the six regressions with $\mathrm{DL}_{\mathrm{CO}}$ in the atopics declining approximately $.4 \mathrm{ml} / \mathrm{min}-$ mmHg) $)^{-1}$ per year faster than non-atopics. This finding is inexplicable.

With respect to the exposure indices, TLC was not significantly related to any of the six exposure indices. $K$ and $\mathrm{DL}_{\mathrm{CO}}$ had a significant $(\mathrm{p}<.05)$ relation to exposure in all six regressions but it was paradoxical in nature, i.e., annual declines decrease with increasing exposure. RV and (RV/TLC X 100 were not related to cumulative exposure as a continuous variable or when it was categorized into two or three groups. They both showed a significant ( $p<.05)$ paradoxical relationship with the time above .02 ppr variables, 1.e., annual increases in these two pulmonary functions decreased with increasing time above $.02 \mathrm{ppm}$.

\section{Respiratory Symptoms}

Four patterns of symptoms as determined by the questionnatre are examined in this analysis. 
(1) upper respiratory symptoms: drip at the back of the nose, hay fever or its symptoms, sinus trouble or postnasal drip;

(2) lower respiratory symptoms: usual cough, phlegm, wheezing, attacks of shortness of breath with wheezing, or breathlessness when walking with other people;

(3) bronchit1s: usual cough and phlegm more than three months in the preceding year;

(4) dyspnea: Grade 2 or higher where Grade 2 = when hurrying on level, Grade 3 = when walking with others, Grade $4=$ stop for breath when walking at own pace.

To be included in the longitudinal respiratory symptom analyses a participant must have had both an initial interview and a final (i.e, , the latest of the last three visits) follow-up interview in order to determine respiratory symptom status for each of these visits. Two hundred and three of the total of 274 participants had sufficient information to determine at least one of the four respiratory symptom complexes considered. Table 22 presents summary statistics on these 203 participants and the 71 without sufficient information. There were no important differences between the two groups. One participant lacked data on the explanatory variables and was discarded from the analyses.

Tables 23 and 24 present for each of the four symptom complexes the number of participants in each of the four categories: (1) symptoms present at both the initial and last usable interview, (2) symptoms present at initial interview and absent at last usable interview, (3) symptoms absent at initial interview and present at the last usable interview, and (4) symptoms absent at both the initial and last usable interview. These numbers are broken down by cumulative exposure category using $.0682 \mathrm{ppm}$ months as the dividing point in Table 23 and by time above .02 ppm category using .19 months as the dividing point in Table 24. Each table further subdivides the exposure category by atopic and clgarette smoking status.

If a higher proportion of participants in the higher exposure category acquired a symptom pattern between the initial and last usable interview (using those with any type of change as the denominator), this was taken as evidence of an exposure related effect. A11 four symptom patterns exhibited this effect using either cumulative exposure or time above .02 ppm category to represent exposure. Howeyer, statistical significance was not obtained. The lowest p-value was .13 for the relationship between bronchitis and cumulative exposure category. 
For upper respiratory symptoms and dyspnea the percentage of participants changing symptom category who went from asymptomatic to symptomatic significantly exceeded $50 \%$. This together with high prevalence rates for upper $(38 \%)$ and lower $(30 \%)$ respiratory symptoms at the initial interview suggests a hazardous local environment, either general or work related, or both.

However, we have little hard information on conditions at the plant prior to TDI exposure to support this hypothesis. Moreover, note should be taken that the symptom complex defined as lower respiratory symptoms is quite broad in nature. It only requires a positive response to any one of the following questions:

(1) Do you usually cough first thing in the morning in bad weather?

(2) Do you usually cough at other times during the day or at night in bad weather?

(3) Do you usually bring up phlegm, sputum or mucous from your chest first thing in the morning in bad weather?

(4) Do you usually bring up phlegm, sputum or mucous from your chest at any other times during the day or night in bad weather?

(5) Does your breathing ever sound wheezy or whistling?

(6) Do you have attacks of shortness of breath with wheezing at present?

(7) Do you get short of breath when walking with other people your own age on level ground?

A similar remark holds for upper respiratory symptoms, Evidence that the high prevalence of lower respiratory symptoms is possibly due to the measuring instrument was found in results from other studies of this Unit. Lower respiratory symptom prevalences from four other studies were $41.0 \%$, $34.4 \%, 46.5 \%$ and $28.5 \%$. The first three populations were exposed to either suspected or confirmed respiratory hazards: cottonseed dust, coffee dust, and asbestos, respectively. The $28.5 \%$, which is comparable to the $29.5 \%$ observed in the study population of this report prior to TDI exposure, comes from a working population not exposed to any known respiratory hazard.

Table 24A presents prevalences for bronchitis and dyspnea at initial and final interviews by smoking-cumulative exposure category. These prevalences were obtained for Table 23 by collapsing across atoplc status. For both bronchitis and dyspnea, the increase in prevalence from initial to final interview is greater in $>.0682$ ppm-months exposure category irrespective of smoking category. However, in no case did statistical significance obtain. 


\section{E. Immunology}

IgE (I.U./ml) and eosinophil levels $\left(\mathrm{ccm}^{-1}\right.$ ) were determined at all nine visits and the first six, respectively, To control for possible seasonal effect on these two variables, a Fall and a Spring average were calculated for each participant. Average IgE levels across participants were higher in the Fall than in the Spring $(269.0$ vs $155.0, p<.001)$. There was no difference between average Fall and Spring eosinophil levels (227,0 vs 224.0).

Associations were sought between Fall IgE and eosinophil levels with atopy as deflined by two or more positive skin test reactions to common allergens, pulmonary function at the time of initlal visit, and longitudinal course of pulmonary function.

Fall IgE level was moderately correlated with skin test atopy (point biserial coefficient $=.17, \mathrm{p}=, 01$ ) while Fall eosinophil level was not correlated with it (point biserial coefficient $=.09, p=.12$ ).

Pulmonary function (in percent predicted) at inftial interview was not significantly assoclated with IgE level dichotomized at 300 . Only $K$ was significantly associated $(\mathrm{p}=.01)$ with eosinophil level dichotomized at 250. Those with an eosinophil level less than 250 had mean $K$ percent predicted equal to 101.9 as opposed to 94.4 for those with eosinophil levels greater than 250. No pulmonary function annual change showed a significant relationship between either IgE dichotomized at 300 or eosinophil level dichotomized at 250 after controlling for the cumulative exposure greater than .0682 variable and pack-years of smoking.

\section{F. Detailed Analysis of $\mathrm{FEV}_{1}$ Slope}

\section{(1) Results}

After performing the large number of regressions reported in Tables 8-13, a detailed analysis of the relationship between FEV 1 slope and dichotomized (at .0682 ppm-months) cumulative exposure was performed, $\mathrm{FEV}_{1}$ slope was singled out for the following three reasons:

1. There is an extensive body of knowledge on FEV slope e.g., (3), (4), (5), (35), (36), (37), (38), (39), (40) to which our results could be related.

2. $\mathrm{FEV}_{1}$ when adjusted for body stature is a reliable and sensitive Indicator of large airways obstruction.

3. The $12 \mathrm{ml} / \mathrm{yr}$ difference in $\mathrm{FEV}_{1}$ between the two cumulative exposure categories (Table 16), although statistically significant after controlling for atopy and pack years, is blologically small; it would be helpful to compare this exposure effect to that of clgarète smoking. 


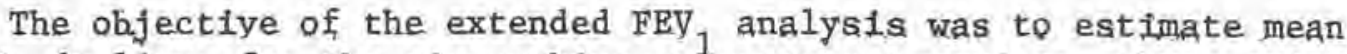
annual FEV declines for the six smoking-exposure categorles: three categories of smoking (never, ex, and current cigarette smoking) by two categories of exposure (less than or equal to .0682 ppm-months, and greater than .0682 ppm-months). This would allow a comparison of the smoking effect in the $\leq .0682 \mathrm{ppm}$-months group with the exposure effect in the never smokers, Atopy was not included in this analysis because the previous analyses had indicated that it was not an important influencing variable.

Fletcher et al (3) have observed that FEV, level as measured by $\mathrm{FEV}_{1}$ divided by the third power of height, (1.e., $\mathrm{FEV}_{1} / \mathrm{ht} \mathrm{t}^{3}$ in units of $\mathrm{Cl} / \mathrm{m}^{3}$ ) is associated with the annual decline prior to the study period. Consequently, in determining correlation between $\mathrm{FEV}_{1}$ slope and exposure, adjustment should be made for $\mathrm{FEV}_{1} / \mathrm{ht}^{3}$ to allow for the posstbility of an excess of rapid pre-study decliners (as measured by low $\mathrm{FEV}_{1} / \mathrm{ht}^{3}$ ) in the high exposure group which could otherwise lead to a spurious correlation between FEV, slope and exposure. In addition, there should also be adjustment for age since $\mathrm{FEV}_{1} / \mathrm{ht}^{3}$ and possibly $\mathrm{FEV}_{1}$ slope are related to age.

$\mathrm{FEV}_{1} / \mathrm{ht}^{3}$ was obtained for each participant by averaging the ayailable FEV 's for that participant, multiplying this average by 100 and then diyiding by helght cubed, helght measured in meters. This quantity, referred to as FEV 1 level, was inftially categorized using division points of $55,65,75$ and 85. Average $\mathrm{FEV}_{1}$ slopes for these categories are shown below.

MEAN FEV 1 SLOPE BY FEV 1 LEVEL CATEGORY

\begin{tabular}{ccc}
$\begin{array}{c}\mathrm{FEV}_{1} / \mathrm{ht}^{3} \\
\left(\mathrm{Cl} / \mathrm{m}^{3}\right)\end{array}$ & $\mathrm{n}$ & $\begin{array}{c}\text { Mean } \\
\mathrm{FEV}_{1} \text { SIope } \\
(\mathrm{ml} / \text { year) }\end{array}$ \\
\hline$<55$ & 21 & -47.5 \\
$55-64$ & 58 & -20.1 \\
$65-74$ & 76 & -22.6 \\
$75-84$ & 49 & -20.3 \\
$85+$ & 19 & -26.2
\end{tabular}

Because of the lack of association between FEV ${ }_{1}$ slope and level among the four highest categories, FEV 1 level was dichotomized using a division point of 55 Centilitres per meter cubed. This lack of assoctation is in accordance with results reported by Fletcher et al (3), 
Before presenting the $\mathrm{FEV}_{1}$ slope analyses, we give the results of an analysis relating $\mathrm{FEV}_{1}$ level to age, smoking and exposure.

Logistic regression of the dichotomized FEV level yielded a significant age effect $(\mathrm{p}<.01)$, a marginally significant ex-smoking effect as compared to never smokers (one-talled p-value $=.07$ ) and a significant current smoking effect as compared to never smokers (one-tailed p-value $=.03$ ). In addition to these expected relationships, there was a significant association $(p=.05)$ between $\mathrm{FEV}_{1}$ level and exposure after controlling for age and smoking. There was a smafler proportion of participants with low FEV level in the high exposure category than in the low category. This finding appears to argue against a TDI exposure effect as measured by $\mathrm{FEV}_{1}$ level. However, as discussed by Fletcher et al (3), FEV level measures the effect of $\mathrm{FEV}_{1}$ slope prior to the study as opposed to FEV 1 slope over the period of study. Thus, a possible explanation for the negative association between FEV 1 level and exposure is one of selection, whereby the rapid FEV 1 decliners Prior to TDI exposure selected themselves into the low exposure category. Furthermore, that there is a deficiency of participants with low FEV 1 level in the high exposure group is consistent with their younger mean age ( 31.7 vs 37.6 years) since FEV 1 level has not been adjusted for age. That the high exposure group is younger is consistent with the fact that the jobs which lead to the high exposure category are entry level jobs. These necessarily go to new hirees who would tend to be young.

In any event, it is important in assessing the relationship between FEV $_{1}$ slope and exposure over the period of this study to adfust for FEV level $_{1}$ because the known positive assoclation between low FEV 1 level and large $\mathrm{FEV}_{1}$ declines would tend to minimize the effect of exposure.

In order to estimate cell means for the s1x smoking-exposure categories while controlling for age and FEV 1 level, the regression procedure outlined in Appendix 2 was utillzed with $\mathrm{FEV}_{1}$ slope as the independent variable and the following dependent variables: .0682 ppm-months.

1. A dummy variable representing high TDI exposure - greater than

2. Two dummy variables, one representing ex-smokers and one representing current smokers.

3. The products of the two variables in 2 , with the variable in 1 .

4. Age.

than 55).

5. A dumny variable representing low $\mathrm{FEV}_{1}$ level $\left(\mathrm{FEV}_{1} / \mathrm{ht}^{3}\right.$ less 
The results of the regression are presented in the Table 16B by smoking-exposure-FEV ${ }_{1}$ level category.

Cell means have been adjusted to the mean study population age of 35.6 years in order to account for differing age distributions within the cells. The esimated cell means in the low FEV level category should be interpreted cautiously, espectally for those cells which contain a small number of participants, since they are the result of an extrapolation.

The coefficient of age in the multiple regression was -5.8 milli1itres per decade (one-talled p-value $=.03$ ). A weak acceleration of FEV, loss with increasing age of approximately 5.5 millilitres per decade was also shown by Kauffmann et al (35) in a group of Paris area workers. Kauffman's age effect disappeared after adjustment for FEV 1 level. In contrast, the age effect observed in the present study occurs after controlling for $\mathrm{FEV}_{1}$ level, TDI exposure and smoking status,

After adjuşting for age, TDI exposure, and smoking status, those with $\mathrm{FEV}_{1}$ level $\leq 55 \mathrm{cl} / \mathrm{m}^{3}$ had mean $\mathrm{FEV}_{1}$ annual decline of $203^{\mathrm{ml} / \text { year }}$ (one-tailed $\mathrm{p}$-value $=.04)$ more than those with $\mathrm{FEV}_{1}$ level $>55 \mathrm{cl} / \mathrm{m}^{3}$. This shows, following the arguments presented by Fletcher et al (3), that there are a group of people, namely those with low FEV leve1, in this study who are lifelong rapid decliners. This lifelong rapid decline should not be attributed to TDI expos-

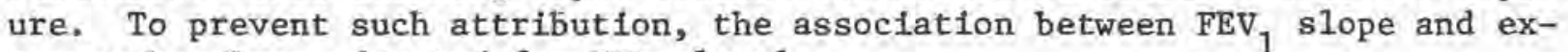
posure has been adjusted for $\mathrm{FEV}_{1}$ level.

Among the never smokers, after adjusting for age and FEV, level, those with greater than $.0682 \mathrm{ppm}$-months of TDI exposure declined on the average $38 \mathrm{ml} /$ year (one-tailed p-value $=.001$ ) more than those with less exposure. In the ex smokers, $3 / \mathrm{m} 1$ year difference between exposure groups was not significant. The $11 \mathrm{ml} /$ year difference in the current smokers had a one-tailed p-value of 0.1 .

Turning to the smoking effect in the $\leq .0682$ ppm-months participants there was, after adjusting for age and $\mathrm{FEV}_{1}$ level, a significant (one-tailed p-value $=.004)$ difference of $27 \mathrm{ml}$ per year between current smokers and never smokers. The $14 \mathrm{ml} /$ year difference between current smokers and ex smokers was almost significant (one-talled $\mathrm{p}$-value $=.06$ ). The $14 \mathrm{ml} /$ year difference between ex smokers and never smokers had a one-talled p-value of . 12 .

The $38 \mathrm{ml} /$ year exposure effect in the never smokers and the 27 $\mathrm{ml} /$ year current clgarette smoking effect in the low exposure group were not significantly different (p-value $=.32)$. 
The average FEV decline, the precision of an individual FEV, determination, the precisfon of a participant's FEV slope, and the effect of cigarette smoking observed in this study, are alf consistent with the results of other investigators.

Our average $\mathrm{FEV}_{1}$ slope of $-24 \mathrm{ml}$ /year (with standard error of 3.2 ) is comparable to the $-30 \mathrm{~m} 1$ /year measured by Fletcher et al (3). Ferris et al (36) observed a mean $\mathrm{FEV}_{1}$ annual change of $-37 \mathrm{~m} 1 /$ year over six years in a population of males with mean age 53 years. Higgins et al (37) found an average $\mathrm{FEV}_{1}$ annual change of $-34 \mathrm{ml} /$ year in males aged 25 to 34 years and a -45 $\mathrm{ml} /$ year average annual change in males aged 55-64 years. The follow-up period for this study was nine years. Petty et al (38) observed over six years a mean FEV, annual change of -19 ml/year in a population of males, 27 per cent of which had (FEV /FVC) X 100 less than 60. Kauffmann et a1 (35) observed a $-47 \mathrm{ml} /$ year mean annual $\mathrm{FEV}_{1}$ annual change over 12 years in a population of males with mean age 41 years. Lebowitz et al (39) and Pham et al (40) were unable to demonstrate significant changes in FEV over a three year period. The average FEV decline of $24 \mathrm{ml}$ /year observed in this study at 7.5 times its standard error ts highly significant.

As mentioned in the Spirometry Results Section, the observed standard deviation of a single $\mathrm{FEV}_{1}$ determination of $133 \mathrm{ml}$ is comparable to the $120 \mathrm{ml}$ of Berry (4) and $160 \mathrm{ml}$ of Fletcher et al (3). Additionally, we observed a standard error of $25 \mathrm{ml} /$ year for the slope of a particlpant present at all nine visits over the full 5.5 years of the study. This compares with the $20 \mathrm{ml} / \mathrm{year}$ of Fletcher et al (3) for a study of eight years and sixteen visits.

Fletcher et a1 (3) found a $15 \mathrm{~m} 1 /$ year difference in FEV slope between current and never smokers. Kauffmann's (35) estimate of this difference was 10 $\mathrm{ml}$ per year. Results presented by Ferris et al (36) lead to an estimate of 13 $\mathrm{ml} /$ year. When averaged over exposure categories, we observed a $14 \mathrm{ml} /$ year difference. In the low exposure group, the difference was 27 m1/year.

The comparability of our general results, i.e, those not related to TDI exposure, with those of other investigators, demonstrates that the elevated $\mathrm{FEV}_{1}$ 's at visit 5 have not produced a blas in the FEV 1 slope measurements. This external validation provides justification beyond that given in the Spirometry Results section for discounting the visit $5 \mathrm{FEV}_{1}$ measurements effect on FEV slope. Although we were able to detect a visit 5 bias, we have provided evidence that it did not affect our results. This demonstrates an inherent strength of any longitudinal study of three or more visits; in two-visit studies, it is impossible to detect such bias. 
The $38 \mathrm{ml} /$ year exposure effect in the never smokers was not significantly different (p-value $=.32$ ) from the $27 \mathrm{ml} /$ year smoking (current) effect in the low exposure group. This comparability of cigarette smoking with TDI exposure was also found when the smoking-exposure interactions were omitted from the regression equations, In such a regression, the exposure and cigarette smoking effects were both $16 \mathrm{ml} / \mathrm{year}$.

At the time of entry into the study, current smokers had averaged one pack of cigarettes per day for an average length of 18 years. Thus, the data suggest that this amount of smoking produces an annual decline in FEV, equivalent to the decline associated with TDI exposure at a concentration of $.0011 \mathrm{ppm}$ for 62 months in a never smoker. The fact that the effect of TDI exposure was observed in the never smokers and not in the current cigarette smokers suggests that smoking may mask the effect of TDI exposure. 


\section{TDI REACTORS}

\section{A. Clinical and Epidemiologic Features}

We consider those persons TDI clinically "sensitive" who develop recurrent respiratory signs and symptoms upon repeated exposure to low concentrations of TDI, or in some cases unidentified reactants or byproducts of TDI manufacture. The definition must be qualified because some workers develop reversible airways obstruction in the TDI area, obtain relief upon transferring to other areas, but fall to react to pure TDI vapor in bronchoprovocation challenges.

TDI is an irritant and is detectable in relatively low concentrations by non-sensitized persons. This probably explains why sensitization is most often described by the subject as a "loss of tolerance" to the material. Dry cough is the most frequent symptom, but chest tightness, exertional breathlessness, wheezing and shortness of breath are also common. Orthopnea is usually present in nocturnal attacks. Sputum is uncommonly reported unless it was present prior to sensitization. Reduced strength or stamina were common complaints of those who continued to have TDI exposure, and these symptoms abated following cessation of exposure.

A delay of about one-half hour was the most commonly reported interval between known exposure and onset of symptoms. A majority of persons, however, reported increased symptoms after leaving the plant, suggesting efther a dual or late reaction. Immediate onset, that is, within a few minutes of exposure, was rarely reported,

of 277 persons in the study population, 12 men ( $4.3 \%$ ) became clinically "sensitive" to TDI (see Table 25). Nine of these 12 men became sensitized after less than 12 months of TDI exposure, elght of those after less than four months of exposure. Six of the 12 had known major exposure in TDI spills. Three of the 12 were atopic, that is, had two or more positive reactions to skin testing with common tnhalant allergens. Six persons underwent bronchoprovocation challenge with pure TDI vapor; two of these reacted, and four did not react, to levels of less than $.02 \mathrm{ppm}$. Five of the 12 had never smoked. The sensitized persons were rather evenly divided between operators in the TDI area and maintenance workers in the same area. The lone sensitized subject from outside the TDI area was a chemical engineer who may have been exposed in laboratory work.

Figures 4 and 5 display the results of longitudinal lung function testing for the nine TDI clinically "sensitive" individuals with lung function testing after sensitization. Eight of the 12 sensitized men were tested prior to start-up of TDI production, and therefore prior to exposure. The others were transferred 
into the TDI area or hired at different times, and were first studied at the succeeding visit for data collection. Three subjects (numbers 110 , 197, and 200) have shown declines in both FEV and FEF $25-75$ despite removal from the TDI area. Two subjects $(033$ and 035$)$ have shown stable FEV 1 values but declines in FEF $25-75^{\circ}$. Four persons show stable to slightly increasing values for $\mathrm{FEV}_{1}$ after removal from TDI exposure. Two of the subjects still work in the TDI area and both have stable expiratory flow rates.

Under the present conditions, however, removal from the TDI area cannot be considered an absolute guarantee of no further exposure. Large accidental TDI emissions and certain wind conditions can disperse the material to other parts of the chemical complex. Perceptible amounts of TDI can also be detected around workers with contaminated clothing and shoes, and this can be responsible for temporary contamination of such facilities as lunch rooms and the medical department. There are thus opportunities for intermittent, low-level exposures to TDI or to other materials from TDI synthesis, in distant areas of the chemical manufacturing complex.

\section{B. Immunologic Findings}

In this longitudinal study, 1mmunologic tests were performed to determine whether exposure to TDI had an effect on total immunoglobulin levels; whether presence of atopy was a factor in development of TDI "sensitivity"; whether total blood eosinophil levels alter following exposure to TDI; and whether development of humoral antibodies was a mechanism in TDI "sensitivity."

The results of skin testing with common inhalant allergens showed that there was a similar distribution of atopic individuals among the various exposure groups and that this presence of atopy was not a factor in development of TDI "sensitivity" $(7,8)$. Total blood eosinophil counts were not significantly altered by exposure to TDI (8). Immunoglobulins $G, A, M$, $D$, and $E$ were not significantly changed by TDI exposure $(8,9,10)$. Quantitation of specific antibodies was undertaken by skin testing with a TDI-human serum albumin (TDI-HSA) conjugate. Results of skin testing indicated that TDI-HSA was a poor antigen and that anti-TDI antibodies of IgE type could not be detected using this material (9). Further, the radloallergosorbent test (RAST) was of little use with this antigen. Prausnitz-Kistner ( $P-K)$ testing in monkeys was also evaluated as a method for determining development of TDI specific IgE antibodies. All results were negative (9). Passive cutaneous anaphylaxis (PCA) in guinea pigs was used to detect hererocytotropic antibodies. No positive PCA tests were obtained on serum samples from workers following exposure (9). 


\section{Provocative Inhalation Challenge with TDI}

During our prospective studies we found that approximately $5 \%$ of workers developed clinical"sensitivity" (i.e., they complained of wheezing and shortness of breath when in a TDI containing area) (9). These subjects, where possible, were challenged with TDI $(8,10)$. They were brought to Tulane University and exposed for 15 minutes to saline vapor on day 1, 0.005 ppm TDI on the second day, and on subsequent days to 0.01 and 0.02 ppm until a 20\% drop in $\mathrm{FEV}_{1}$ was observed. Expiratory flows were derived from a forced vital capacity maneuver and determined with an electric dry rolling seal spirometer which provided output for volume-time and volumeflow plots of maximum forced expiration. Peak flow was also determined in a separate maneuver using a Wright's peak flow meter. Lung function testing was performed prior to exposure, and at $5,10,15,30,45,60,90$, and 120 minutes and thereafter at hourly intervals following challenge. The workers were challenged in a single blind fashion in an exposure chamber with dimensions of $2.25 \times 1.89 \times 2.55$ meters $\left(10.84 \mathrm{~m}^{3}\right)$ which was under slight negative pressure (Figure 6) (10). The atmospheres of TDI were generated by controlled evaporation of TDI accomplished by passing air over the surface of TDI contained in a $250 \mathrm{ml}$ gas washing bottle with effective surface area $60.8 \mathrm{~cm}^{2}$. The flow rate was controlled by a callbrated rotameter at between 2 to 6 liters per minute, depending on concentration of isocyanate vapor required. Circulation was obtained by a small fan; temperature in the room was maintained at 23 to $24^{\circ} \mathrm{C}$ and humidity was 45 to $55 \%$. TDI quantitation was accomplished with a mode1 7000 TDI monitor. The subject was seated throughout the cha1lenge with his breathing zone close to the end of the monitor to ensure accurate measurement of the concentration of TDI inhaled. Throughout the challenge, the subject was observed through a glass window in the air lock door by a physician. Persons reacting to TDI inhalation challenge showed three types of response $(6,8,11)$. A total of 28 TDI clinically "sensitive" Individuals (six of whom were in the original study population) were tested by provocative inhalation challenge with TDI. Of these 28 persons tested, 10 reacted to TDI with a drop in $\mathrm{FEV}_{1}$ of greater than $20 \%$. Six showed an Immediate bronchospastic response, beginning within 15 minutes after the challenge. In two workers, a late response was seen beginning at least one hour after the cha1lenge and, in a further two individuals, a dual response was seen with the characteristics of both the immediate and late reaction. In some individuals, a dose response was also seen, i.e, challenge with $0.005 \mathrm{ppm}$ did not elicit an adverse response but challenge with $0.01 \mathrm{ppm}$ would elicit a bronchospastic reaction (Figure 7).

\section{Challenge Testing with Methacholine Chloride (Mecholy1)}

A total of 10 workers reporting "sensitivity" to TDI and 10 non-sensitive, non-exposed workers were challenged with methacholine at the work plant. Seven of the ten "sensitive" individuals responded to challenge with a greater than $20 \%$ drop in $\mathrm{FEV}_{1}$, whereas only one of the 10 non-sensitive workers reacted (12). 
All subjects were tested for pulmonary function prior to commencement of challenge and demonstrated baseline flow parameters within $80 \%$ of predicted normal values. Five breaths of physlologic phosphate buffered saline were inhaled through a Bird Mark 8 nebulizer and lung function was measured at 1,5 and 3 minutes after administration. Methacholine was administered, starting at a concentration of 5 and increasing through 10 to $25 \mathrm{mg} / \mathrm{ml}$. One breath of the $5 \mathrm{mg} / \mathrm{ml}$ solution was followed by progressive increases in number of breaths with each of the three concentrations to a maximum of five breaths of the $25 \mathrm{mg} / \mathrm{ml}$ concentration. The procedure was stopped when efther a $20 \%$ drop in $\mathrm{FEV}_{1}$ occurred or, in the absence of any airway response, when the maximum of five breaths of $25 \mathrm{mg} / \mathrm{ml}$ was reached. Methacholine dose response regression slopes were graphed for the subjects, where possible, with a cumulative breath unit equivalent to one breath of $1 \mathrm{mg} / \mathrm{ml}$ methacholine on the abcissa and percentage drop in $\mathrm{FEV}_{1}$ on the ordinate (11), All subjects who were shown to be reactive to TDI by provocative inhalation challenge also demonstrated high sensitivity to methacholine.

E. Study of the Effect of Pretreatment with Disodium Cromoglycate:

Some of the workers reacting to TDI were pretreated with 40 mg of disodium cromoglycate (DSCG) which was administered by spinhaler 30 minutes before re-exposing to the concentration of TDI which had initiated the adverse pulmonary reaction. Workers with both 1 mmediate and dual responses were tested. Lung function measurements were determined as for the regular TDI inhalation challenge. In all three TDI reactive individuals tested, (two showing an immediate response to the challenge with TDI and the one showing a dual response) their adverse bronchial responses were inhibited by pretreatment with disodium cromoglycate (11, 13) (F1gure 8).

\section{F. Lymphocyte Transformation and Leukocyte Histamine Release:}

Cellular studies 1ncluded 1ymphocyte transformation following exposure of cells to the TDI-HSA conjugate and histamine release from leukocytes following exposure to TDI-HSA was measured. These tests were performed on samples collected from 1ndividuals reporting "sensitivity" to TDI. No lymphocyte stimulation was measured and no histamine released from leukocytes was detected (6).

\section{G. Lymphocyte cAMP Dose Response Studies:}

As previously reported $(12,14)$, we showed that TDI acts as a partial adrenergic agonist, however, this effect was seen with cells of normal individuals. We therefore examined the effect of TDI upon 1 ymphocytes from TDI reactive Individuals. Quantitation was performed by means of a method 
developed in our laboratory (14) where 1ymphocytes were separated by Ficol1Hypaque density gradient centrifugation, incubated with dilutions of isoproterenol, prostaglandin $E_{1}$ or TDI, followed by washing, precipitation with trichloroacetic acid, freeze thawing, extraction with ether, and quantitation by radioimmunoassay. Results were interpolated from a standard graph and expressed as percent stimulation of cAMP formation. Dose response regression lines were determined by means of the Inear ascending portion of the slopes. Blood samples for lymphocyte cAMP dose response studies of TDI reactors were obtained prior to, and at 15 and 120 minutes after provocative inhalation challenge (PIC). In 1ymphocytes of the two TDI reactors tested to date, dose response slopes following stimulation with either TDI, 1soproterenol or prostaglandin $\mathrm{E}_{1}$ were markedly reduced when compared with those of normal individuals and non-TDI reactors (FIgure 9). Dose response slopes did not differ from pre-exposure baseline levels, following challenge with TDI (11).

\section{H. Plasma Histamine Levels:}

Samples for venous plasma histamine determination were collected prior to exposure, and at 1, 5, 10, 15, and 120 minutes after exposure. Histamine was determined by the enzyme isotopic method of Beaven,

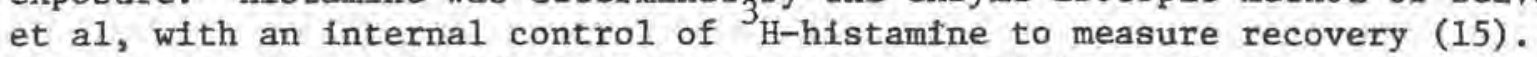
A11 samples from individual patients were assayed in quadruplicate. Plasma histamine levels of six subjects were tested. Two were individuals with a strong history of TDI sensitivity who reacted to provocative inhalation challenge (PIC) with TDI. Two had a weak history of sensitivity and did not react to PIC. In no case was histamine release into venous plasma demonstrable following inhalation challenge with TDI. Baseline plasma histamine levels were all within normal limits (1I).

\section{Determination of Serum Complement and Split Products of Complement}

Functional levels of total complement (CH50) were quantitated by standard techniques in fresh serum or serum frozen at $-70^{\circ} \mathrm{C}$ on samples collected before exposure and 1, 5, 10, 15, and 120 minutes after TDI exposure (11). A hemolytic assay was also used to measure the alternative complement pathway proteins (APCH50). Split products and factor B in plasma were measured by an immunoelectrophoretic assay and split products of C3 were determined by the counterimmunoelectrophoretic assay of Arroyave and Tan. Two TDI reactors and five persons demonstrated to be negative by provocative inhalation challenge were tested. Baseline CH50 and APCH50 levels were all within normal limits (60 to 120 and 15 to 45 units, respectively) for all workers and no significant changes in these complement levels were seen following inhalation challenge with TDI (11). 


\section{J. Loss of TDI and Methacholine Reactivity after Removal from Isocyanate Exposure:}

One of the TDI reactive individuals, who had been studied intensive1y, has been followed longitudinally after moving to a new job which does not entail exposure to isocyanates. This individual reacted originally to an exposure for 10 minutes of $0.005 \mathrm{ppm}$ of TDI with an immediate bronchospastic response. He was highly sensitive to methacholine, showing a $38 \%$ drop in $\mathrm{FEV}_{1}$ when he received one breath of $5 \mathrm{mg} / \mathrm{m} 1$ of methacholine (16).

Six months after removal from an isocyanate containlng environment, he was re-challenged with TDI and did not react to 15 minutes exposure to $0.02 \mathrm{ppm}$ of TDI. He was re-tested for methacholine sensitivity and it was found that three breaths of the $5 \mathrm{mg} / \mathrm{ml}$ concentration were required to initiate a $20 \%$ reduction in $\mathrm{FEV}_{1}$. After a further six months (i.e., one year following removal from TDI), he was again tested by methacholine challenge. At this testing, he failed to react to 5 breaths of $25 \mathrm{mg} / \mathrm{ml}$ of methacholine.

Concurrent with methacholine and TDI inhalation challenges, blood samples were drawn for cyclic AMP dose-response slopes following stimulation of his lymphocytes by prostaglandin $E_{1}$, isoproterenol and TDI. Initially, he was shown to have a markedly reduced dose response slope to all three agonists compared with normals. Six months later, there was a slight improvement in the dose response slopes. The results of the dose response slopes on his latest testing await completion.

\section{K. Concurrent Development of Food Allergy and Isocyanate Reactivity}

A further interesting aspect of this worker was that he claimed to have become highly sensitive to radishes at about the same time he became sensitive to TDI. He was challenged by permitting him to eat one small 5 gram radish and pulmonary function testing was performed. He had an immediate severe reaction following one bite of the radish with a $75.4 \%$ decrease in $\mathrm{FEV}_{1}$. He now reports that, at one year following removal from the TDI area, he has eaten a radish which is approximately four times as large as the one used in the testing with no ill effects. Interestingly, radishes contain allyl isothiocyanate and benzyl isothiocyanate (17). A manuscript reporting our findings with this worker is in preparation (18).

\section{Toly1-specific IgE Antibodies in Serum of TDI Reactive Individuals:}

We assisted Dr. M. Karol of the University of Pittsburgh by providing serum samples from TDI reactors to enable her to develop a new 
antigen for RAST. This antigen consists of p-tolyl isocyanate conjugated to human serum albumin (TMI-HSA). The serum samples we supplied were from highly reactive individuals. Four of the five serum samples sent to Dr. Karol were shown to contain tolyl-specific IgE antibodies (19). Using antigen provided by Dr. Karol, we were able to confirm these results on the same serum samples in our laboratories. Later we prepared our own TMI-HSA antigen and compared this with the antigen produced by Dr. Karol. The Pearson's correlation of coefficience test was applied to the results of RAST using the same sera with both antigens. A value of 0.96 was obtained, indicating that our antigen was essentially identical to that produced by Dr. Karol. Using our antigen, we tested serum samples from a total of 26 individuals who had been shown by ourselves and another center to be reacting to provocative inhalation challenge with TDI. Depending on the method of evaluation of the results of the RAST, only 15 to $18 \%$ of the individuals were shown to have toly1specific IgE antibodies (20) (Figure 10). These results show that there are antibodies involved in TDI asthma in a few individuals but would suggest that a humoral mechanism is not the definitive mechanism of TDI reactivity.

In summary, our studies of TDI "sensitive" individuals show that asthmatic reactions can be elicited by brief exposure to very low concentrations of TDI. These reactions may be immediate, late or dual reactions such as those induced by avian protein, certain organic dusts or Aspergillus fumigatus allergens. However, our negative findings with plasma histamine and complement are evidence against an inmunologic mechanism. Our findings, that persons who react to TDI are also reactive to methacholine, confirm that TDI reactive individuals have irritable airways. However, our demonstration that not all methacholine sensitive individuals react to TDI suggests that reactivity to TDI is not a non-specific reaction (11). Whether methacholine reactivity is pre-existing or develops concurrently with development of sensitivity to TDI is not known and awaits results of prospective studies although the results of our longitudinal study of one sensitive worker suggest the latter $(\mathrm{N})$.

The demonstration of the partial agonistic activity of TDI $(12,14)$ is of great interest. TDI reactive individuals have decreased adrenergic agonist dose-response slopes which are associated with in vivo responses to TDI challenge (11). These results are in agreement with current concepts of asthma. Szentivanyi's theory of the mechanism of asthma proposes that a defective beta adrenergic response is present in asthmatic individuals and that this deficlency may be responsible for two effects: First, it may prevent production of sufficient levels of cyclic AMP in mast cells to protect against release of pharmological mediators such as histamine and slow reactive substance of anaphylaxis which are ultimately responsible for the bronchospastic response. Second, a deficiency in the ability to produce cyclic AMP can have a deleterious effect on the delicate cyclic nucleotide 
balance required to maintain smooth muscle tone. Thus, our studies of TDI reactive individuals, to date, suggest that the most likely mechanism of TDI asthma is pharmacologic rather than allergic, although the latter possibility still cannot be excluded.

Our findings that DSCG may Inhibit asthmatic reactions under controlled conditions (11, 16) agree with the concept of the action of this drug and suggest that DSCG may be a useful prophylact1c measure for workers who develop TDI reactivity. Expanded testing in both the laboratory and the field will be necessary before a definitive statement can be made however.

Our findings in the worker who has been studied extensively following removal from the TDI containing area, suggest that TDI reactivity is reversible when the isocyanate exposure is stopped (18). The demonstration of increased reactivity to methacholine and diminished CAMP dose response suggests that TDI in some way acts to alter receptors on the cells to cause decreased cholinergic and adrenergic function. The loss of methacholine sensitivity suggests that this effect of TDI upon receptors may be transient and may be reversed, with the worker reverting to his prior health following removal from isocyanate exposure. Similar loss of bronchial hyperreactivity has been demonstrated following removal of reactive individuals from Western red cedar wood dust exposure.

\section{CONCLUSIONS}

(1) Throughout the five-year period of this study, a comprehensive environmental survey of the plant and its workers using state of the art, continuous area and personal monitors demonstrated that all workers in the study population had some degree of TDI exposure, whtch depended upon job and location. There were frequent excursions above the current threshold 1 imit value of $0.02 \mathrm{ppm}$ ceiling. These exposures occurred even though the plant is modern and uses currently available control technology.

(2) During annual one-month periods of concentrated maintenance activity in which the plant is completely overhauled, there were higher than usual TDI concentrations measured at the breathing zones of maintenance workers.

(3) Although there was daily variation in TDI concentration, there were no systematic exposure trends demonstrated over the five-year period of the study. 
(4) In this five-year Iongitudinal study, $\mathrm{FEV}_{1}, \mathrm{FEV} \%$ and $\mathrm{FEF}_{25}-75 \%$ annual declines are significantly related (after controlling for smoking and atopic status) to TDI dose, where dose is measured by either (a) two cumulative exposure categories (division point $=.0682$ ppm-months) or (b) two "time above $0.02 \mathrm{ppm}^{\prime \prime}$ categortes (division point $=.19$ months).

(5) The effect of TDI exposure on $\mathrm{FEV}_{1}$ annual change appears primarily in the non-smokers and may be masked by smoking. In this population smoking on the average a pack of cigarettes a day for 18 years and a TDI total dose in excess of .0682 ppm-months had a simflar effect on $\mathrm{FEV}_{1}$ mean annual changes.

(6) $\mathrm{FEV}_{1}$ and $\mathrm{FEV} \%$ annual declines in the high exposure categories were not significantly different from annual declines predicted for members of the general population from cross-sectional studies. FEF $25-75$ and $\mathrm{FEF}_{50}$ annual declines were significantly greater than expected in both exposure categories. Both $\mathrm{DL}_{\mathrm{CO}}$ and $\mathrm{K}$ (diffusion constant) annual declines were significantly greater than expected, but were Inexplicably negatively related to dose. The same held for RV and RV/TLC annual increases. TLC annual change showed a significant increase instead of expected no change.

(7) TDI dose as estimated by cumulative exposure and peak exposure as measured by time spent above $0.02 \mathrm{ppm}$ correlated equally well with annual change in lung function.

(8) $\mathrm{FEV}_{1}, \mathrm{FVC}, \mathrm{RV}$ and RV/TLC annual changes were significantly related to pack-years of cigarette smoking with associations in the expected direction. Only $\mathrm{K}$ annual decline was related to atopic status and that assoclation was an inexplicable negative one.

(9) Prevalences of bronchitis and dyspnea increased from preexposure baseline in the high exposure category, as measured by cumulative exposure, to a greater extent than in the low category. These differences in symptom increases between exposure categorles were not statistically significant ( $\mathrm{p}$-values equal to .13 and .18 , respectively).

(10) Clinically important bronchial hypersensitivity to TDI developed in $4.3 \%$ of the study population, usually within a few months of first exposure.

(11) Neither atopy nor smoking served to identffy persons at higher rlsk of developing TDI reactivity. Half of the TDI reactors had been exposed to high levels during a spll1 or equipment malfunction.

(12) Some TDI reactors have falled to attain pre-exposure or

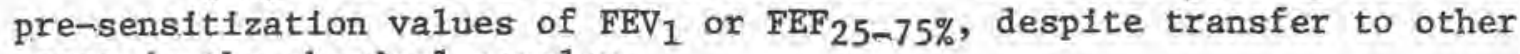
areas in the chemical complex. 
(13) There is persuasive clinical evidence for sensitization in some persons who fail to react to low concentrations (less than or equal to $0.02 \mathrm{ppm}$ for 15 minutes) of pure TDI vapor in the exposure chamber.

(14) TDI, at certain concentrations, acts as a partial agonist upon lymphocytes to stimulate cyclic adenosine monophosphate levels. At lower concentrations, it can block cyclic AMP stimulation by isoproterenol, and prostaglandin $E_{1}$ but not histamine.

(15) TDI reactors are hypersensitive to methacholine (heightened bronchoconstriction as determined by a standard inhalation multiple breath technique), but not all methacholine sensitive individuals are TDI reactive.

(16) Lymphocytes of TDI-sensitive individuals have decreased ability to respond to cyclic AMP stimulants such as the beta agonists isoproterenol, prostaglandin $\mathrm{E}_{1}$ and TDI.

(17) Provocative Inhalation challenge studies show that airways reactivity to TDI is reproductble in the laboratory environment and can be blocked by disodium cromoglycate. During bronchial reactions, no changes in serum complement components are observed and there is no release of histamine detectable in peripheral plasma.

(18) RAST with p-toly1 isocyanate conjugated to human serum albumin only detects tolyl specific IgE antibodies in serum of $15-18 \%$ of subjects proven by provocative inhalation challenge to be TDI reactive. Thus, demonstration of toly1 specific serum IgE antibody cannot bie used to diagnose clinical sensitivity to TDI.

(19) In addition to the above mentioned immunologic and pharmacologic activities, TDI does not appear to have an effect upon:

(a) Induction of specific antibodies in man as demonstrable by hemaglutination, RAST, Prausnitz-Kìstner, passive cutaneous anaphylaxis or direct skin testing with TDI human serum albumin conjugates,

(b) Changes in levels of serum IgG, A, M or E.

(c) Induction of non-specific histamine release from leukocytes in vitro or in vivo.

(d) Induction of peripheral blood lymphocyte blastogenic transformation employing cells from "sensitive" subjects. 
APPENDIX 1

\author{
ENVIRONMENTAL CHARACTERIZATION
}

\title{
A. Introduction
}

This report summarizes the environmental characterization activities in a new TDI manufacturing plant for a period of five years (1973-78). This exposure characterization survey was perhaps the most extensive and thorough survey undertaken of any TDI manufacturing plant in the world. Vast amounts of data were collected using the best and the state of the art monitoring techniques and methods. During the course of the study several papers were published (21-27), covering various aspects and findings of environmental characterization as related to the other parts of the study. Five annual progress reports containing environmental characterization sections have also been submitted.

As expected in such longitudinal studies, the study goes through an evolutionary process. During the period of five years there were tremendous advancements made in the fields of personal and area monitoring, laboratory and field calibration of monitors, and also the recognition of the advantages and limitations of the measurement techniques. Also during the study, the Tulane industrial hygienist developed a good rapport with his counterpart in the plant and also with the supervisors, shift foreman and other workers of the plant. Better insight was gained about the administrative set up and manufacturing operation of the plant. Appropriate refinements and changes in environmental characterization survey had to be made throughout the course of the study to adapt to these evolutionary changes. This progress report will delineate these evolutionary changes during the study and the necessary refinements made to accommodate these changes.

\section{B. Monitoring Techniques}

At the time of the writing of the proposal, the method widely used for analysis of TDI in air was a wet chemical method based on impinger sampling and colorimetry developed by Marcali (28). Until recently this was the standard recommended method for analysis of TDI. Because it is an impinger sampling method it is not ideally suited for personal sampling and the method can give only the integrated time welghted average, During the latter part of 1973 a continuous paper tape monitor for area measurement of TDI became commercially available, This instrument is based on a paper tape method developed by Reilly in 1968 (29). Three of these portable area monitors were acquired for the study. The TDI monitor based upon an original design by Dunlap Limited, in collaboration with ICI, Ltd. of U.K., continuously monitors concentrations of TDI in the atmosphere in the range of 0.0 to $0.08 \mathrm{ppm}$. It has a meter readout 
as well as audible and visible alarms and output connections for an external recorder. Sensitivity and specificity to TDI is obtained by utilizing a continuous reel of chemically lmpregnated paper tape to sample the air. The tape is supplied in a cassette which will run for 168 hours or one week continuousiy.

In operation, the metered volume of atmosphere is drawn through the tape as it moves past the exposure orifice. If TDI is present, a stain is developed on the tape; the intensity being proportional to the concentration of TDI. The exposed tape then moves past two photo detectors. One detector measures reflected light from the unexposed half and the other from the exposed half. The two signals are compared electronically and an output signal, proportional to the TDI concentration compensated for minor tape variations, is displayed in parts per million of TDI. The concentration is also continuously recorded on a strip chart recorder. A typical recorder printout is given in Figure 11.

This was a major development in monitoring of TDI. These monttors were initially evaluated in the laboratory. For the evaluation the monitors needed to be dynamically callbrated in the laboratory. There were no simple methods avaflable at the time to generate standard atmosphere of TDI for dynamic calibration. Therefore, the diffusion cell method based on the work of Allshiller and Cohen (30) was used to generate standard atmospheres of TDI and was subsequently used to dynamically calibrate the monitors (25). Although no exhaustive interference study was performed at this time, under ideal conditions of the laboratory the monitors correlated $(r=.994)$ well with the standard Marcali method. The monitors were then evaluated in the field against the standard method by simultaneous sampling at varfous locations. Although the correlation ( $r=0.81$ ) in the field testing was not as good as in the laboratory looking at the graph of concentration by standard method vs the monitor indicates (see Figure 12) that at higher TDI concentrations ( $>.005 \mathrm{ppm}$ ) the Marcali method was reading consistently higher than the paper tape monitor. This could be explained by the positive interference in the standard method due to the primary aromatic amines. The primary aromatic amine (Toluene diamine) can be potentially present in the air because it is one of the raw materials used in the manufacture of TDI and it can also be formed by the hydrolysis of TDI itself elther with molsture or by hydrochloric acid in the alr. Hydrochloric acid can be in the air because it is one of the by-products in the manufacture of TDI. Although not confirmed by our untt, it has been reported that the toluene diamine does not interfere with the paper tape monitor method. Therefore, it was concluded the standard method would be overestimating the TDI concentration and cannot be used for TDI exposure characterization. Since then, the paper tape monitors were used exclusively for measuring exposures to TDI. 
C. Area Monitoring

Three model 7000 TDI Area Monitors (31) were used ueginning August, 1973, until the end of 1975. The TDI Druming Bullding and several locations in the plant were monitored. The concentration profile for the two years (August 73 to July 75) in the plant and the Drumming Building is given in Figure 13, where the ordinate indicates the "weekly time weighted averages" expressed as ppm TDI and the abcissa the dates. It is clear from Figure 13 that there is no consistent pattern of exposure. There are a few discontinuities in the profile; they represent perlods where no exposure data are available because of breakdown or malfunction of the TDI monitor. The levels of TDI both in the plant and the Druming Building vary randomly and the exposures for the operators in the Druming Bullding are different and independent of the exposure levels for the plant operators.

During this period there were a number of excursions above the proposed threshold limit value (TLV) of $0.005 \mathrm{ppm}$ TWA and also a few excursions above the current ILV value of $0.02 \mathrm{ppm}$. The percent excursions of weekly time weighted averages above both these levels is given in Table 26. Although from Table 26 it appears that in general the operators working in the plant have higher TDI exposures than those working in the Dauming Building, the table could be misleading for the following reasons: (1) The plant's physical structure is open and unprotected and direction, wind speed, humidity, temperature and precipitation. The Druming Building is a closed system and the wind direction, wind speed and precipitation will have minimal effect on the concentration inside the building. (2) The operators in the plant are not stationary at one location in the plant; they move around considerably. In the Drumming Bullding, the operator's movements are localized and restricted. (3) The plant is much more complex with multiple potential sources of emissions of TDI. To completely characterize and define the environmental levels of TDI, several area monitors would be needed. Even then, since the operators move about the plant it would be extremely difficult to monitor the exact individual exposure. The obvious alternative for quantitation of dose each worker recelves is through personal monitoring which will be discussed in the following section.

In order to evaluate whether the levels of TDI in the plant and the Dramming Building have Increased or decreased an histogram or a frequency distribution of the weekly time weighted averages was prepared, showing the number of weeks for each exposure 1nterval. The two-year period was divided to coincide approximately with the pulmonary function and clinical tests of the workers. The histograms for the plant and the Druming Building are shown in Figures 14 and 15 respectively. The mean value and the standard deviation for each time period is shown along with the histogram. The values indicate that there was 1ittle improvement in TDI levels in the plant until March, 1975, and in the Druming Building there was slight increase in the exposure levels at that time. 
The area monitoring activities were suspended for the studies because as is shown later on in this section, there was no correlation at all because the area monitor estimates of exposure to personal breathing zone estimates of concentration for people working in any general area where the area monitor is located.

D. Personal Monitoring

In June of 1975, continuous TDI personal monitors, based on the paper tape method, capable of continuously monitoring TDI, in the breathing zone of workers for up to eight hours, became commercially available for the first time. Our group acquired 12 personal monitors (Model MCM 4000) along with a reader/recorder (Model MCM 4100); a required accessory to get the exposure profile. The personal TDI monitor essentially works on the same principle as the area TDI monitor. The only differences are in the personal monitor the tape moves at a rate of $2 \mathrm{~cm} / \mathrm{hr}$ compared to $10 \mathrm{~cm} / \mathrm{hr}$ in the area monitor. However, in order to compensate for the stain intensity the sampling rate of personal monitor is $100 \mathrm{ml} / \mathrm{min}$ compared to $500 \mathrm{ml} / \mathrm{min}$ for the area monitor. The personal monitor only collects the alr sample on paper tape. After the collection period, the stain intensity on the paper tape is read using the reader recorder. The concentration profile is recorded on a chart paper called the TDI Datagram. A typical datagram is shown in Figure 16. The datagram also electronically integrates the area under the curve and records the total dose for eight hours in ppm-hrs unit. In other words, the datagram provided by the personal TDI monitor, gives a total history of the TDI exposure to the worker for eight hours on a work shift.

The TDI personal monitors were thoroughly evaluated in the laboratory before they were routinely used in the fleld. The flow rates were checked and adjusted and the battery packs were checked to see if they are capable of sampling at $100 \mathrm{ml} / \mathrm{min}$ for eight hours when they are fully charged according to manufacturer's spectfication. The rate of movement of the tapes was checked in all monitors and was confirmed to be $2.0 \mathrm{~cm} / \mathrm{hr}$. The monitors which could not sustain $100 \mathrm{ml} / \mathrm{min}$ flow rate or if the tape movement was erratic were sent back to the manufacturer. The reasons for not sustaining $100 \mathrm{ml} / \mathrm{min}$ could either be because of a bad battery or because of breakdown of the pump. In either case, appropriate measures were taken to assure proper performance of the personal monttor. The personal monitors were also dynamically calibrated against the standard method. The details of calibration are given in the next section.

Beginning in July, 1975, the workers in the TDI plant, TDI Drumming Building and Tank Farm, Hydrogen and Carbon Monoxide (HYCO) plant, Toluene diamine (TDA) plant, Phosgene plant, Hydrazine plant and a11 the maintenance personnel in these plants were monitored almost continuous ly till the middle of 1978 (three years). Programming schedules were drawn up for six month 
periods in advance. The plant manager, superintendent, safety director and all senior supervisors and shift foremen were given a copy of the schedule. A typical schedule is given in Table 27. The personal samplings were done based on the job title rather than the personnel. In this plant, each job title associated with a certain plant uniquely defined a certain job function. All the job titles in the TDI plant, TDI Drumming, HYCO, Phosgene, TDA plants were monitored. All the job titles were monitored during al1 the three shifts $(8-4,4-12$, and $12-8)$, except the maintenance, drumming personnel and the control population. The maintenance and druming personnel work only during the day shift and so were monitored only in day shifts. The control population were also personally monitored only in the day shift.

'Before embarking on a comprehensive personal monitoring survey, a study was made to determine how well the area monitoring data in the plant and Druming Bullding and personal monitoring of job titles who should be working in the respective areas compared. In other words, whether the TDI levels measured by area monitors truly reflected the personnel exposures. Table 28 summarizes the results of this study. It clearly shows that the area monitors cannot be rellably used for measuring worker exposure. Even those 8-hour-TWA where the correlation was good between area and personal monitors inspection of the respective concentration profiles revealed that the integrated TWA correlation was only coincidental. The individual peaks and excursions were not similar in the datagram and the area monitor strip chart. This study reinforced the need for extensive personal monitoring for exposure characterization.

E. Quality Assurance Programs for Monitoring

(1) General Precautions:

Recognizing the importance of quality control in data collection for such long range prospective studies appropriate measures were taken early in the study. Quality control checks and measures were made in every step of data collection. The technician responsible for checking and issuing the area and personal monitor was given a written protocol of the procedures. He was properly instructed and trained to use the monitoring instrument in terms of calibration, testing of optics, flow rate, zero adjustments, changing of tapes, testing tape movement, etc. The technician maintained a log book, where he entered date, monitor number, calibration, flow rate adjustments and any other relevant adjustments he makes to the personal monitors before it is issued to the workers. He notes the time, date, the monitor number and the name of the person It was issued to for that day. During the shift the monitors were randomly checked to see if they are properly worn. At the end of the shift, the flow rates are checked 
again and noted. Within 24 hours after collection, the paper tapes are read in the reader recorder. During that time, the paper tapes are stored in the dark. As soon as the paper tape is read, the name, job title, the date, shift,time of monitoring and the location of work is entered on the datagram in the field. The datagrams were then checked by the industriaI hygienist at Tulane and then were read and coded for storage in computer. The analysis of the personal monitoring and other data is described elsewhere in the report. All the personal monitors were sent back to the manufacturer for service maintenance and quality control after about 18 months use.

\section{Calibration}

The area and personal monitors were routinely calibrated according to the manufacturer's specification. In the case of area TDI monitor the calibration is checked every day with the "calibration strip" provided with the instrument and the flow meter is checked and necessary adjustments made if necessary. In the case of personal monftors, the battery packs were charged for 14 hours at the end of every eight hour use. The flow rate of the personal monitors were checked using a calibrated rotameter before and after each use. The reader recorder is properly zeroed and the calibration checked before using each day.

In order to establish that the "calibration strip" provided by the manufacturer is accurate, the area monitor is first calibrated with the "calibration strip". Then it is dynamically callbrated against the Marcali method by generating an atmosphere of known TDI concentration. Initially, the standard atmosphere of TDI was generated using the diffusion cell method. Later on in the study a new and more convenient generating method based on permeation was developed (6). When both the area monitor and the Marcali method indicate within experimental errors the same concentration, it is assumed the monitor is calibrated; if not, the standard method concentration is assumed correct and the reasons for differences are investigated. The personal monttors along with the reader/recorder system were also dynamically calibrated the same way.

\section{(3) Interference Studies}

One of the reasons for not using the standard Marcali method for exposure characterization is because the primary amines such as toluene diamine positively interfere in the determination. The toluene diamine (TWA) is a potentlal air contaminant in the manufacture of TDI because TDA is one of the raw materials used. TDA can also be produced in the air by hydrolysis reaction of TDI with moisture or HC1 in the air. Relative humidIty levels in the plant range between $70-80 \%$ through the year. Hydrochloric acid also can potentially be present in the afr because for every mole of 
TDI manufactured, four moles of HCI is obtained as a by-product. HCI wIll readily hydrolyze TDI to TDA.

In the paper tape method, TDA is not an interferent. Investigation in our laboratory has shown that chlorine and nitrogen dioxlde react with the paper to produce a diffuse brown stain. This brown stain is distinctly different from the characteristic bluish-purple stain produced by TDI. The techniclan handling the paper tape for the personal monitor was specifically instructed to check the tapes usually for unusual stains and vold them if there were any on the tapes. Also a preliminary survey of chlorine concentrations in the air was made using Matheson-K1tagawa chlorine detector tubes. Generally, the chlorine levels at different locations in the plant were less than the detection limit of $0.3 \mathrm{ppm}$ at which level the interference in the monitor is not significant. Figure 17 shows the extent of interference of chlorine and nitrogen dioxide with the paper tape monitor.

\section{(4) Evaluation of Response of Reader/Recorder for Personal Monitor Tape}

The miniature continuous paper tape personal monitors (Model MCM-4000) and the Reader/Recorder Model MCM-4100 were evaluated for short term response on exposures to TDI. This kind of an evaluation was felt to be very important because in the real iffe situation the monitor is seeing an environment where the concentration of TDI is rapidly fluctuating and changing in time and space. At the end of the work shift when the tape is removed from the monitor and fed into the reader/recorder the recorder draws out a nice datagram in 30 seconds as shown in Figure 16 . Unt11 now, no one has investigated the degree of accuracy with respect to time, resolution and a combination of time-concentration exposure patterns. The personal monitor has been dynamically calibrated at known concentrations for long periods of time and it has been proved that it reads accurately. This kind of testing does not tell anything about short-term responses, resolution of peaks, or effects on peak broadening, etc. This kind of analysis was important for the study because in one of the analyses of the exposure data we were interested in the amount of time an operator spends above levels of .005, $.01, .02, .04, .06$, and $.08 \mathrm{ppm}$. The study has revealed a significant 1imitation of the personal monitoring system. Figure 18 will be used to explain this limitation. As an example, if a worker wearing the monitor were to be exposed as follows (see Figure 8), 0-10 mins at $0 \mathrm{ppm}$ exposure; 10 to $30 \mathrm{mins}$ at $.02 \mathrm{ppm}$ exposure, 30 to $40 \mathrm{~min}$ at $0 \mathrm{ppm}$ exposure, and 40 to $50 \mathrm{~min}$ again at $.02 \mathrm{ppm}$. Figure 18 shows approximately the shape of peaks obtained compared to what theoretically should be obtained. The worker has been exposed to 30 mins at $.02 \mathrm{ppm}$. Thus, the times measured will be underestimated at lower concentrations. These kind of errors is both time and concentration dependent. Thus, every time the concentration changes up or down because of this response and resolution effect the time estimated would be erroneous. These kinds of rapid changes in concentration and time exposed 
is a very feasible situation in the TDI plant. We also noted that in spite of the peak broadening and shortening effect, the total dose which is the area under all the peaks is correct. Therefore, the calculation of the time weighted average concentration is correct.

The reasons for these response effects are:

(a) Because the paper tape in the personal monitor moves at a speed of $2 \mathrm{~cm} / \mathrm{hr}$, the whole history of exposure for 8 hours is recorded in $16 \mathrm{~cm}$ length of the tape.

(b) The tape runs through the reader/recorder at a speed of a $1 \mathrm{~cm} / \mathrm{second}$. In other words, the eight hours of exposure history is read in 16 seconds.

(c) The recorder pen does not respond with the same speed. Therefore, the time estimate errors are amplified at higher concentrations and lower times of exposure. At concentration less than .01 ppm, the errors do not seem to be very significant.

(d) Because the photometer scans the stain throughout its length, the peak broadening compensates for peak height and the total effective area under the curve is measured accurately. Therefore, the total dose and time weighted average measurements are accurate.

In spite of these 1imitations considering the accuracy of TWA measurements, the capabllity of indicating the exposure proflles and the versatility and simplicity of the paper tape monitors we feel the paper tape personal monitors are the best method currently avallable for environmental characterization of TDI for long-term epidemiologic studies,

\section{(5) Effect of Temperature on Measurements of TDI w1th}

\section{Continuous Reading Monitors}

There are no published reports so far about the effect of temperature on the measurement of TDI using the Mode1 7000 TDI monitor. The personal and/or area monitoring was done throughout the year and the monitors were subjected to a wide range of temperatures $\left(0-35^{\circ} \mathrm{C}\right)$. Therefore, a study was conducted to evaluate the performance of these monitors at various temperatures. Figure 19 shows a plot of the ratio of Marcall method concentration to the Model $700 \mathrm{C}$ reading vs temperature for various TDI concentrations.

The monitor seems to agree well ( $<20 \%$ error) with the Marcali method at $0^{\circ}, 9^{\circ} \mathrm{C}, 17^{\circ} \mathrm{C}$ and $23^{\circ} \mathrm{C}$. At $4^{\circ} \mathrm{C}$, there are 3 points: one with 
$40 \%$ error and two with 1 ess than $30 \%$ error. Because the study was conducted outdoors during winter time, we could not repeat the study at $4^{\circ} \mathrm{C}$. Considering the variability of temperature, humidity, formation of TDI condensation aerosols, etc., we feel there is no significant temperature effect on measurement with continuous monitor.

Effect of Humidity on Measurement of TDI with Continuous Reading Monitors

Standard atmospheres of TDI were generated at various humidities and simultaneously measured with the Model 7000 monitor and the Marcali method. Figure 20 shows the results of this study. The paper tape monitor consistently reads lower at $0 \% \mathrm{RH}$. Between 20 to $100 \% \mathrm{RH}$, the average errors are within $20 \%$. Since the average relative humidity at the plant is between 70 to $80 \%$, we assumed that the humidity does not have any significant effect on measurements of afrborne TDI.

\section{F. $\quad$ Miscellaneous Studies}

Because phosgene is one of the raw materlals used in the manufacture of TDI and it is a well known respiratory irritant, a pilot scale survey was made to determine the extent of exposure to the study population. Personal phosgene monitors (MCM-4000) similar to the YDI monitors were used for this evaluation. Table 29 summarizes the results of this survey. It is clear from this table that the phosgene exposures were relatively minimal (0.004 ppm) when compared to the NIOSH recommended TWA of $0.1 \mathrm{ppm}$ for up to 10 hour-day work week and a ceiling of $0.2 \mathrm{ppm}$. 
APPENDIX 2

\section{STATISTICAL CONSIDERATIONS}

\section{A. Statistical Methodology Used to Define Exposure Categorles}

In the Environmental Characterization section, three exposure categories based on TDI concentration as measured by 8-hour time-weighted averages and four exposure categortes based on peak TDI exposure as measured by time the instantaneous TDI concentration was above .02, .04, .06, and $.08 \mathrm{ppm}$ were defined. This section describes the statistical methodology used to construct these exposure categorles.

The construction of the exposure categorles based on TDI concentration begins with 8-hour tine-weighted averages for 1949 personal samples on $42 \mathrm{job}$ titles. Since the frequency distribution of the time-weighted averages was markedly skewed to the right, the time-welghted averages were transformed by taking logarithms to the base 10. The logarithm scale was divided into elght categorles using division points $-3.60,-3.30,-3.00$, $-2.70,-2.40,-2.10$, and -1.80 , These points correspond to division points $.00025, .0005, .001, .002, .004, .008$, and $.016 \mathrm{ppm}$ on the original scale. The lowest category on the $\log _{10}$ scale is called category 1 , the next highest category 2 , etc.

The frequency distribution by $\log _{10}$ category for the 1949 personal samples is given in Figure 1. It is approximately symmetrical. function:

Each of the $42 \mathrm{jobs}$ is represented by its cumulative distribution

$$
\left(\mathrm{p}_{1}, \mathrm{p}_{2}, \mathrm{P}_{3}, \mathrm{p}_{4}, \mathrm{p}_{5}, \mathrm{p}_{6}, \mathrm{p}_{7}\right)=\left(\mathrm{p}_{1}\right)_{ \pm=1}^{7}
$$

where $p_{1}$ is equal to the proportion of time-weighted averages in $\log _{10}$ scale category 1 or less. The distance between two Jobs represented by:

$$
\left(p_{11}\right)_{1}^{7}=1 \quad \text { and } \quad\left(p_{21}\right)_{1}^{7}=1
$$

Is then defined to be:

$$
\left[\sum_{i=1}^{7} \quad\left(\mathrm{p}_{11}-\mathrm{p}_{21}\right)^{2}\right]^{1 / 2}
$$

Then two jobs are "similar" if the distance between them 18 small and "dissimilar" if the distance between them is large. 
Figures 21 and 22 contain histograms for several jobs together with the distances between them.

The distance between E-operators in druming and the bug pond operators is 1.13 making them far apart. The histogram in Figure 21 visually confirms this separation. On the other hand, the TDI foreman and the D-operators in phosgene (Figure 22) are quite similar with .097 distance between them. Intermedlate between those two extremes are A-operators in TDI and D-operators in phosgene (Figure 22) with . 37 distance between them, TDI foreman and bug pond operators (Figure 2I) with distance .56 between them, and E-operators in druming and TDI foreman (Figure 21) with distance .67 between them.

Using those 21 jobs with 10 or more personal samples, a cluster analysis was performed utilizing the above distance function. The BMDP2M ( 32 ) cluster analysis of cases algorithm using options SUMOFSQ and NO STANDARDIZE with weights equal to the number of samples in job was used to perform the computations. When this algorithm combined clusters, the cumulative distribution of the new cluster was computed as the weighted average of the two component cumulative distributions using weights equal to the number of samples in each component.

Visual inspection, without knowledge of job titles, of the cluster tree produced by BMDP2M resulted in three distinct clusters of Jobs forming the basis of three exposure categories. Each of the remaining 21 jobs was then assigned to the category corresponding to the cluster to which it was nearest.

Histograms on the $\log$ scale and descriptive statistics in ppm for each of the three exposure categories are presented in Figure 2 and Table 5 respectively. The jobs which make up each category are 11sted in Table 4. The distances between the HIGH and MODERATE categories and between the MODERATE and LOW categorles are .56 and, 41 respectively,

In determining the peak exposure categories described on the Environmental Section, all 2093 personal samples were used. A job was represented by four numbers

$$
\left(q_{2}, q_{4}, q_{6}, q_{8}\right)
$$

where $q_{1}$ equals the proportion of time above .01 ppm for $1=2,4,6,8$.

Dfstance between jobs was defined in a manner analogous to that in the cumulative exposure case and a similar clustering performed. This resulted in four peak exposure categories as described in Tables 6 and 7 . 
B. Statistical Methodology Used in Long1tudinal Pulmonary Function Analysis

A large part of our effort in accessing the respiratory health effects of exposure to TDI has been directed at relating, after controlling for smoking and atopic status, pulmonary function annual change to an index of exposure. Annual change for a partlcular pulmonary function parameter, say $\mathrm{FEV}_{1}$, was computed for each study participant with three or more usable determinations of $\mathrm{FEV}_{1}$ as the slope of the least squares regression line using $\mathrm{FEV}_{1}$ as dependent variable and time since inftial visit as the independent variable. In this section, the statistical methodology for relating annual changes determined in this way to explanatory varlables is developed.

For the $i^{\text {th }}(1=1,2, \ldots, N)$ study participant, let

$$
y_{1 j}=a_{1}+\beta_{1}\left(t_{1 j}-\bar{t}_{1}\right)+n_{1 j}
$$

denote the linear regression of $\mathrm{FEV}_{1}$ on time, Here the $t_{1 j}$ 's $\left(j=1, \ldots, \mathrm{n}_{1}\right)$ represent those time points for which usable $\mathrm{FEV}_{1}$ 's are available for the $1^{\text {th }}$ participant, $\bar{t}_{i}$ is the mean of the $t_{i j}$ 's, the error terms $\eta_{1 j}$ are assumed independent and nomally distributed with mean 0 and variance $\tau^{2}$ Independent of study participant, $\alpha_{1}$ is the value of the $1^{\text {th }}$ study participant's true regrassion line at $\bar{t}_{1}$, and $B_{1}$ is the slope of the true regression 1ine. Then each $\alpha_{1}$ and $B_{1}$ are estfmated respectively by the usual least squares estimators:

$$
\begin{aligned}
& a_{i}=\frac{1}{n_{1} \sum_{j=1}^{n_{1}} y_{1 j} \text { and }} n_{n_{1}}^{\sum_{j=1}^{j} y_{1 j}\left(t_{1 j}-\bar{t}_{1}\right)} \\
& \sum_{j=1}^{n_{1}}\left(t_{1 j}-\bar{t}_{1}\right)^{2}
\end{aligned}
$$


In addition, $\tau^{2}$ is estimated by

$$
\tau^{2}=\sum_{i=1}^{N} \sum_{j=1}^{n} \frac{\left(y_{1 j}-a_{1}-b_{1}\left(t_{1 j}-\bar{t}_{1}\right)\right)^{2}}{\sum_{i=1}^{N}\left(n_{1}-2\right)}
$$

with $\sum_{j=1}^{i}\left(n_{1}-2\right)$ degrees of freedom. Moreover, the varfance of the estimator $b_{1}$ is given by

$\frac{\tau^{2}}{\sum_{j=1}^{n} \quad\left(t_{i j}-\bar{t}_{1}\right)^{2}}$

which depends on the observation times for the $i^{\text {th }}$ participant.

Now let $x_{11}, x_{12}, \ldots, x_{1 k}$ denote the independent variables for the $i^{\text {th }}$ participant with $x_{11}=1$ for all 1 . For example with $k=4$, $x_{12}$ might be cumulative exposure, $x_{13}$ a dumny variable representing atopic status, and $\mathrm{x}_{14}=$ pack=years of cigarette smoking. Then we wish to estimate the coefficients in the expression

$$
\beta_{1}=\sum_{j-1}^{k} \quad \gamma_{j} \quad x_{1 j}+\varepsilon_{1}
$$

where $\beta_{1}$ is the true slope for the $1^{\text {th }}$ participant, the $\varepsilon_{1}$ are independent and normally distributed with mean 0 and variance $\sigma^{2}$. Thus $\sigma^{2}$ is the variance of the time annual changes. $\beta_{1}$ not accounted for by explanatory variables $\mathrm{x}_{11}, \ldots, \mathrm{x}_{1 \mathrm{k}}$. 
Standard regression techniques using the observed slopes as dependent variable can not be used to estimate the $\gamma^{\prime} s$ in (1) because the variance of the observed slopes is not homogeneous. In order to take this lack of homogeneity into account, we proceed as follows:

$$
\begin{gathered}
\text { Assume } b_{1} \text { and } B_{1} \text { are related by } \\
b_{i}=\beta_{1}+\delta_{1}
\end{gathered}
$$

where the $\delta_{1}$ are independent and normally distributed with mean 0 and variance $\tau^{2} \sum_{j=1}^{n} \quad\left(t_{1 j}-E_{1}\right)^{2}$. Furthermore, assume that the $\varepsilon_{1}$ in (1) and the $\delta_{1}$ are independent. It then follows that the observed slopes $b_{1}$ satisfy

$$
\sigma_{i}=\sum_{j=1}^{k} \quad \gamma_{j} x_{1 j}+\varepsilon_{1}+\delta_{1}
$$

where the $\delta_{1}+\varepsilon_{1}$ are Independent and normally distributed with mean 0 and variance

$$
\left.\sigma^{2}+\tau_{j=1}^{2} \sum_{j=1 j}^{n}-\bar{t}_{i}\right)^{2}
$$

In this model $\sigma^{2}=\operatorname{Varlance}\left(\varepsilon_{1}\right)$ is the variance of the true slopes not accounted for by the $x_{11}, x_{12}, \ldots, x_{1 k}, \tau^{2}$ is the residual variance about an Individual partictpant's regression line, and $\tau^{2} \sum_{j=1}^{n}\left(t_{1 j}-\bar{t}_{1}\right)^{2}$ is the variance of the estimation error associated with the observed slope $b_{i}$. 
Since the coefficients $\gamma_{f}$ in (2) are the same as those in (1), model (2) which relates the observed slopes to explanatory variables can be used to estimate the coefficients in model (1) which relates true slopes to the explanatory variables. Because the variances of the $\varepsilon_{1}+\delta_{1}$ in (2) are heterogeneous, unwelghted multiple regression techniques should not be used to estimate the $\gamma_{j}$ 's in (2). Since consistent estimators of $\sigma^{2}+\tau^{2} \sum_{j=1}^{n}\left(t_{i j}-\bar{t}_{1}\right)^{2}$, as required by weighted regression procedures are not available, the $\gamma_{f}^{\prime}$ s and $\sigma^{2}$ have been estimated by maximizing the I1kelthood of $b_{i}$ 's with respect to the $\gamma_{j}^{\prime} s$ and $\sigma^{2}$ at the observed value of

$$
\hat{\tau}^{2}=\frac{\sum_{j=1}^{N} \sum_{j=1}^{n}\left(y_{1 j}-a_{1}-b_{1}\left(t_{1 j}-\bar{t}_{1}\right)\right)^{2}}{\sum_{\substack{j=1 \\ 1}}^{N}\left(n_{1}-2\right)}
$$
Specifically, letting $k_{1}=\sum_{j=1}^{n_{1}} \quad\left(t_{1 j}-\bar{t}_{1}\right)^{2}$, the $\log$ Iikelihood of the $\beta_{i}$ 's is

$$
-\frac{N}{2} \ln 2-\sum_{i=1}^{N} \frac{1}{2} \ln \left(\sigma^{2}+\tau^{2} / k_{1}\right)-\sum_{i=1}^{N} \frac{\left(b_{1}-\sum_{j=1}^{k} \gamma_{j} x_{i j}\right)^{2}}{2\left(\sigma^{2}+\tau^{2} / k_{1}\right)}
$$

whtck. yield likelthood equations at the observed value of $\hat{\tau}^{2}$ : 


$$
\left.\begin{array}{l}
\sum_{i=1}^{N} \frac{\left(b_{1}-\sum_{j=1}^{k} \gamma_{j} x_{1 j}\right) x_{1 l}=0}{\left(\sigma^{2}+\hat{\tau}^{2} / k_{1}\right)} \\
\sum_{i=1}^{N}\left\{\frac{\left(b_{1}-\sum_{j=1}^{k} \gamma_{j} x_{1 j}\right)^{2}}{\left(\sigma^{2}+\hat{\tau}^{2} / k_{1}\right)^{2}}-\frac{1}{\sigma^{2}+\hat{\tau}^{2} / k_{1}}\right\}
\end{array}\right\}
$$

A solution to these equations was obtained using the International Mathematical and Statistical Libraries' subroutine ZSYSTM which solves systems of non-1inear equations.

Starting values for this iterative procedure were obtained in the following manner:

1. Letting $b_{1}=\theta+\varepsilon_{1}+\delta_{1}$ with the variance of $\varepsilon_{1}$ equal to $\sigma_{0}^{2}$ and

$$
\bar{b}=\frac{\sum_{i=1}^{N} k_{1} b_{1}}{\sum_{i=1}^{N} K_{1}},
$$

it follows (See Section 16.5 of (34) for an analogous computation) that the expected value of

$$
\frac{1}{N-1} \sum_{1=1}^{N} K_{1}\left(b_{1}-\bar{b}\right)^{2} \text { is } \hat{\tau}^{2}+\frac{W 0}{N-1} \sigma_{0}^{2}
$$




$$
\begin{gathered}
\text { where } W_{0}=\sum_{i=1}^{N} K_{1}-\frac{\sum_{i=1}^{N} K_{1}^{2}}{\sum_{i=1}^{N} K_{1}} \text { This results in } \\
\hat{\sigma}_{0}^{2}=\frac{\sum_{1-1}^{N} K_{i}\left(b_{i}-\bar{b}\right)^{2}-(N-1) \tau^{2}}{W_{0}}
\end{gathered}
$$

as an estimate of $\sigma_{0}^{2}$.

2. Regress $b_{1}$ on the $x_{11}, x_{12}, \ldots, x_{1 k}$ using weights equal to

$\left(\hat{\sigma}_{0}^{2}+\frac{\tau^{2}}{\mathrm{~K}_{i}}\right)^{-1}$ and take as starting values for the iterative equation solving procedure, $\hat{\sigma}_{0}^{2}$ and the coefficients $\gamma_{01}, \gamma_{02}, \ldots, \gamma_{0 k}$ obtained from this weighted regression.

The variance-covariance matrix of the estimators was estimated by the inverse of the negative of the information matrix evaluated at the solution of the likelihood equations. Inference on the estimated regression coefficients was based on the asymptotic normallty of maximum likelihood estimators.

As examples of above procedure, consider the following two cases using $\mathrm{FEV}_{1}$ annual change: 
(1) $\quad k=1$ and $x_{11}=1$ for all 1 .

(2) $k=4$ and $x_{11}=1$ for al1 1 .

$$
\begin{aligned}
& x_{12}=\left\{\begin{array}{l}
0 \text { if cumulative exposure } \leq .0682 \text { ppm-months } \\
1 \text { otherwise }
\end{array}\right. \\
& x_{13}=\left\{\begin{array}{l}
0 \text { if } 1^{\text {th }} \text { participant is non-atoplc } \\
1 \text { otherwise, and }
\end{array}\right.
\end{aligned}
$$

$$
x_{14}=\text { pack-years of cigarette smoking . }
$$

In this situation $\mathrm{N}=223$,

$$
\begin{aligned}
& \hat{\tau}^{2}=.017572 l^{2} \text { with } 928 \text { degrees of freedom, } \\
& \frac{\sum_{1=1}^{N} K_{1} b_{1}}{\sum_{1=1}^{N}} K_{1} \\
& \sum_{i=1}^{N} K_{1}\left(b_{1}=\bar{b}\right)^{2}=6.2107, \text { and } \\
& \sigma_{0}^{2}=.000791 l^{2} .
\end{aligned}
$$

Then for example (1) using $-.0240 \ell$ for $\gamma_{01}$ and $.000791 \ell^{2}$ for - 
$\hat{\sigma}_{0}^{2}$, we obtaln; $\hat{\gamma}_{1}=-.0244 l$ with standard error $=.00316$ and

$\hat{\sigma}^{2}=.000652 \ell^{2}$. In this case, $\gamma_{1}=-.0244$ is the maximum likelihood estimate of mean $\mathrm{FEV}_{1}$ annual change and $\hat{\sigma}=.0255 \ell$ is the maximum likelihood estimate of between true slopes standard deviation.

$$
\text { The quantity } .000652+\frac{.017572}{\sum\left(t_{j}-\bar{t}\right)^{2}}
$$

is the estimated variance of an observed slope calculated from time points

$t_{1}, t_{2}, \ldots, t_{n}$ and $.000652 /\left(.000652+\frac{.017572)}{\Sigma\left(t_{j}-\bar{t}\right)^{2}}\right.$ is the proportion

of this variance due to "between true slopes". Th1s is the variability we are attempting to explain by exposure to TDI, atopic status, and pack years of smoking. For a particlpant with $\mathrm{FEV}_{1}$ readings at all nine visits $\Sigma(t,-\bar{t})^{2}=26.45$ so that 49.5 per cent of variability in such a participant's annual change is available for explanation by the explanatory variables. For example (2) startings values $-.0118,-.0123, .0010,-.00059$, and .000791 were obtained for the intercept, coefficlent of exposure categorization, coefficlent of atopic status, coefficlent of pack-years, 
and $\sigma^{2}$ respectively. Five iterations were required to satisfy the ZSYSTM stopping criteria with EPS $=10^{-6}$ and NSIG $=9$ (See IMSL ZSYSTM documentation for definitions of EPS and NSIG.) The resulting regression equation 1s:

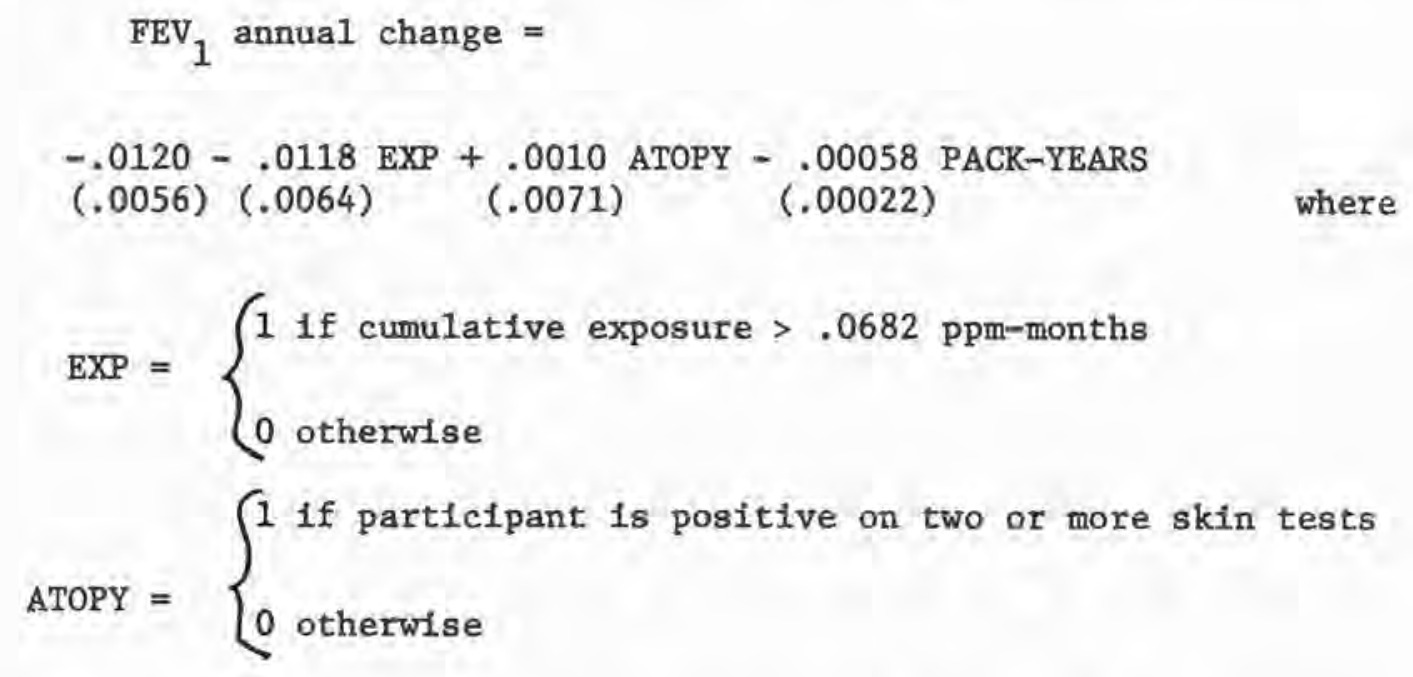

and the numbers in parentheses are the standard errors of the regression

coefflcient. The maximum likelihood estimate of $\sigma^{2}$ (the between true slope varlability after removing variability explained by exposure category, atopic status, and pack years of smoking) is .000591 $\ell^{2}$. Thus using the results of previous example, 9.4 percent of the true slope vartability is explained by these three variables. 
APPENDIX 3

Interview Forms, Symptom Criteria, and Editorlal Programs 
Tul-LSU Sch. Med. Pul, Dis.-Immuno.
OCCUPATION IL STUDY VIII Inte rview

Olin

ready to he keypunched

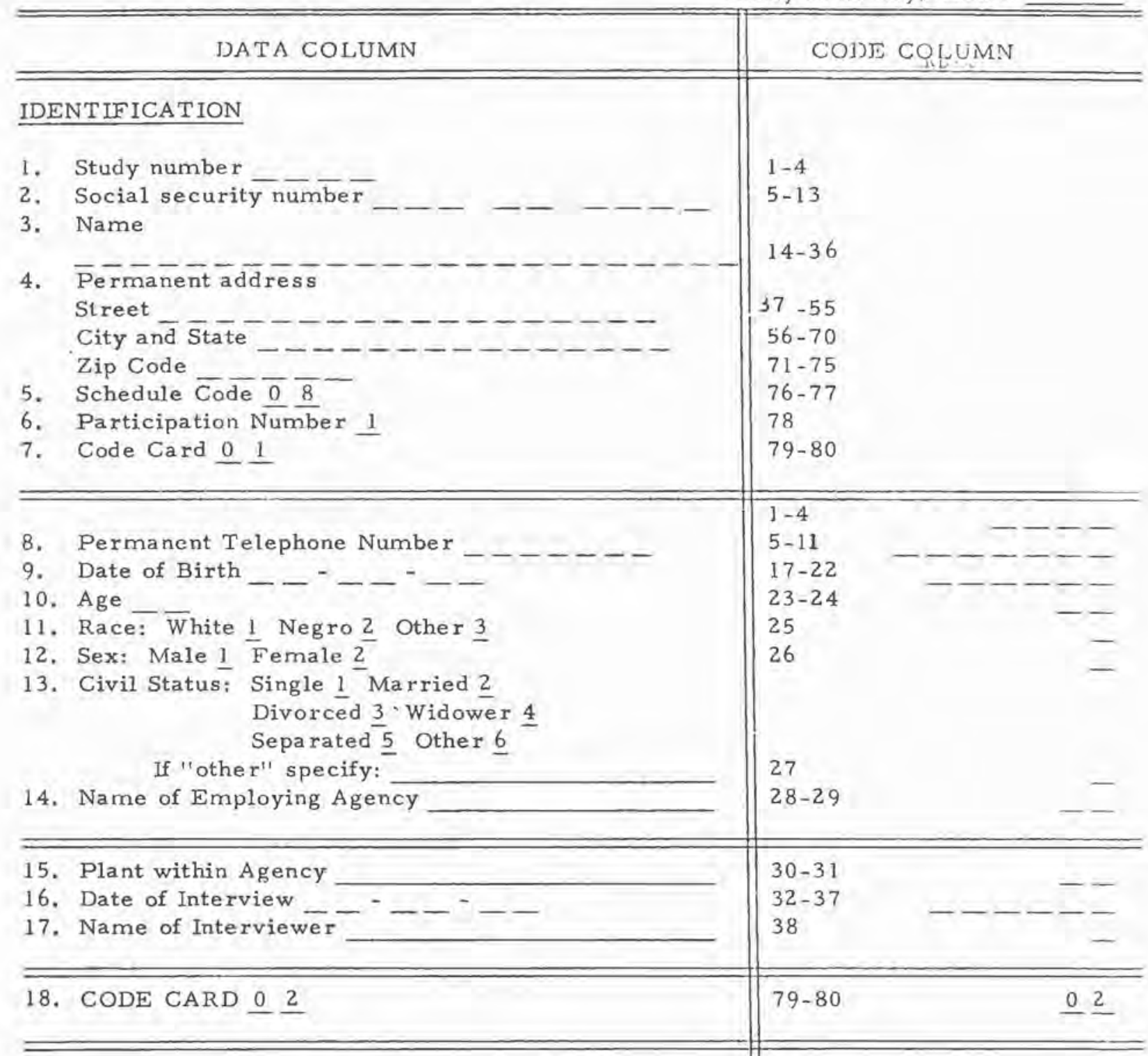




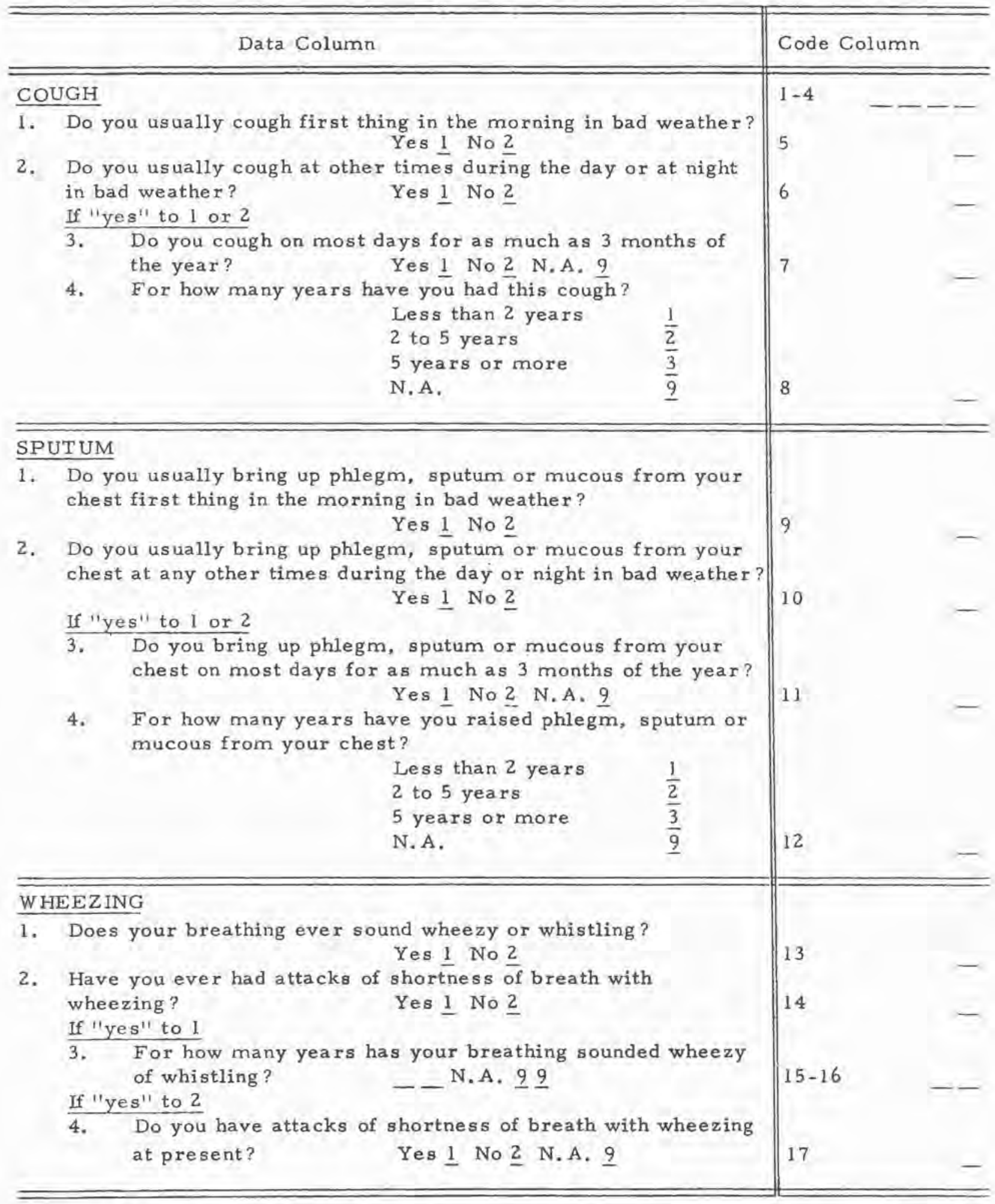




\begin{tabular}{l||l}
\hline \hline Data Column & Code Column \\
\hline
\end{tabular}

\section{BREATHLESSNESS}

1. Are you troubled by shortness of breath when hurrying on level ground or walking up a slight hill? Yes $1 \underline{1}$ No $\underline{2}$

2. Do you get short of breath when walking with other people your own age on level ground? Yes 1 No $\underline{2}$ If "yes" to 1 or 2

$$
\text { Yes } 1 \text { No } \underline{2}
$$

3. For how many years have you had shortness of breath?

$$
\text { N. A. } \underline{9} \underline{9}
$$

\section{CHEST ILLNESS}

1. During the past 3 years, how much trouble have you had with illnesses such as chest colds, bronchitis or pneumonia?

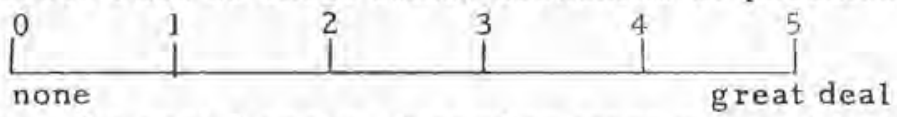

2. During the past 3 years, how often were you unable to do your usual activities because of illnesses such as chest colds, bronchitis or pneumonia?

One time
$2-5$ times
more than 5 times $\quad \frac{1}{3}$

3. Do you think you have ever had any of these chest disorders: asthma, any kind of bronchial trouble, or emphysema?

$$
\text { Yes } \underline{1} \text { No } \underline{2} \text { D.K. } 3
$$

4. Has a doctor ever told you that you had a sthma, some kind of bronchial trouble, or emphysema? Yes $\underline{1}$ No $\underline{2}$ If "yes" to 4

5. Which type?

6. Have you ever had repeated attacks of pneumonia? N. A. 9

$$
\text { Yes } 1 \text { No } 2
$$

7. Have you ever been hospitalized for

$\begin{array}{ll}\text { Pleurisy } & \text { Yes } \frac{1}{1} \text { No } \frac{2}{2} \\ \text { Tuberculosis } & \text { Yes } \underline{1} \text { No } \underline{2}\end{array}$

8. Have you ever had a chest injury or chest operation? If "yes" when?

$$
\text { Yes } 1 \text { No } \underline{2}
$$

NASAL CATARRH

1. Do you usually have a drip at the back of your nose? If "yes" to I

$$
\text { Yes } 1 \text { No } \underline{2}
$$

2. Do you have a drip at the back of your nose for as much as three months?

3. Have you ever had hay fever?

\section{Yes 1 No 2 N.A. $\underline{9}$} Yes $\frac{1}{1}$ No $\frac{2}{2}$
$20-21$ 
Tul-LSU Sch. Med.

OCCUPATIONAL STUDY VIII

Schedule B

Pul. Dis.-Immuno.

Inter view

Page 4

Olin

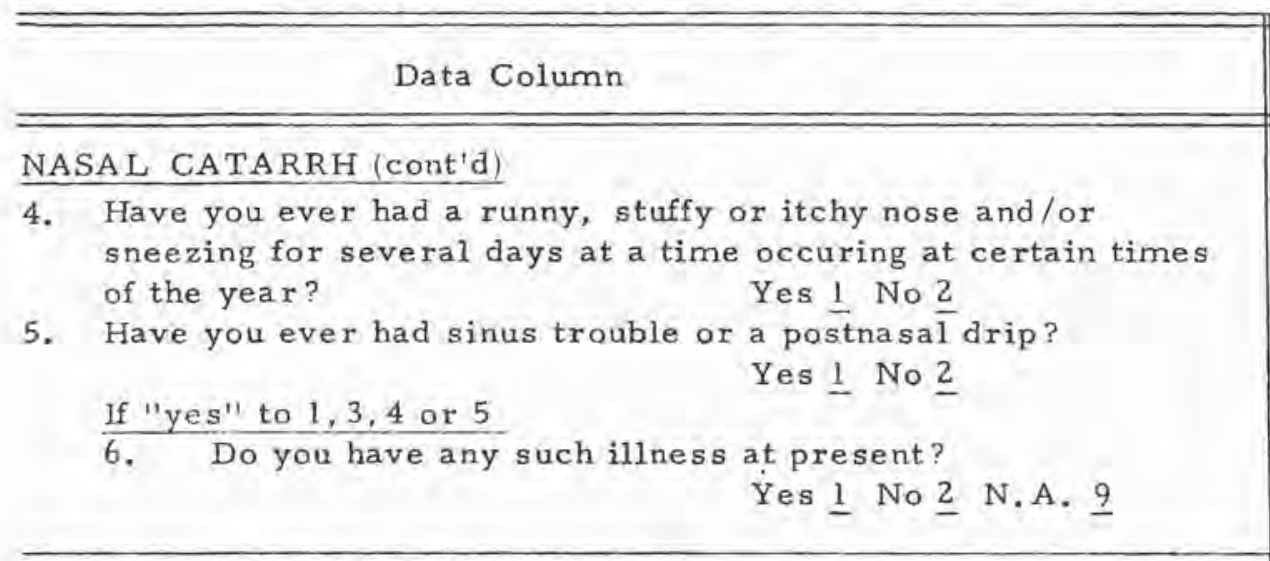

ADDITIONAL A LLERGY HISTORY

1. Have you ever had atopic dermatitis, by which I mean a scaling rash that occurs in elbow creases, behind the knees and/or sometimes behind the ears? Yes 1 No 2

2. Have you ever had urticaria, by which I mean swollen red spots on the skin which may or may not be itchy?

If "yes" to 1 or 2

Yes 1 No $\underline{2}$

3. Do you have either such illness at present?

Yes 1 No 2 N.A. $\underline{9}$

4. Have you had more than 2 head colds each yea $\bar{r}$ for some time? If "yes" to 4

Yes 1 No $\underline{2}$

5. When you have a head cold, do you have runny, stuffy or itchy nose and/or sneezing for several days at a time?

Yes 1 No 2 N.A. $\underline{9}$

6. Do any members of your immediate family (mother, father, brothers, sisters) have any of the allergies I have mentioned: a) asthma (attacks of shortness of breath with wheezing); b) hay fever; sinus trouble; post nasal drip; a runny, stuffy or itchy nose and/or sneezing for several days at a time occurring at certain times of the year; c) atopic dermatitis or d) urticaria? Yes $\underline{1}$ No $\underline{2}$ If "yes" to 6

7. Which family member and what type allergy? Mother 1

Allergy: a $\underline{1} \quad b \underline{2} \quad c \underline{3} \quad d \underline{4}$

Father $\underline{2}$

Allergy: a $\underline{1} \quad b \underline{2} \quad c \underline{3} \quad d \underline{4}$

Sister 3

Allergy: a 1 b 2 c $\underline{3}$ d $\underline{4}$

Brother 4

Allergy: $a \underline{1} b \underline{2} \quad c \underline{3} \quad d \underline{4}$

Code Column

34

35

36

37

38

39

40

41

42

45

46

50

51

55

56

60

61 
Tul-LSU Sch. Med. Pul. Dis.-Immuno.
OCCUPATIONA L STUDY VIII

Interview

Olin
Schedule B

Page 5

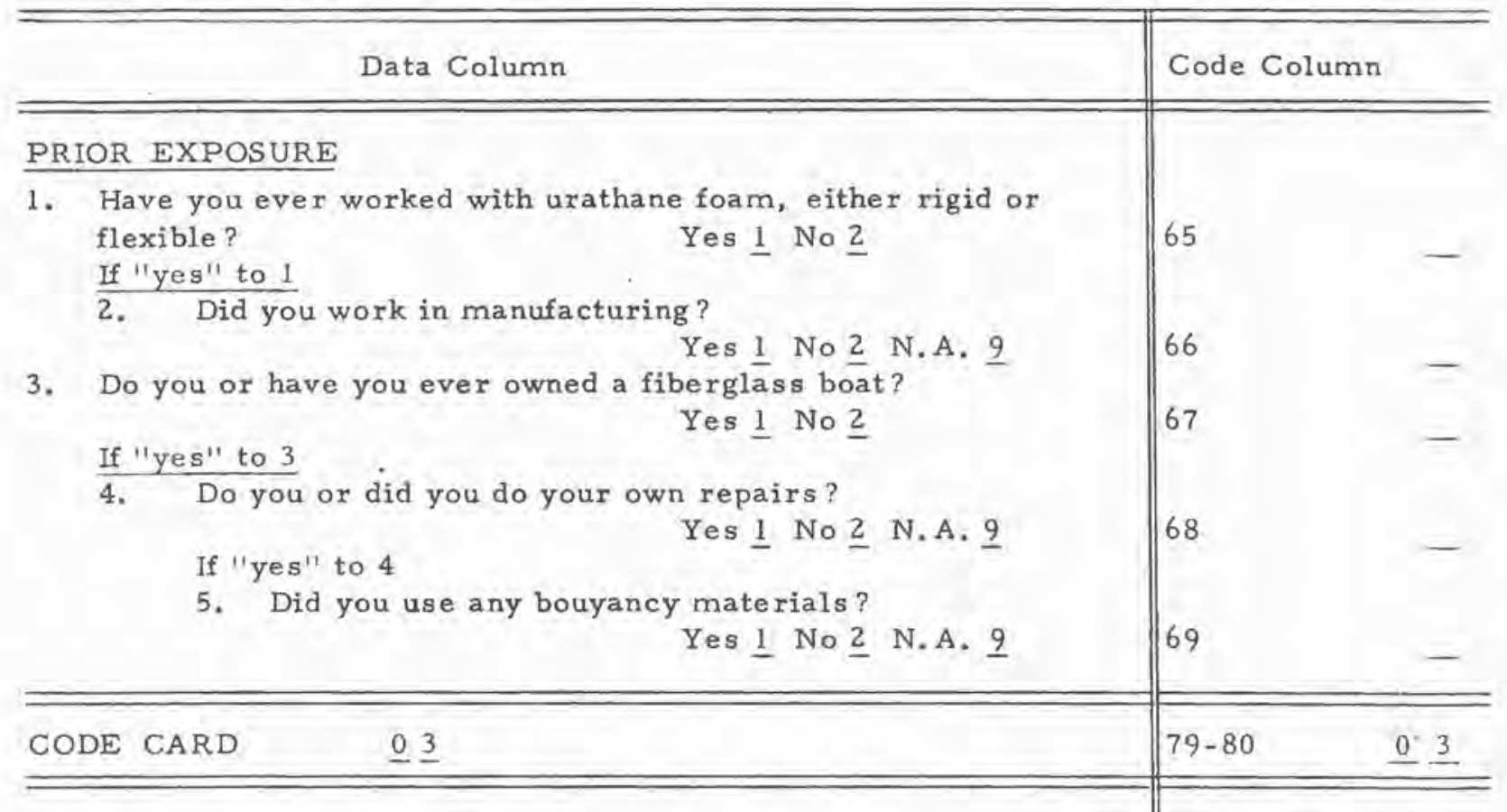


Tul-LSU Sch. Med.

Pul. Dis.-Immuno.
OCCUPATIONAL STUDY VIII

Interview

Olin
Schedule B

Page 6

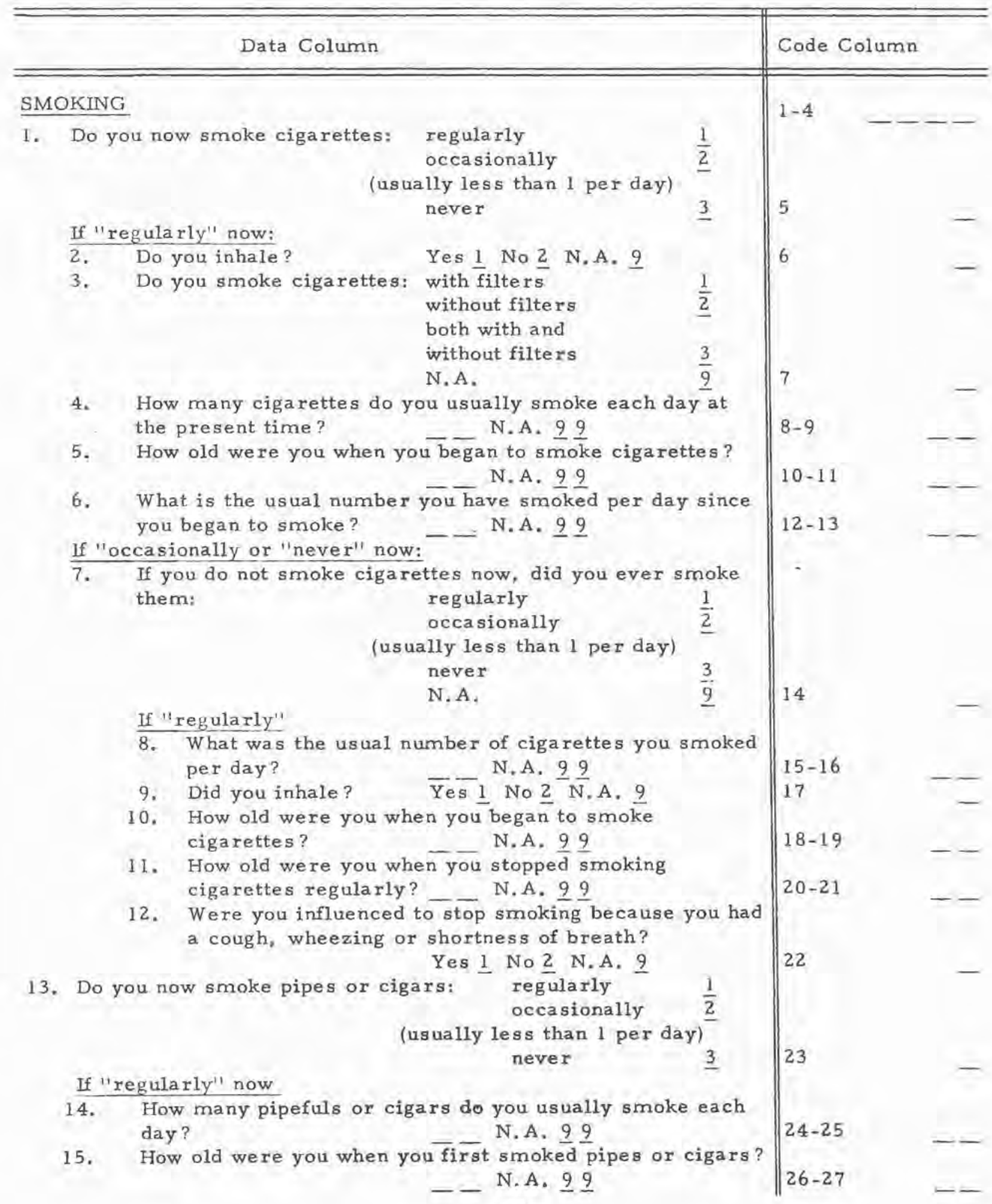


Tul-LSU Sch. Med. Pul. Dis.-Immuno.

Olin

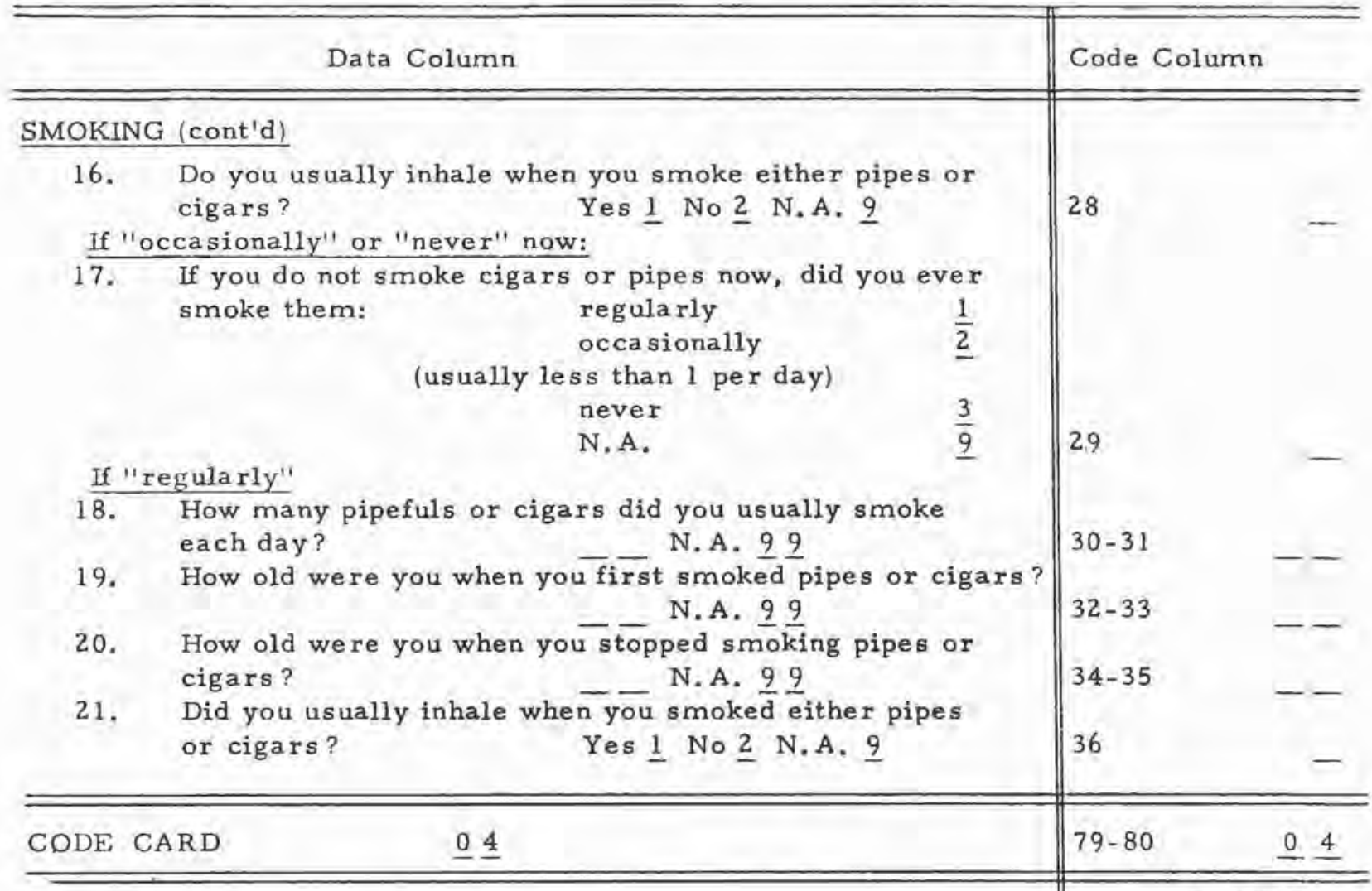

April, 1973 
OCCUPATIONAL HISTORY

Now I would like for you to tell me about each of the places you have worked and the types of jobs you have done. Please begin by telling me about your present job. Include part time jobs. Exclude jobs held for less than one (1) year.

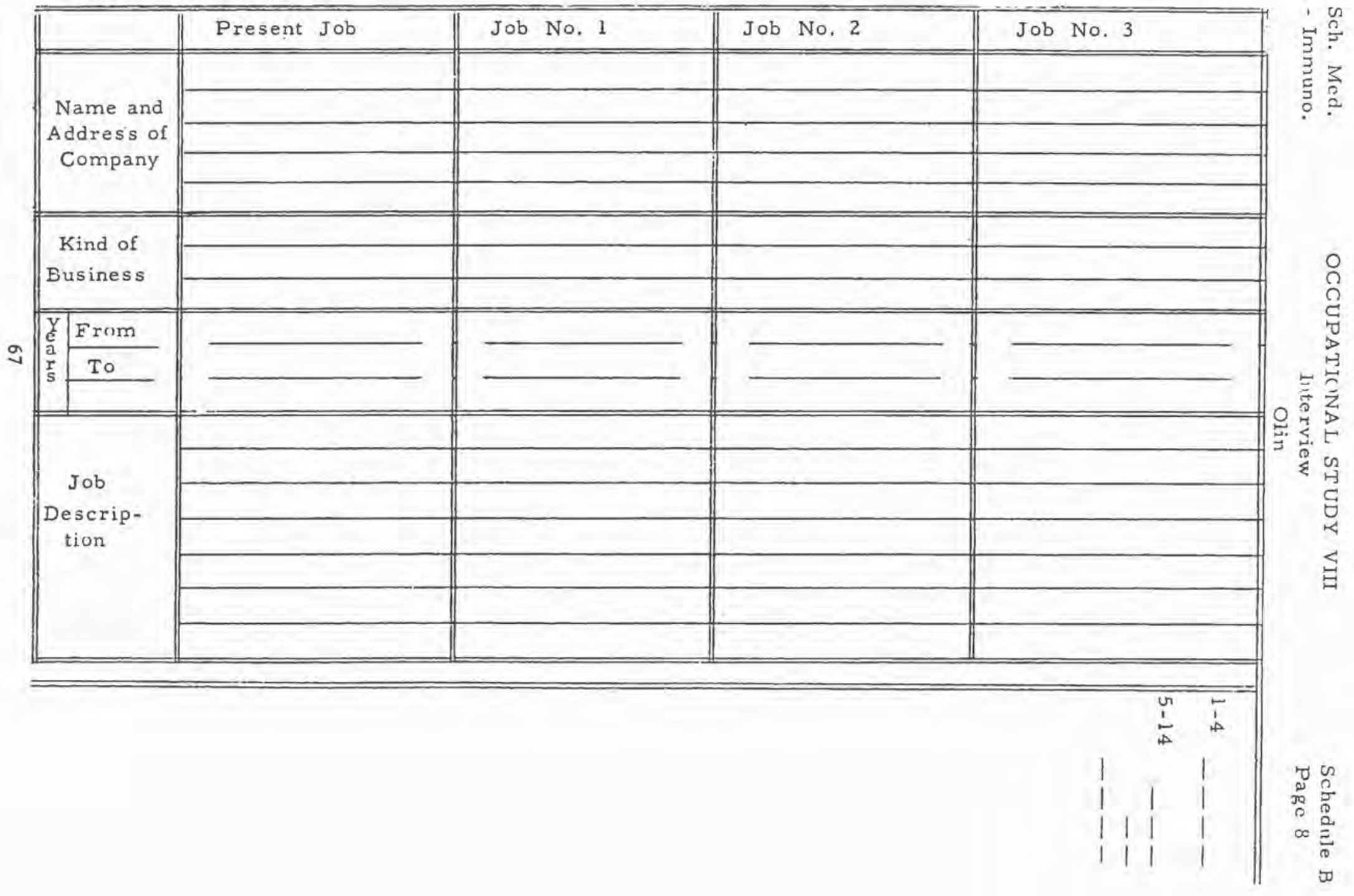


Tul,-LSU Sch. Med.

Pul. Dis.-Immuno.

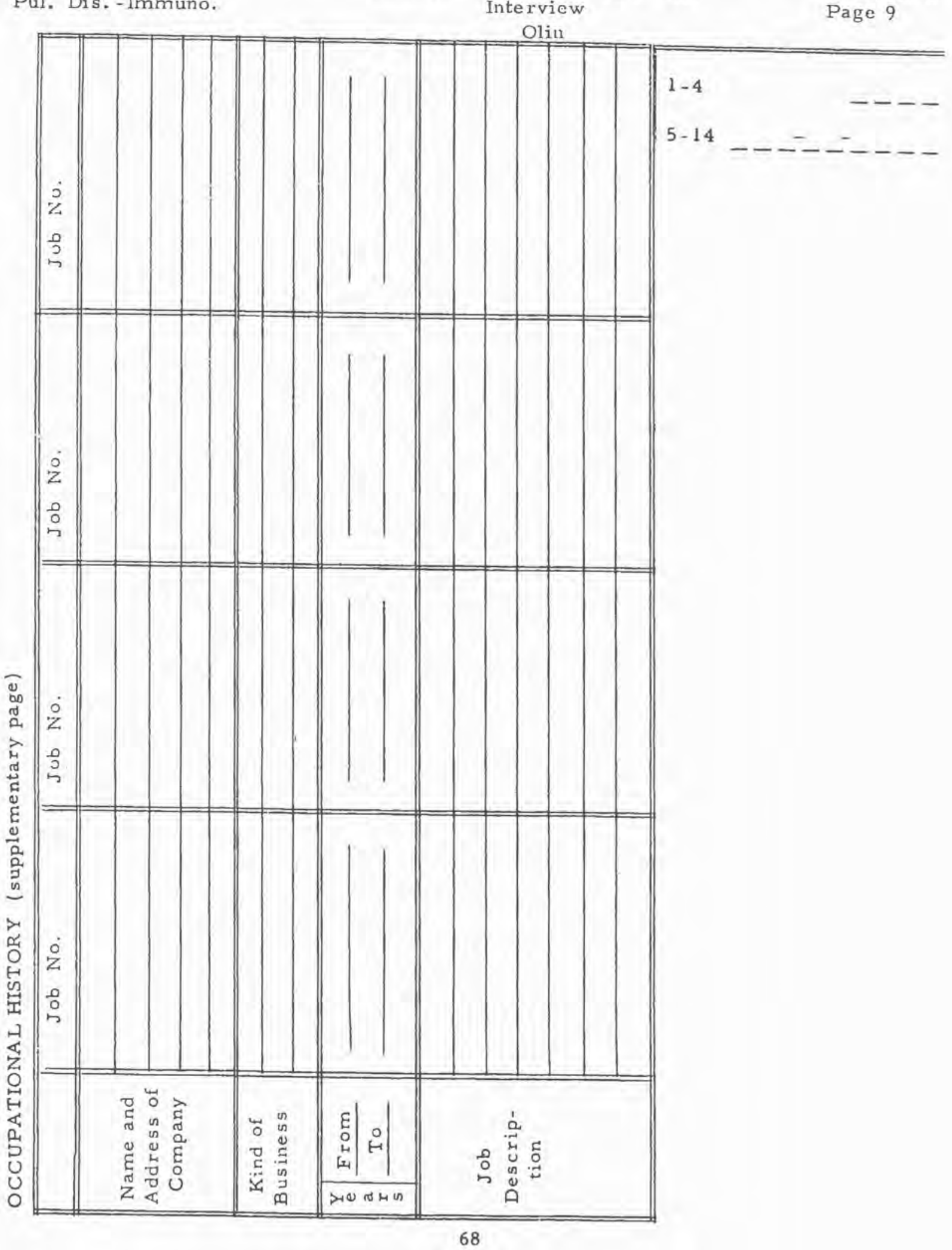

Schedule B

Page 9 
Tul, Sch. Med.

Pal. Dis. - Immuno.
ÓCCUPATIONA1, STUDY VIII

Follow-UP I'iter view

Oli.
Schedule bl

ready to he keypunched

DATA COLUMN
Name:
Study Number: $-\frac{---}{\text { Date: } \frac{-}{\text { mo. }}-\frac{-}{\mathrm{yr} .}}$
Day

A. ACUTE EXPOSURE EXPERIENCE

1. Have you had any reaction to a gas exposure in the last 6 months? Yes 1 No 2

If "Yes" to 1 fill out the accompanying addendum.

"The following questions relate to your usual state of health in the last 6 months and do not include symptoms you may have had immediately following gas exposures, Please answer yes or no whenever possible."

B. COUGH (Count a cough with first smoke or on first going out of doors but exclude clearing thorat, a single or occasional cough.)

2. Do you usually cough first thing in the morning in bad weather?

3. Do you usually cough during the day or night in bad weather?

$1+\cdots$

If "Yes" to 2 or 3:

4. Have you coughed like this on most days for as much as 3 months in the last 6 months?

Yes 1 No 2 N.A. $\underline{9}$ CODE COLUM

C. PHLEGM (Count swallowed phlegm or phlegm more than twice a day but exclude phlegm from the nose.)

5. Do you usually bring up phlegm, sputum or mucus from your chest first thing in the morning in bad weather? Yes 1 No 2 는

6. Do you usually bring up phlegm, sputum, or mucus from your chest during the day or night in bad weather?

If "Yes" to 5 or 6:

7. Have you brought up phlegm like this on most days for as much as 3 months in the last 6 months?

$$
\text { Yes } 1 \text { No } 2 \text { N.A. } 9
$$


Tul. Sch. Med.

Ptil. Dis, - Immuno.
OCCUPATIONA STUDY VIII

Follow-Up Interview

Olin

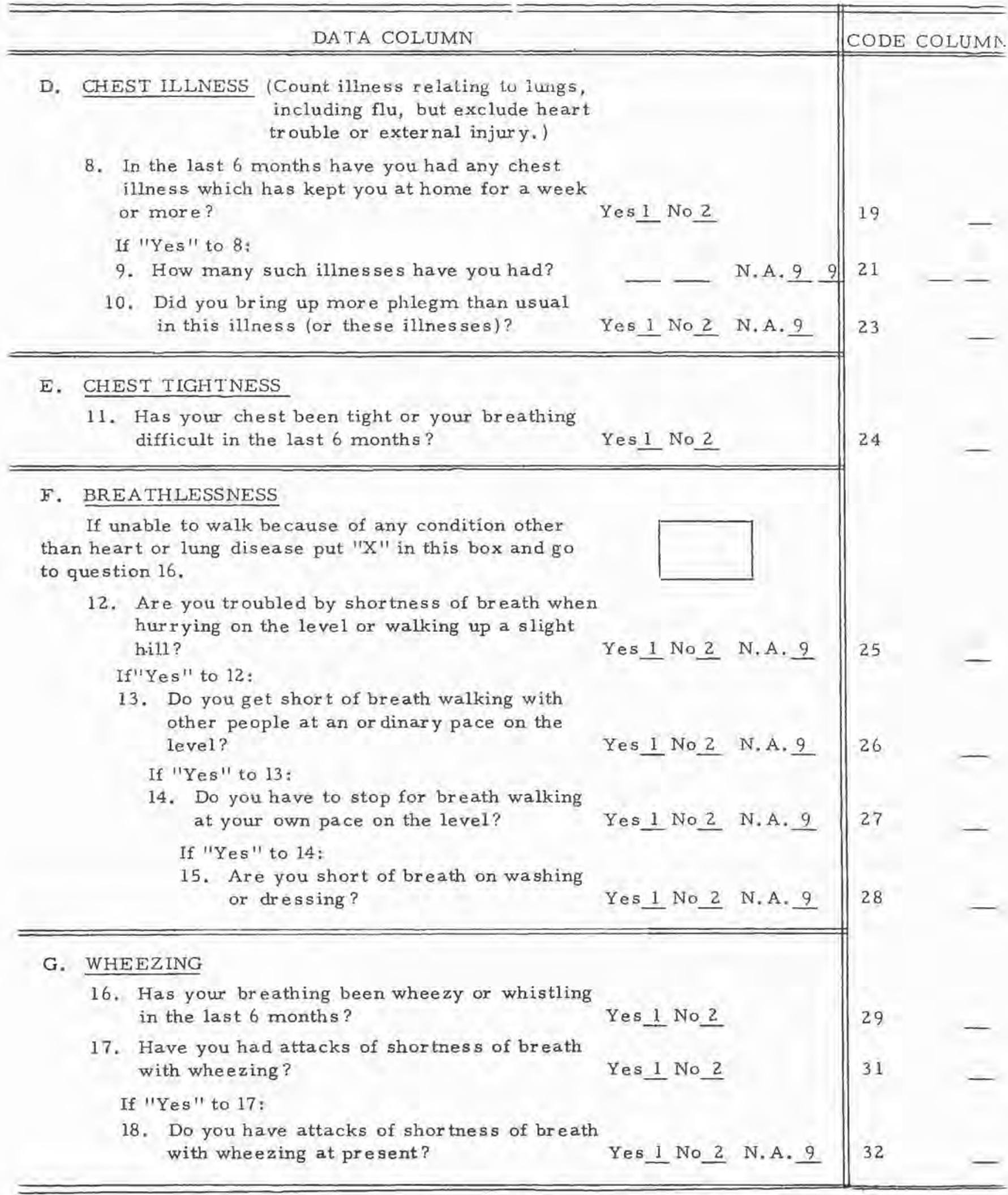


Tul, Sch. Med.

Pù̀l. Dis. - Immuno.
OCCUPATIONAL STUDY VIII

Follow - Up 'nter view
Schedule $b_{3}$

$$
\text { Oli: }
$$

H. NASAL CATARRH

19. Do you usually have a drip at the back of your nose?

If "Yes" to 19:

20. Have you had a drip at the back of your nose for as much as 3 of the last 6 months?

21. Do you have a runny, stuffy, or itchy nose, or sneezing for several days at a time occurring at certain times of the year?

22. Do you have sinus trouble or a postnasal drip?

Yes 1 No 2

Yes_ 1 No_ 2 N.A. 9

Yes 1 No 2

Yes_1 No 2

Yes 1 No 2

23. Have you had asthma in the last 6 months?

24. How many head colds have you had in the last 6 months?

If other than "none":

25. How many weeks did they last, all together?

26. When you have a head cold do you have a runny, stuffy or itchy nose, or sneezing for several days at a time?

27. Do you take medication for allergies? If "Yes":

28. What medication?

29. How frequently?

J. OTHER ILLNESSES

30. Since we last saw you, has a doctor told you that you had...

a. a heart condition?

b. T,B. ?

c. emphyserna?

d. chronic bronchitis?

e. pneumonia?

If "Yes" to pneumonia: How many times?

31. Have you had any operations or injuries affecting your chest or been told something was wrong with your chest $x$-ray since we last saw you?

Yes 1 No 2

Yes 1 No 2

Yes 1 No 2 .

\section{N.A. 99}

33

34

35

36

37

38

41

43

44

If "Yes" to 31: Please describe: 
Tul. Sch. Med.

Pul. Dís, -Immuno.
OCCUPATIONA L STUDY VIII

Follow-Up Interview

Olin

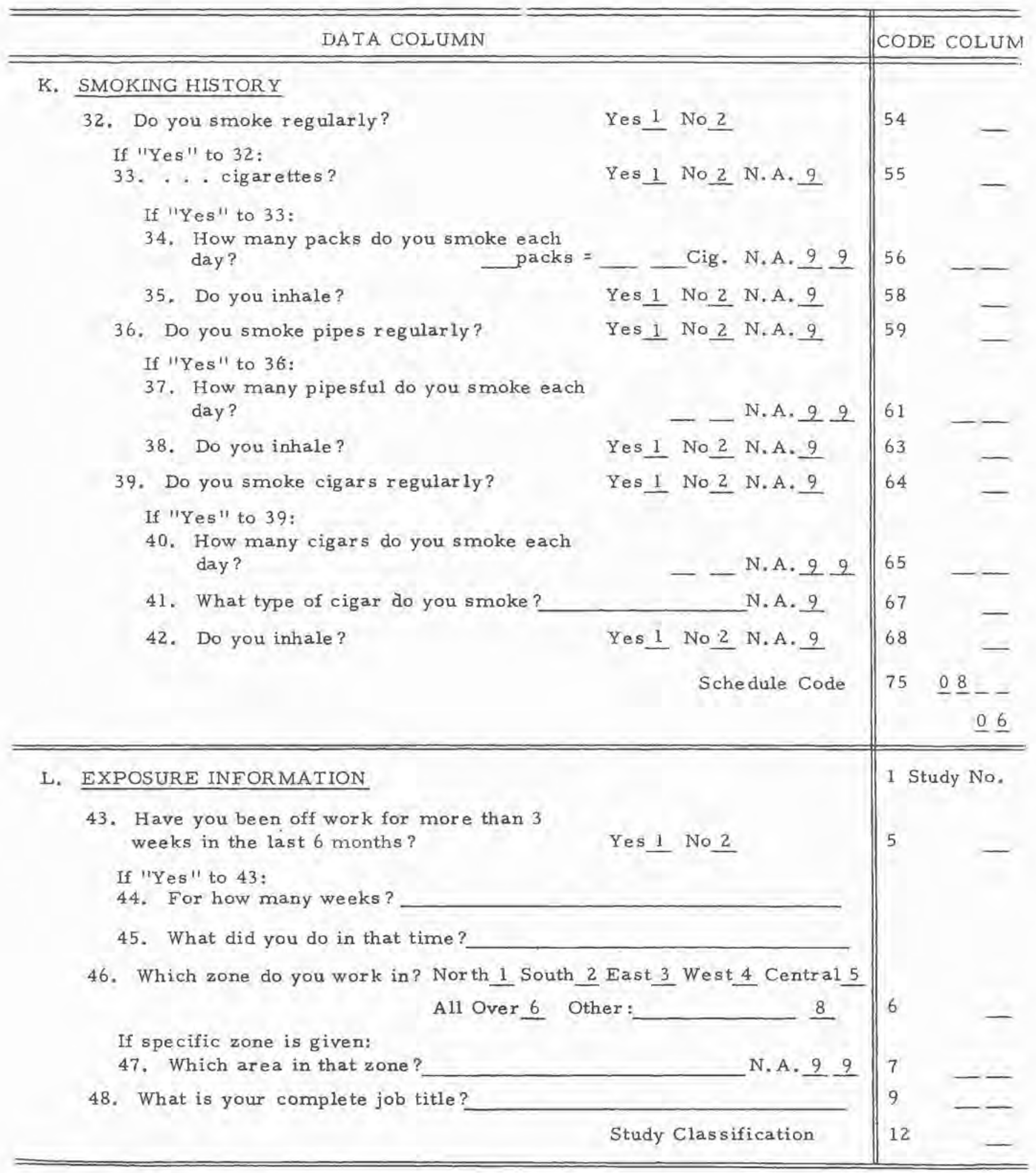


Tul. Sch. Med.

Pul. Dis.-Immuno.
OCCUPATIONAL STUDY VIII

Follow-Up Interview

Olin

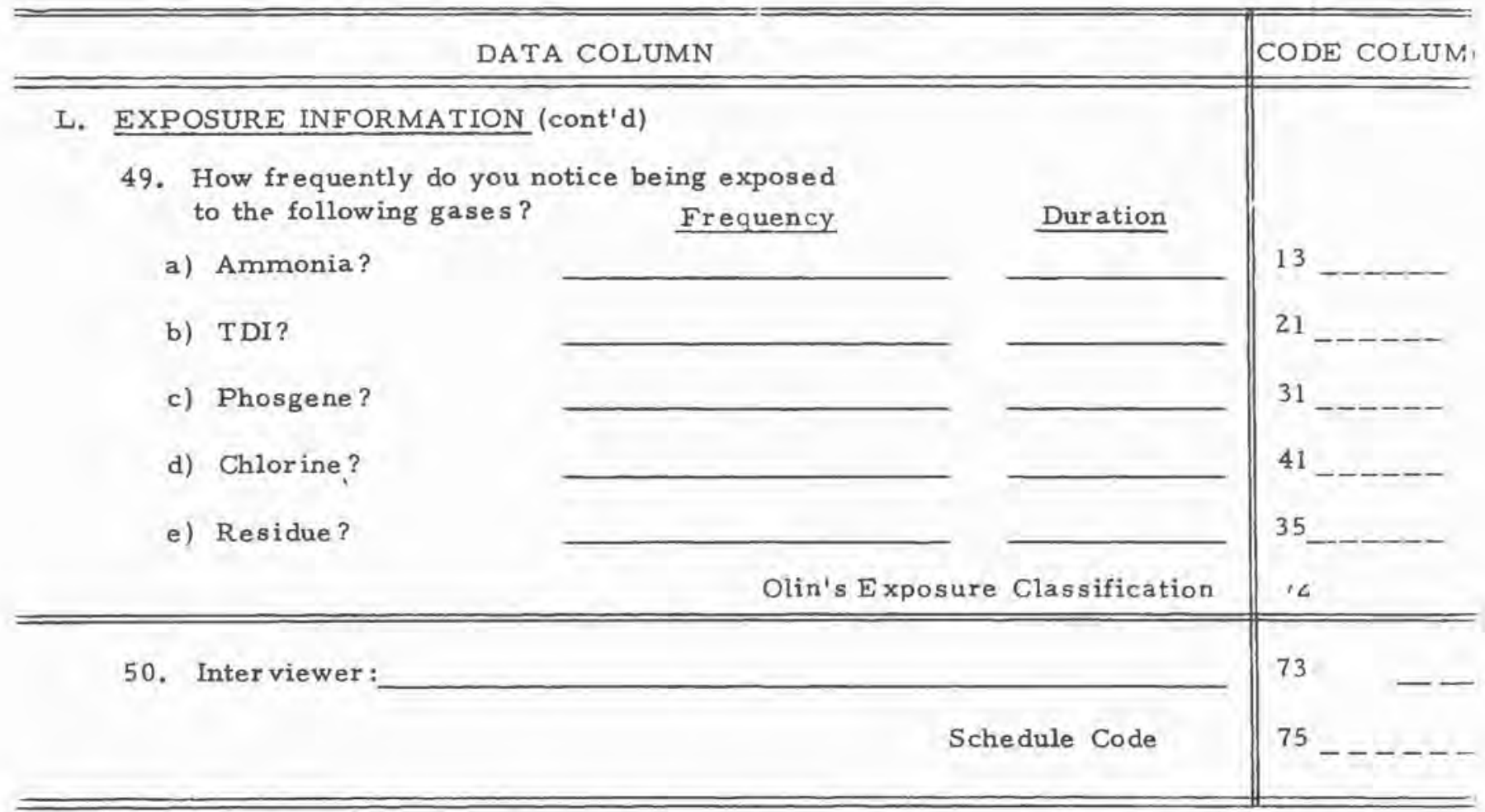

Rev. $11 / 76$ 
Lui. ..... Med.

Pul. Dis.-Immuno.
ULUUPALU ALSIUIS VIII

Follow-Up Interview

Olin

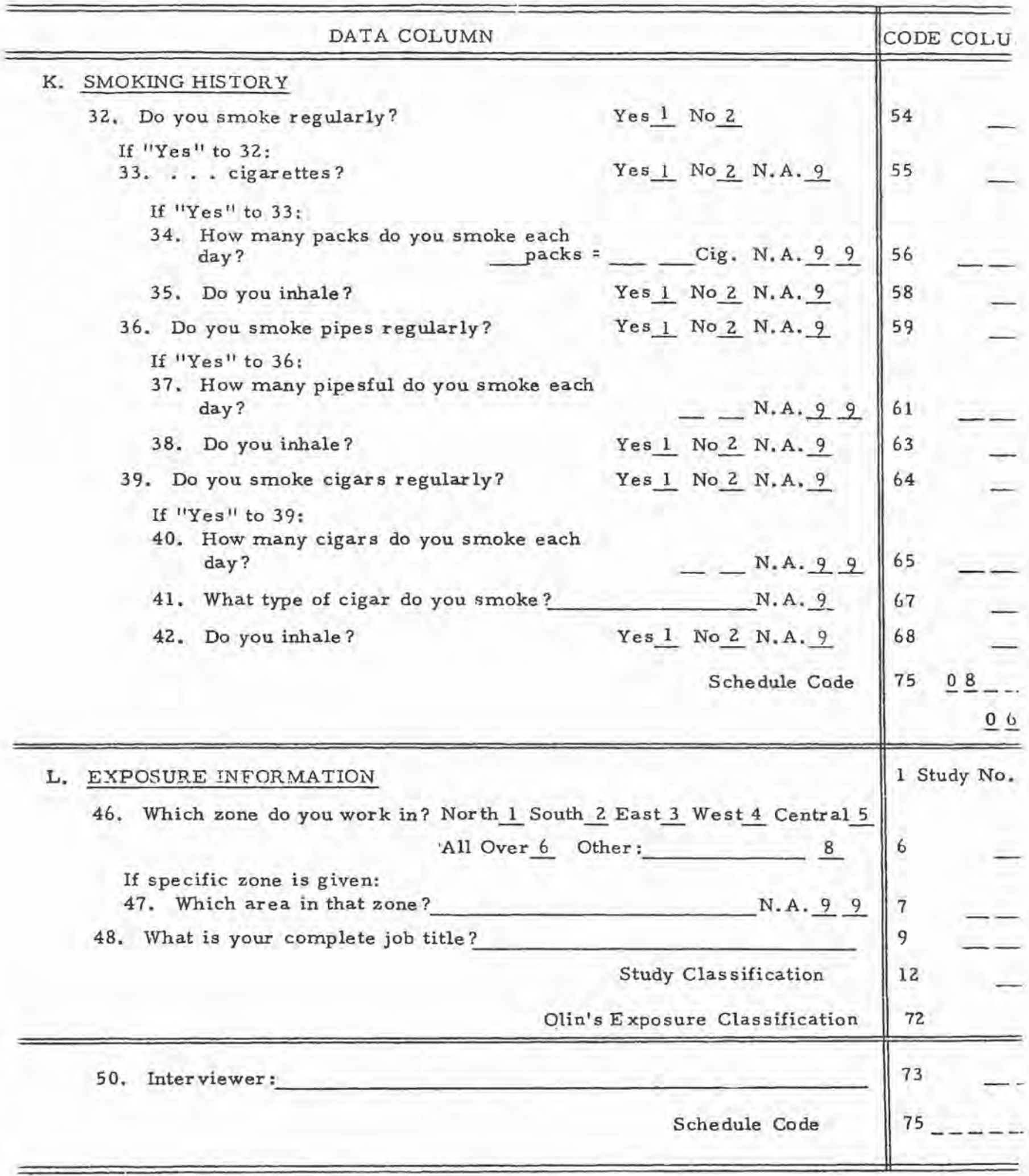


SYMPTOM CLASSIFICATIONS

\section{Initial Interview}

Bronchitis

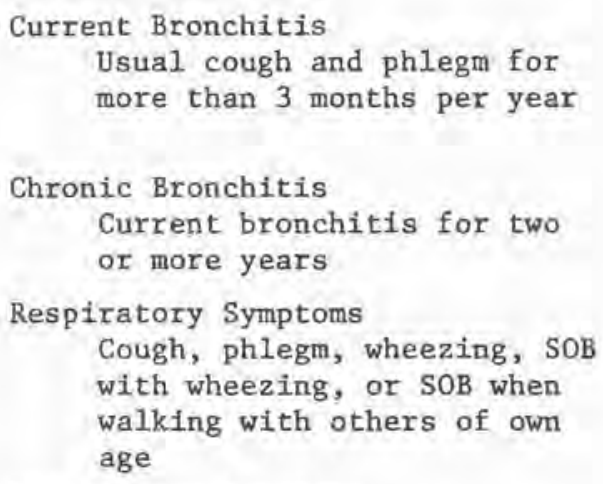

Upper Respiratory Symptoms Drip at back of nose, hay fever, or current sinus trouble

Dyspnea

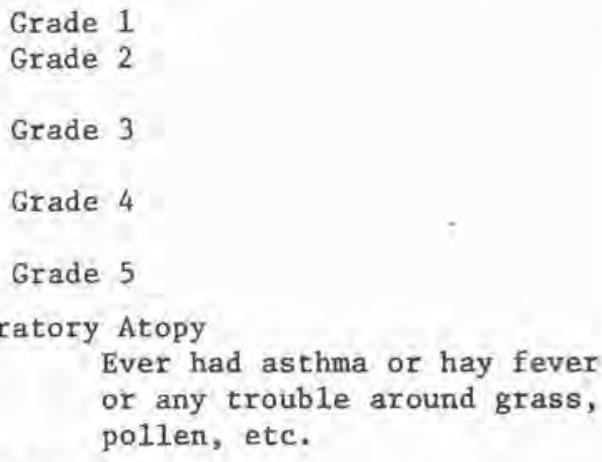

Smoking

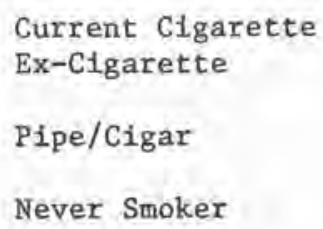

1 in $\operatorname{cc} 5$ or 6 and

1 in cc 7 and

1 in $\operatorname{cc} 9$ or 10 and

1 in ec 11

Current bronchitis and

2 or 3 in cc 8 and

2 or 3 in cc 12

1 in cc 5 or 6 or 9 or 10 or $1 \overline{3}$ or $\overline{17}$

or 19

1 in cc 32 or 36

\section{Fo11ow-Up Interview}





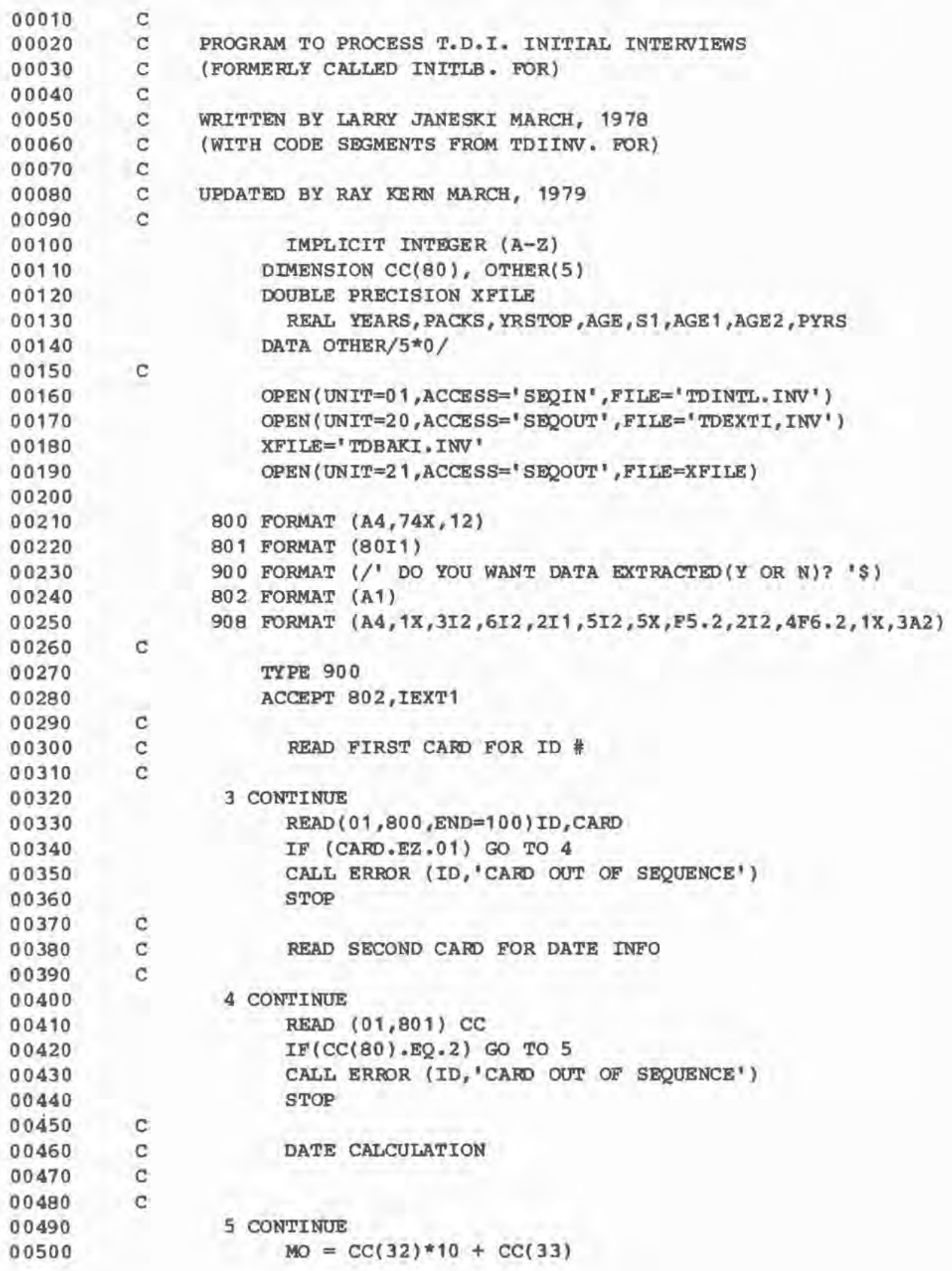




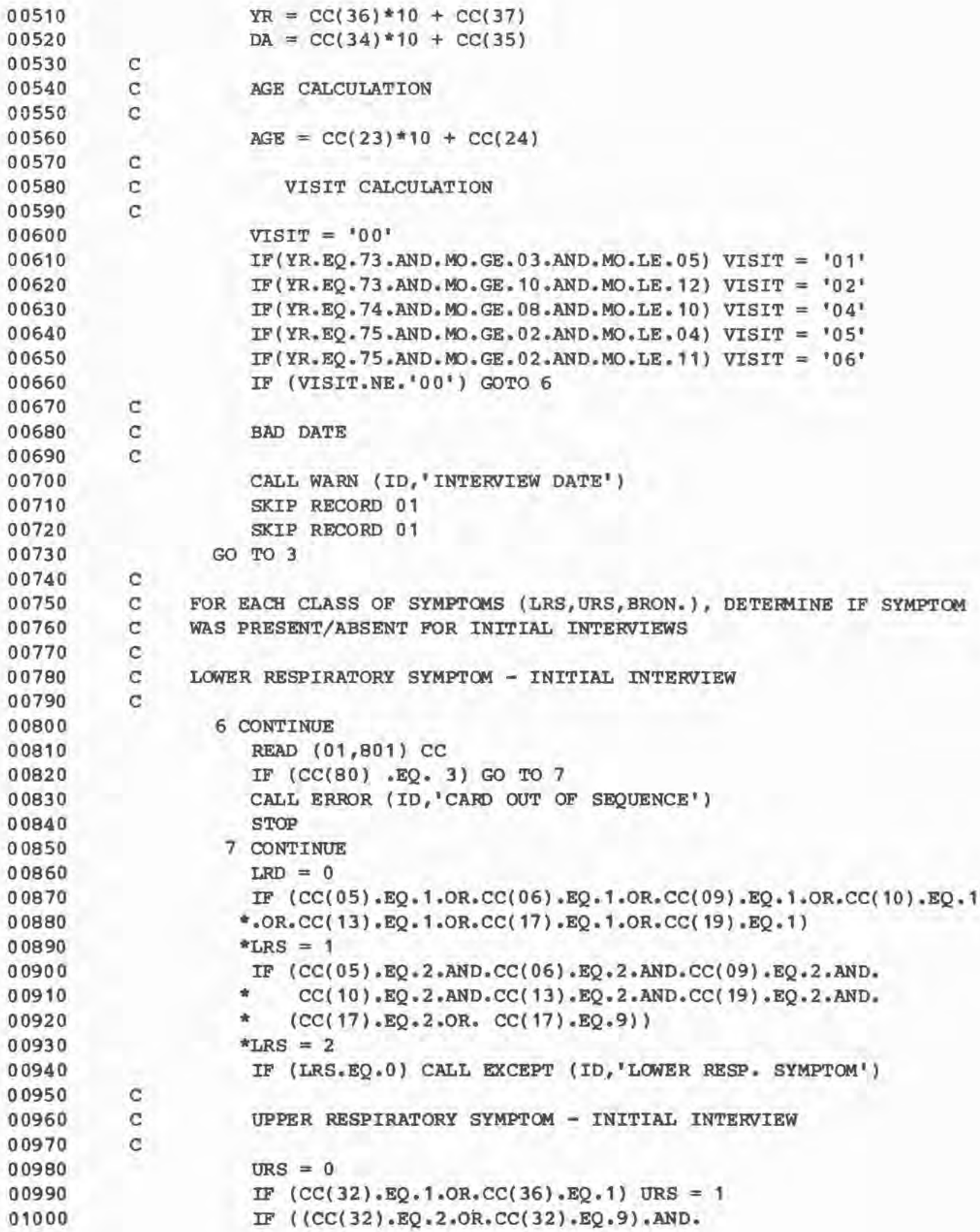

$\mathrm{YR}=\operatorname{CC}(36) * 10+\operatorname{CC}(37)$

AGE CALCULATION

$\mathrm{AGE}=\mathrm{CC}(23) * 10+C C(24)$

VISIT CALCULATION

VISIT $=100^{\prime}$

IF (YR.EQ.73.AND, MO.GE.03.AND.MO.LE.05) VISIT $=' 01$ ' IF ( YR.EQ.73.AND.MO.GE, 10.AND.MO.LE.12) VISIT $={ }^{\prime} 02{ }^{\prime}$ IF (YR.EQ .74.AND.MO.GE.08.AND.MO.LE.10) VISIT $={ }^{\prime} 04^{\prime}$ IF (YR,EQ.75.AND.MO.GE.02.AND.MO.LE.04) VISIT $=' 05^{\prime}$ IF (YR.EQ.75.AND.MO.GE.02.AND.MO.LE.11) VISIT $=106^{\prime}$ IF (VISIT.NE.'00') GOTO 6

BAD DATE

CALL WARN (ID, 'INTERVIEW DATE')

SKIP RECORD 01

SKIP RECORD 01

GO TO 3

FOR EACH CLASS OF SYMPTOMS (LRS, URS,BRON.), DETERMINE IF SYMPTOM WAS PRESENT/ABSENT FOR INITIAL INTERVIEWS

LOWER RESPIRATORY SYMPTOM - INITIAL INTERVIEW

6 CONTINUE READ $(01,801) \mathrm{CC}$ IF (CC(80).EQ. 3) GO TO 7

CALL ERROR (ID, 'CAFD OUT OF SEQUENCE') STOP

7 CONTINUE

$\mathrm{IRD}=0$

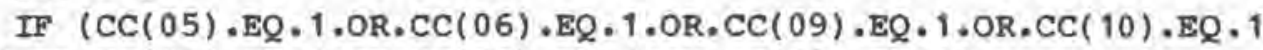

*.OR.CC( 13) .EQ.1.OR.CC(17) .EQ.1.OR.CC(19) . EQ.1)

*LRS $=1$ IF (CC $(05) \cdot \mathrm{EQ} \cdot 2 \cdot \mathrm{AND} \cdot \mathrm{CC}(06) \cdot \mathrm{EQ} \cdot 2 \cdot \mathrm{AND} \cdot \mathrm{CC}(09) \cdot \mathrm{EQ} \cdot 2$. AND * $\quad C C(10) \cdot \mathrm{EQ} \cdot 2$.AND.CC(13) .EQ - 2.AND.CC(19) .EQ . 2.AND.

* $(C C(17) \cdot E Q \cdot 2 \cdot O R$. CC (17) .EQ.9))

*IRS $=2$

IF (LRS.EQ.0) CALL EXCEPT (ID, 'LOWER RESP. SYMPTOM')

UPPER RESPIRATORY SYMPTOM - INITIAL INTERVIEW

URS $=0$

IF $(\mathrm{CC}(32) \cdot \mathrm{EQ} \cdot 1 \cdot \mathrm{OR}, \mathrm{CC}(36) \cdot \mathrm{EQ} \cdot 1)$ URS $=1$

IF $((\mathrm{CC}(32) \cdot \mathrm{EQ} \cdot 2 . \mathrm{OR} \cdot \mathrm{CC}(32) \cdot \mathrm{EQ} \cdot 9)$. AND. 


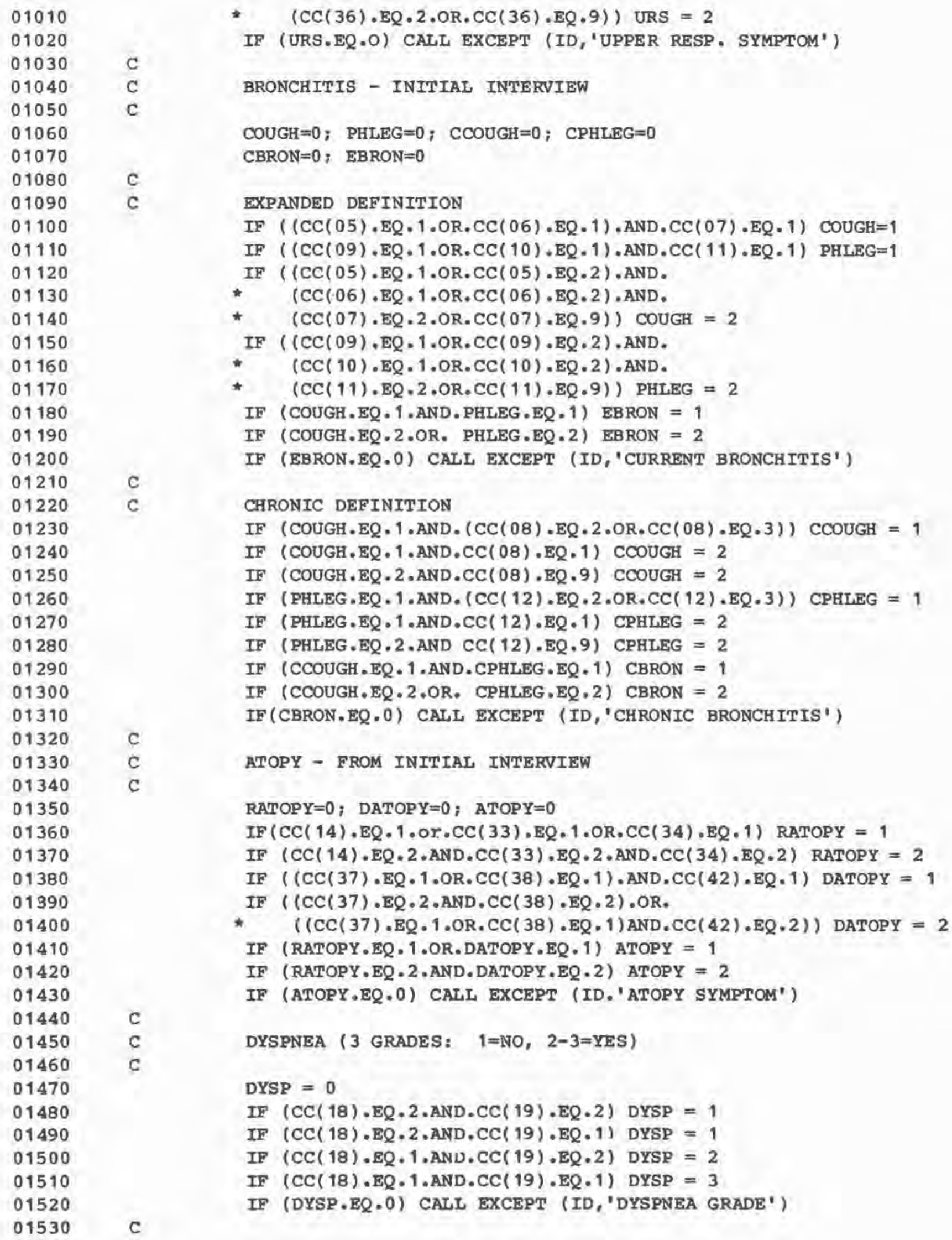

C

C

c

c

C

c

C

c

c

c

C c

C

$+\quad(C C(36) \cdot E Q \cdot 2 \cdot O R \cdot C C(36) \cdot E Q \cdot 9))$ URS $=2$ IF (URS.EQ.O) CALL EXCEPT (ID, 'UPPER RESP. SYMPTOM')

BRONCHITIS - INITIAL INTERVIEW

COUGH $=0$; $\mathrm{PHLEG}=0$; $\mathrm{CCOUGH}=0$; CPHLEG $=0$

$\mathrm{CBRON}=0 ; \quad \mathrm{EBRON}=0$

EXPANDED DEFINITION

IF ( $(\mathrm{CC}(05), \mathrm{EQ} \cdot 1 \cdot \mathrm{OR}, \mathrm{CC}(06) \cdot \mathrm{EQ} \cdot 1) \cdot \mathrm{AND}, \mathrm{CC}(07) \cdot \mathrm{EQ} \cdot 1) \quad \mathrm{COUGH}=1$

IF $((C C(09) \cdot \mathrm{EQ} \cdot 1 \cdot \mathrm{OR} \cdot \mathrm{CC}(10) \cdot \mathrm{EQ} \cdot 1) \cdot \mathrm{AND} \cdot \mathrm{CC}(11) \cdot \mathrm{EQ} \cdot 1)$ PHLEG $=1$

IF $((C C(05) \cdot E Q \cdot 1.0 R \cdot C C(05) \cdot E Q \cdot 2) \cdot A N D$.

* (CC $(06) \cdot \mathrm{EQ} \cdot 1 . \mathrm{OR} \cdot \mathrm{CC}(06) \cdot \mathrm{EQ} \cdot 2) \cdot \mathrm{AND}$.

* $\quad(\mathrm{CC}(07) \cdot \mathrm{EQ} \cdot 2 \cdot \mathrm{OR} \cdot \mathrm{CC}(07) \cdot \mathrm{EQ} \cdot 9))$ COUGH $=2$

IF $((\mathrm{CC}(09), \mathrm{EQ} \cdot 1.0 \mathrm{R} \cdot \mathrm{CC}(09), \mathrm{EQ} \cdot 2)$. AND.

- $\quad(\mathrm{CC}(10) \cdot \mathrm{EQ} \cdot 1 \cdot \mathrm{OR} \cdot \mathrm{CC}(10) \cdot \mathrm{EQ} \cdot 2) \cdot \mathrm{AND}$.

* $\quad(\operatorname{CC}(11) \cdot \mathrm{EQ} \cdot 2 \cdot \mathrm{OR} \cdot \mathrm{CC}(11) \cdot \mathrm{EQ} \cdot 9))$ PHLEG $=2$

IF (COUGH.EQ 1 . AND.PHLEG .EQ.1) EBRON $=1$

IF (COUGH.EQ.2.OR. PHLEG.EQ.2) EBRON $=2$

IF (EBRON.EQ.0) CALL EXCEPT (ID,'CURRENT BRONCHITIS')

CHRONIC DEFINITION

IF (COUGH.EQ.1.AND. ( $\mathrm{CC}(08) \cdot \mathrm{EQ} \cdot 2 \cdot \mathrm{OR} \cdot \mathrm{CC}(08) \cdot \mathrm{EQ} \cdot 3)$ ) CCOUGH $=1$

IF (COUGH.EQ.1.AND.CC $(08) \cdot \mathrm{EQ} \cdot 1)$ CCOUGH $=2$

IF (COUGH.EQ -2.AND.CC $(08) \cdot \mathrm{EQ} \cdot 9)$ CCOUGH $=2$

IF (PHLEG . EQ .1.AND. $(\mathrm{CC}(12) \cdot \mathrm{EQ} \cdot 2 \cdot \mathrm{OR} \cdot \mathrm{CC}(12) \cdot \mathrm{EQ} \cdot 3)$ ) CPHLEG $=1$

IF (PHLEG.EQ 1 . AND.CC $(12) \cdot \mathrm{EQ} \cdot 1$ ) CPHLEG $=2$

IF (PHLEG.EQ.2.AND CC(12).EQ.9) CPHLEG $=2$

IF (CCOUGH.EQ.1.AND. CPHLEG .EQ.1) $\mathrm{CBRON}=1$

IF (CCOUGH.EQ.2.OR. CPHLEG.EQ,2) CBRON $=2$

IF (CBRON,EQ.O) CALL EXCEPT (ID, 'CHRONIC BRONCHITIS')

ATOPY - FROM INITIAL INTERVIEW

RATOPY $=0$; DATOPY $=0$; $A T O P Y=0$

$\operatorname{IF}(\mathrm{CC}(14) \cdot \mathrm{EQ} \cdot 1 \cdot \mathrm{Or} \cdot \mathrm{CC}(33) \cdot \mathrm{EQ} \cdot 1 \cdot \mathrm{OR} \cdot \mathrm{CC}(34) \cdot \mathrm{EQ} \cdot 1)$ RATOPY $=1$

IF $(C C(14) \cdot E Q \cdot 2 \cdot A N D \cdot C C(33) \cdot E Q \cdot 2 \cdot A N D \cdot C C(34) \cdot E Q \cdot 2)$ RATOPY $=2$

IF $((C C(37) \cdot E Q \cdot 1 \cdot O R \cdot C C(38) \cdot E Q \cdot 1) \cdot A N D \cdot C C(42) \cdot E Q \cdot 1)$ DATOPY = 1

IF $((\mathrm{CC}(37) \cdot \mathrm{EQ} \cdot 2 \cdot \mathrm{AND} \cdot \mathrm{CC}(38) \cdot \mathrm{EQ} \cdot 2) \cdot \mathrm{OR}$.

* ((CC (37) $\cdot \mathrm{EQ} \cdot 1 \cdot \mathrm{OR} \cdot \mathrm{CC}(38) \cdot \mathrm{EQ} \cdot 1) \mathrm{AND} \cdot \mathrm{CC}(42) \cdot \mathrm{EQ} \cdot 2))$ DATOPY $=2$

IF (RATOPY $\cdot E Q \cdot 1 \cdot O R \cdot D A T O P Y \cdot B Q \cdot 1)$ ATOPY $=1$

IF (RATOPY,EQ - 2, AND.DATOPY,EQ.2) ATOPY $=2$

IF (ATOPY.EQ.0) CALL EXCEPT (ID.'ATOPY SYMPTOM')

DYSPNEA ( 3 GRADES: $1=\mathrm{NO}, 2$-3=YES)

DYSP $=0$

IF $(C C(18) \cdot E Q \cdot 2 \cdot A N D \cdot C C(19) \cdot E Q \cdot 2)$ DYSP $=1$

IF $(C C(18) \cdot E Q \cdot 2 \cdot A N D, C C(19) \cdot E Q \cdot 1)$ DYSP $=1$

IF $(C C(18) \cdot E Q \cdot 1 \cdot A N D \cdot C C(19) \cdot E Q \cdot 2)$ DYSP $=2$

IF $(C C(18) \cdot E Q \cdot 1 \cdot A N D \cdot C C(19) \cdot E Q \cdot 1)$ DYSP $=3$

IF (DYSP.EQ.0) CALL EXCEPT (ID,'DYSPNEA GRADE') 


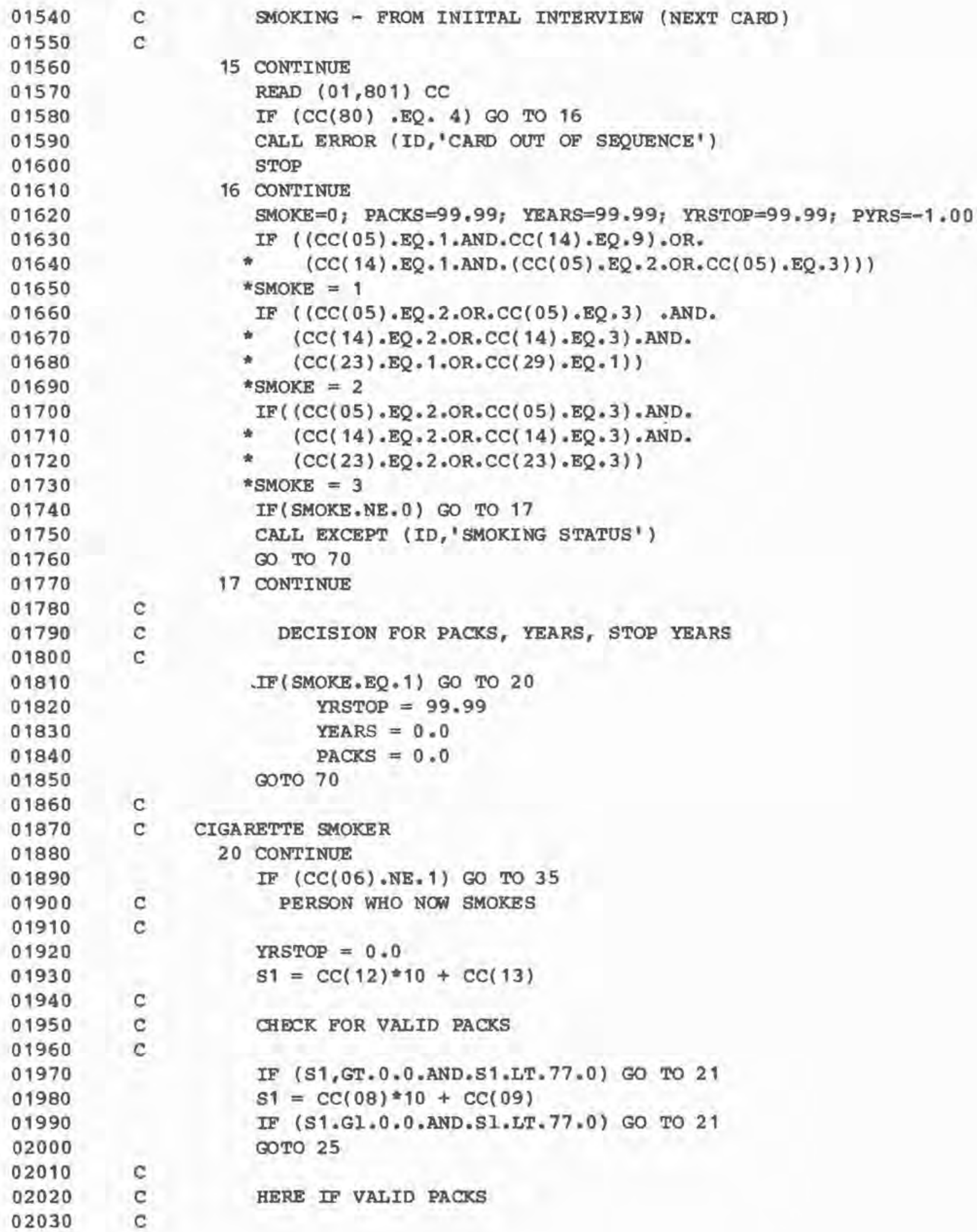




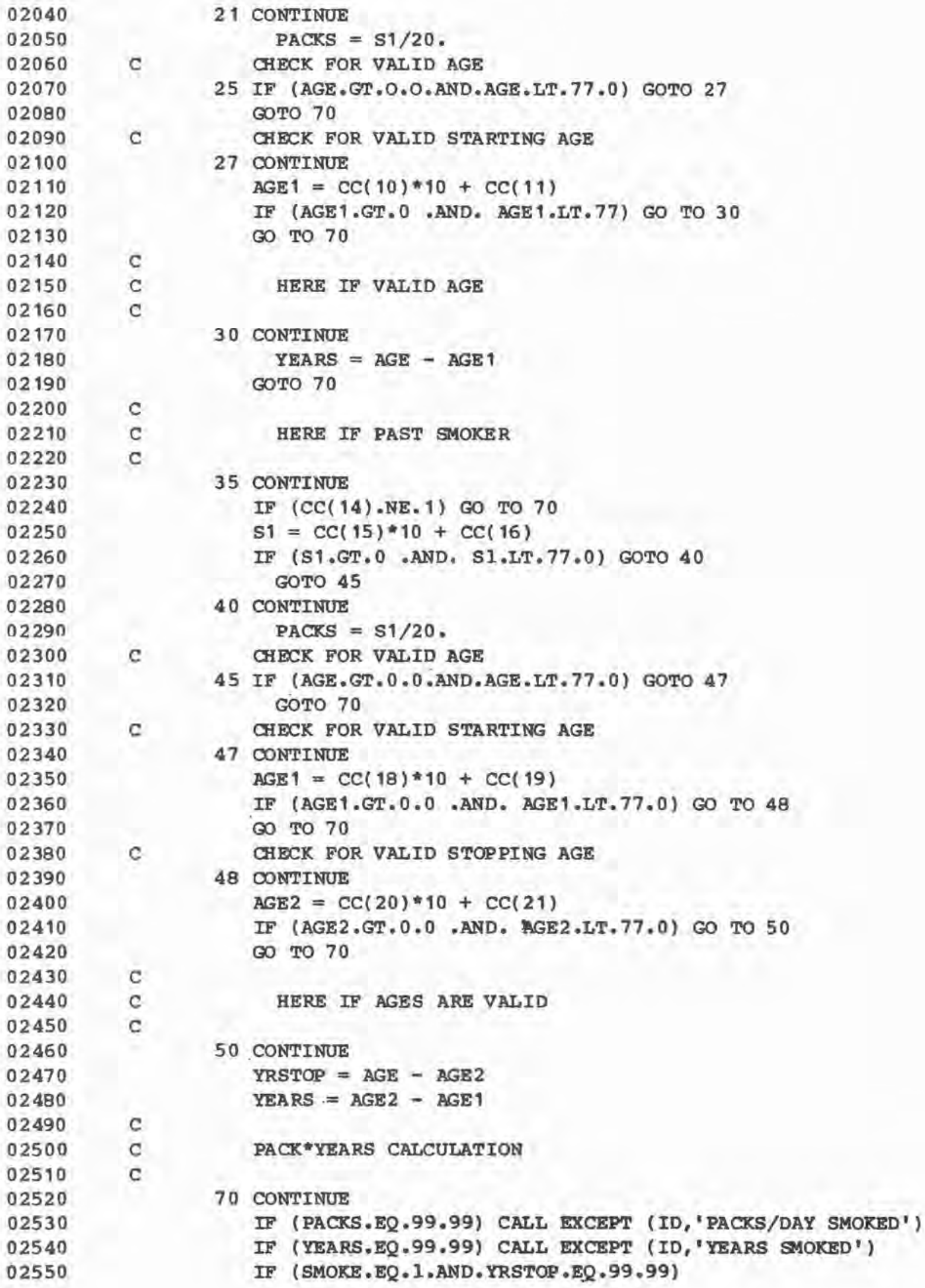

02040

02050

02060

02070

02080

02090

02100

02110

02120

02130

02140

02150

02160

02170

02180

02190

02200

02210

02220

02230

02240

02250

02260

02270

02280

0229 م

02300

02310

02320

02330

02340

02350

02360

02370

02380

02390

02400

02410

02420

02430

02440

02450

02460

02470

02480

02490

02500

02510

02520

02530

02540

02550

21 CONTINUE

PACKS $=\$ 1 / 20$.

C

CHECK FOR VALID AGE

25 IF (AGE.GT.0.0.AND.AGE.LT.77.0) GOTO 27

GOTO 70

C

CHECK FOR VALID STARTING AGE

27 CONTINUE

$A G E 1=C C(10) * 10+C C(11)$

IF (AGE1.GT.0 .AND. AGE1.IT.77) GO TO 30

GO TO 70

C

C

c

HERE IF VAIID AGE

30 CONTINUE

YEARS = AGE - AGE 1

GOTO 70

c

C

HERE IF PAST SMOKER

35 CONTINUE

IF (CC(14).NE.1) GO TO 70

$s 1=\operatorname{CC}(15) \cdot 10+\operatorname{CC}(16)$

IF (S1.GT.0 .AND, S1.LT.77.0) GOTO 40 GOTO 45

40 CONTINUE PACKS $=\$ 1 / 20$.

CHECK FOR VALID AGE

45 IF (AGE.GT.0.0.AND.AGE.IT.77.0) GOTO 47 GOTO 70

C CHECK FOR VALID STARTING AGE

47 CONTINUE

AGE $1=\operatorname{CC}(18) * 10+C C(19)$

IF (AGE1.GT.0.0.AND. AGE1.LT.77.0) GO TO 48

(S) TO 70

C

CHBCK FOR VALID STOPPING AGE

48 ONTINUE

$\mathrm{AGE} 2=\mathrm{CC}(20) * 10+\mathrm{CC}(21)$

IF (AGE2,GT.0.0 .AND. AGE2.LT, 77.0) GO TO 50

GO TO 70

HERE IF AGES ARE VALID

50 CONTINUE

YRSTOP $=\mathrm{AGE}-\mathrm{AGB} 2$

YEARS $=$ AGE2 - AGE1

PACK"YEARS CALCULATION

70 CONTINUE

IF (PACKS.EQ.99.99) CALL EXCEPT (ID,'PACKS/DAY SMOKED')

IF (YEARS,EQ.99.99) CALL EXCEPT (ID, 'YEARS SMOKED')

IF (SMOKE.EQ.1.AND.YRSTOP,EQ.99.99) 


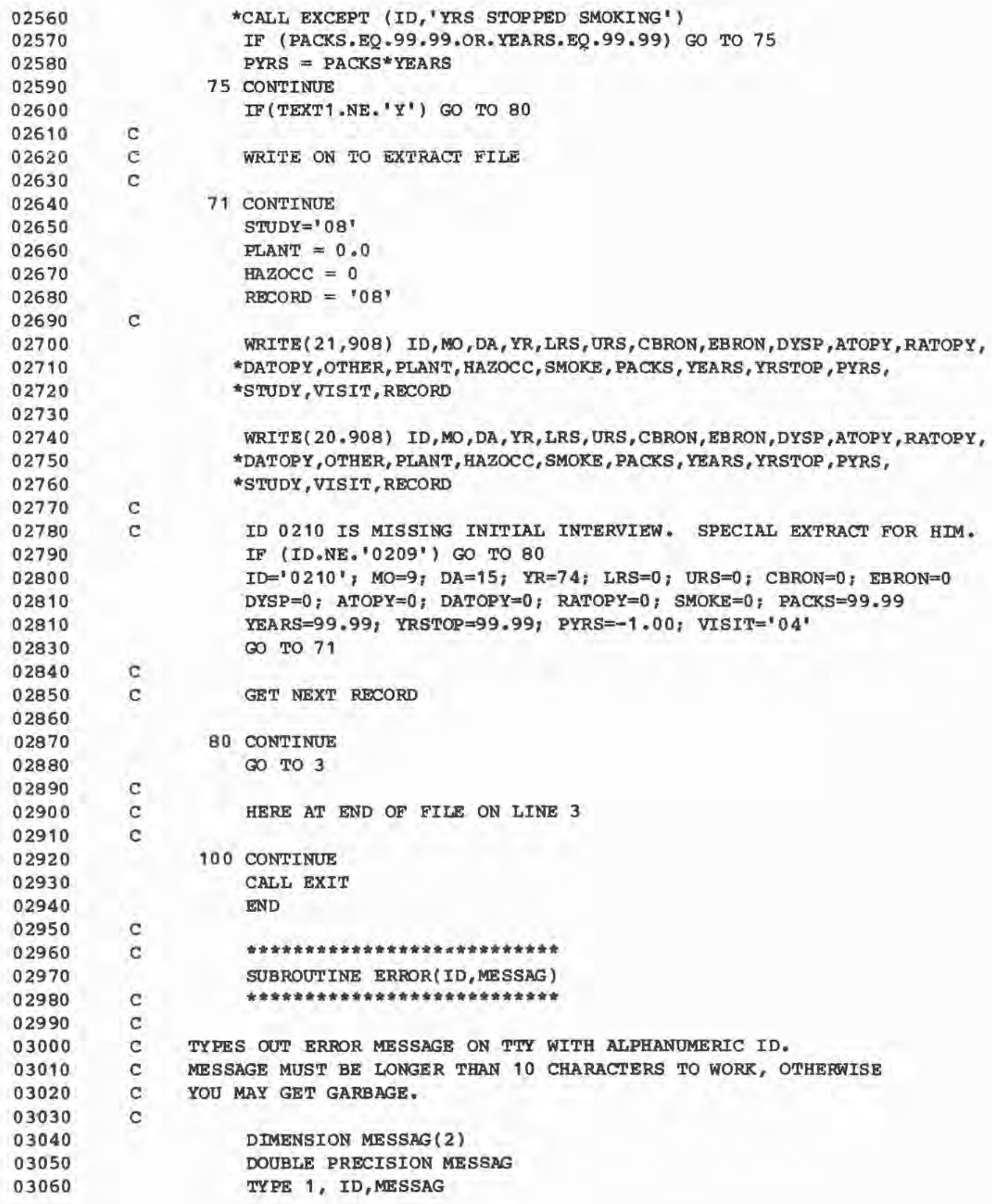

C

c

C

C

c

C

C

80 CONTINUE

GO TO 3

c

C

C

C
C
C
C
C
C
C
C

"CALL EXCEPT (ID,'YRS STOPPED SMOKING')

IF (PACKS.EQ.99.99.OR. YEARS. EQ.99.99) GO TO 75 PYRS $=$ PACKS $*$ YEARS

75 CONTINUE

IF(TEXT1.NE.' $Y$ ') GO TO 80

WRITE ON TO EXTRACT FILE

71 CONTINUE

STUDY $=108$ '

PLANT $=0.0$

HAZOCC $=0$

RECORD $=' 08$ '

WRITE ( 21 , 908) ID, NO, DA, YR, LRS, URS, CBRON, EBRON, DYSP, ATOPY , RATOPY, *DATOPY , OTHER, PLANT, HAZOCC, SMOKE, PACKS, YEARS, YRSTOP, PYRS,

*STUDY, VISIT, RECORD

WRITE (20.908) ID, MO, DA, YR, IRS, URS, CBRON, EBRON, DYSP, ATOPY, RATOPY, *DATOPY, OTHER, PLANT, HAZOCC, SMORE, PACKS, YEARS, YRSTOP, PYRS,

*STUDY, VISIT, RECORD

ID 0210 IS MISSING INITIAL INTERVIEW. SPECIAL EXTRACT FOR HIM. IF (ID.NE.'0209') GO TO 80

$I D=10210^{\prime}$; $M O=9 ; D A=15 ; Y R=74 ; L R S=0$; URS $=0$; $C B R O N=0$; EBRON $=0$ DYSP $=0$; $A T O P Y=0$; DATOPY $=0$; RATOPY $=0$; SMOKE $=0$; $P A C K S=99.99$ YEARS $=99.99$, YRSTOP $=99.99$, PYRS $=-1.00 ;$ VISIT $=.04^{\prime}$ GO TO 71

HERE AT END OF FILE ON LINE 3

100 CONTINUE

CALL EXIT

END

C TYPES OUT ERROR MESSAGE ON TTY WITH ALPHANUMERIC ID.

C MESSAGE MUST BE LONGER THAN 10 CHARACTERS TO WORR, OTHERWISE

C YOU MAY GET GARBAGE.

DIMENSION MESSAG (2)

DOUBLE PRECISION MESSAG

TYPE 1, ID, MESSAG 
03070

03080

03090

03100

03110

03120

03130

03140

03150

03160

03170

03180

03190

03200

03210

03220

03230

03240

03250

03260

03270

03280

03290

03300

03310

03320

03330

03340

03350

03360

03370

03380

03390
1 FORMAT (/"** ERROR ID ',A4,': ',2A10) RETURN

END

C

C

C

C

C

C

C

C

TYPES OUT EXCEPTION MESSAGE ON TTY WITH ALPHANUMERTC ID. MESSAGE MUST BE LONGER THAN 10 CHARACTERS TO WORK, OTHERWISE YOU MAY GET GARBAGB.

DIMENSION MESSAG (2)

DOUBLE PRECISION MESSAG

TYPE 1, ID, MESSAG

1 FORMAT (/' EXCEPTION ID ',A4,': ',2A10) RETURN

END

C

C

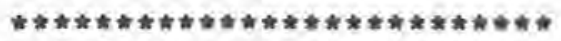

SUBROUTINE WARN (ID, MESSAG)

C

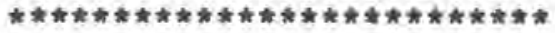

TYPES OUT WARNING MESSAGE ON TTY WITH ALPHANUMERIC ID.

C MESSAGE MUST BE LONGER THAN 10 CHARACTERS TO WORK, OTHERWISE YOU MAY GET GARBAGE.

C

DIMENSION MESSAG ( 2 )

DOUBLE PRECISION MESSAG

TYPE 1, ID, MESSAG

1 FORMAT $\left(/{ }^{\prime}\right.$ ' WARNING ID ', A4, ':, $2 \mathrm{~A} 10$ )

RETURN

END 
. 


\section{Itsting of Computer Program to Edit Follow-up Interview}

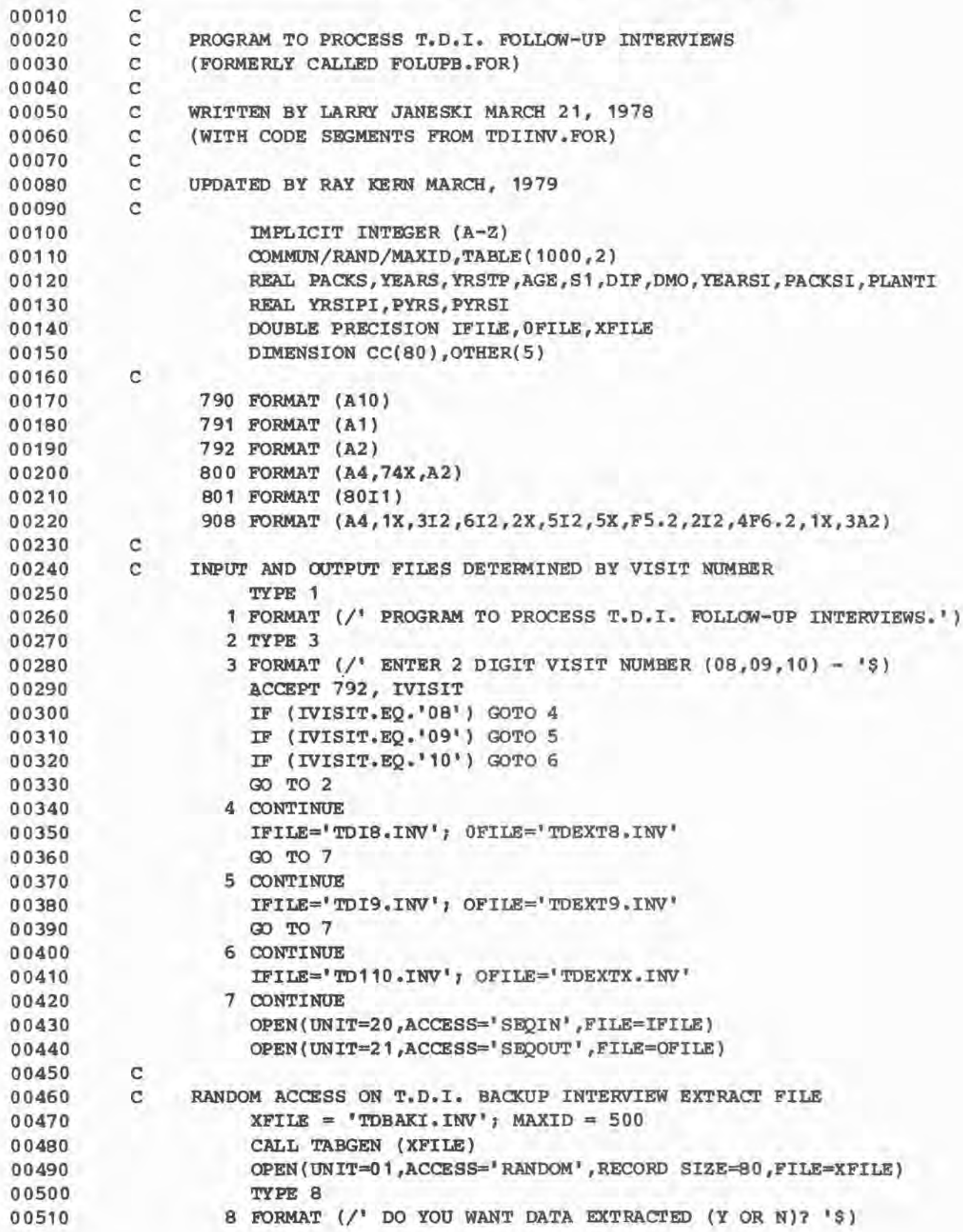




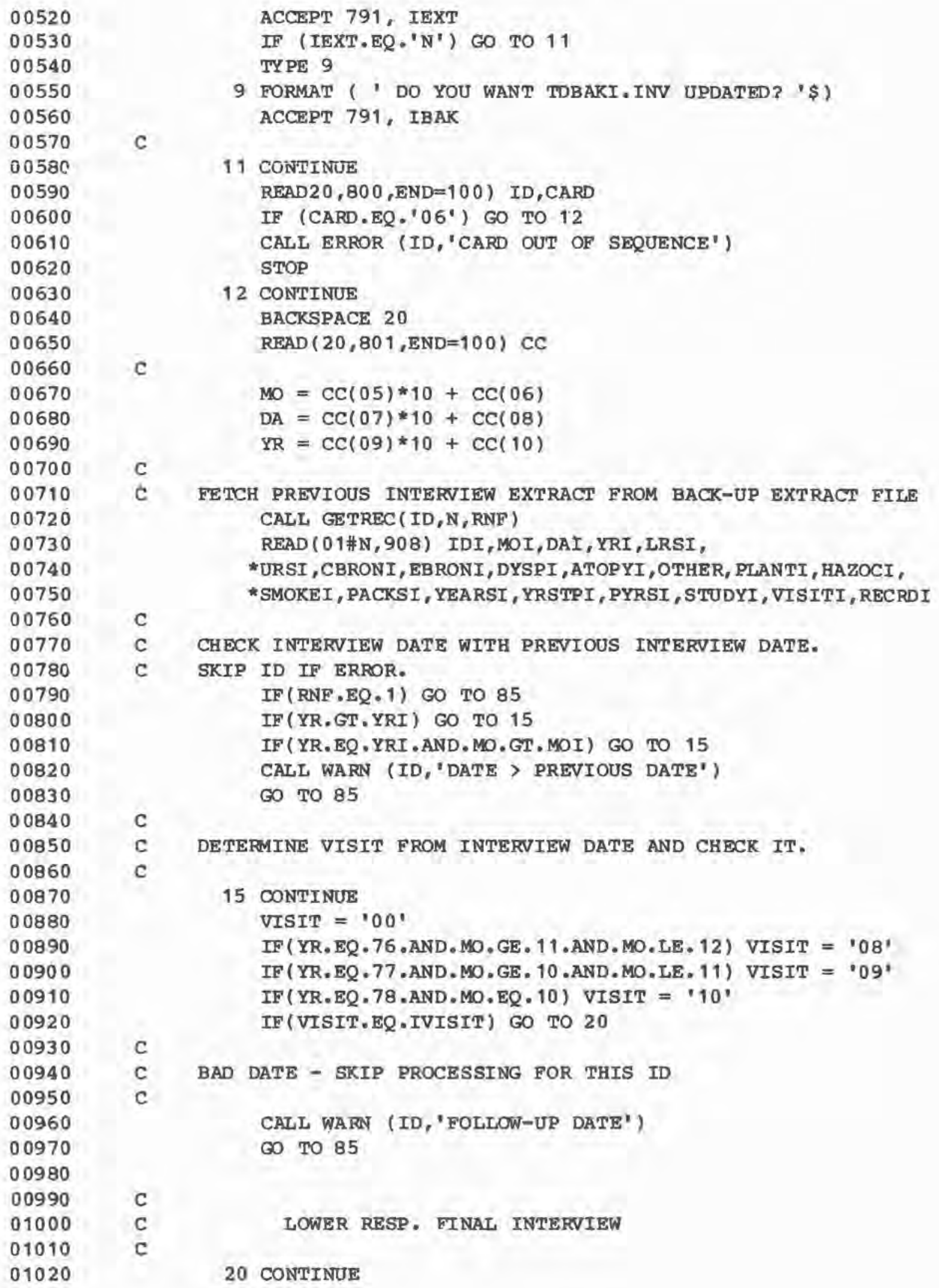


01030

01040

01050

01060

01070

01080

01090

01100

01110

01120

01130

01140

01150

01160

01170

01180

01190

01200

01210

01220

01230

01240

01250

01260

01270

01280

01290

01300

01310

01320

01330

01340

01350

01360

01370

01380

01390

01400

01410

01420

01430

01440

01450

01460

01470

01480

01490

01500

01510

01520

01530
LRS $=0$

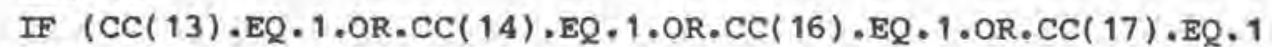

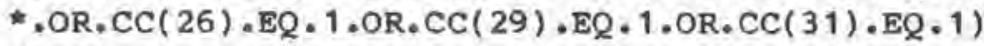

*LRS $=1$

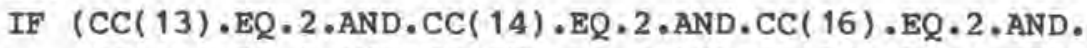

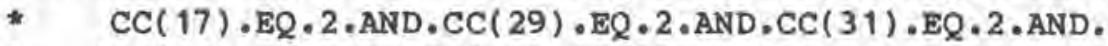

* (CC(26).EQ.2.OR.CC(26).EQ.9))

*LRS $=2$

IF (LRS .NE, 0) GO TO 25

CALL EXCEPT (ID, 'LOWER RESP, SYMPTOM')

C

C

C

URS - FINAL INTERVIEW

25 CONTINUE

URS $=0$

IF $(C C(34) \cdot E Q \cdot 1 \cdot O R \cdot C C(36) \cdot E Q \cdot 1)$ URS $=1$

IF $((C C(34) \cdot E Q \cdot 2 \cdot O R \cdot C C(34) \cdot E Q \cdot 9) \cdot A N D \cdot C C(36) \cdot E Q \cdot 2)$ URS $=2$

IF (URS - NE. 0) GO TO 30

CALL EXCEPT (ID,'UPPER RESP. SYMPTOM')

C

C

$\mathrm{C}$

C

C

C

40 CONTINUE

$\mathrm{CC} 25=\mathrm{CC}(25) ; \quad \mathrm{CC} 26=\mathrm{CC}(26) ; \mathrm{CC} 27=\mathrm{CC}(27) ; \mathrm{CC} 28=\mathrm{CC}(28)$

IF (CC25.EQ - 2.AND.CC26.EQ -9.AND.CC27.EQ •9.AND.CC28.EQ.9) DYSP=1

IF (CC25.EQ - 1 .AND.CC26.EQ -2.AND.CC27.EQ -9.AND.CC28.EQ.9) DSYP=2

IF (CC25.EQ 1 . AND.CC26.EQ - 1.AND.CC27.EQ - 2.AND.CC28.EQ.9) DYSP=3

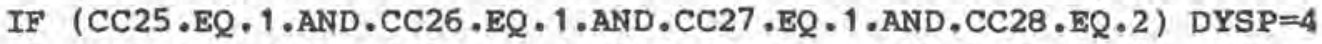

IF (CC25.EQ 1 .AND.CC26.EQ - 1.AND.CC27.EQ 1 .AND.CC28.EQ - 1) DYSP=5

IF (DYSP.EQ.O) CALL EXCEPT (ID, 'DYSPNEA GRADE')

C

C

$\mathrm{C}$

SMOKING UPDATE

SMOKE $=0$; PACKS $=99.99$, YEARS $=99.99$; YRSTP $=99.99 ;$ PYRS $=-1.00$ 


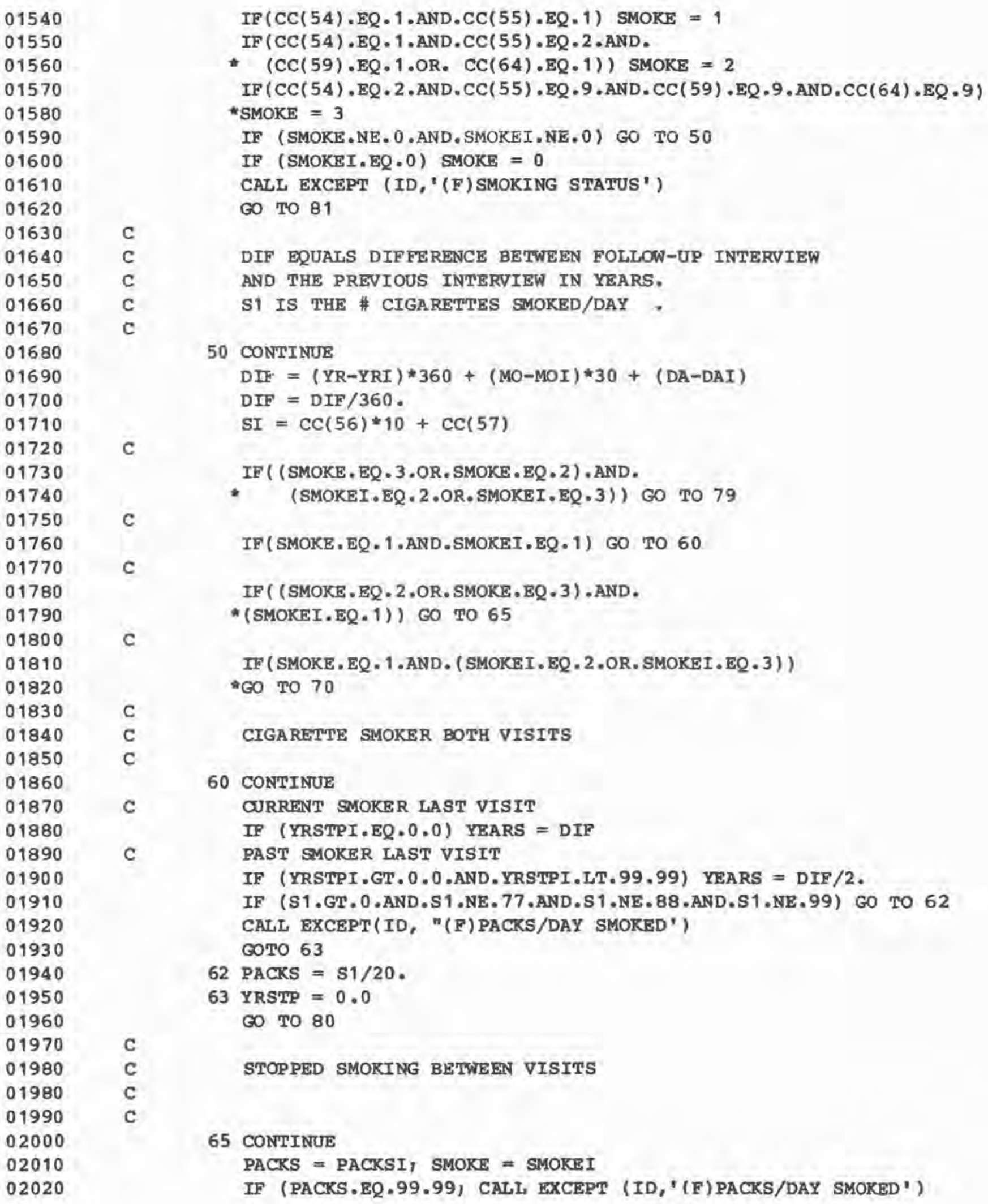

C

C

C

C

C

C

C

c

C

C

C

C

C

C

C

C.

C

$\operatorname{IF}(C C(54) \cdot E Q \cdot 1 \cdot A N D \cdot C C(55) \cdot E Q \cdot 1)$ SMOKE $=1$

IF (CC ( 54$) \cdot \mathrm{EQ} \cdot 1$. AND . CC (55) . EQ . 2 . AND .

$+(C C(59) \cdot E Q \cdot 1 \cdot O R \cdot C C(64) \cdot E Q \cdot 1))$ SMOKE $=2$

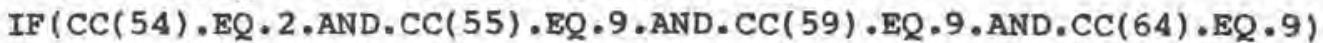

- SMOKE $=3$

IF (SMOKE.NE.0.AND.SMOKEI.NE.0) GO TO 50

IF $($ SMOKEI, EQ.0) SMOKE $=0$

CALL EXCEPT (ID, '(F) SMOKING STATUS')

GO TO 81

DIF EQUALS DIFFERENCE BETWEEN FOLLOW-UP INTERVIEW

AND THE PREVIOUS INTERVIEW IN YEARS.

S1 IS THE \# CIGARETTES SMOKED/DAY -

50 CONTINUE

DIF $=(Y R-Y R I) * 360+(M O-M O I) * 30+(D A-D A I)$

$\mathrm{DIF}=\mathrm{DIF} / 360$.

$S I=C C(56) * 10+C C(57)$

IF ( (SMOKE, EQ - 3.OR, SMOKE . EQ . 2) . AND.

* (SMOKEI.EQ.2.OR.SMOKEI.EQ.3)) GO TO 79

IF (SMOKE, EQ . 1.AND.SMOKEI, EQ .1) GO TO 60

IF ( (SMOKE • EQ - 2.OR. SMOKE • EQ - 3) -AND.

* (SMOKEI.EQ.1)) GO TO 65

IF (SMOKE.EQ . 1.AND. (SMOKEI . EQ . 2.OR. SMOKEI.EQ • 3))

-GO TO 70

CIGARETTE SMOKER BOTH VISITS

60 CONTINUE

CURRFNT SMOKER LAST VISIT

IP (YRSTPI.EQ *0.0) YEARS = DIF

PAST SMOKER LAST VISIT

IF (YRSTPI.GT.0.0.AND.YRSTPI.LT.99.99) YEARS = DIF/2.

IF (S1.GT.0.AND.S1.NE.77.AND.S1.NE.88.AND.S1.NE.99) GO TO 62

CALL EXCEPT(ID, "(F) PACKS/DAY SMOKED')

GOTO 63

62 PACKS $=51 / 20$.

63 YRSTP $=0.0$

GO TO 80

STOPPED SMOKING BETWEEN VISITS

65 CONTINUE

PACKS = PACKSI, SMOKE = SMOKEI

IF (PACKS.BQ.99.99) CALI EXCEPT (ID, '(F) PACKS/DAY SMOKED') 
02030

02040

02050

02060

02070

02080

02090

02100

02110

02120

02130

02140

02150

02160

02170

02180

02190

02200

02210

02220

02230

02240

02250

02260

02270

02280

02290

02300

02310

02320

02330

02340

02350

02360

02370

02380

02390

02400

02410

02420

02430

02440

02450

02460

02470

02480

02490

02500

02510

02520

02530
IF (YRSTPI.EQ.0.0) GO TO 66

IF (YRSTPI.GT.0.0.AND.YRSTPI.LT.99.99) GO TO 67

C ERROR ON LAST VISIT YEARS STOPPED SMOKING

CALL EXCEPT (ID,'(F) YRS STOPPED SMOKE')

GO TO 80

C

CURRENT SMOKER LAST VISIT

66 CONTINUE

YEARS $=\mathrm{DIF} / 2$,

YRSTP $=\mathrm{DIF} / 2$.

GO TO 80

PAST SMOKER LAST VISIT

67 CONTINUE

YEARS $=0.0 ;$ PACKS -0.0

YRSTP $=$ YRSTPI + DIF

IF (YEARS.EQ.99.99) CALL EXCEPT (ID,'(F) YEARS SMOKED')

GO TO 80

C

C

C

STARTED SMOKING BETWEEN VISITS

70 CONTINUE

IF(S1.GT.0.AND.S1.NE.77.AND.S1.NE.88.AND.S1.NE.99) GO TO 72

CALL EXCEPT (ID,'(F) PACKS/DAY SMOKED')

GO TO 73

72 PACKS $=51 / 20$.

73 YRSTP $=0.0$

YEARS $=\mathrm{DIF} / 2$.

GO TO 80

NEVER SMOKED IN EITHER VISIT

79 CONTINUE

PACKS $=0.0$

YEARS $=0.0$

YRSTP $=99.99$

IF $($ SMOKEI.EQ.2) SMOKE $=2$

QO TO 80

C

C

C

PACK-YEARS UPDATE

80 CONTINUE

IF (PACKS,BQ.99.99.OR. YEARS.EQ.99.99) GO TO 81

PYRS = PACKS*YEARS

WRITE ON TO EXTRACTION FILE

81 CONTINUE

IF (IEXT.NE.' $Y$ ') GO TO 85

STUDY $=108$ '

PLANT $=0.0$

HAZOCC $=0$

RBCORD $=.08$ ' 


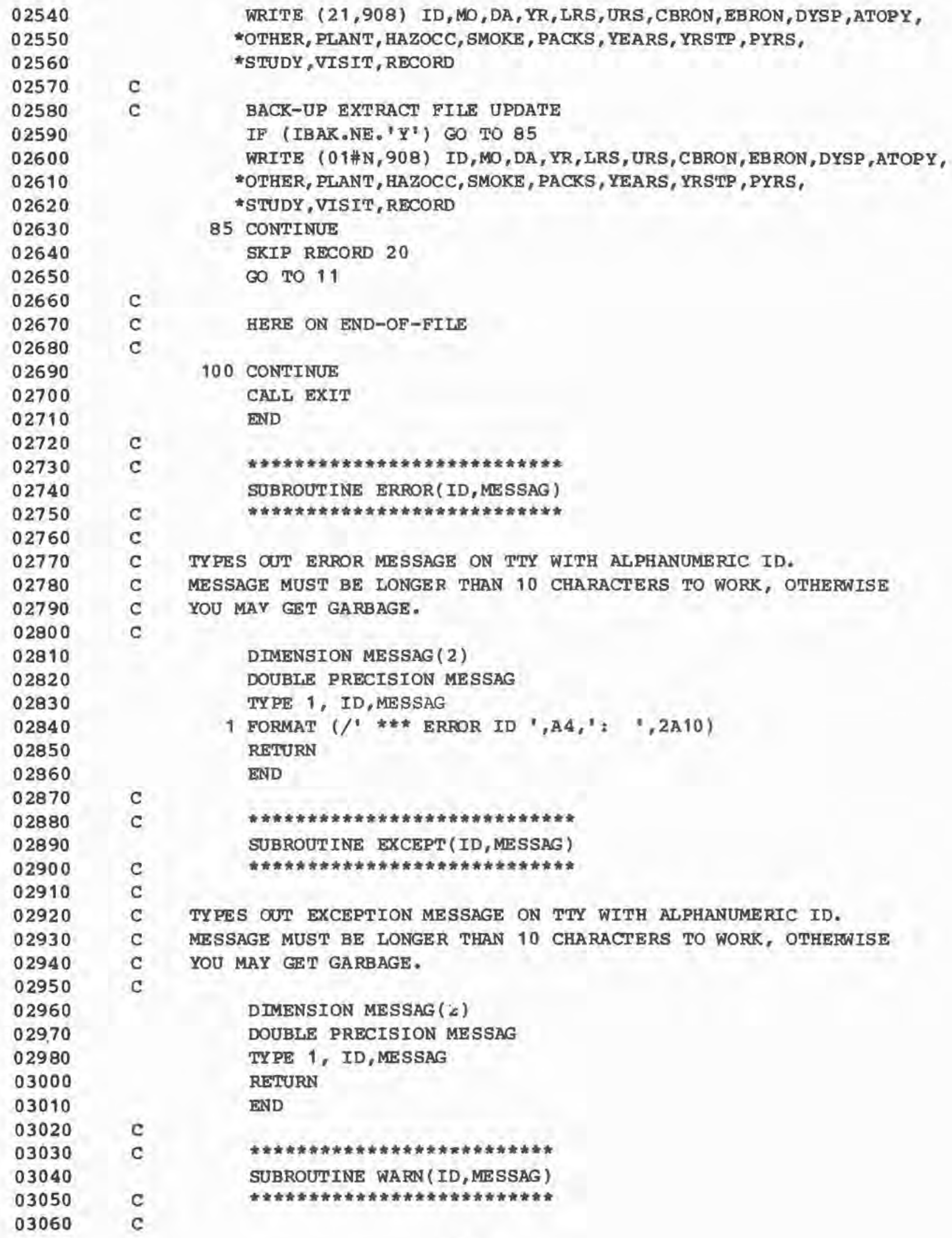




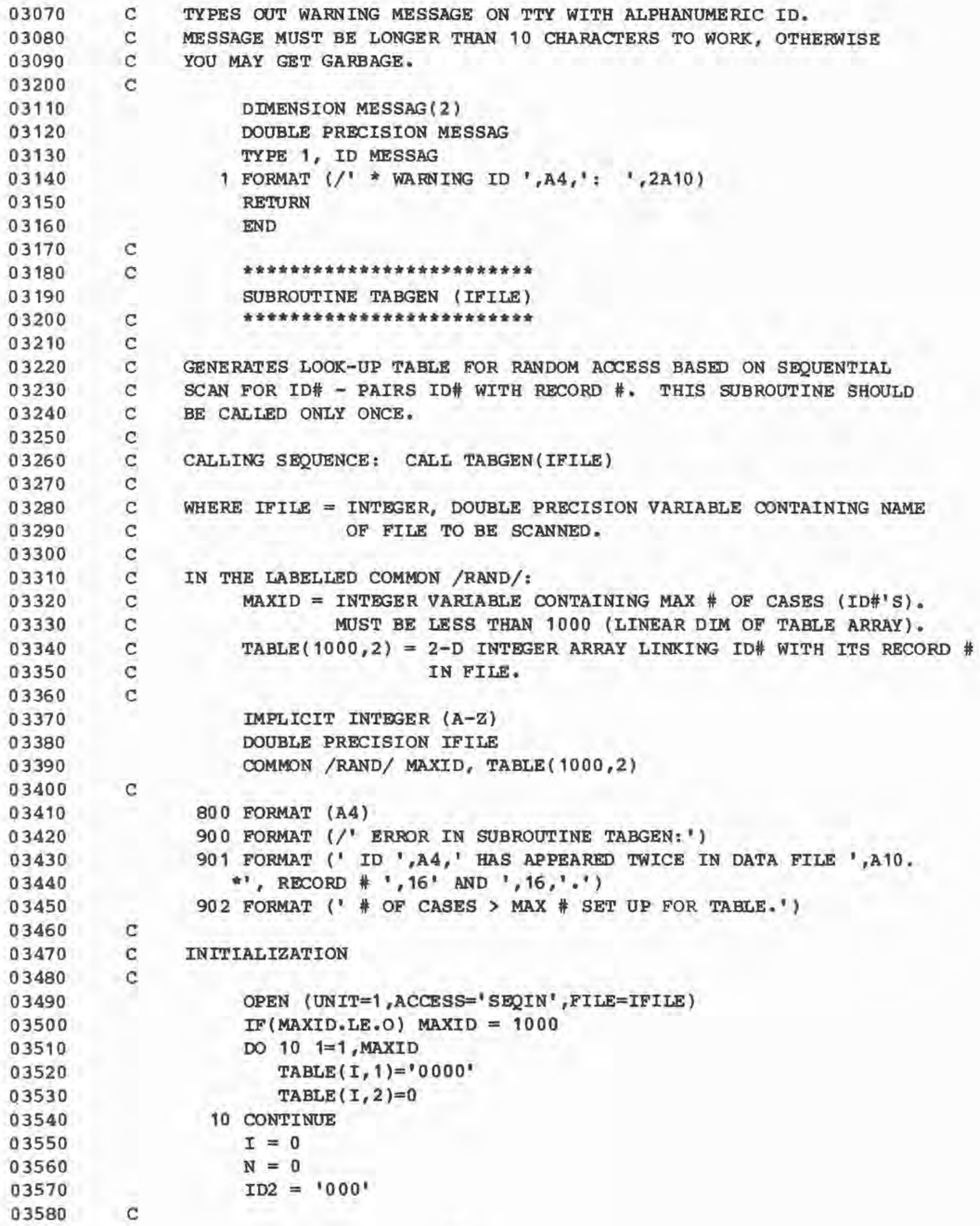

c

c

C

C 


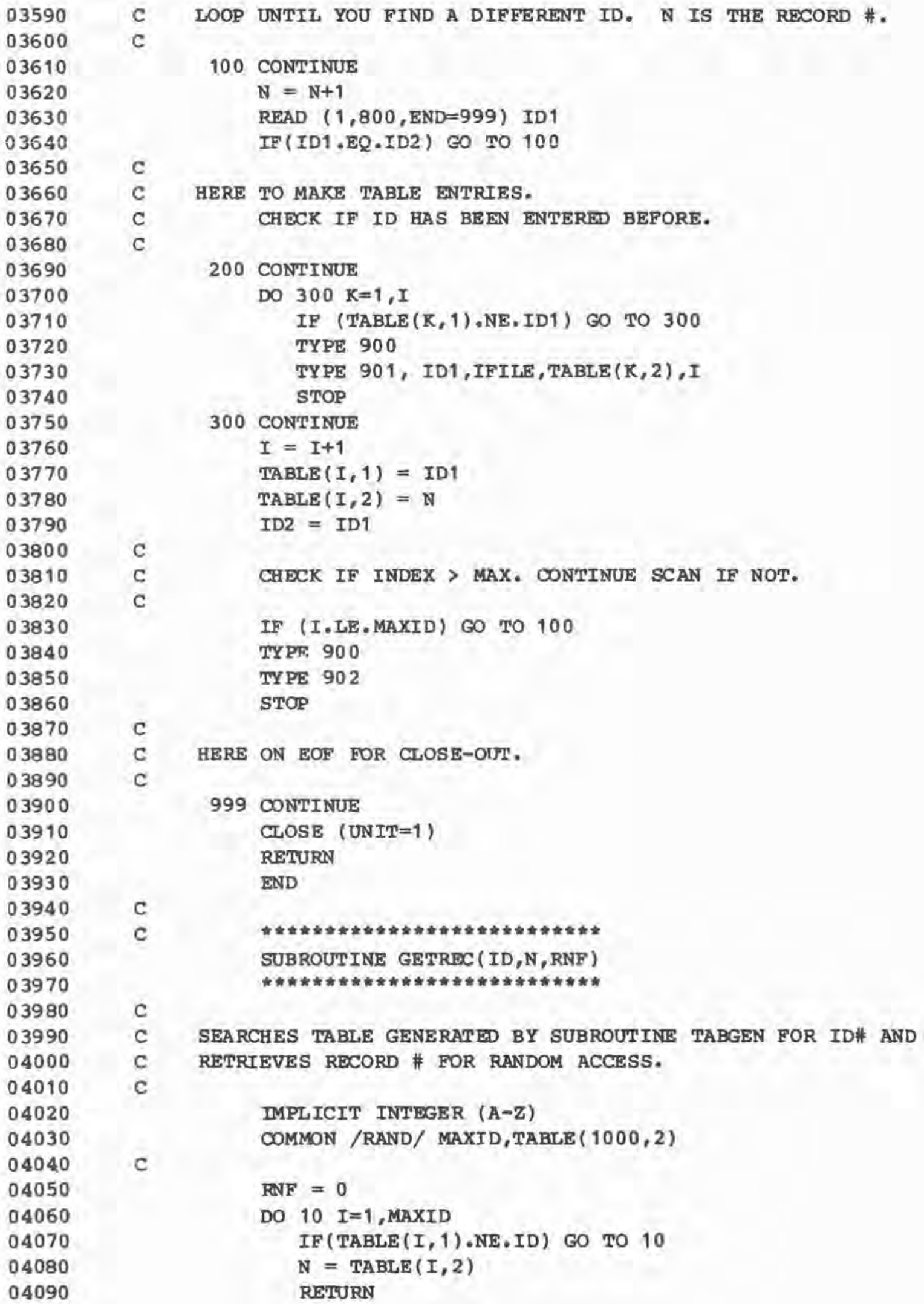




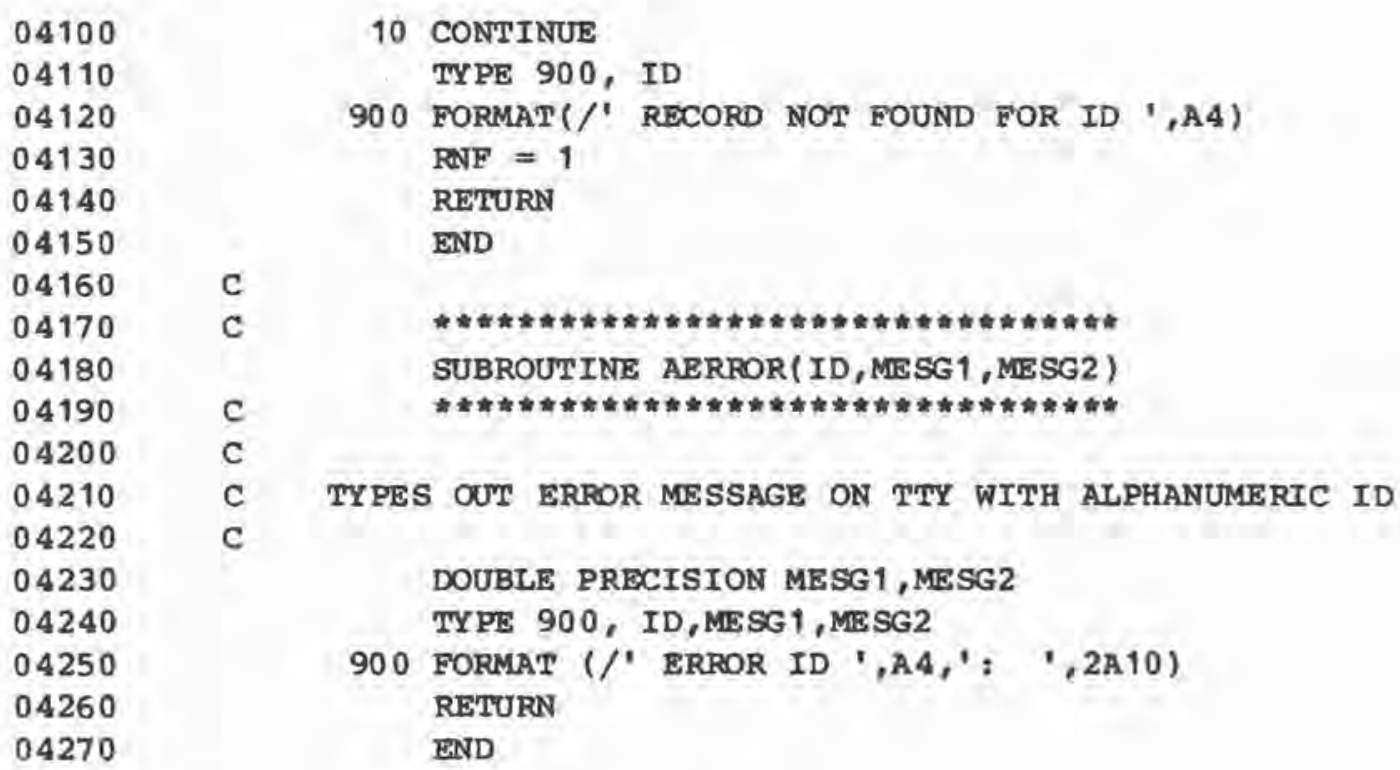

04270

10 CONTINUE TYPE 900 , ID

900 FORMAT(/' RECORD NOT FOUND FOR ID ',A4) $\mathrm{RNF}=1$ 


\section{References}

1. Cotes, J.E.: Lung Function Assessment and Application in Medicine. Blackwell Scientific Publications, 1975, Oxford.

2. Knudson, R.J., Slatin, R.C., Lebowitz, M.D., and Burrows, B.: The Maximal Expiratory Flow-Volume Curve - Normal Standards, Variability, and Effects of Age. Amer.Rev.Resp.Dis. 113, $587-600,1976$.

3. Fletcher, C., Peto, R., Tiner, C., and Speizer, F.: The Natura1 History of Chronic Bronchitis and Emphysema. Oxford University Press, 1976, Oxford.

4. Berry, G.: Longttudinal Observations, Their Usefulness and Limitations with Special Reference to the Forced Expiratory Volume. Bul1. Physio-path. resp., 10, 643-655, 1974

5. Berry, G., McKerrow, C.B., Molyneux, M.K.B., Rossiter, C.E., Tombleson, J.B.C.: A study of acute and chronic changes in ventilatory capacity of workers in Lancashire cotton mills. Brit.J.Industr.Med.: 30, 25-36, 1973.

6. Butcher, B.T., Jones, R.N., O'Ne11, C.E., Glindmeyer, H.W., Diem, J.E., Dharmarajan, V., Weill, H. and Salvaggio, J.E.: Longitudinal study of workers employed in the manufacture of toluene dilsocyanate. Amer.Rev.Resp.Dis., 116, 411-421, 1977.

7. Weill, H, Salvaggio, J., Neilson, A., Butcher, B.T., and Ziskind, M.: Respiratory effects in toluene diisocyanate manufacture: A multidisciplinary approach. Env. Health Perspectives, 11, 101-108, 1975.

8. Butcher, B.T., Salvaggio, J.E., Weill, H, and Ziskind, M.M.: Toluene diisocyanate (TDI) pulmonary disease: Immunologic and inhalation challenge studies. J. Allergy Clin.Immuno1., 58, 89-100, 1976.

9. Butcher, B.T.: Immunologic aspects of toluene dilsocyanate (TDI) sensitivity in exposed workers at a TDI plant. Proceedings of the Fifth Annual Workshop of the Asthma and Allergic Disease Centers, Pub. NIAID, U.S.D.H.E.W. PP. 171-175, 1975.

10. Butcher, B.T.: Inhalation challenge testing with toluene disocyanate (TDI). J. Allergy Clin.Immuno1., (In Press) 1979. 
11. Butcher, B.T., Karr, R.M., O'Ne11, C.E., Wilson, M.R., Dharmarajan, V., Salvaggio, J.E. and Weil1, H.: Inhalation challenge and pharmacologic studies of toluene dilsocyanate (TDI) sensitive workers. J. Allergy Clin. Immuno1. 64, 146-152, 1979.

12. Butcher, B.T., Salvaggio, J.E., O'Neil, C.E., Weil1, H. and Garg, 0: Toluene dilsocyanate (TDI) pulmonary disease: Immunopharmacologic and mecholyl challenge studies. J. Allergy Clin. Immunol. 59, 223-230, 1977.

13. Butcher, B.T. and Karr, R.M.: TDI induced asthma, in "Diagnosis and management of industrial, drug and radiation hazards - selected topics." Volume 1. Grune and Stratton. (In Press), 1979.

14. Davies, R.J., Butcher, B.T., O'Neil, C.E. and Salvaggio, J.E.; The in vitro effect of toluene dilsocyanate on 1ymphocyte cyclic adenosine monophosphate production by isoproterenol, prostaglandin and histamine - a possible mode of action. J. Allergy C1In. Immunol. $60,233-239,1977$.

15. Beaven, M.A., Jacobsen, S. and Horakova, Z: Modification of the enzymatic isotopic assay of histamine and its application to measurement of histamine in tissues, serum and urine. Clin. Chim. Acta, 37, 91, 1972.

16. Karr, R.M., Davies, R.J., Butcher, B.T., Lehrer, S.B., Wilson, M., Dharmarajan, V., and Salvaggio, J.E.: Allergy Grand Rounds Occupational Asthma. J. Allergy Clin. Immuno1., 61, 54-65, 1978.

17. Mitche11, J.C. and Jordan, W.P.: Allergic contact dermatitis from radish, Raphanus saturis. Brit. J. Dermato1. 91, 183-189, 1974.

18. Butcher, B.T., O'Neil, C/E., Karr, R.M., Weil1, H., and Salvaggio, J.E.: Longitudinal study of isocyanate sensitive worker with concurrent development of food allergy shows loss of pharmacologic and methacholine reactivity. (In preparation).

19. Karol, M.H., Ioset, M.M., and Alarle, Y,C.; Tolyl-specific IgE antibodies in workers with hypersensitivity to toluene disocyanate. Am. Ind. Hyg. Assoc. J., 39, 454, 1978.

20. Butcher, B.T., O'Ne1l, C.E. and Salvaggio, J.E.; Radioallergosorbent testing (RAST) of TDI reactive individuals using p-tolyl-isocyanate (TMI) antigen. J. Allergy C1in. Immuno1., (Submitted), 1979. 
21. Weil1, H., Salvaggio, J., Neilson, A., Butcher, B., and Ziskind, M.; Respiratory effects in toluene dilsocyanate manufacture: A multidisciplinary Approach. Environ. Hlth. Perspect. 11, 101-108, 1975.

22. Butcher, B.T., Jones, R.N., O'Ne11, C.E., Glindmeyer, H.W., Diem, J.E., Dharmarajan, V., Wel11, H, and Salvaggio, J.E.: Longitudinal study of workers employed in the manufacture of toluene difsocyanate. Am. Rev. Resp. Dis., 116, 411-421, 1977.

23. Dhamarajan, V.: Analysis of TDI and MDI in air. Am.Ind.Hyg.Assoc.J., $38,725,1977$.

24. Dharmarajan, V., Well1, H., and Self, C.W.: Environmental characterization of toluene dilsocyanate in a manufacturing plant. Am. Ind. Hyg. Assoc. J., 39, 414-418, 1978.

25. Nellson, A. and Booth, K.S.: A technique for dynamic calibration of a continuous toluene difsocyanate monftor. Am. Ind. Hyg. Assoc. J. 36, 169-171, 1975.

26. Dharmarajan, V. and Rando, R.J. A new method for the generation of standard atmospheres of organo isocyanates. Am. Ind. Hyg. Assoc. J. (In Press), 1979.

27. Dharmarajan, V.: Occupational exposures to methylene bisphenylisocyanate (MDI): Gaseous or aeroso1? J. Environ. Pathol. and Toxicol. 2. $1-8,1979$.

28. Marcal1, K.: Microdetermination of toluene dilsocyanate in atmospheres. Ana1. Chem. 29, 552-558, 1957.

29. Reilly, D.A.: A test-paper method for the determination of toluene difsocyanate vapor in air. Analyst, $93,178-185,1968$.

30. Allshuller, A.P. and Cohen, I.R, : Application of diffusion cells to the production of known concentrations of gaseous hydrocarbons. Anal. Chem., 32, 802-810, 1960.

31. Model 7000 TDI Monitors are distributed in U.S.A. by MDA Scientific, Inc., 808 Busse Highway, Park Ridge, I11., 60068.

32. Dixon, W.J.: BMDP, Blomedical Computer Programs, UnIversity of California Press, Berkeley, 1975.

33. IMSL Reference Manual, Edition 6, International Mathematical and Statistical Libraries, Houston, 1977. 
34. Graybi11, Franklin A.: An Introduction to Linear Statistical Models Vol 1, McGraw-H1ll Book Company, Inc., 1961, New York.

35. Kauffmann, F., Drouet, D., Lellouch, J., and Brille, D.: Twelve years spirometric changes among Paris area workers. Int. Journ. of Epid. $\underline{8}$, 201-202, 1979.

36. Ferris B G, Chen H, Pulco S and Murphy R L H, Chronic Non specific Respiratory Disease in Berlin, New Hampshire, 1967 to 1973. A further Followmup study. Arerican Review of Respiratory Disease 114, 475, 1976.

37. Higgins I T T, Gilson J C, Ferris B G, Waters M E, Campbell H and Higgins $M$ W. IV. Chronic resplratory disease in an industrial town: a nine-year follow-up study. Preliminary Report. American Journal of Public Health 58: 1667, 1968.

38. Petty T L, PIerson D J, Dick N P, Hudson L D and Walker S H. Follow-up evaluation of a prevalence study for chronic bronchitis and Chronic Airways Obstruction. American Revlew of Resplratory Disease 114: $881,1976$.

39. Lebowitz M D. Longitudinal changes in lung function and respiratory symptoms. Paper presented IEA Meeting, Puerto Rico, September 1977.

40. Pham Q T, Benis A M, Muir J M, Sadoul and Haluska J. Follow-up study of construction workers with obstructive lung disease. Scandinavian Journal of Respitratory Diseases $58: 215,1977$. 
Table 1

PARTICIPATION BY VISIT

SPIROMETRY

\begin{tabular}{|c|c|c|c|c|c|c|c|c|c|c|}
\hline Visit Date & $4-73$ & $11-73$ & $9-74$ & $3-75$ & $10-75$ & $3-76$. & $11-76$ & $12-77$ & $10-78$ & TOTAL \\
\hline Number Added & 168 & 27 & 25 & 34 & 23 & - & - & - & - & 277 \\
\hline Permanently Lost & - & 6 & 9 & 3 & 11 & 13 & 7 & 13 & 9 & 71 \\
\hline $\begin{array}{l}\text { Eligible from Previous } \\
\text { Visit }\end{array}$ & - & 162 & 180 & 202 & 225 & 235 & 228 & 215 & 206 & \\
\hline Total Eliglble & 168 & 189 & 205 & 236 & 248 & 235 & 228 & 215 & 206 & \\
\hline $\begin{array}{l}\text { Refused } \\
\text { (\% of Elig. from Prev.) }\end{array}$ & 0 & $\begin{array}{l}3 \\
(1.9)\end{array}$ & $\begin{array}{l}7 \\
(3.9)\end{array}$ & $\begin{array}{l}12 \\
(5.9)\end{array}$ & $\begin{array}{l}21 \\
(9.3)\end{array}$ & $\begin{array}{l}25 \\
(10.6)\end{array}$ & $\begin{array}{l}37 \\
(16.2)\end{array}$ & $\begin{array}{l}35 \\
(16.3)\end{array}$ & $\begin{array}{l}36 \\
(17.5)\end{array}$ & \\
\hline $\begin{array}{l}\text { Temporar1ly Lost } \\
\text { (\% of Elig. from Prev.) }\end{array}$ & $\begin{array}{l}2 \\
(1.2)\end{array}$ & $\frac{11}{(6.8)}$ & $\begin{array}{l}13 \\
(7.2)\end{array}$ & $\begin{array}{l}21 \\
(10 \cdot 4)\end{array}$ & $\begin{array}{l}17 \\
(7 \cdot 6)\end{array}$ & $\begin{array}{l}24 \\
(10.2)\end{array}$ & $\begin{array}{l}25 \\
(11.0)\end{array}$ & $\begin{array}{l}34 \\
(15.8)\end{array}$ & $\begin{array}{l}29 \\
(14.1)\end{array}$ & \\
\hline $\begin{array}{l}\text { Complete Spirometry } \\
\text { (\% of Total Eligible) }\end{array}$ & $\begin{array}{l}144 \\
(85.7)\end{array}$ & $\begin{array}{l}145 \\
(76.7)\end{array}$ & $\begin{array}{l}168 \\
(81.9)\end{array}$ & $\begin{array}{l}197 \\
(83.5)\end{array}$ & $\begin{array}{l}200 \\
(80.6)\end{array}$ & $\begin{array}{l}175 \\
(74.5)\end{array}$ & $\begin{array}{l}161 \\
(70.6)\end{array}$ & $\begin{array}{l}142 \\
(66.0)\end{array}$ & $\begin{array}{l}135 \\
(65.5)\end{array}$ & \\
\hline $\begin{array}{l}\text { Complete Spirometry } \\
\text { (\% of Ellgible - } \\
\text { Refused - Temp. Lost) }\end{array}$ & $\begin{array}{l}144 \\
(86.7)\end{array}$ & $\begin{array}{l}145 \\
(82.8)\end{array}$ & $\begin{array}{l}168 \\
(90.8)\end{array}$ & $\begin{array}{l}197 \\
(97.0)\end{array}$ & $\begin{array}{l}200 \\
(95.2)\end{array}$ & $\begin{array}{l}175 \\
(94.1)\end{array}$ & $\begin{array}{l}161 \\
(97.0)\end{array}$ & $\begin{array}{l}142 \\
(97.3)\end{array}$ & $\begin{array}{l}135 \\
(95.7)\end{array}$ & \\
\hline
\end{tabular}


Table 2

DESCRIPTIVE STATISTICS AT INITIAL VISIT

FOR THE 274 MALE PARTICIPANTS

\begin{tabular}{|c|c|c|c|c|}
\hline & & & & $\underline{\mathrm{n}}$ \\
\hline 1. & Race: & $85 \%$ & white & 274 \\
\hline 2. & Cigarette Smoking: & $51.1 \%$ & current & 273 \\
\hline & & $22.6 \%$ & Ex & \\
\hline & & $25.9 \%$ & Never & \\
\hline 3. & $\begin{array}{l}\text { Atopy (positive to } 2 \text { or } \\
\text { more skin tests) }\end{array}$ & $20.1 \%$ & Atopic & 274 \\
\hline 4. & Upper respiratory symptoms & $38.7 \%$ & Positive & 273 \\
\hline 5. & Lower respiratory symptoms & $29.6 \%$ & Positive & 272 \\
\hline 6. & Bronchitis & $3.6 \%$ & Posttive & 273 \\
\hline 7. & Dyspnea & $84.3 \%$ & GRADE I & 271 \\
\hline & & $11.7 \%$ & GRADE II & \\
\hline & & $2.9 \%$ & GRADE III & \\
\hline & & $\underline{\mathrm{n}}$ & Mean & $\begin{array}{c}\text { Standard } \\
\text { Deviation }\end{array}$ \\
\hline 8. & Age (years) & 274 & 35.9 & 11.3 \\
\hline 9. & Height (Inches) & 274 & 69.9 & 2.56 \\
\hline 10. & Pack-years & 273 & 14.37 & 16.3 \\
\hline 11. & $\mathrm{IgE} I \mathrm{IO} / \mathrm{m} 1$ & 271 & 181.8 & 287.7 \\
\hline 12. & FEV\% $\mathrm{P}^{(1)}$ & 244 & 100.2 & 13.3 \\
\hline 13. & FVC\% P & 244 & 102.7 & 12.3 \\
\hline 14. & $\mathrm{FEF}_{25-75 \%} \mathrm{P}$ & 244 & 91.0 & 26.5 \\
\hline 15. & $\mathrm{RV} \% \mathrm{P}$ & 217 & 99.4 & 25.7 \\
\hline 16. & TLC\% P & 217 & 101.0 & 11.6 \\
\hline 17. & $\mathrm{DL}_{\mathrm{CO}} \% \mathrm{P}$ & 212 & 99.0 & 16.7 \\
\hline 18. & $\mathrm{~K} \% \mathrm{P}$ & 212 & 99.7 & 17.3 \\
\hline
\end{tabular}

(1)\% predicteds are taken from the pulmonary function measurements at the time of the initial interview or the next visit at which the pulmonary function measurement was taken if it was not done at the visit of the inftial interview. 
Table 3

DESCRIPTIVE STATISTICS (In pP⿴囗)

FOR 8-HOUR TIME-WEIGHTED AVERAGES

8-Hour Time-Weighted Averages Used to Develop Exposure Categories
"Turnaround Time"

8-Hour Time-Weighted Averages
MAX

$\mathrm{P}_{75}$

MEAN

MEDIAN

$\mathrm{P}_{25}$

MIN

S. D.

GEO. MEAN

GEO. S. D.

n (samples)
.0250

.0036

.0035

.0020

.0011

.0001

.0045

.0020

2.94

1949
.0250

.0067

.0055

.0030

.0020

.0001

.0059

.0036

2.55

144 
JOB TITLES BY TIME-WEIGHTED AVERAGE EXPOSURE CATEGORY

\begin{tabular}{|c|c|c|c|c|}
\hline $\begin{array}{l}\text { Exposure } \\
\text { Category }\end{array}$ & $\begin{array}{c}\text { Job } \\
\text { Code } \\
\end{array}$ & Job & Location & $\begin{array}{c}\text { Number } \\
\text { of } \\
\text { Samples }\end{array}$ \\
\hline \multirow[t]{5}{*}{$\mathrm{HIGH}$} & 13001 & C Operator & TDI & 222 \\
\hline & 15050 & E Operator & Drumming & 199 \\
\hline & 15051 & E Operator & Tank Farm & 5 \\
\hline & 31030 & M11lwright & Phosgene & 12 \\
\hline & 33030 & Welder & Phosgene & $I$ \\
\hline \multirow[t]{14}{*}{ MODERATE } & 1001 & Foreman & TDI & 239 \\
\hline & 12001 & B Operator & TDI & 208 \\
\hline & 14030 & D Operator & Phosgene & 224 \\
\hline & 30001 & Unsp. Maint. & TDI & 7 \\
\hline & 30021 & Unsp. Maint. & Machine Shop & 4 \\
\hline & 31001 & Millwright & TDI & 51 \\
\hline & 32001 & Boilermaker & TDI & 17 \\
\hline & 33001 & Welder & TDI & 31 \\
\hline & 34001 & Pipefitter & TDI & 30 \\
\hline & 36001 & Instruments & TDI & 7 \\
\hline & 36019 & Instruments & Shop & 5 \\
\hline & 41002 & Unspec. Samp1. & TDI Lab & 7 \\
\hline & 42002 & A Sampler & TDI Lab & 14 \\
\hline & 43002 & B Sampler & TDI Lab & 7 \\
\hline \multirow[t]{23}{*}{ LOW } & 1014 & Foreman & Soda Ash & 4 \\
\hline & 1017 & Foreman & $\mathrm{T} 101$ & 4 \\
\hline & 11001 & A Operator & TDI & 69 \\
\hline & 11010 & A Operator & TDA & 60 \\
\hline & 12020 & B Operator & Hyco & 88 \\
\hline & 13010 & C Operator & TDA & 89 \\
\hline & 13040 & C Operator & POL-DNT & 14 \\
\hline & 14040 & D Operator & POL-DNT & 124 \\
\hline & 15010 & E Operator & TDA & 35 \\
\hline & 15030 & E Operator & Phosgene & 1 \\
\hline & 19052 & Operator & Bug Pond & 99 \\
\hline & 31012 & Millwright & Sodium Nitrate & 2 \\
\hline & 33009 & Welder & Ammonia & 6 \\
\hline & 33027 & Welder & Pilot Plant & 3 \\
\hline & 35001 & Electrician & TDI & 15 \\
\hline & 35018 & Electrician & Shop & 6 \\
\hline & 36009 & Instruments & Ammonia & 6 \\
\hline & 37028 & Carpenter & Shop & 4 \\
\hline & 40002 & Chemist & TDI Lab & 15 \\
\hline & 53029 & clerical & CAR Warehouse & 2 \\
\hline & 57012 & Truck Driver & Sodium Nitrate & 4 \\
\hline & 58012 & Warehouseman & Sodium N1trate & 5 \\
\hline & 71021 & Machinist & Shop & 4 \\
\hline
\end{tabular}


Table 5

8-HOUR TIME-WEIGHTED AVERAGE DESCRIPTIVE STATISTICS (in ppm) BY EXPOSURE CATEGORY

$\begin{array}{lccc}\text { CATEGORY } & \text { HIGH } & \text { MODERATE } & \text { LOW } \\ \text { MAX. } & .0250 & .0250 & .0248 \\ \mathrm{P}_{75} & .0088 & .0035 & .0020 \\ \text { MEAN } & .0068 & .0032 & .0016 \\ \text { MEDIAN } & .0050 & .0020 & .0013 \\ \text { P }_{25} & .0025 & .00130 & .0007 \\ \text { MIN. } & .0001 & .0001 & .0001 \\ \text { S. D. } & .0062 & .0039 & .0018 \\ \text { GEO. MEAN } & .0045 & & .0011 \\ \text { GEO. S. D. } & 2.69 & .0020 & 2.37 \\ \text { II } & 439 & 2.68 & 659\end{array}$


Table 6

JOB TITLES BY PEAK EXPOSURE CATEGORY

\begin{tabular}{|c|c|c|}
\hline Category I: & $\begin{array}{l}15050 \\
30001 \\
31030 \\
33030\end{array}$ & $\begin{array}{l}\text { E Operator in Drumming } \\
\text { Unspecifled Maintenance in TDI } \\
\text { Millwright in Phosgene } \\
\text { Welder in Phosgene }\end{array}$ \\
\hline Category II: & $\begin{array}{l}12001 \\
13001 \\
31001 \\
33001 \\
34001\end{array}$ & $\begin{array}{l}\text { B operator in TDI } \\
\text { C operator in TDI } \\
\text { Millwright in TDI } \\
\text { Welder in TDI } \\
\text { Pipe Fitter in TDI }\end{array}$ \\
\hline Category III: & $\begin{array}{l}01001 \\
14030 \\
15051 \\
32001 \\
37001 \\
42002\end{array}$ & $\begin{array}{l}\text { Foreman in TDI } \\
\text { D Operator in Phosgene } \\
\text { E Operator in TK Farm } \\
\text { Bollermaker in TDI } \\
\text { Carpenter in TDI } \\
\text { A Sampler in TDI Lab }\end{array}$ \\
\hline Category IV: & $\begin{array}{l}01014 \\
01017 \\
11001 \\
11010 \\
12020 \\
13010 \\
13040 \\
14040 \\
15010 \\
15030 \\
19052 \\
30021 \\
\\
31010 \\
31012 \\
33009 \\
33010 \\
33020 \\
33027 \\
35001 \\
35018 \\
36001 \\
36009 \\
36019 \\
36020 \\
36030 \\
37028 \\
38001 \\
39001 \\
40002 \\
41002 \\
43002 \\
53029 \\
57012 \\
58012 \\
71021\end{array}$ & $\begin{array}{l}\text { Foreman in Soda Ash } \\
\text { Foreman in T-101 } \\
\text { A Operator In TDI } \\
\text { A Operator in TDA } \\
\text { B Operator in HYCO } \\
\text { C Operator in TDA } \\
\text { C Operator in POL-DNT } \\
\text { D Operator in POL-DNT } \\
\text { E Operator in TDA } \\
\text { E Operator in Phosgene } \\
\text { Operator in Bug Pond } \\
\text { Unspecified Maint. in } \\
\quad \text { Machine Shop } \\
\text { Millwright in TDA } \\
\text { Millwright in Sodium Nitrate } \\
\text { Welder In Ammonia } \\
\text { Welder in TDA } \\
\text { Welder in HYCO } \\
\text { Welder in Pilot Plant } \\
\text { Electrician in TDI } \\
\text { Electrician in Electric Shop } \\
\text { Instruments in TDI } \\
\text { Instruments in Amonia } \\
\text { Instruments in Instr. Shop } \\
\text { Instruments in HYCO } \\
\text { Instruments in Phosgene } \\
\text { Carpenter in Carpenter Shop } \\
\text { Insulator in TDI } \\
\text { Maint. Supervisor In TDI } \\
\text { Chemist/Analyst in TDI Lab } \\
\text { Unspecified Sampler in TDI Lab } \\
\text { B Sampler in TDI Lab } \\
\text { Clerical in CAR Warehouse } \\
\text { Truck Driver or Laborer in } \\
\text { Warehouseman in Sodium N1trate } \\
\text { Machinist in Machine Shop }\end{array}$ \\
\hline
\end{tabular}


Table 7

Percentage of Time Spent Above Selected Concentration Levels by Peak Exposure Category

$$
\text { Percentage of time above: }
$$

Number of

\begin{tabular}{cccccccc} 
Category & $.005 \mathrm{ppm}$ & $.01 \mathrm{ppm}$ & $.02 \mathrm{ppm}$ & $.04 \mathrm{ppm}$ & $.06 \mathrm{ppm}$ & $.08 \mathrm{ppm}$ & Samples \\
\cline { 2 - 5 } I & 36.1 & 20.1 & 10.6 & 5.5 & 3.9 & 3.4 & 219 \\
II & 24.0 & 12.1 & 5.0 & 2.4 & 1.6 & 1.4 & 618 \\
III & 10.7 & 4.0 & 1.4 & 0.5 & 0.3 & 0.2 & 518 \\
IV & 3.2 & 0.7 & 0.3 & 0.1 & 0.1 & 0.0 & 738
\end{tabular}

A11 Categories Combined

14.6

$\begin{array}{lll}6.9 & 3.0 & 1.4\end{array}$

1.0

0.8

2093 
Table 8

ANNUAL CILNGE REGRESSION COEFFICIENTS ${ }^{(1)}$ USING CUMULATIVE EXPOSURE, ATOPIC STATUS AND PACK-YEARS AS EXPLANATORY VARIABLES

\begin{tabular}{|c|c|c|c|c|c|c|}
\hline & $\pi$ & Intercept & $\begin{array}{l}\text { Cumulative } \\
\text { Exposure }\end{array}$ & Atopy & $\begin{array}{l}\text { Pack- } \\
\text { Years }\end{array}$ & $\begin{array}{l}\text { \% Variability } \\
\text { Explained }\end{array}$ \\
\hline $\mathrm{FEV}_{1} \mathrm{~L} / \mathrm{yr}$ & 223 & $\begin{array}{l}-.0103 \\
(-1.09)\end{array}$ & $\begin{array}{l}-.0770 \\
(-.81)\end{array}$ & $\begin{array}{l}.0011 \\
(.15)\end{array}$ & $(-2.55)$ & 7.36 \\
\hline FVC $\quad L / y x$ & 223 & $\begin{array}{l}-.0039 \\
(-.40)\end{array}$ & $\frac{.0455}{(.47)}$ & $\begin{array}{l}-.0070 \\
(-.97)\end{array}$ & $\begin{array}{l}-.00071 \\
(-3.13)\end{array}$ & 20.3 \\
\hline FEV\% $(y r)^{-1}$ & 223 & $\begin{array}{l}-.2041 \\
(-1.52)\end{array}$ & $\begin{array}{l}-1.372 \\
(-1.01)\end{array}$ & $\begin{array}{l}.1246 \\
(1.21)\end{array}$ & $\begin{array}{l}-.00332 \\
(-1.03)\end{array}$ & 3.0 \\
\hline $\mathrm{FEF}_{25-75} \mathrm{~L} / \mathrm{sec}-\mathrm{yr}$ & 223 & $\begin{array}{l}-.0736 \\
(-3.23)\end{array}$ & $\begin{array}{l}-.00275 \\
(-1.19)\end{array}$ & $\begin{array}{l}.0249 \\
(1.44)\end{array}$ & $\begin{array}{l}-.00024 \\
(-.43)\end{array}$ & 4.1 \\
\hline $\mathrm{FEF}_{50} \mathrm{~L} / \mathrm{sec}-\mathrm{yr}$ & 223 & $\frac{-.1115}{(-3.50)}$ & $\begin{array}{l}-.000386 \\
(-.12)\end{array}$ & $(1.54)$ & $\begin{array}{l}-.00036 \\
(-.48)\end{array}$ & 6.5 \\
\hline$K(m i n-m n H g-y r)^{-1}$ & 164 & $\begin{array}{r}-.169 \\
(-4.99)\end{array}$ & $\begin{array}{l}1.276 \\
(3.31)\end{array}$ & $\begin{array}{l}-.0155 \\
(-.58)\end{array}$ & $\begin{array}{l}-.00072 \\
(-.85)\end{array}$ & 28.8 \\
\hline $\mathrm{DL}_{\mathrm{CO}} \frac{\mathrm{ml}}{\mathrm{mIn-mmHg-yr}}$ & 164 & $\begin{array}{l}-1.127 \\
(-4.97)\end{array}$ & $\begin{array}{l}7.926 \\
(3.07)\end{array}$ & $\begin{array}{r}-.433 \\
(-2.43)\end{array}$ & $\begin{array}{l}-.0015 \\
(-.27)\end{array}$ & 47.5 \\
\hline RV $L / y r$ & 179 & $\begin{array}{l}.0391 \\
(3.09)\end{array}$ & $\begin{array}{r}-.126 \\
(-.99)\end{array}$ & $\begin{array}{l}-.00222 \\
(-.24)\end{array}$ & $\begin{array}{l}.00104 \\
(3.58)\end{array}$ & 30.9 \\
\hline TLC L/yr & 179 & $(1.81)$ & $\begin{array}{l}.00371 \\
(.02)\end{array}$ & $\begin{array}{l}-.0106 \\
(-.93)\end{array}$ & $\begin{array}{l}.00048 \\
(1.38)\end{array}$ & 5.5 \\
\hline$(\mathrm{RV} / \mathrm{TLC}) \times 100(\mathrm{yr})^{-1}$ & 179 & $\begin{array}{l}.4400 \\
(3.04)\end{array}$ & $\frac{-1.112}{(-.77)}$ & $\begin{array}{l}-.0181 \\
(-.17)\end{array}$ & $\begin{array}{l}.0114 \\
(3.44)\end{array}$ & 46.4 \\
\hline
\end{tabular}

(1) The numbers in parentheses are the regression coefficients divided by their standard errors. They should be compared to normal distribution percentiles for tests of significance. 
Table 9

ANNUAL CHANGE REGRESSION COEFFICIENTS ${ }^{(1)}$ USING DICHOTOMIZED CUMULATIVE EXPOSURE, ATOPIC STATUS, AND PACK-YEARS AS EXPLANATORY VARIABLES

\begin{tabular}{|c|c|c|c|c|c|c|}
\hline & $\mathrm{n}$ & Intercept & $\begin{array}{c}\text { Cumulative } \\
\text { Expasure } \\
\text { Category II }\end{array}$ & Atopy & $\begin{array}{l}\text { Pack- } \\
\text { Years }\end{array}$ & $\begin{array}{c}\text { \% Variability } \\
\text { Explained }\end{array}$ \\
\hline $\mathrm{FEV}_{1} \mathrm{~L} / \mathrm{yr}$ & 223 & $\begin{array}{l}-.0120 \\
(-2.14)\end{array}$ & $\begin{array}{l}-.0118 \\
(-1.82)\end{array}$ & $\begin{array}{l}.0009 \\
(.13)\end{array}$ & $\begin{array}{l}-.00058 \\
(-2.60)\end{array}$ & 9.4 \\
\hline FVC L/yr & 223 & $\begin{array}{l}-.0006 \\
(-.10)\end{array}$ & $\begin{array}{l}.0012 \\
(.19)\end{array}$ & $\begin{array}{l}-.0069 \\
(-.95)\end{array}$ & $\begin{array}{l}-.00071 \\
(-3.17)\end{array}$ & 19.2 \\
\hline FEV\% $(y \tau)^{-1}$ & 223 & $\begin{array}{l}-.2358 \\
(-2.94)\end{array}$ & $(-2.2024$ & $\begin{array}{l}.1216 \\
(1.19)\end{array}$ & $\begin{array}{l}-.0034 \\
(-1.08)\end{array}$ & 6.30 \\
\hline $\mathrm{FEF}_{25-75} \mathrm{~L} / \mathrm{sec}-\mathrm{yc}$ & 223 & $\begin{array}{l}-.0801 \\
(-5.96)\end{array}$ & $\begin{array}{l}-.0406 \\
(-2.63)\end{array}$ & $(1.42)$ & $\begin{array}{l}-.00025 \\
(-.46)\end{array}$ & 11.1 \\
\hline $\mathrm{FEF}_{50} \mathrm{~L} / \mathrm{sec}-\mathrm{yr}$ & 223 & $\begin{array}{l}-.1031 \\
(-5.44)\end{array}$ & $\begin{array}{l}-.0285 \\
(-1.31)\end{array}$ & $\begin{array}{l}.0373 \\
(1.55)\end{array}$ & $\begin{array}{l}-.00041 \\
(-.54)\end{array}$ & 6.6 \\
\hline $\mathrm{K}(\mathrm{min}-\mathrm{mrHg}-\mathrm{yr})^{-I}$ & 164 & $(-4.0934$ & $\begin{array}{l}.0518 \\
(1.97)\end{array}$ & $\begin{array}{l}-.00642 \\
(-.24)\end{array}$ & $\begin{array}{l}-.00101 \\
(-1.19)\end{array}$ & 16.3 \\
\hline $\mathrm{DL}_{\mathrm{CO}} \frac{\mathrm{ml}}{\mathrm{m} 1 \mathrm{n}-\mathrm{mmHg}-\mathrm{yr}}$ & 164 & $\begin{array}{l}-.6578 \\
(-4.64)\end{array}$ & $(1.86)$ & $(-2.09)$ & $\begin{array}{l}-.0033 \\
(-.58)\end{array}$ & 33.6 \\
\hline RV L/yr & 179 & $(3.83)$ & $\begin{array}{l}-.0061 \\
(-.07)\end{array}$ & $\begin{array}{l}-.00289 \\
(-.31)\end{array}$ & $(3.67)$ & 27.1 \\
\hline TLC $\mathrm{L} / \mathrm{yr}$ & 179 & $\begin{array}{l}.0278 \\
(3.11)\end{array}$ & $(.0000)$ & $\begin{array}{l}-.0105 \\
(-.93)\end{array}$ & $(1.38)$ & 5.6 \\
\hline$(\mathrm{RV} / \mathrm{TLC}) \times 100(\mathrm{yr})^{-1}$ & 179 & $\begin{array}{l}.3331 \\
(3.93)\end{array}$ & $\begin{array}{l}.0313 \\
(.32)\end{array}$ & $\begin{array}{l}-.0246 \\
(-.23)\end{array}$ & $\begin{array}{l}.0117 \\
(3.52)\end{array}$ & 41.7 \\
\hline
\end{tabular}

${ }^{(1)}$ See Footnote ${ }^{(1)}$ of Table 8 .

${ }^{(2)}$ Cumulative Exposure Category II has value if cumulative exposure is $>.0682$ ppm-months and 0 otherwise. Thus, its coefficient estimates the difference between the two catcgorles after controlling for the other variables. 
Table 10

ANNUAL CHANGE REGRESSION COEFFICIENTS ${ }^{(1)}$ USING THREE CURULATIVE EXPOSURE CATEGORIES ${ }^{(2)}$, ATOPIC STATUS, AND PACK-YEARS AS EXPLANATORY VARIABLES

\begin{tabular}{|c|c|c|c|c|c|c|c|}
\hline & $\mathrm{n}$ & Intercept & $\begin{array}{l}\text { Cumulative } \\
\text { Exposure } \\
\text { Category II A }\end{array}$ & $\begin{array}{c}\text { Cumulative } \\
\text { Exposure } \\
\text { Category II B }\end{array}$ & Atopy & $\begin{array}{l}\text { Pack- } \\
\text { Years }\end{array}$ & $\begin{array}{c}\% \text { Variabilit } \\
\text { Explained }\end{array}$ \\
\hline FEV 1 L/yr & 223 & $\begin{array}{l}-.0123 \\
(-2.21)\end{array}$ & $\begin{array}{l}-.0187 \\
(-2.25)\end{array}$ & $\begin{array}{l}.0132 \\
(1.31)\end{array}$ & $\begin{array}{l}.0020 \\
(.28)\end{array}$ & $\begin{array}{l}-.00057 \\
(-2.59)\end{array}$ & 13.2 \\
\hline FVC L/yr & 223 & $\begin{array}{l}-.0008 \\
(-.15)\end{array}$ & $\begin{array}{l}-.0049 \\
(-.56)\end{array}$ & $(1.10)$ & $\begin{array}{l}-.0060 \\
(-.82)\end{array}$ & $\begin{array}{l}-.00072 \\
(-3.17)\end{array}$ & 21.1 \\
\hline FEV\% $(y r)^{-1}$ & 223 & $\begin{array}{l}-.2374 \\
(-2.97)\end{array}$ & $\begin{array}{l}-.2339 \\
(-1.95)\end{array}$ & $\begin{array}{l}.0597 \\
(.41)\end{array}$ & $(1.23)$ & $\begin{array}{l}-.0034 \\
(-1.07)\end{array}$ & 7.0 \\
\hline${ }^{\mathrm{FEF}}{ }_{25-75} \mathrm{~L} / \mathrm{sec}-\mathrm{yr}$ & 223 & $\begin{array}{l}-.0806 \\
(-6.00)\end{array}$ & $\begin{array}{l}-.0494 \\
(-2.46)\end{array}$ & $\begin{array}{l}.0166 \\
(.68)\end{array}$ & $\begin{array}{l}.0256 \\
(1.49)\end{array}$ & $\begin{array}{l}-.00024 \\
(-.44)\end{array}$ & 13.0 \\
\hline $\mathrm{FEF}_{50} \mathrm{~L} / \mathrm{sec}-\mathrm{yr}$ & 223 & $\begin{array}{l}-.1032 \\
(-5.44)\end{array}$ & $\begin{array}{l}-.0304 \\
(-1.07)\end{array}$ & $\begin{array}{l}.0035 \\
(.10)\end{array}$ & $\begin{array}{l}.0377 \\
(1.56)\end{array}$ & $\begin{array}{l}-.00041 \\
(-.54)\end{array}$ & 6.7 \\
\hline$K(m i n-m m H g-y r)^{-1}$ & 164 & $\begin{array}{l}-.0921 \\
(-4.46)\end{array}$ & $\begin{array}{l}-.0308 \\
(-.86)\end{array}$ & $(3.26)$ & $\begin{array}{l}-.00870 \\
(-.33)\end{array}$ & $\begin{array}{l}-.00107 \\
(-1.29)\end{array}$ & 35.1 \\
\hline $\mathrm{DL}_{\mathrm{CO}} \frac{\mathrm{ml}}{\mathrm{min}-\mathrm{mmHg}-\mathrm{yr}}$ & 164 & $\begin{array}{l}-.6468 \\
(-4.68)\end{array}$ & $\begin{array}{r}-.208 \\
(-.86)\end{array}$ & $(3.12)$ & $\begin{array}{l}-.3892 \\
(-2.22)\end{array}$ & $\begin{array}{l}-.00370 \\
(-.67)\end{array}$ & 66.1 \\
\hline RV $\mathrm{L} / \mathrm{yr}$ & 179 & $\begin{array}{l}.0288 \\
(3.85)\end{array}$ & $\begin{array}{l}.00467 \\
(.40)\end{array}$ & $\begin{array}{l}-.00951 \\
(-.69)\end{array}$ & $\begin{array}{l}-.00334 \\
(-.35)\end{array}$ & $\begin{array}{l}.00107 \\
(3.65)\end{array}$ & 27.1 \\
\hline $\operatorname{ILC} L / y r$ & 179 & $\begin{array}{l}.0276 \\
(3.10)\end{array}$ & $\begin{array}{l}-.00860 \\
(-.62)\end{array}$ & $\begin{array}{l}.0154 \\
(.94)\end{array}$ & $\begin{array}{l}-.00978 \\
(-.87)\end{array}$ & $\begin{array}{l}.00049 \\
(1.40)\end{array}$ & 5.5 \\
\hline$(\mathrm{RV} / \mathrm{TLC}) \times 100^{\circ}(\mathrm{yr})^{-1}$ & 179 & $\begin{array}{l}.3359 \\
(3.97)\end{array}$ & $\begin{array}{l}.1122 \\
(.86)\end{array}$ & $\begin{array}{l}-.1455 \\
(-.93)\end{array}$ & $\begin{array}{l}-.0312 \\
(-.29)\end{array}$ & $\begin{array}{l}.0117 \\
(3.51)\end{array}$ & 43.8 \\
\hline
\end{tabular}

${ }^{(1)}$ See Footnote (1) of Table 8 .

(2) Cumulative Exposure Category II A has value 1 if cumulative exposure is $>.0682$ ppm-months and 0 otherwise, Cumulative Exposure Category II $B$ has value 1 if cumulative exposure is $>$. 1 ppm-months and 0 otherwise. The coefficient of Cumulative Exposure Category II A (resp. Cumulative Exposure Category II B) estimates the difference between the two lowest (resp. highest) categories after controlling for the other variables. 
Table 11

ANNUAL CHANGE REGRESSION COEFFICIENTS ${ }^{(1)}$ USING TIME ABOVE $.02 \mathrm{ppm}$, ATOPIC STATUS, AND PACK-YEARS AS EXPLANATORY VARIABLES

$\mathrm{FEV}_{1} \mathrm{~L} / \mathrm{yr}$

FVC L/yr

FEV\% L/yr

$\mathrm{FEF}_{25-75} \mathrm{~L} / \mathrm{sec}-\mathrm{yr}$

$\mathrm{FEF}_{50} \quad \mathrm{~L} / \mathrm{sec}-\mathrm{yr}$

$\mathrm{K}(\mathrm{min}-\mathrm{mmH} \mathrm{g}-\mathrm{yr})^{-1}$

$\mathrm{DL}_{\mathrm{CO}}-\frac{\mathrm{ml}}{\mathrm{min}-\mathrm{mmHg}-\mathrm{yr}}$

RV L/yr

TLC L/yr

$(\mathrm{RV} / \mathrm{TLC}) \times 100(\mathrm{yr})^{-1}$

\begin{tabular}{|c|c|c|c|c|c|}
\hline $\mathrm{n}$ & Intercept & $\begin{array}{c}\text { Time Above } \\
.02 \text { ppm }\end{array}$ & Atopy & $\begin{array}{l}\text { Pack- } \\
\text { Years }\end{array}$ & $\begin{array}{l}\% \text { Variability } \\
\text { Explained }\end{array}$ \\
\hline 223 & $\begin{array}{l}-.0141 \\
(-2.51)\end{array}$ & $\begin{array}{l}-.0043 \\
(-1.05)\end{array}$ & $\begin{array}{l}.0010 \\
(.14)\end{array}$ & $\begin{array}{l}-.00057 \\
(-2.56)\end{array}$ & 9.51 \\
\hline
\end{tabular}

.0032

(.75)

$-.0070$

$(-.96)$

$-.00071$

$(-.35)$

$-.452$

$(-1.93)$

$223-.0853$

$(-6.31)$

$223-.1107$

(5.83)

$.1231 \quad-.0035$

(1.24) (-1.08)

$164-.0968$

$(-4.47)$

$164-.6482$

$(-4.45)$

179

.0361

(4.93)

179

.0322

$(4.69)$

179
$-.0184$

$(-1.83)$

$-.0066$

$(-.47)$

.0380

(2.14)

.0246

(1.42)

$-.00024$

$(-.44)$

$.0375-.00038$

(1.55) (-.50)

.1761
$(1.48)$

$-.0083$

$(-.31)$

$-.0009$

$(-1.10)$

$-.382$

$(-2.11)$

$-.00305$

$(-, 53)$

$-.0129$

$(-2,38)$

$-.0017$

$(-.19)$

.00102

(3.55)

$-.00733$

$-.00996$

$(-.88)$

.00045

(1.29)

$-.0114$

$(-.11)$

$(3.40)$
19.7

6.2

7. 6

4.7

16.6

27.3

38.1

9.9

55.4
$(-2.20)$

\section{(1)}

of Table 8. 
Table 12

ANNUAL CHANGE REGRESSION COEFFICIENTS (1) USING DICHOTOMIZED TIME ABOVE $.02 \mathrm{ppm}$, ATOPIC STATUS, AND PACK-YEARS AS EXPLANATORY VARIABLES

FEV 1 L/yr

EVC L/yr

FEV\% yr $^{-1}$

$\mathrm{FEF}_{25-75} \mathrm{~L} / \mathrm{sec}-\mathrm{yr}$

$\mathrm{FEF}_{50} \mathrm{~L} / \mathrm{sec}-\mathrm{yr}$

$\mathrm{K}(\mathrm{min}-\mathrm{mmHg}-\mathrm{yr})^{-I}$

$\mathrm{DL}_{\mathrm{CO}} \frac{\mathrm{ml}}{\mathrm{min}-\mathrm{mmHg}-\mathrm{yr}}$

RV L/yr

TLC L/yr

$(\mathrm{RV} / \mathrm{TLC}) \times 100(\mathrm{yr})^{-1}$

\begin{tabular}{|c|c|c|c|c|c|}
\hline$n$ & Intercept & $\begin{array}{l}\text { ak Exposure } \\
\text { Category II }\end{array}$ & Atopy & $\begin{array}{l}\text { Pack- } \\
\text { Years }\end{array}$ & $\begin{array}{c}\% \text { Variability } \\
\text { Explained }\end{array}$ \\
\hline 223 & $\begin{array}{c}-.0127 \\
(-2.29)\end{array}$ & $\begin{array}{l}-.0108 \\
(-1.64)\end{array}$ & $\begin{array}{l}.00058 \\
(.08)\end{array}$ & $\begin{array}{l}-.00058 \\
(-2.61)\end{array}$ & 10.9 \\
\hline 223 & $\begin{array}{l}.0005 \\
(.09)\end{array}$ & $\begin{array}{l}-.0015 \\
(-.22)\end{array}$ & $\begin{array}{l}-.0069 \\
(-.95)\end{array}$ & $\begin{array}{l}-.00072 \\
(-3.18)\end{array}$ & 18.6 \\
\hline 223 & $\begin{array}{l}-.2594 \\
(-3.26)\end{array}$ & $\begin{array}{l}-.1541 \\
(-1.63)\end{array}$ & $(1.13)$ & $\begin{array}{l}-.0034 \\
(-1.07)\end{array}$ & 6.0 \\
\hline 223 & $\begin{array}{l}-.0847 \\
(-6.34)\end{array}$ & $\begin{array}{l}-.0317 \\
(-1.99)\end{array}$ & $\begin{array}{l}.0232 \\
(1.35)\end{array}$ & $\begin{array}{l}-.00024 \\
(-.45)\end{array}$ & 10.0 \\
\hline 223 & $\begin{array}{l}-.0999 \\
(-5.34)\end{array}$ & $\begin{array}{l}-.0396 \\
(-1.77)\end{array}$ & $(1.50)$ & $\begin{array}{l}-.00045 \\
(-.60)\end{array}$ & 8.7 \\
\hline 164 & $\begin{array}{l}-.0977 \\
(-4.64)\end{array}$ & $\begin{array}{l}.0646 \\
(2.50)\end{array}$ & $\begin{array}{l}-.0058 \\
(-.22)\end{array}$ & $\begin{array}{l}-.00101 \\
(-1.19)\end{array}$ & 24.3 \\
\hline 164 & $\begin{array}{l}-.6560 \\
(-4.64)\end{array}$ & $(1.82)$ & $\begin{array}{l}-.3706 \\
(-2.06)\end{array}$ & $\begin{array}{l}-.00338 \\
(-.60)\end{array}$ & 31.4 \\
\hline 179 & $(4.69)$ & $\begin{array}{l}-.0172 \\
(-1.92)\end{array}$ & $\begin{array}{l}-.00285 \\
(-.30)\end{array}$ & $(3.60)$ & 32.4 \\
\hline 179 & $\begin{array}{l}.0331 \\
(3.81)\end{array}$ & $\begin{array}{l}-.0158 \\
(-1.48)\end{array}$ & $\begin{array}{l}-.0105 \\
(-.94)\end{array}$ & $(1.31)$ & 11.3 \\
\hline 179 & $(4.70)$ & $\begin{array}{l}-.1427 \\
(-1.40)\end{array}$ & $\begin{array}{l}-.0240 \\
(-.22)\end{array}$ & $\begin{array}{l}.0115 \\
(3.46)\end{array}$ & 44.2 \\
\hline
\end{tabular}

${ }^{(1)}$ See Footnote ${ }^{(1)}$ of Table 8.

(2) Peak Exposure Category II has value $11 \mathrm{f}$ time above $.02 \mathrm{ppm}$ is $>.19$ months and 0 otherwise. Thus, its coefficient estimates the difference between the two categories after controlling for the other variables. 
Table 13

ANNUAL CHANGE REGRESSION COEFFICIENTS ${ }^{(1)}$ USING THREE TIME ABOVE .02 pPM CATEGORIES, ATORIC STATUS, AND PACK-YEARS AS EXPIANATORY VARIABLES

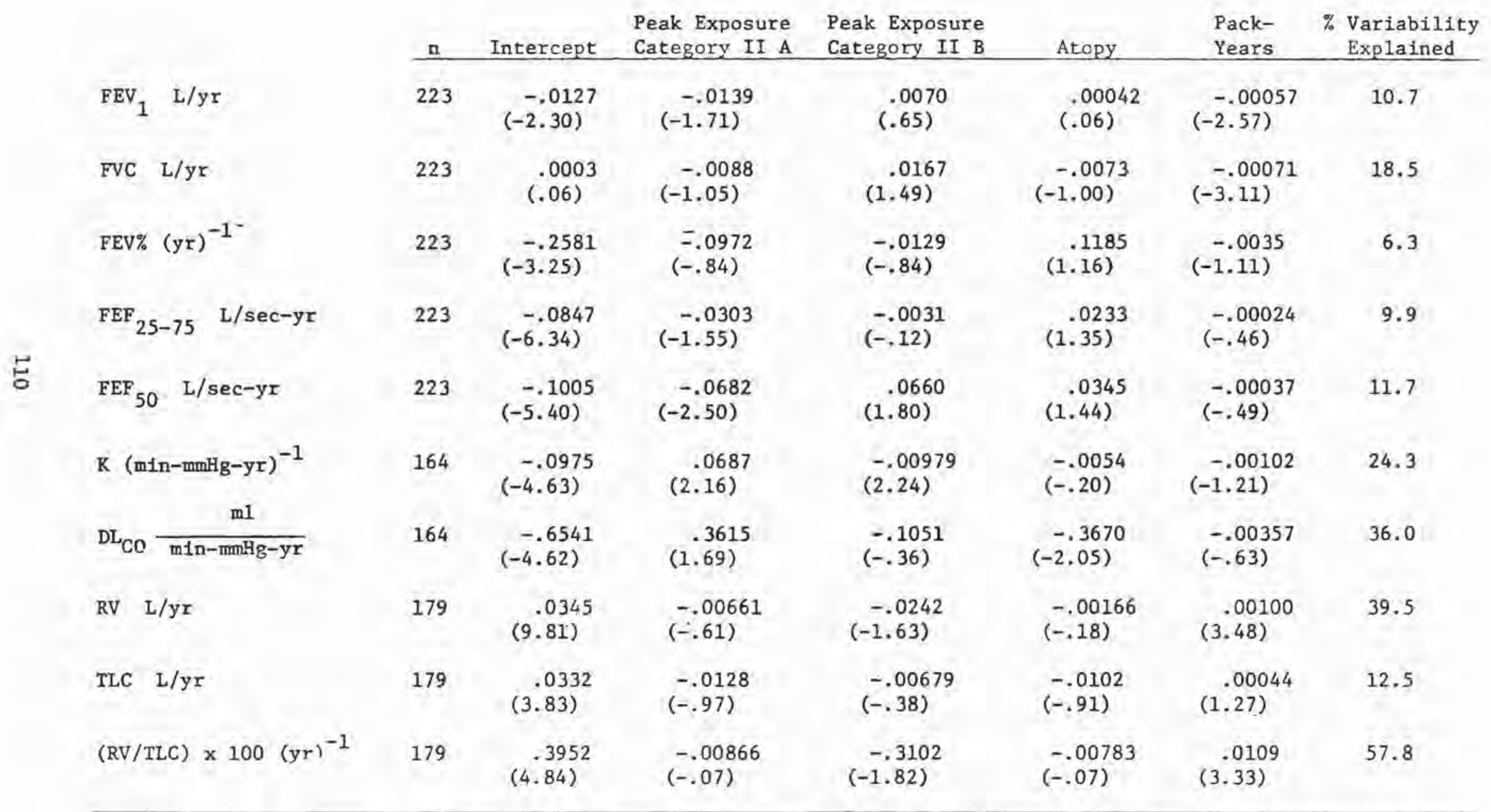

(1) See Footrote (1) of Table 8

(2) Peak Exposure Category II A has value 1 if time above .02 ppm $>.19$ months and 0 otherwise. Peak Exposure Category II B has value of time above .02 ppm $>1$ month and 0 otherwise. Thus, the coefficient of peak Exposure Category II A (resp., Peak Exposure Category II B) est1mates the difference between the two lowest (resp. highest) categories after controlling for the other variables. 
Table 14

ESTIMATED POPULATION MEAN ANNUAL CHANGES AND OTHER STATISTICS

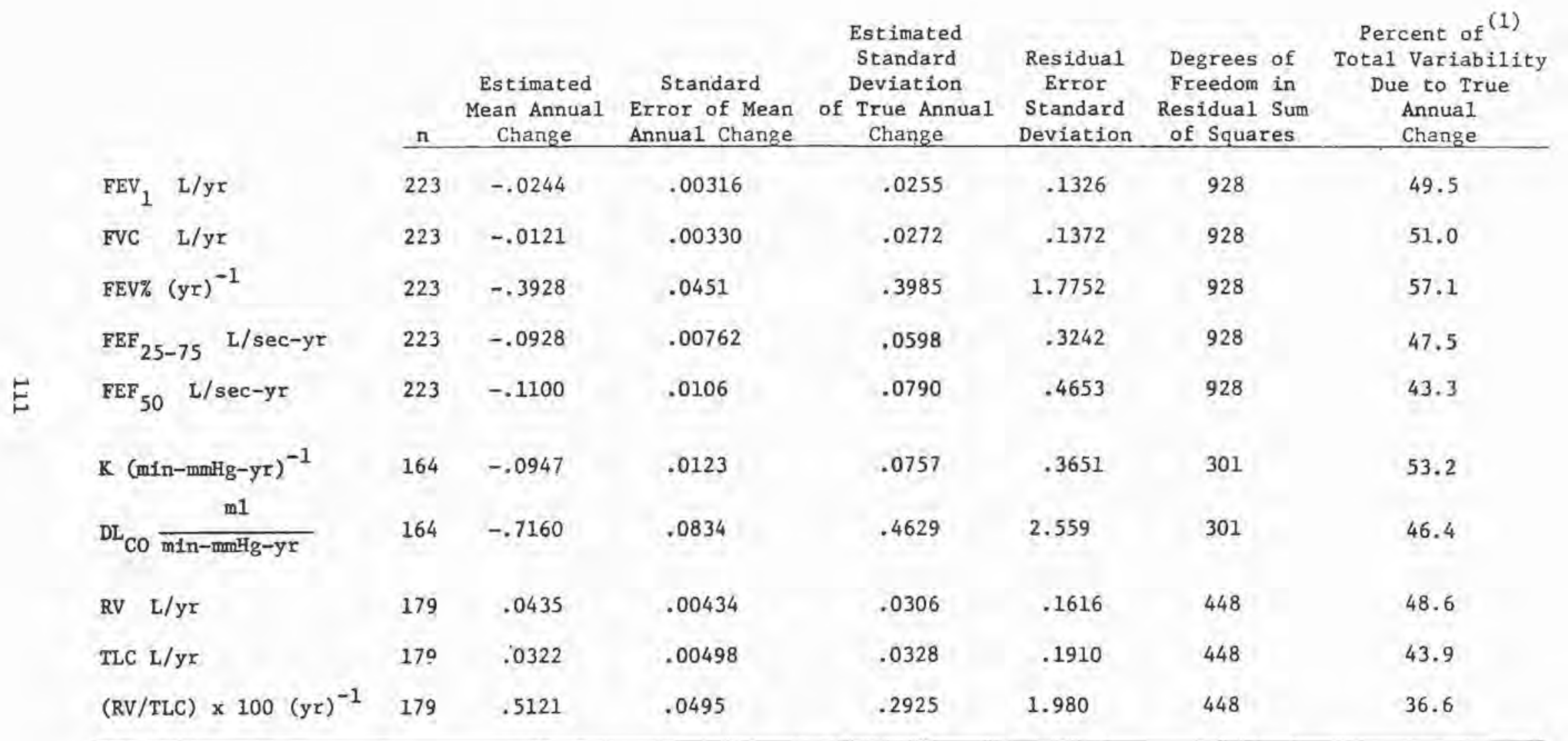

(1) Percent of total variability due to true annual change for a participant with usable data at all nine visits. For a participant present at fewer than nine visits, the percent of total variability due to true annul c' ange will be smaller. 
Table 15

Sumnary Stat1stics on 274 Participants by Number of Visits with Complete Spirometry

$\begin{array}{lcc} & \begin{array}{c}\text { Number of } \\ \text { visits } \geq 3\end{array} & \begin{array}{c}\text { Number of } \\ \text { visits <3 }\end{array} \\ \text { n } & 226 & 48 \\ \text { \% White } & 85.4 & 83.3 \\ \text { \% Lower Respiratory Symptoms } & 29.8 & 29.8 \\ \text { \% Upper Respiratory Symptoms* } & 42.0 & 23.4 \\ \text { \% Bronchitis } & 3.5 & 4.3 \\ \text { \% Intervilew Atopic } & 33.8 & 25.5 \\ \text { \% Atopic* } & 23.0 & 6.3 \\ \text { \% Dyspnea } & 14.3 & 17.0 \\ \text { \% Current Cigarette Smokers } & 50.9 & 53.2\end{array}$

\begin{tabular}{|c|c|c|c|c|c|c|}
\hline & \multicolumn{3}{|c|}{ Number of visits $\geq 3$} & \multicolumn{3}{|c|}{ Number of visits $<3$} \\
\hline & Mean & $\begin{array}{l}\text { Standard } \\
\text { Deviation }\end{array}$ & $n^{(1)}$ & Mean & $\begin{array}{l}\text { Standard } \\
\text { Deviation }\end{array}$ & $\mathrm{n}$ \\
\hline Age (years) & 35.6 & 11.0 & 226 & 35.5 & 12.6 & 48 \\
\hline Height (Inches) & 70.0 & 2.5 & 226 & 69.8 & 2.9 & 48 \\
\hline Pack-years & 13.7 & 14.9 & 226 & 17.4 & 21.9 & 47 \\
\hline $\mathrm{FEV}_{1} \% \mathrm{P}^{(2)}$ & 100.4 & 13.4 & 207 & 99.2 & 13.3 & 37 \\
\hline FVC $\% \mathrm{P}$ & 102.9 & 12.4 & 207 & 101.4 & 12.0 & 37 \\
\hline FEF \% P & 91.5 & 26.9 & 207 & 88.2 & 24.5 & 37 \\
\hline RV \% P & 99.3 & 25.2 & 186 & 100.4 & 28.8 & 31 \\
\hline TLC $\% \mathrm{P}$ & 101.3 & 11.6 & 186 & 99.5 & 11.6 & 31 \\
\hline $\mathrm{K} \% \mathrm{P}$ & 99.7 & 17.7 & 181 & 99.7 & 14.2 & 31 \\
\hline $\begin{array}{c}\text { Cumulative Exposure* } \\
\text { (ppm-months) }\end{array}$ & .0725 & .0354 & 225 & .0231 & .0169 & 30 \\
\hline $\begin{array}{l}\text { Time above } \\
\qquad .02 \text { ppm (months)* }\end{array}$ & .55 & .72 & 225 & .29 & .33 & 30 \\
\hline
\end{tabular}

$*_{\mathrm{p}}<.05$

(1) $n$ represents number of participants with usable data.

(2)\% predicteds are taken from the pulmonary function measurement at the time of the inftial intervlew or the next visit at which the pulmonary function measurement was taken if it was not done at the visit of the initial interview. 
Table 16

\section{ESTIMATED MEAN ANNUAL CHANGES \\ IN SPIROMETRIC TESTS BY}

TWO CUMULATIVE EXPOSURE CATEGORIES

FOR NON-ATOPICS WITH

14 PACK-YEARS OF SMOKING

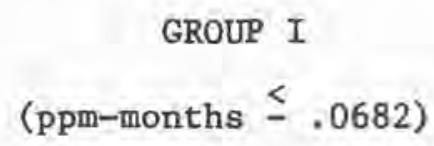

$\underline{149}$

$\mathrm{FEV}_{1} \mathrm{ml} / \mathrm{yr} \quad-20$

FVC $\mathrm{ml} / \mathrm{yr} \quad-11$

FEV\% $\quad(y r)^{-1}$

$\mathrm{FEF}_{25-75^{\mathrm{ml}} / \mathrm{sec}-\mathrm{yr}}$

$\mathrm{FEF}_{50} \mathrm{ml} / \mathrm{sec}-\mathrm{yr}$
$-0.28$

$-84$

$-109$
GROUP II

(ppm-months $>.0682)$

$\underline{74}$

$-32$

$-9$

$-.48$

$-125$

$-137$

${ }^{1}$ p-values are significance levels for one-tailed tests of significance for differences between the two groups after controlling for other varfables. 
Table 16A

Descriptive Statistics at Entry to Study

by Cumulative Exposure Category

\begin{tabular}{|c|c|c|}
\hline & $\begin{array}{c}\text { Cumulative } \\
\text { Exposure }\end{array}$ & $\begin{array}{l}\text { Cumulative } \\
\text { Exposure }\end{array}$ \\
\hline & $\leq .0682 \mathrm{ppm}-$ months & $>.0682$ ppm-months \\
\hline$n$ & 149 & 74 \\
\hline Race (\% White) & 84.1 & 87.8 \\
\hline Age (years) & $37.6 \pm 11.0$ & $31.7 \pm 9.8$ \\
\hline Height (inches) & $69.8 \pm 2.5$ & $70.3 \pm 2.4$ \\
\hline Smoking (\% current cigarette) & 51.0 & 50.0 \\
\hline (\% ex-c1garette) & 24.8 & 21.6 \\
\hline (\% never) & 24.2 & 28.4 \\
\hline \% LRS & 31.1 & 27.4 \\
\hline$\%$ URS & 46.4 & 33.8 \\
\hline$\%$ Bronchitis & 4.6 & 1.4 \\
\hline Dyspnea (\% Grade I) & 83.3 & 90.4 \\
\hline (\% Grade II) & 12.7 & 8.2 \\
\hline (\% Grade III) & 4.0 & 1.4 \\
\hline$\%$ Atop1c & 21.9 & 25.7 \\
\hline
\end{tabular}


Table 16B

FEV, Slope (m1/year)* by Smoking Exposure Category

Controlling for Age and $\mathrm{FEV}_{1}$ Level

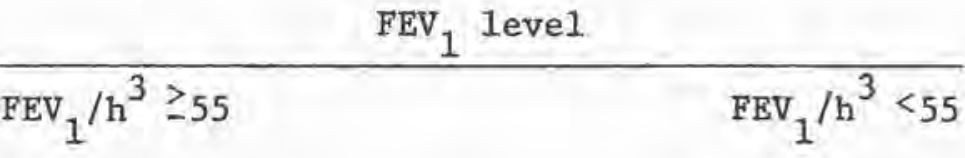

Exposure

$\leq .0682$ ppm-months

\begin{tabular}{|c|c|}
\hline 1 & -37 \\
$\mathrm{n}=35$ & $\mathrm{n}=21$ \\
\hline-12 & -15 \\
$\mathrm{n}=31$ & $\mathrm{n}=16$ \\
\hline-26 & -37 \\
$\mathrm{n}=64$ & $\mathrm{n}=35$ \\
\hline
\end{tabular}

Exposure

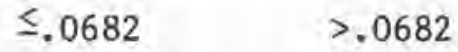

ppm-months ppm-months

\begin{tabular}{|c|c|}
\hline-18 & -57 \\
$\mathrm{n}=1$ & $\mathrm{n}=0$ \\
\hline-32 & -35 \\
$\mathrm{n}=6$ & $\mathrm{n}=0$ \\
\hline-46 & -57 \\
$\mathrm{n}=12$ & $\mathrm{n}=2$ \\
\hline
\end{tabular}

*Ce11s means were estimated using the multiple regression procedure described in the text. This procedure used age as one of the covariates. The cells means presented above are adjusted to the average age ( 35.6 years) of the study group.

Tests of Significance

(1) age effect $\quad-5.8 \mathrm{ml} /$ decade

one-tailed p-value $=.03$

(2) Iow $\mathrm{FEV}_{1}$ effect $-20 \mathrm{~m} 1 /$ year

one-tailed $\mathrm{p}$-value $=.04$

(3) exposure effect in never smokers $-38 \mathrm{ml} /$ year

one-talled p-value $=.001$

(4) Smoking effect in $\leq .0682$ exposure category exsmoker - never smoker effect $-13 \mathrm{ml} /$ year

one-tailed p-value $=.12$

current smoker - ex-smoker effect $-14 \mathrm{ml} /$ year one-talled $\mathrm{p}$-value $=.06$

current smoker-never smoker effect $-27 \mathrm{ml} /$ year one-tailed p-value $=.004$ 
Table 17

ESTIMATED MEAN ANNUAL CHANGES IN FEV, FEV\%, AND FEF $_{25-75}$ BY CUMULATIVE EXPOSURE FOR NON-ATOPICS WITH 14 PACK-YEARS OF SMOKING

n

$\mathrm{FEV}_{1} \mathrm{ml} / \mathrm{yr}$

FEV\% $(y r)^{-1}$

$\mathrm{FEF}_{25-75} \mathrm{ml} / \mathrm{sec}-\mathrm{yr}$

$$
\begin{aligned}
& \text { GROUP } \text { I } \\
&\text { (ppm-months } \leq .0682)
\end{aligned}
$$

GROUP II A $(.0682<$ ppm-months $\leq .1)$
GROUP II B (ppm-months $>.1$ )

37

37
$-.52$
$(\mathrm{p}=.68)$
$-.46$

$-.29 \quad(p=.05)$

$-133$

$(\mathrm{p}=.50)$

$-117$

(1) p-values are significancè levels for differences between adjacent categories after controlling for other variables. 
Table 18

ESTIMATED MEAN ANNUAL CHANGES IN SPIROMETRIC TESTS

BY TWO TIME ABOVE .02 PPM CATEGORIES

FOR NON-ATOPICS WITH 14 PACK-YEARS OF SMOKING

\begin{tabular}{lccc} 
& $\begin{array}{c}\text { GROUP I } \\
\text { (months } \leq .19)\end{array}$ & $\begin{array}{c}\text { GROUP II } \\
\text { (months }>.19)\end{array}$ \\
\cline { 2 - 2 } & 140 & $(\mathrm{p}=.051)^{1}$ & 83 \\
FEV $_{1}$ & -21 & $(\mathrm{p}=.413)$ & -32 \\
FVC & -10 & $(\mathrm{p}=.052)$ & -11 \\
FEV\% & -.31 & $(\mathrm{p}=.023)$ & -.46 \\
FEF $_{25-75}$ & -88 & $(\mathrm{p}=.038)$ & -146 \\
EEF $_{50}$ & -106 & & \\
\hline
\end{tabular}

(1) $\mathrm{p}$-values are significance levels for one-tailed tests of significance for differences between the two groups after controlling for the other variables. 
Table 19

ESTIMATED MEAN ANNUAL CHANGES IN FEV 1 , FEV\%, $\mathrm{FEF}_{25-75}$, AND FEF 50 BY TIME ABOVE .02 PPI CATEGORY FOR NON-ATOPICS WITH 14 PACK-YEARS OF SMOKING

$\mathrm{n}$

$$
\mathrm{FEV}_{1} \mathrm{~m} 1 / \mathrm{yr}
$$$$
\text { FEV\% }(y r)^{-1}
$$$$
\text { FEF } 25-75 \mathrm{~m} 1 / \mathrm{sec}-\mathrm{yr}
$$$$
\mathrm{FEF}_{50} \quad \mathrm{ml} / \mathrm{sec}-\mathrm{yr}
$$

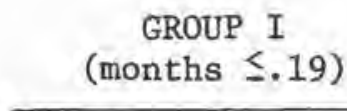

$$
140
$$$$
-21 \quad(\mathrm{p}=.087)
$$$$
-.31
$$$$
-88
$$$$
-106
$$$$
(\mathrm{p}=.40)
$$$$
(p=.12)
$$$$
(\mathrm{p}=.012)
$$

$$
\begin{gathered}
\text { GROUP II A } \\
(.19<\text { months } \leq 1)
\end{gathered}
$$

47

$$
-35
$$$$
-.40
$$$$
-118
$$$$
-174
$$

GROUP II B (months >1)

36

$-28$

$-.42$

$-121$

$-108$

(1) $\mathrm{p}$-values are significance levels for differences between adjacent categories after controlling for other variables. 
SUMMARY STATISTICS ON 274 PARTICIPANTS BY NUMBER

OF VISITS WITH COMPLETE DIFFUSING CAPACITY

DETERMINATIONS

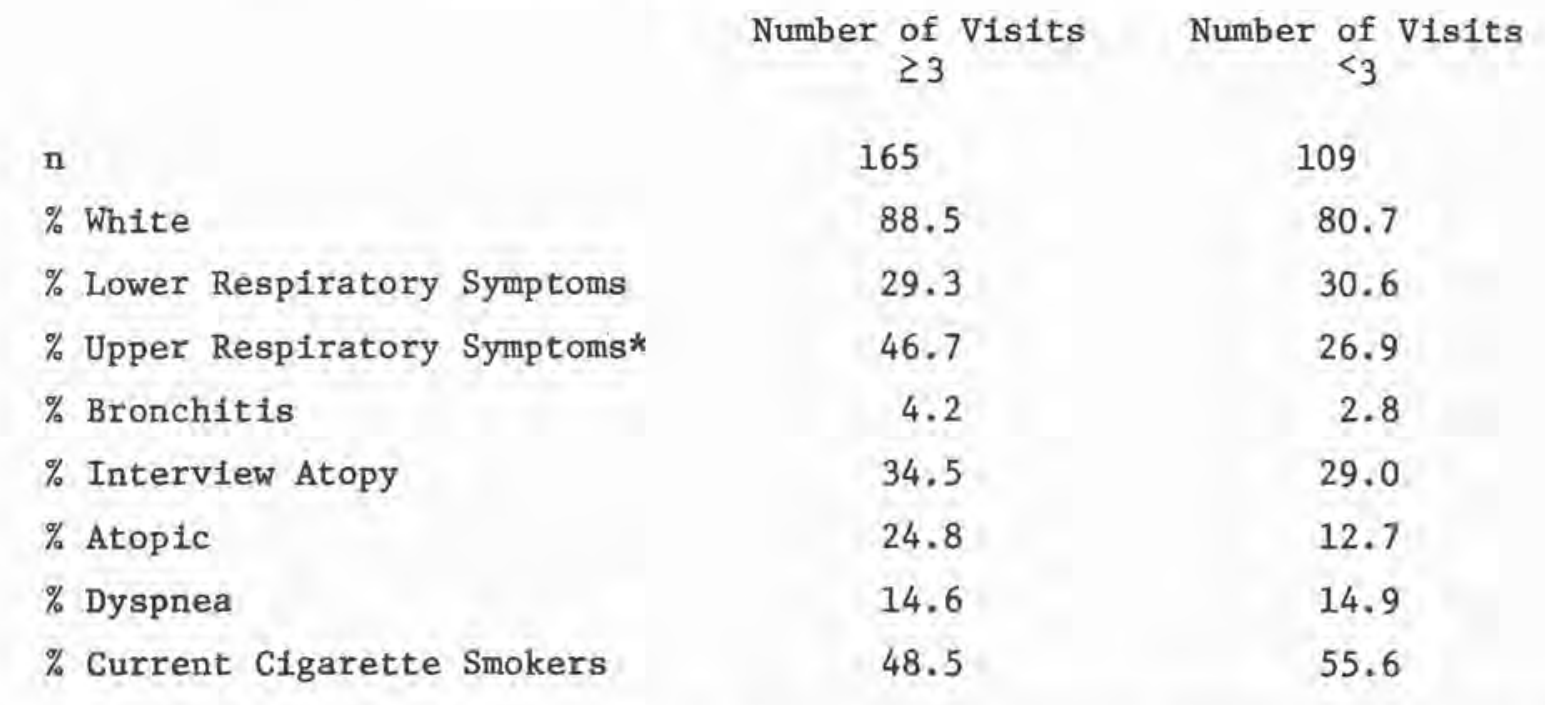

\begin{tabular}{|c|c|c|c|c|c|c|}
\hline & $\begin{array}{l}\text { Numbe } \\
\text { Mean }\end{array}$ & $\begin{array}{l}\text { of Visits } \\
\text { Standard } \\
\text { Deviation }\end{array}$ & $n^{(1)}$ & $\begin{array}{l}\text { Number } \\
\text { Mean }\end{array}$ & $\begin{array}{l}\text { of Visits } \\
\text { Standard } \\
\text { Deviation }\end{array}$ & $<3$ \\
\hline Age (years) & 36.0 & 11.0 & 165 & 35.9 & 11.8 & 109 \\
\hline Height (inches) & 70.1 & 2.5 & 165 & 69.7 & 2.6 & 109 \\
\hline Pack-years & 14.0 & 15.0 & 165 & 14.9 & 18.2 & 108 \\
\hline $\mathrm{FEV}_{1} \% \mathrm{P}^{(2)}$ & 100.7 & 12.7 & 151 & 99.5 & 14.4 & 93 \\
\hline FVC $\% \mathrm{P}$ & 103.2 & 12.1 & 151 & 101.8 & 12.7 & 93 \\
\hline FEE \% P & 91.1 & 26.1 & 151 & 90.9 & 27.4 & 93 \\
\hline $\mathrm{RV} \% \mathrm{P}$ & 100.0 & 24.5 & 139 & 99.0 & 27.9 & 78 \\
\hline TLC \% P & 102.0 & 11.7 & 139 & 100.0 & 11.5 & 78 \\
\hline $\mathrm{K} \% \mathrm{P}$ & 99.9 & 17.4 & 135 & 99.4 & 17.1 & 77 \\
\hline $\begin{array}{l}\text { Cumulative Exposure* } \\
\text { (ppm-months) }\end{array}$ & .068 & .031 & 164 & .039 & .023 & 77 \\
\hline $\begin{array}{l}\text { Time above } .02 \mathrm{ppm} \\
\text { (months) }\end{array}$ & .49 & .67 & 164 & .42 & .49 & 77 \\
\hline
\end{tabular}

$* \mathrm{p}<, 05$

(1) $\mathrm{n}$ represents the number of participants with usable data.

(2)\% predicteds are taken from the pulmonary function measurement at the time of the inftial interview or the next visit at which the pulmonary measurement was taken if it was not done at the visit of the initial interview. 
Table 21

SUMMARY STATISTICS ON 274 PARTICIPANTS BY NUMBER OF VISITS WITH COMPLETE LUNG VOLUME DETERMINATIONS

n

$\%$ White

\% Lower Respiratory Symptoms

\% Upper Respiratory Symptoms*

$\%$ Bronchitis

$\%$ Interview Atopy

$\%$ Atopic

$\%$ Dyspnea

$\%$ Current Cigarette Smokers

$$
\text { Number of Visits Number of Visits }
$$

182

92

87.4

81.5

28.7

31.9

44.0

28.6

3.8

3.3

34.1

28. 9

24.2

12.0

13.3

17,7

48.4

\begin{tabular}{|c|c|c|c|c|c|c|}
\hline & \multicolumn{3}{|c|}{ Number of Visits $\geq 3$} & \multicolumn{2}{|c|}{ Number of Visits } & \multirow[t]{2}{*}{$<3$} \\
\hline & Mean & & $n^{(1)}$ & Mean & & \\
\hline Age (years) & 35.7 & 11.0 & 182 & 36.5 & 11.9 & 92 \\
\hline Height (Inches) & 70.1 & 2.5 & 182 & 69.5 & 2.6 & 92 \\
\hline Pack-years & 13.5 & 14.8 & 182 & 16.2 & 19.0 & 91 \\
\hline $\mathrm{FEV}_{1} \%$ (2) & 101.3 & 12.9 & 165 & 98.0 & 14.0 & 79 \\
\hline FVC $\%$ P & 103.6 & 12.3 & 165 & 100.8 & 12.3 & 79 \\
\hline FEF \% P & 92.0 & 25.9 & 165 & 88.9 & 28.0 & 79 \\
\hline $\mathrm{RV} \% \mathrm{P}$ & 98.8 & 24.6 & 151 & 100.9 & 28.3 & 66 \\
\hline TLC $\% P$ & 101.7 & 11.6 & 151 & 99.5 & 11.6 & 66 \\
\hline $\mathrm{K} \% \mathrm{P}$ & 99.5 & 17.4 & 146 & 100.2 & 17.1 & 66 \\
\hline $\begin{array}{l}\text { Cumulative Exposure* } \\
\text { (ppm-months) }\end{array}$ & .08 & .03 & 181 & .03 & .02 & 60 \\
\hline $\begin{array}{l}\text { Time Above .02 ppm } \\
\text { (months) }\end{array}$ & .57 & .75 & 181 & .38 & .45 & 60 \\
\hline
\end{tabular}

$*_{\mathrm{p}}<.05$

(1) $n$ represents the number of participants with usable data.

(2)\% predicteds are taken from the pulmonary function measurement at the time of the Initial interview or the next visit at which the pulmonary function measurement was taken if 1 t was not done at the visit of the initial interview. 
Table 22

SUMMARY STATISTICS ON 274 PARTICIPANTS BY COMPLETENESS OF INITIAL AND FINAL INTERVIEW

$\begin{array}{lcc} & \text { Complete } & \text { Incomplete } \\ \text { I } & 203 & 71 \\ \text { \% White } & 87.1 & 80.3 \\ \text { \% Interview Atopy } & 37.0 & 30.4 \\ \text { \% Atopic } & 22.2 & 14.1 \\ \text { \% Current Cigarette Smokers } & 52.2 & 48.6\end{array}$

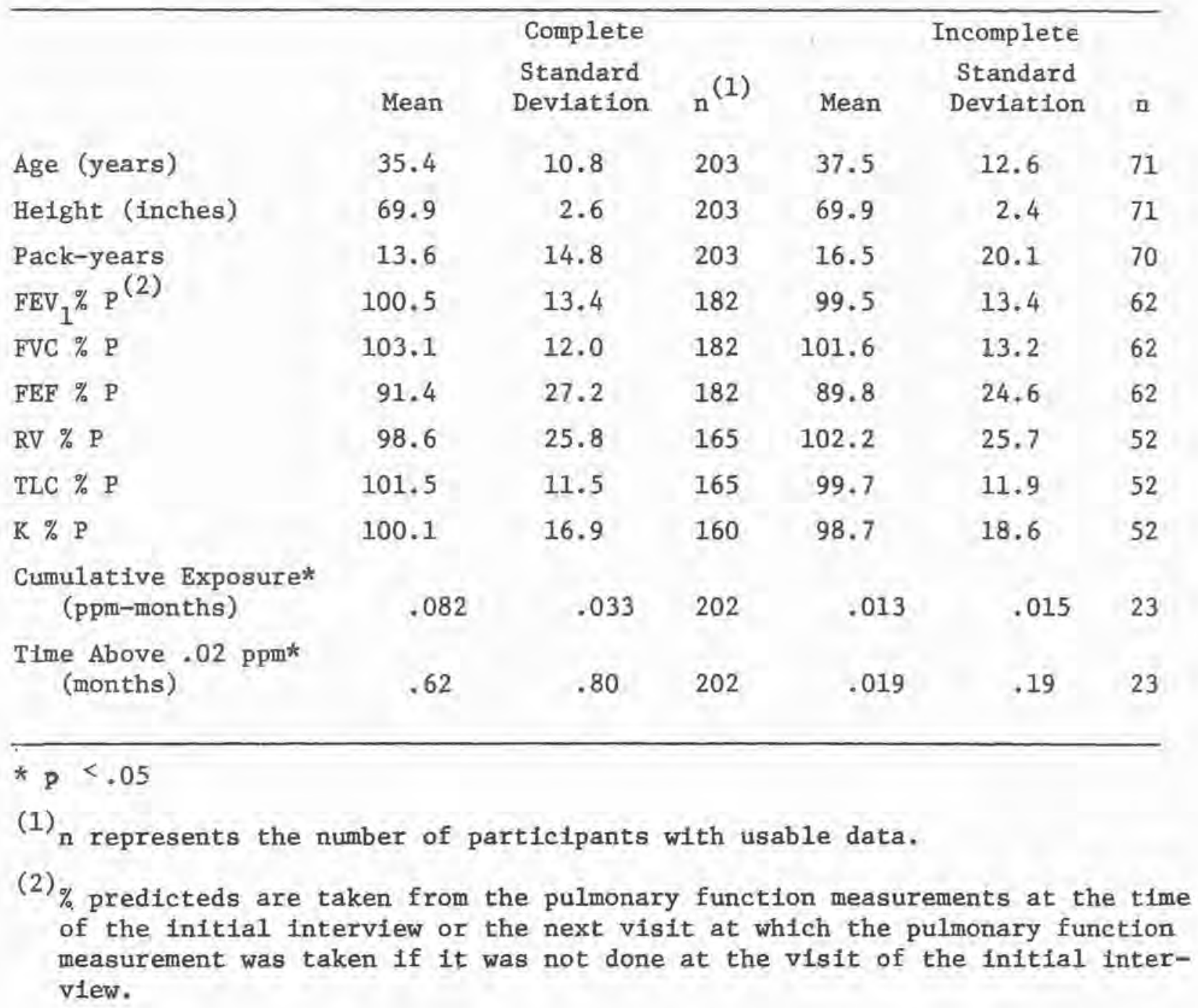


Tab1e 23

LONGITUDINAL CHANGE IN SYMPTOMS

BY CUMULATIVE EXPOSURE CATEGORY

Cumulative Exposure $\leq .0682$

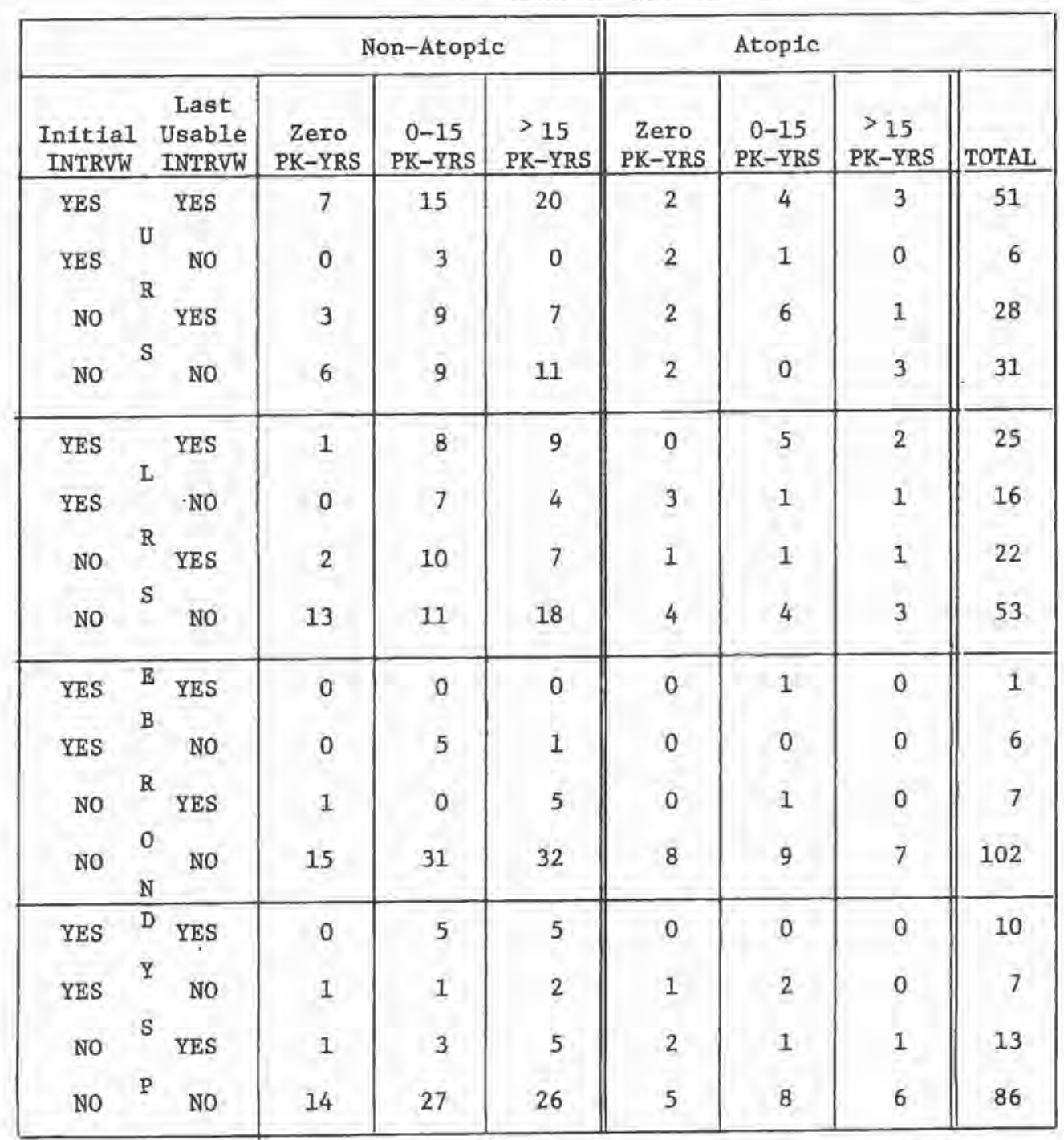

Cumulative Exposure $>.0682$

\begin{tabular}{|c|c|c|c|c|c|c|}
\hline \multicolumn{3}{|c|}{ Non-Atoplc } & \multicolumn{4}{|c|}{ Atopic } \\
\hline $\begin{array}{c}\text { Zero } \\
\text { PK-YRS }\end{array}$ & $\begin{array}{c}0-15 \\
\text { PK-YRS } \\
\end{array}$ & $\begin{array}{c}>1.5 \\
\text { PK-YRS }\end{array}$ & $\begin{array}{c}\text { Zero } \\
\text { PK-YRS } \\
\end{array}$ & $\begin{array}{c}0-15 \\
\text { PK-YRS }\end{array}$ & $\begin{array}{c}>15 \\
\text { PK-YRS }\end{array}$ & TOTAI \\
\hline 2 & 5 & 10 & 3 & 4 & 1 & 25 \\
\hline 1 & 0 & 1 & 0 & 0 & 1 & 3 \\
\hline 8 & 8 & 3 & 2 & 2 & 0 & 23 \\
\hline 9 & 14 & 6 & 1 & 4 & 1 & 35 \\
\hline 1 & 2 & 5 & 1 & 4 & 1 & 14 \\
\hline 0 & 7 & 0 & 0 & 0 & 0 & 7 \\
\hline 3 & 3 & 6 & 0 & 0 & 1 & 13 \\
\hline 16 & 15 & 9 & 5 & 5 & 1 & 51 \\
\hline 0 & 0 & 0 & 0 & 0 & 0 & 0 \\
\hline 0 & 1 & 0 & 0 & 0 & 0 & 1 \\
\hline 1 & 2 & 1 & 1 & 1 & 1 & 7 \\
\hline 19 & 24 & 19 & 5 & 9 & 2 & 78 \\
\hline 1 & 3 & 2 & 0 & 0 & 0 & 6 \\
\hline 0 & 0 & 3 & 0 & 0 & 0 & 3 \\
\hline 1 & 4 & 5 & 1 & 2 & 2 & 15 \\
\hline 18 & 20 & 10 & 5 & 7 & 1 & 61 \\
\hline
\end{tabular}


Table 24

LONGITUDINAL CHANGE IN SYMPTOMS

BY TIME ABOVE .02 ppm CATEGORY

Time above $.02 \mathrm{ppm} \leq 0.19$

\begin{tabular}{|c|c|c|c|c|c|c|c|c|c|c|c|c|c|c|c|c|}
\hline \multirow[b]{2}{*}{$\begin{array}{l}\text { Initial } \\
\text { INTRVW }\end{array}$} & \multicolumn{5}{|c|}{ Non-Atopic } & \multicolumn{4}{|c|}{ Atopic } & \multicolumn{3}{|c|}{ Non-Atopic } & \multicolumn{4}{|c|}{ Atopic } \\
\hline & & $\begin{array}{l}\text { Last } \\
\text { Usable } \\
\text { INTRVW }\end{array}$ & $\begin{array}{c}\text { Zero } \\
\text { PK-YRS } \\
\end{array}$ & $\begin{array}{c}0-15 \\
\text { PK-YRS } \\
\end{array}$ & $\begin{array}{c}>15 \\
\text { PK-YRS }\end{array}$ & $\begin{array}{c}\text { Zero } \\
\text { PK-YRS } \\
\end{array}$ & $\begin{array}{c}0-15 \\
\text { PK-YRS }\end{array}$ & $\begin{array}{c}>15 \\
\text { PK-YRS } \\
\end{array}$ & TOTAL & $\begin{array}{c}\text { Zero } \\
\text { PK-YRS }\end{array}$ & $\begin{array}{c}0-15 \\
\text { PK-YRS }\end{array}$ & $\begin{array}{c}>15 \\
\text { PK-YRS }\end{array}$ & $\begin{array}{c}\text { Zero } \\
\text { PK-YRS } \\
\end{array}$ & $\begin{array}{c}0-15 \\
\text { PK-YRS }\end{array}$ & $\begin{array}{c}>15 \\
\text { PK-YRS }\end{array}$ & TOTAL \\
\hline YES & & YES & 6 & 16 & 22 & 3 & 5 & 3 & 55 & 3 & 4 & 8 & 2 & 3 & 1 & 21 \\
\hline YES & & No & 0 & 2 & 0 & 2 & 1 & 1 & 6 & 1 & 1 & 1 & 0 & 0 & 0 & 3 \\
\hline NO & R & YES & 4 & 10 & 7 & 2 & 5 & 1 & 29 & 7 & 7 & 3 & 2 & 3 & 0 & 22 \\
\hline NO & S & NO & 9 & 11 & 11 & 2 & 1 & 3 & 37 & 6 & 12 & 6 & 1 & 3 & 1 & 29 \\
\hline YES & & YES & 2 & 6 & 8 & 1 & 4 & 3 & 24 & 0 & 4 & 6 & 0 & 5 & 0 & 15 \\
\hline YES & L & NO & 0 & 9 & 4 & 3 & 1 & 1 & 18 & 0 & 5 & 0 & 0 & 0 & 0 & 5 \\
\hline NO & R & YES & 2 & 9 & 9 & 1 & 1 & 1 & 23 & 3 & 4 & 4 & 0 & 0 & 1 & 12 \\
\hline & S & NO & 15 & 15 & 19 & 4 & 6 & 3 & 62 & 14 & 11 & 8 & 5 & 3 & 1 & 42 \\
\hline YES & E & YES & 0 & 0 & 0 & 0 & 1 & 0 & 1 & 0 & 0 & 0 & 0 & 0 & 0 & 0 \\
\hline YES & B & NO & 0 & 4 & 1 & 0 & 0 & 0 & 5 & 0 & 2 & 0 & 0 & 0 & 0 & 2 \\
\hline NO & $\mathbf{R}$ & YES & 1 & 0 & 5 & 1 & 1 & 0 & 8 & 1. & 2 & 1 & 0 & 1 & 1 & 6 \\
\hline & 0 & NO & 18 & 35 & 34 & 8 & 10 & 8 & 113 & 16 & 20 & 17 & 5 & 8 & 1 & 67 \\
\hline YES & $\begin{array}{l}\mathrm{D} \\
\mathrm{Y}\end{array}$ & YES & 0 & 4 & 6 & 0 & 0 & 0 & 10 & 1 & 4 & 1 & 0 & 0 & 0 & 6 \\
\hline YES & $\mathrm{s}$ & No & 1 & 1 & 2 & 1 & 1 & 0 & 6 & 0 & 0 & 3 & 0 & 1 & 0 & 4 \\
\hline NO & P & YES & 2 & 3 & 5 & 2 & 1 & 2 & 15 & 0 & 4 & 5 & 1 & 2 & 1 & 13 \\
\hline No & N & & & 31 & & 6 & 10 & 6 & 96 & 16 & 16 & 9 & 4 & 5 & 1 & 51 \\
\hline NO & A & No & 16 & 31 & 27 & & & 0 & 90 & & & & & & & \\
\hline
\end{tabular}


Table 24A

\section{Prevalences for Selected Respiratory Symptom Complexes at the Initial and Final Interviews by Smoking-Cumulative Exposure Categories}

\section{Bronchitis}

$\leq .0682$
$>.0682$
Dyspnea

\begin{tabular}{|c|c|c|c|c|c|c|c|c|c|}
\hline & & & & & & \\
\hline & $\mathrm{n}$ & Intitial & Final & $\begin{array}{c}\text { Mean } \\
\text { Age }\end{array}$ & $\mathrm{n}$ & Initial & Final & $\begin{array}{l}\text { Mean } \\
\text { Pack- } \\
\text { Years }\end{array}$ & $\begin{array}{c}\text { Mean } \\
\text { Age }\end{array}$ \\
\hline$\leq .0682 \mathrm{ppm}-$ months & 24 & $8.3 \%$ & $12.5 \%$ & 36.2 & 92 & $16.3 \%$ & $21.7 \%$ & 20.0 & 38.9 \\
\hline$>.0682$ ppm-months & 26 & $3.8 \%$ & $11.5 \%$ & 28.2 & 59 & 13.6 & $30.5 \%$ & 15.6 & 33.1 \\
\hline
\end{tabular}

Current or Ex-Smokers

Mean

Pack- Mean

Years Age

$20.0 \quad 38.9$

$15.6 \quad 33.1$

Current or Ex-Smokers

$\underline{\text { Never Smokers }}$ 
Table 25

"CIinlcal Reactors" to TDI

\begin{tabular}{|c|c|c|c|c|c|c|c|c|}
\hline I. D. & $\begin{array}{c}\text { Age } \\
\text { In } 1973 \\
\end{array}$ & $\begin{array}{l}\text { Smoking in } \\
\text { Pack-Years } \\
\text { (Initial) } \\
\end{array}$ & $\begin{array}{c}\text { Challenge } \\
\text { Results }\end{array}$ & $\begin{array}{l}\text { Atopic } \\
\geq 2 \text { Skin } \\
\text { Test } \\
\end{array}$ & $\begin{array}{c}\text { Known } \\
\text { Major } \\
\text { Exposure } \\
\end{array}$ & $\begin{array}{l}\text { Time in } \\
\text { Plants } \\
\text { Before } \\
\text { Symptoms } \\
\end{array}$ & $\begin{array}{c}\text { Job When } \\
\text { Became Symptomat1c }\end{array}$ & Comments \\
\hline 0033 & 47 & 47 & - & 0 & + & $<_{1}$ week & B Op TDI & $\begin{array}{l}\text { transferred out of TDI, } \\
\text { then resigned from plant }\end{array}$ \\
\hline 0035 & 26 & 7 & & 0 & 0 & 7 months & D Op TDI & still works in TDI \\
\hline 0037 & 27 & 7 & + & 0 & 0 & 2 months & D Op TDI & $\begin{array}{l}\text { transferred out of TDI } \\
\text { then quit for medical } \\
\text { reasons }\end{array}$ \\
\hline 0045 & 53 & 11 & & 0 & 0 & "weeks" & Foreman TDA & transferred out of TDI \\
\hline 0046 & 26 & 6 & - & + & + & $<_{2}$ months & $\begin{array}{l}\text { Chemlcal Englneer, } \\
\text { East Zone }\end{array}$ & resigned from plant \\
\hline 0110 & 30 & 8 & - & + & + & 4 months & Welder TDI/TDA & transferred out of TDI \\
\hline 0179 & 20 & 0 & & + & 0 & 3 years & C Op TDA & st111 works in TDI \\
\hline 0187 & 26 & 0 & + & & + & 4 months & Pipefitter TDI/TDA & transferred out of TDI \\
\hline 0197 & 61 & 0 & - & 0 & + & 4 months & Pipefitter TDI/TDA & resigned from plant \\
\hline 0200 & 32 & 0 & & 0 & 0 & $2 \frac{1}{2}$ years & Pipefitter TDI/TDA & transferred out of TDI \\
\hline 0218 & 57 & 0 & & 0 & 0 & 3 months & Insulator TDI/TDA & transferred out of TDI \\
\hline 0256 & 33 & 7 & & 0 & + & 2 years & Pipefitter TDI/TDA & transferred out of TDI \\
\hline
\end{tabular}


Table 26

TDI Environmental Exposure Evaluation (8/73 to $7 / 75$ )

\begin{tabular}{ccc}
\hline Location & $\begin{array}{c}\text { Percent Weekly } \\
\text { TWA Excursions } \\
\text { Above } .005\end{array}$ & $\begin{array}{c}\text { Percent Weekly } \\
\text { TWA Excursions } \\
\text { Above } 0.02\end{array}$ \\
\hline TDI Plant & $82.7 \%$ & $24.7 \%$ \\
TDI Drumming Building & $60.3 \%$ & $6.4 \%$ \\
\hline
\end{tabular}


Table 27

PERSONNEL MONITORING SCHEDULE

(January 7 - May 28, 1976)

\begin{tabular}{|c|c|c|c|c|c|c|c|c|}
\hline January & 7 thru & January & 11 & "A" Shift & 4 & $\mathrm{p} \cdot \mathrm{m}$. & -12 & a.m. \\
\hline January & 14 thru & January & 18 & "B" Shift & 4 & p.m. & -12 & a.m. \\
\hline January & 21 thru & January & 25 & "C" Shift & 4 & $\mathrm{p} \cdot \mathrm{m}$. & -12 & a.m. \\
\hline January & 28 thru & February & 1 & "D" Shift & 4 & p.m. & -12 & a.m. \\
\hline February & 6 thru & February & 10 & "D" Shift & 8 & a.m. & -4 & $\mathrm{p}, \mathrm{m}$. \\
\hline February & 13 thru & February & 17 & "A" Shift & 8 & a.m. & -4 & $\mathrm{p} \cdot \mathrm{m}$. \\
\hline February & 20 thru & February & 24 & "B" Shift & 8 & a.m. & -4 & $p, m$. \\
\hline February & 27 thru & March & 2 & "C" Shift & 8 & a.m. & -4 & p.m. \\
\hline March & 6 thru & March & 10 & "C" Shift & 12 & a.m. & -8 & a.m. \\
\hline March & 13 thru & March & 17 & "D" Shift & 12 & a.m. & -8 & a.m. \\
\hline March & 20 thru & March & 24 & "A" Shift & 12 & a.m. & -8 & a.m. \\
\hline March & 27 thru & March & 31 & "B" Shift & 12 & a.m. & -8 & a.m. \\
\hline April & 5 thru & April & 9 & Maintenance & 8 & a.m. & -4 & p.m. \\
\hline April & 12 thru & April & 16 & Maintenance & 8 & a.m. & -4 & p.m. \\
\hline April & 19 thru & April & 23 & Malntenance & 8 & a.m. & -4 & p.m. \\
\hline April & 26 thru & April & 30 & Maintenance & 8 & a.m. & -4 & p.m. \\
\hline May & 3 thru & May & 7 & Drumming Lab & 8 & a.m. & -4 & p.m. \\
\hline May & 10 thru & May & 14 & Drumming Lab & 8 & a.m. & -4 & p.m. \\
\hline May & 17 thru & May & 21 & Drumming Lab & 8 & a.m. & -4 & p.m. \\
\hline May & 24 thru & May & 28 & Drumming Lab & 8 & a.m. & -4 & p.m. \\
\hline
\end{tabular}


Table 28

COMPARISON OF TDI MONITOR VS. PERSONAL MONITOR

\begin{tabular}{|c|c|c|c|c|c|c|c|c|c|c|c|}
\hline \multirow[b]{2}{*}{ Name } & \multirow[b]{2}{*}{ Plant } & \multirow[b]{2}{*}{ Date } & \multicolumn{6}{|c|}{ Exposure in Minutes } & \multirow[b]{2}{*}{$\begin{array}{l}\text { Total } \\
\text { ppm. }\end{array}$} & \multirow{2}{*}{\begin{tabular}{|c|}
$\begin{array}{c}\text { Time- } \\
\text { weighted } \\
\text { average }\end{array}$ \\
\end{tabular}} & \multirow[b]{2}{*}{ Shift } \\
\hline & & & .005 & .01 & .02 & .04 & .06 & .08 & & & \\
\hline Area & TDI & $5-19-75$ & 101.2 & 32.2 & 0 & 0 & 0 & 0 & .0349 & .0044 & $\begin{array}{ll}8 & \mathrm{AM} \\
4 & \mathrm{PM}\end{array}$ \\
\hline $\begin{array}{l}\text { Production } \\
\text { Worker } 1\end{array}$ & TDI & $5-19-75$ & 324 & 306 & 270 & 207 & 192 & 189 & .200 & .025 & $\begin{array}{ll}8 & \mathrm{AM} \\
4 & \mathrm{PM} \\
\end{array}$ \\
\hline $\begin{array}{l}\text { Production } \\
\text { Worker } 2 \\
\end{array}$ & TDI & $5-19-75$ & 168 & 87 & 54 & 9 & 0 & 0 & .054 & .0068 & $\begin{array}{ll}8 & \mathrm{AM} \\
4 & \mathrm{PM} \\
\end{array}$ \\
\hline Area & TDI & $5-20-75$ & 16.1 & 11.5 & 0 & 0 & 0 & 0 & .0139 & .0017 & $\begin{array}{ll}8 & \mathrm{AM} \\
4 & \mathrm{PM}\end{array}$ \\
\hline $\begin{array}{l}\text { Production } \\
\text { Worker } 1\end{array}$ & Unknown & $5-20-75$ & 195 & 162 & 120 & 39 & 0 & 0 & .090 & .0113 & $\begin{array}{l}8 \mathrm{AM} \\
4 \mathrm{PM}\end{array}$ \\
\hline $\begin{array}{l}\text { Production } \\
\text { Worker } 2\end{array}$ & TDI & $5-20-75$ & 330 & 174 & 93 & 39 & 24 & 21 & .105 & .0131 & $\begin{array}{l}8 \mathrm{AM} \\
4 \mathrm{PM}\end{array}$ \\
\hline Area & TDI & $5-22-75$ & 0 & 0 & 0 & 0 & 0 & 0 & .0104 & .0013 & $\begin{array}{l}8 \mathrm{AM} \\
4 \mathrm{PM}\end{array}$ \\
\hline $\begin{array}{l}\text { Production } \\
\text { Worker } 1\end{array}$ & Unknown & $5-22-75$ & 407 & 384 & 183 & 39 & 9 & 0 & .154 & .0193 & $\begin{array}{l}8 \mathrm{AM} \\
4 \mathrm{PM} \\
\end{array}$ \\
\hline $\begin{array}{l}\text { Production } \\
\text { Worker } 2 \\
\end{array}$ & $\operatorname{TDI}$ & $5-22-75$ & 327 & 138 & 48 & 15 & 9 & 9 & .080 & .010 & $\begin{array}{ll}8 & \mathrm{AM} \\
4 & \mathrm{PM} \\
\end{array}$ \\
\hline Area & TDI & $6-25-75$ & 200.1 & 140.3 & 87.4 & 20.7 & 0 & 0 & .124 & .0155 & $\begin{array}{r}4 \mathrm{PM} \\
11 \mathrm{PM}\end{array}$ \\
\hline $\begin{array}{l}\text { Production } \\
\text { Worker } 1\end{array}$ & TDI & $6-25-75$ & & & & & & & & & $\begin{array}{r}4 \mathrm{PM} \\
11 \mathrm{PM} \\
\end{array}$ \\
\hline $\begin{array}{l}\text { Production } \\
\text { Worker } 2\end{array}$ & TDI & $6-25-75$ & 12 & 0 & 0 & 0 & 0 & 0 & .019 & .0024 & $\begin{array}{r}4 \mathrm{PM} \\
11 \mathrm{PM} \\
\end{array}$ \\
\hline $\begin{array}{l}\text { Production } \\
\text { Worker } 3 \\
\end{array}$ & TDI & $6-25-75$ & 9 & 0 & 0 & 0 & 0 & 0 & .018 & .0023 & $\begin{array}{r}4 \mathrm{PM} \\
11 \mathrm{PM} \\
\end{array}$ \\
\hline Area & TDI & $6-26-75$ & 190.9 & 165.6 & 115 & 20.7 & 13.8 & 13.8 & .1213 & .0152 & $\begin{array}{r}4 \text { PM } \\
11 \text { PM } \\
\end{array}$ \\
\hline $\begin{array}{l}\text { Production } \\
\text { Worker } 1\end{array}$ & TDI & $6-26-75$ & 69 & 15 & 0 & 0 & 0 & 0 & .020 & .0025 & $\begin{array}{r}4 \mathrm{PM} \\
11 \mathrm{PM} \\
\end{array}$ \\
\hline $\begin{array}{l}\text { Production } \\
\text { Worker } 2\end{array}$ & Phosgene & $6-26-75$ & 36 & 6 & 0 & 0 & 0 & 0 & .002 & .00025 & $\begin{array}{r}4 \mathrm{PM} \\
11 \mathrm{PM} \\
\end{array}$ \\
\hline $\begin{array}{l}\text { Production } \\
\text { Worker } 3\end{array}$ & TDI & $6-26-75$ & 207 & 84 & 15 & 0 & 0 & 0 & .047 & .0059 & $\begin{array}{r}4 \mathrm{PM} \\
11 \mathrm{PM} \\
\end{array}$ \\
\hline $\begin{array}{l}\text { Production } \\
\text { Worker } 4 \\
\end{array}$ & TDI & $6-26-75$ & 51 & 21 & 6 & 0 & 0 & 0 & .036 & .0045 & $\begin{array}{r}4 \mathrm{PM} \\
11 \mathrm{PM} \\
\end{array}$ \\
\hline Area & Druming & $5-20-75$ & 400.2 & 299 & 69 & 43.7 & 41.4 & 41.4 & .1490 & .0186 & $\begin{array}{l}8 \mathrm{AM} \\
4 \mathrm{PM} \\
\end{array}$ \\
\hline $\begin{array}{l}\text { Production } \\
\text { Worker } 1\end{array}$ & Drumming & $5-20-75$ & 309 & 72 & 45 & 9 & 0 & 0 & .066 & .0083 & $\begin{array}{l}8 \mathrm{AM} \\
4 \mathrm{PM} \\
\end{array}$ \\
\hline $\begin{array}{l}\text { Production } \\
\text { Worker } 2\end{array}$ & Drumming & $5-20-75$ & 174 & 48 & 0 & 0 & 0 & 0 & .036 & .0045 & $\begin{array}{l}8 \mathrm{AM} \\
4 \mathrm{PM} \\
\end{array}$ \\
\hline $\begin{array}{l}\text { Production } \\
\text { Worker } 3\end{array}$ & Drumming & $5-20-75$ & 51 & 30 & 0 & 0 & 0 & 0 & .022 & .0028 & $\begin{array}{ll}8 & \mathrm{AM} \\
4 & \mathrm{PM} \\
\end{array}$ \\
\hline Area & Drumming & $5-23-75$ & 11.5 & 6.9 & 0 & 0 & 0 & 0 & .0297 & .0037 & $\begin{array}{l}8 \mathrm{AM} \\
4 \mathrm{PM} \\
\end{array}$ \\
\hline $\begin{array}{l}\text { Production } \\
\text { Worker } 1\end{array}$ & Drumining & $5-23-75$ & & & & & & & & & $\begin{array}{l}8 \mathrm{AM} \\
4 \mathrm{PM} \\
\end{array}$ \\
\hline $\begin{array}{l}\text { Production } \\
\text { Worker } 2\end{array}$ & Drumming & $5-23-75$ & 360 & 6 & 0 & 0 & 0 & 0 & .050 & .0063 & $\begin{array}{l}8 \mathrm{AM} \\
4 \mathrm{PM} \\
\end{array}$ \\
\hline $\begin{array}{l}\text { Production } \\
\text { Worker } 3 \\
\end{array}$ & Druming & $5-23-75$ & 21 & 0 & 0 & 0 & 0 & 0 & .016 & .002 & $\begin{array}{ll}8 & \mathrm{AM} \\
4 & \mathrm{PM} \\
\end{array}$ \\
\hline
\end{tabular}


Table 29

SUMMARY OF PERSONAL MONITORING FOR PHOSGENE

IN A TDI MANUFACTURING PLANT

\begin{tabular}{|c|c|c|c|c|c|c|c|c|}
\hline \multirow[b]{2}{*}{ Job Title } & \multirow[b]{2}{*}{ Location } & \multirow{2}{*}{$\begin{array}{l}\text { Monitoring } \\
\text { Period } \\
\text { Month-Year }\end{array}$} & \multirow[b]{2}{*}{ Shifts* } & \multirow{2}{*}{$\begin{array}{l}\text { Number } \\
\text { of } \\
\text { Workers }\end{array}$} & \multirow{2}{*}{$\begin{array}{l}\text { Number } \\
\text { of } \\
\text { Readings }\end{array}$} & \multicolumn{3}{|c|}{$\begin{array}{l}\text { Concentration of } \\
\text { Phosgene - PPM }\end{array}$} \\
\hline & & & & & & $\begin{array}{l}\text { Mean 8-h } \\
\text { TWA }\end{array}$ & \pm & SD \\
\hline $\begin{array}{l}\text { Phosgene } \\
\text { Operator }\end{array}$ & $\begin{array}{l}\text { Phosgene } \\
\text { Plant }\end{array}$ & $3 / 76-12 / 76$ & $1,2,3$ & 10 & 71 & 0.004 & \pm & 0.004 \\
\hline $\begin{array}{l}\text { TDI } \\
\text { Operator }\end{array}$ & $\begin{array}{l}\text { TDI } \\
\text { Plant }\end{array}$ & $3 / 76-4 / 76$ & 1,3 & 2 & 6 & 0.004 & \pm & 0.003 \\
\hline $\begin{array}{l}\text { DNT } \\
\text { Operator }\end{array}$ & $\begin{array}{l}\text { TDA } \\
\text { Plant }\end{array}$ & $3 / 76$ & 3 & 3 & 14 & 0.004 & \pm & 0.003 \\
\hline Maintenance & $\begin{array}{l}\text { TDI and } \\
\text { Phosgene } \\
\text { Plant }\end{array}$ & $5 / 76-12 / 76$ & 1 & 6 & 22 & 0.011 & \pm & 0.017 \\
\hline
\end{tabular}

*Shift $1 \quad 8$ a.m. -4 p.m.

Shift 24 p.m. -12 midnight

Shift 312 midnight -8 a.m. 


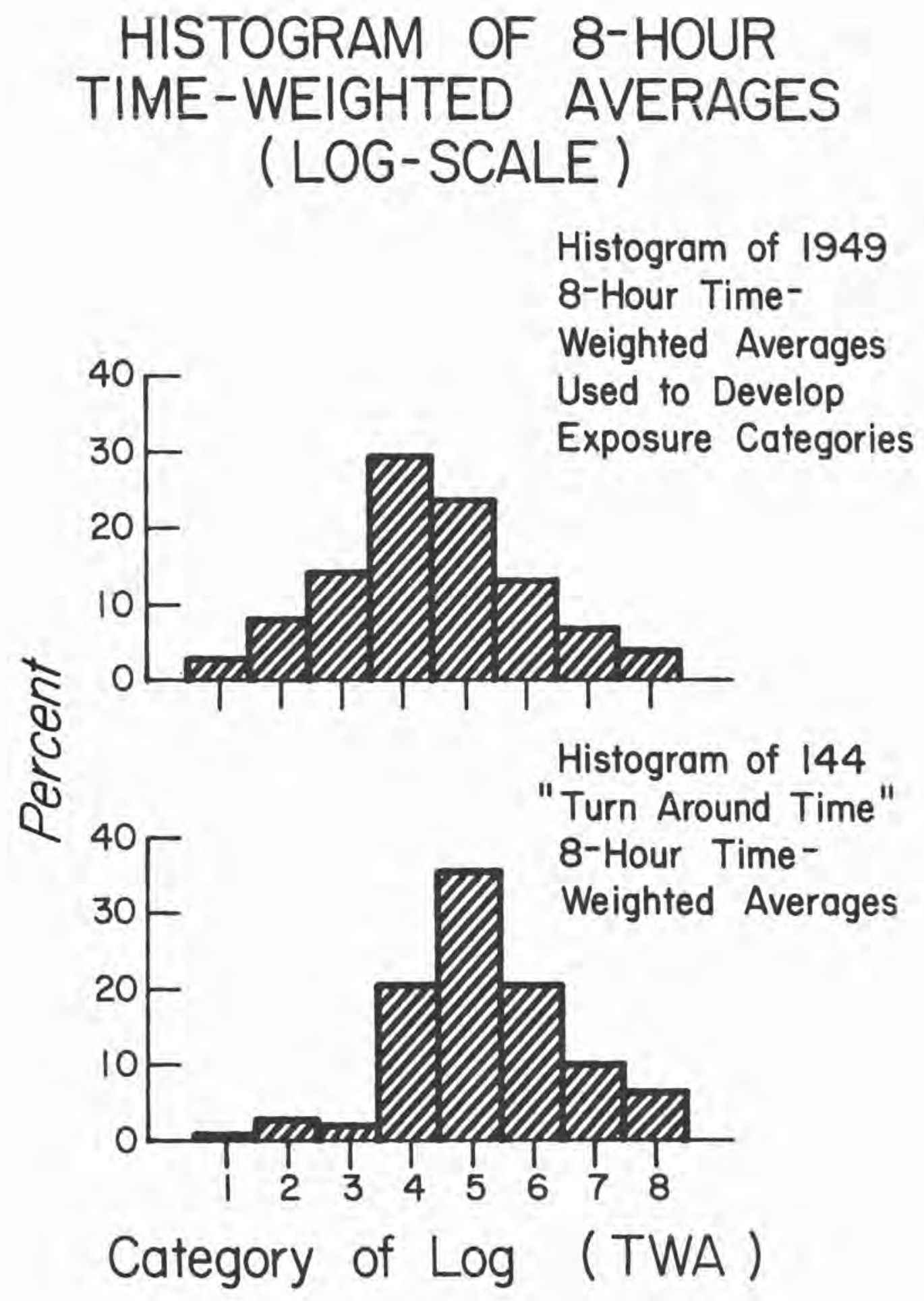

F1gure 1 

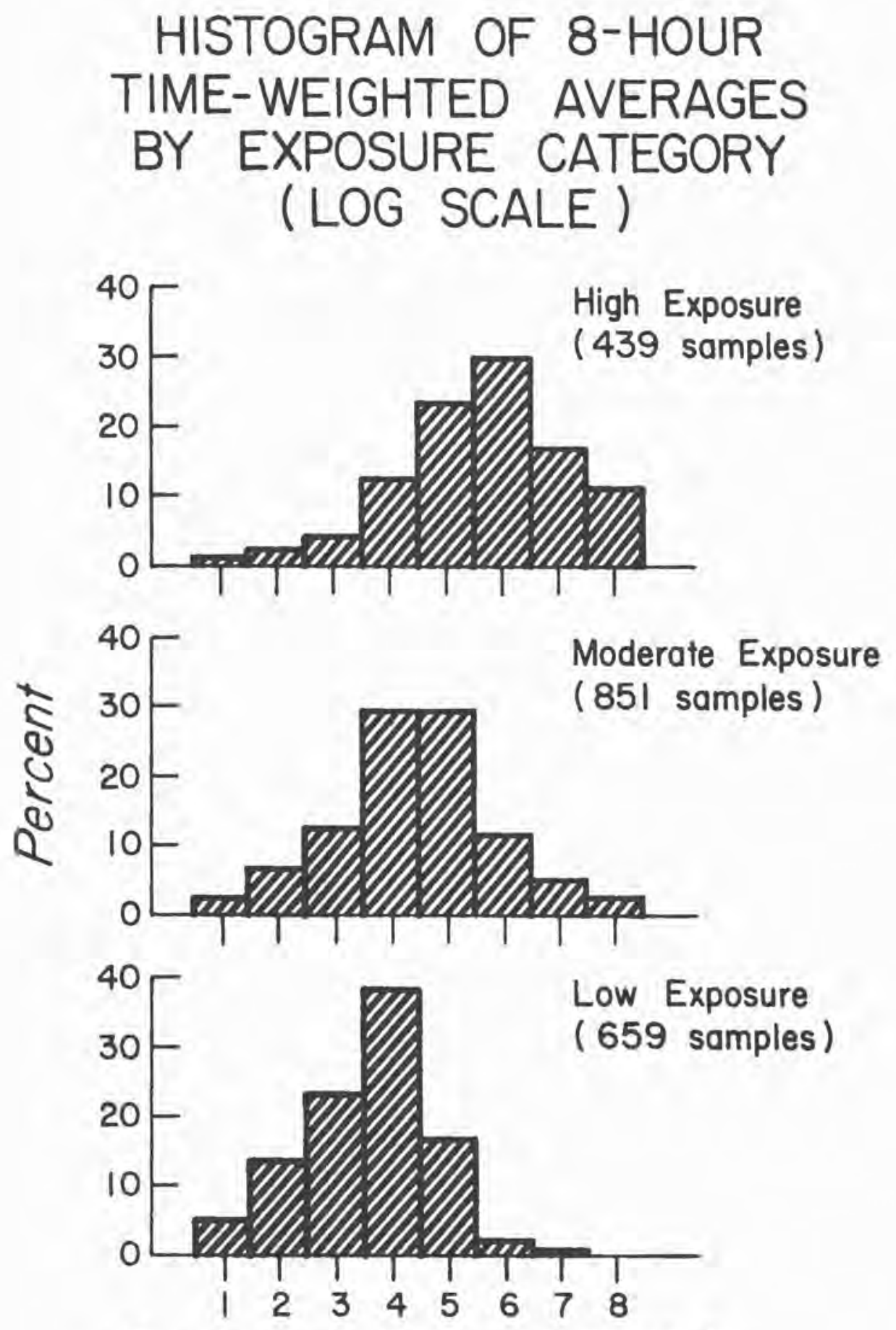

Category of Log (TWA)

Figure 2 
FEV, MEAN BY VISIT FOR THE 33 PARTICIPANTS WITH COMPLETE SPIROMETRY AT ALL NINE VISITS

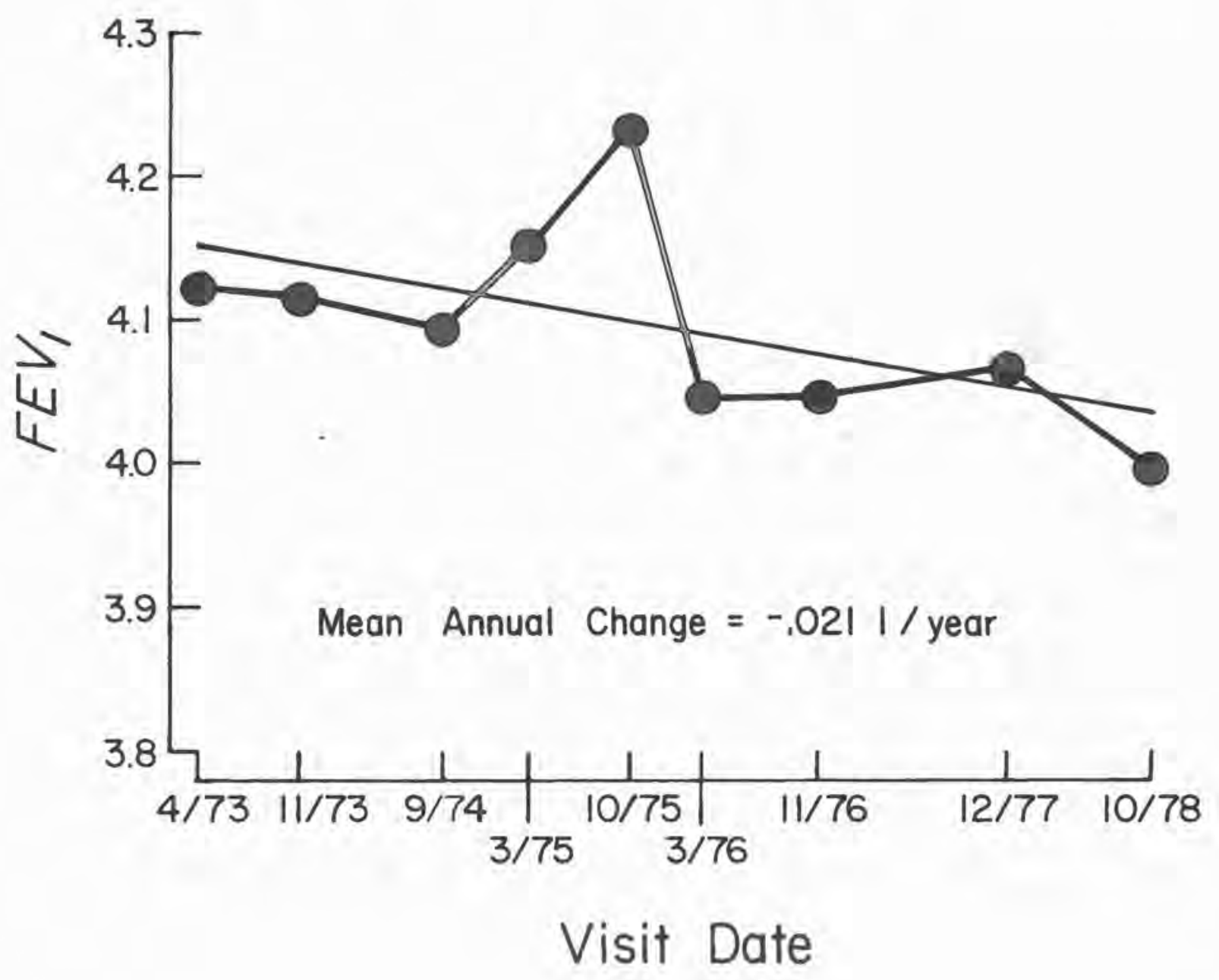

Figure 3 
TDI REACTORS

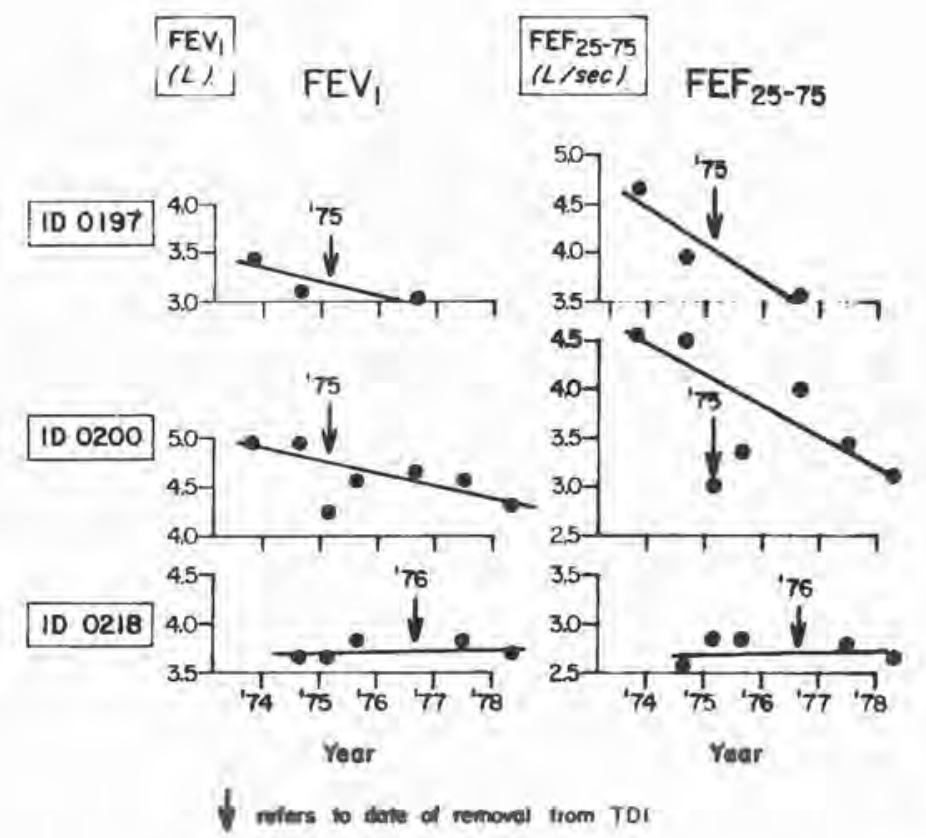

TDI REACTORS

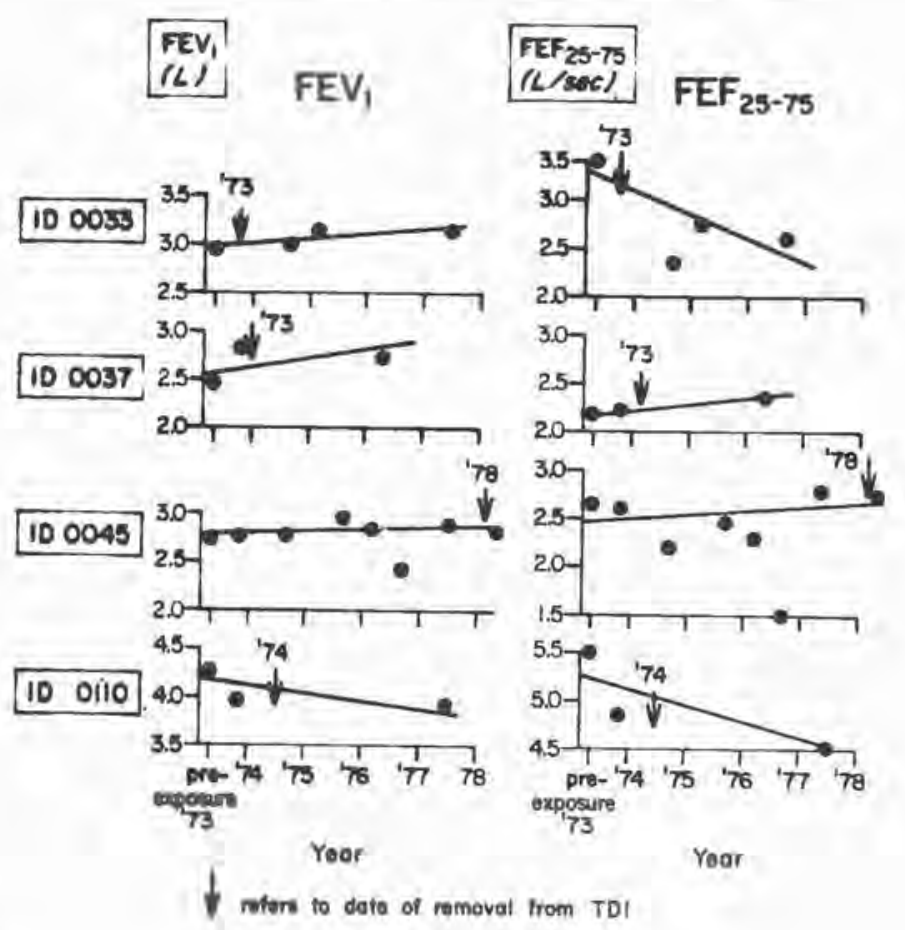

Figure 4 


\section{TDI REACTORS}

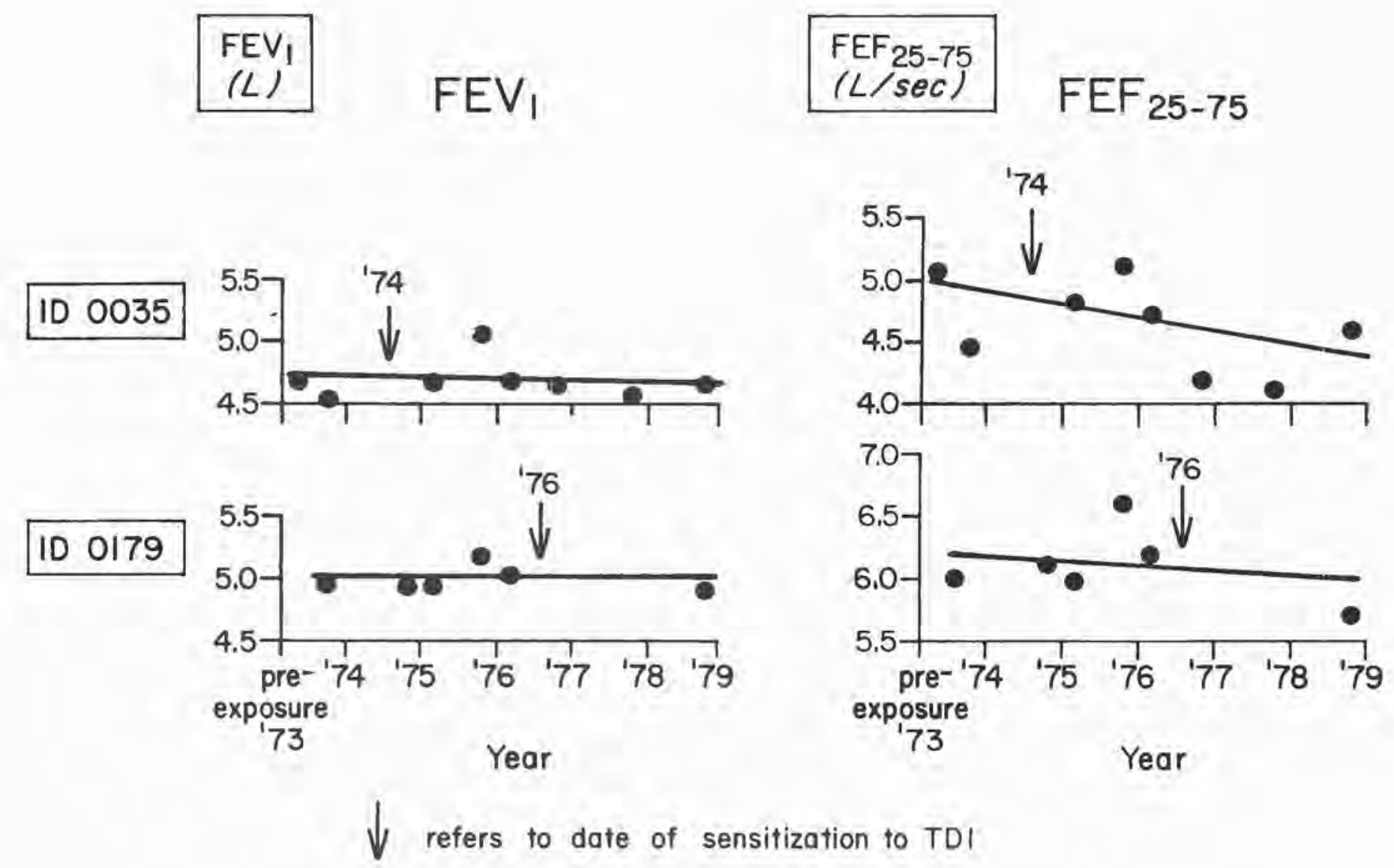

Figure 5 


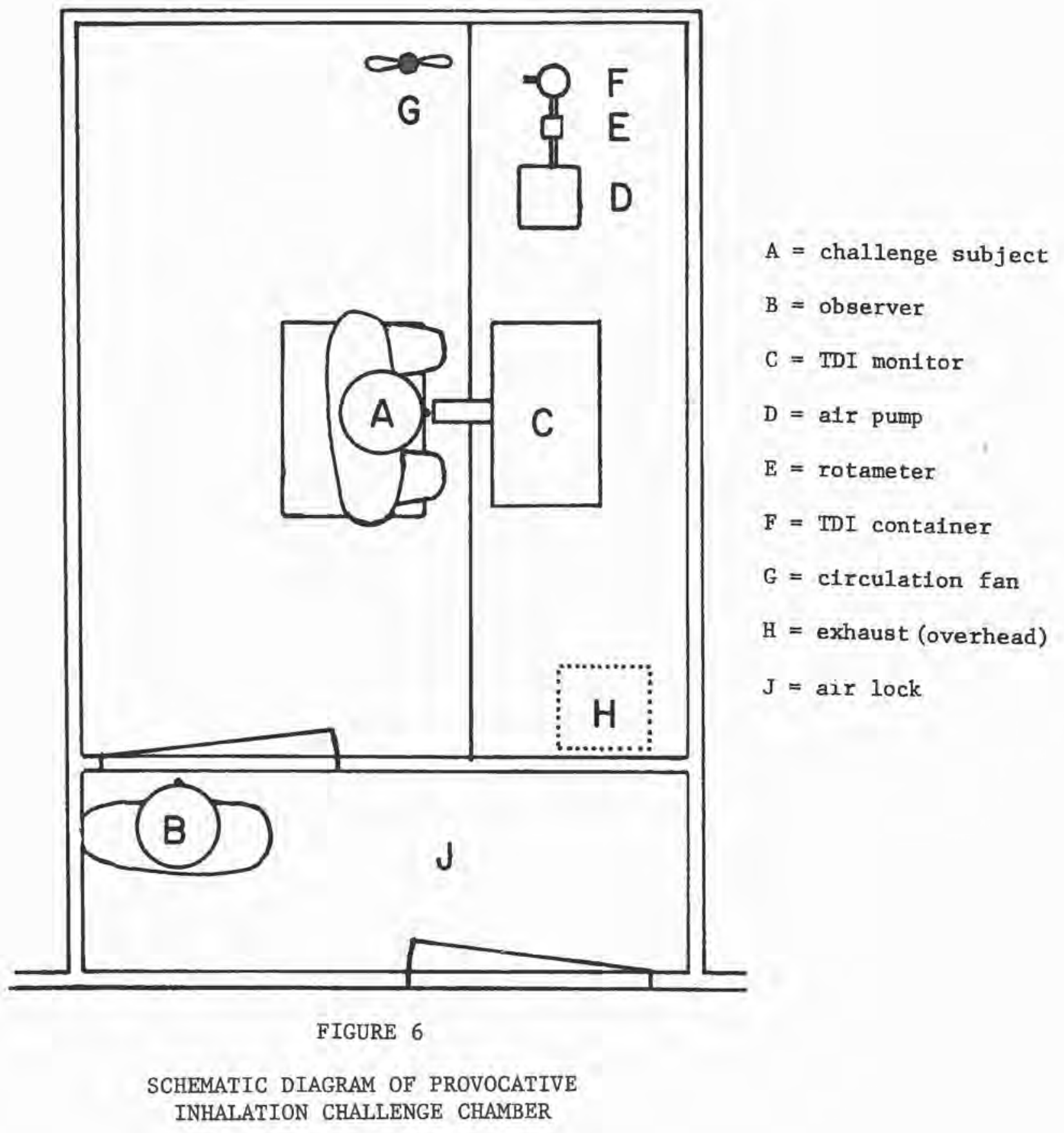




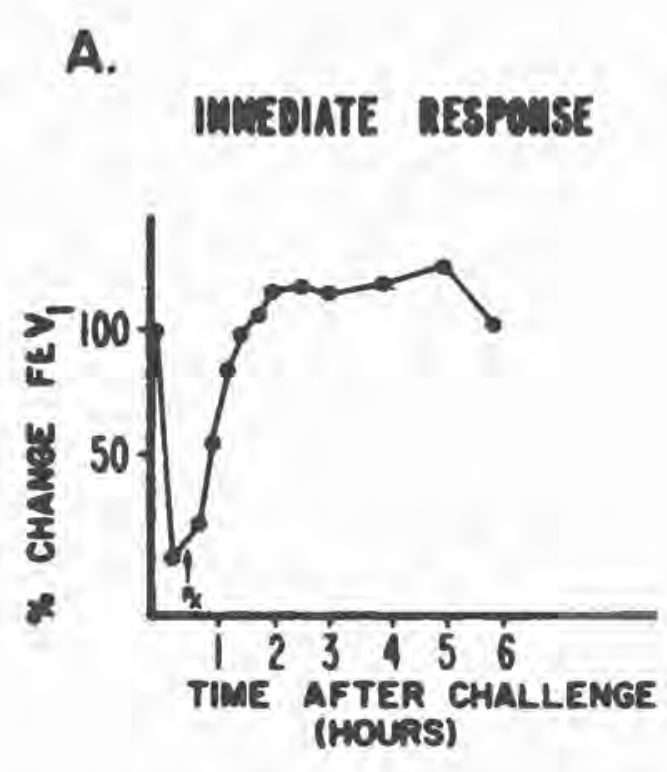

B.

\section{LATE RESPOUSE}

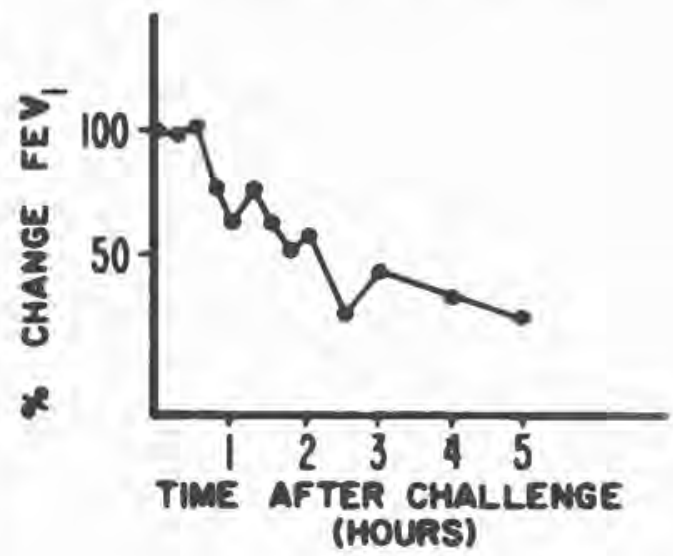

C.

OUAL RESPOHSE

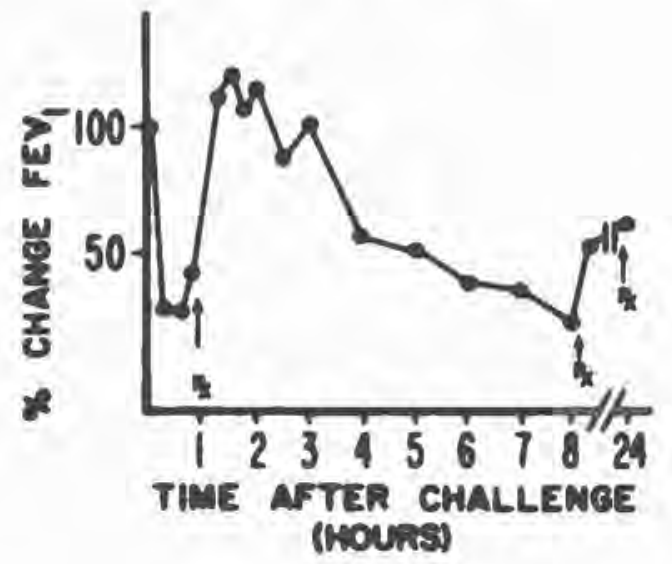

D.

DOSE RESPOUSE

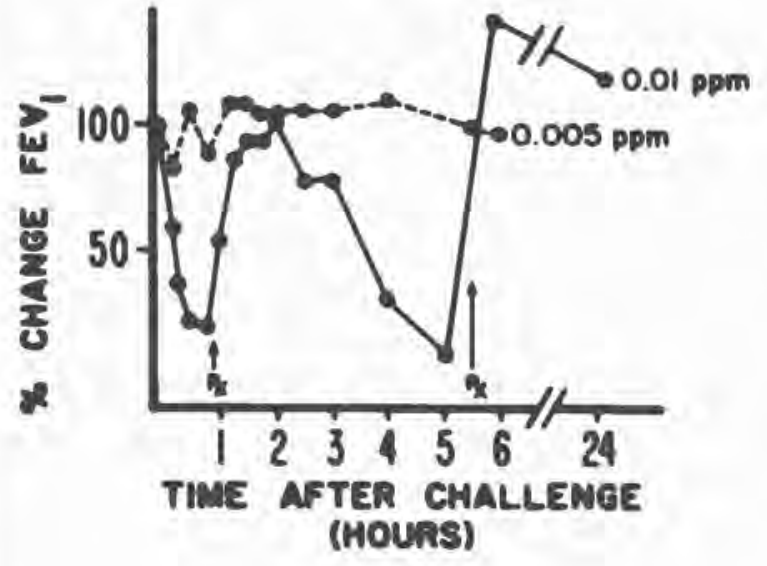

Figure 7

Respiratory Response to Provocative Inhalation

Challenge with TDI 


\section{EFFECT OF CROMALYN ON TDI INDUCED ASTHMA}

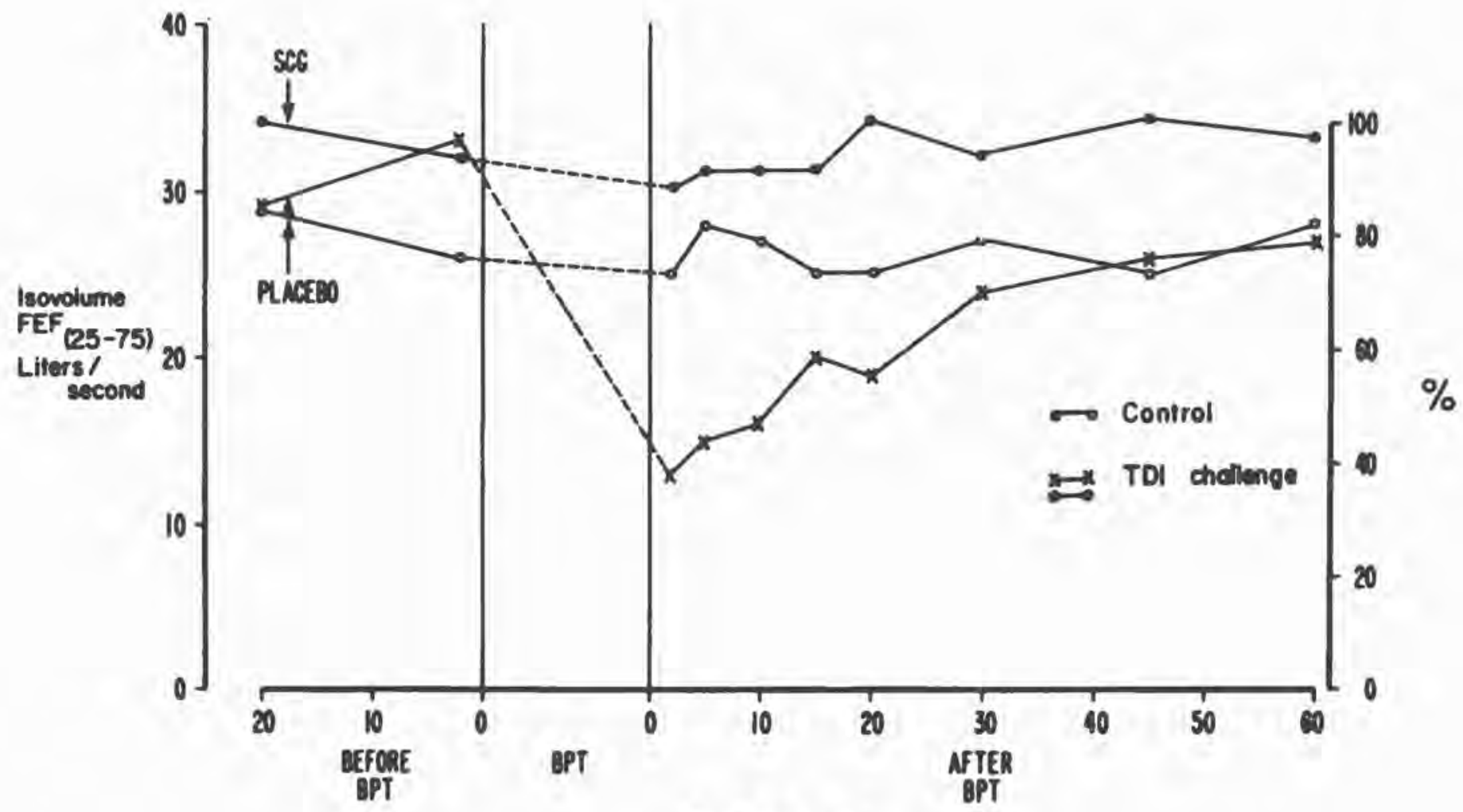

Time in Minutes

Figure 8 


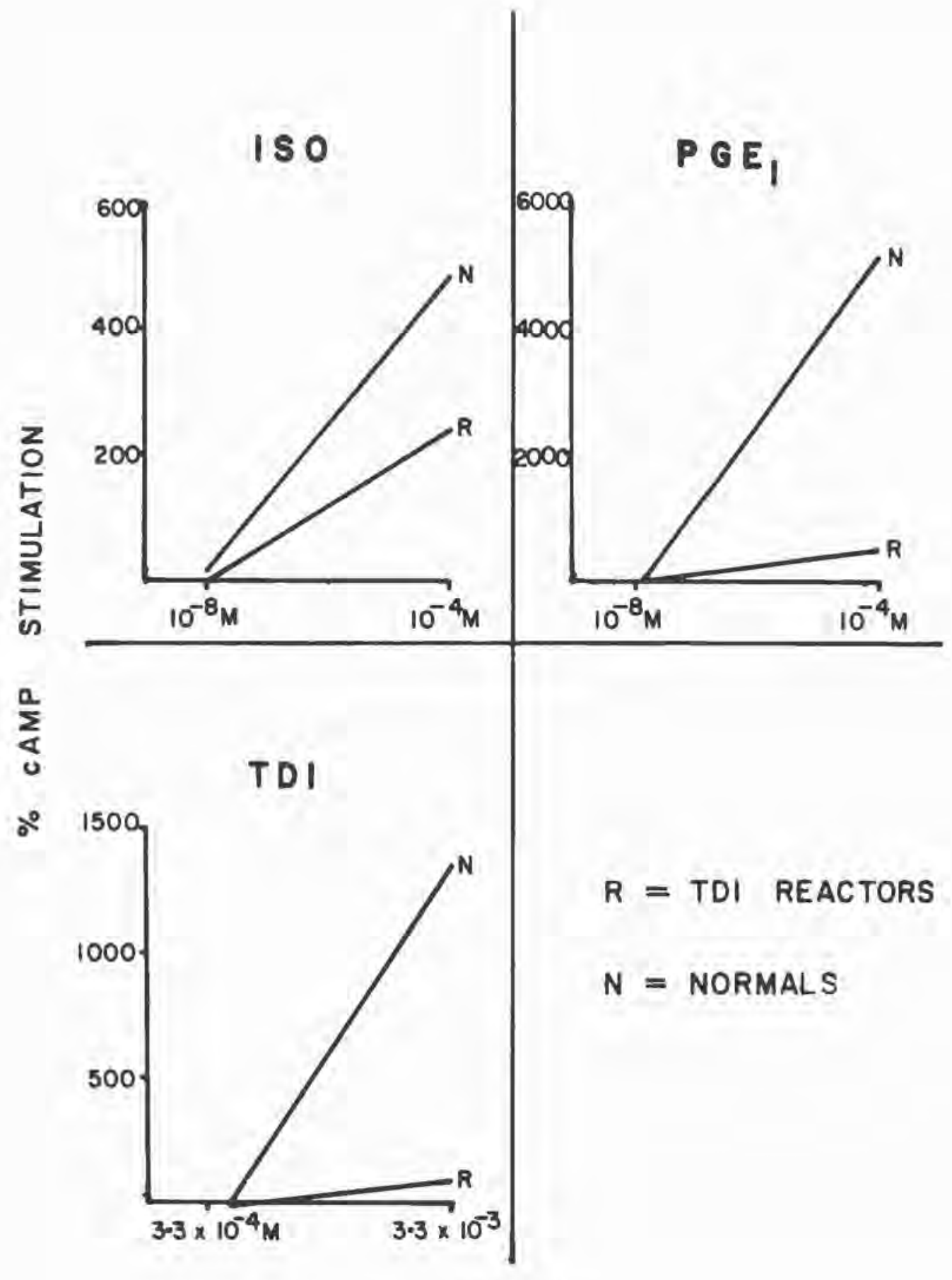

Figure 9

Cyclic Adenosine Monophosphate Dose Response Slopes of TDI Reactors and Normal Individuals to Stimulation with Agonists: Isoproterenol, Prostaglandin $E_{1}$, and TDI 


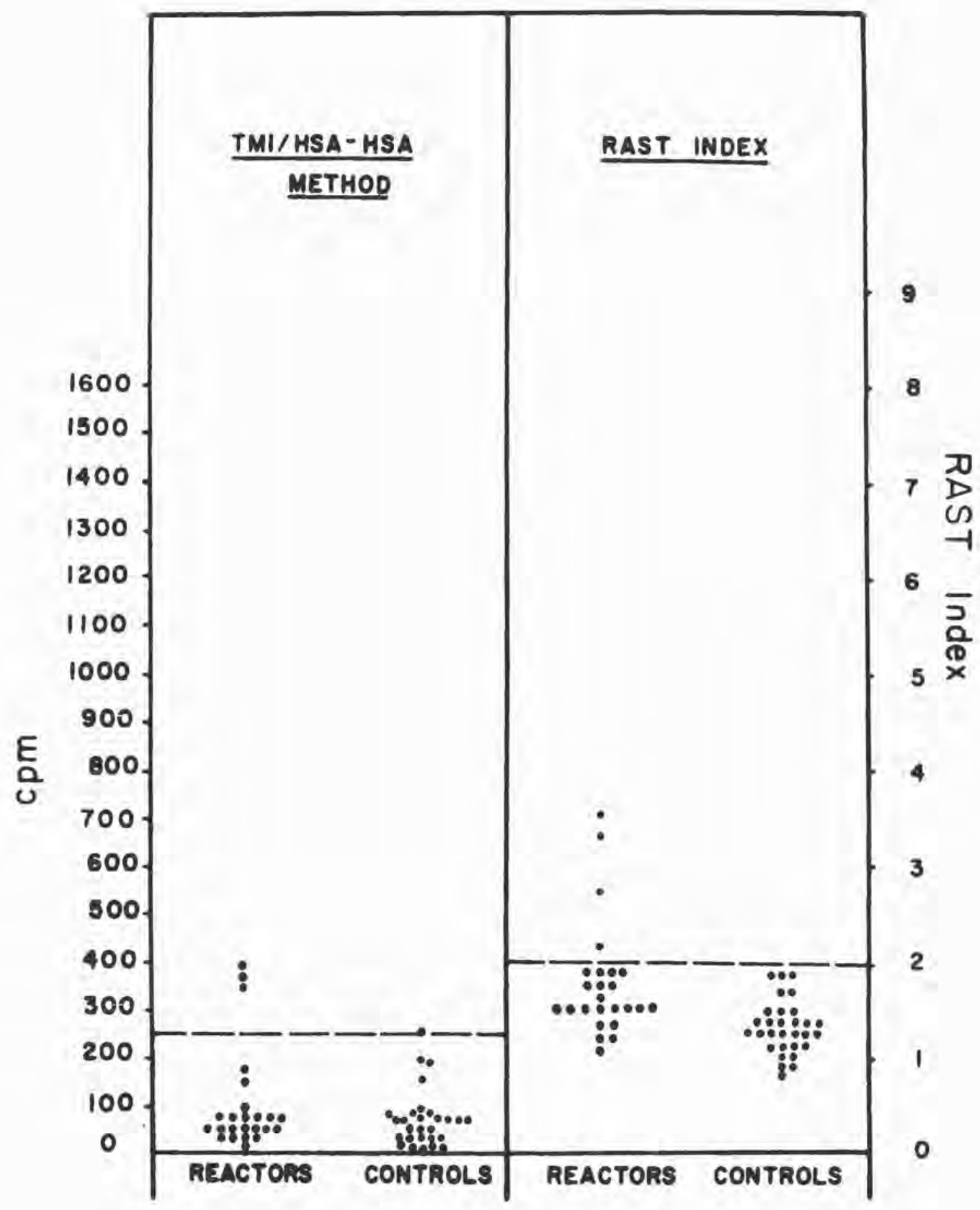

Figure 10

Radioallergosorbent Tests with p-tolyl Monoisocyanate of Sera from TDI Reactors and Controls 


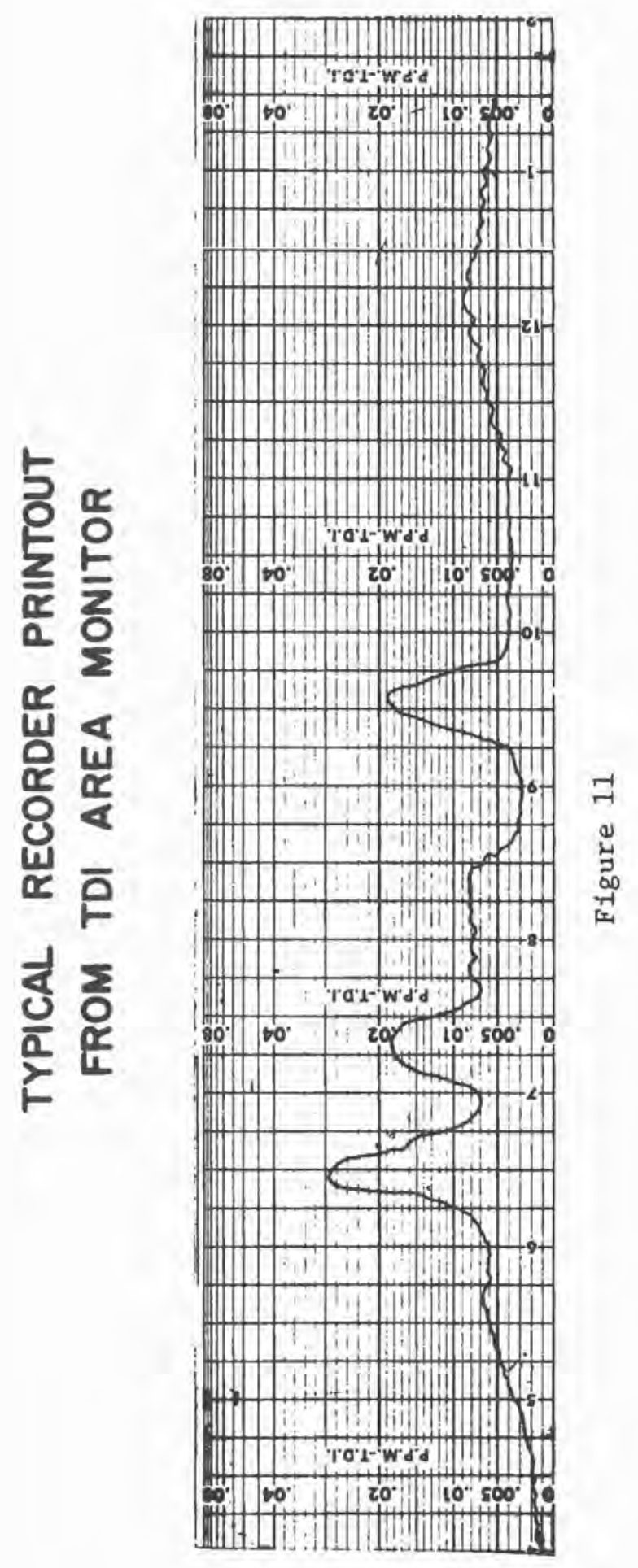

억 


\section{CONCURRENT IMPINGER AND MONITOR TDI LEVELS \\ (field)}

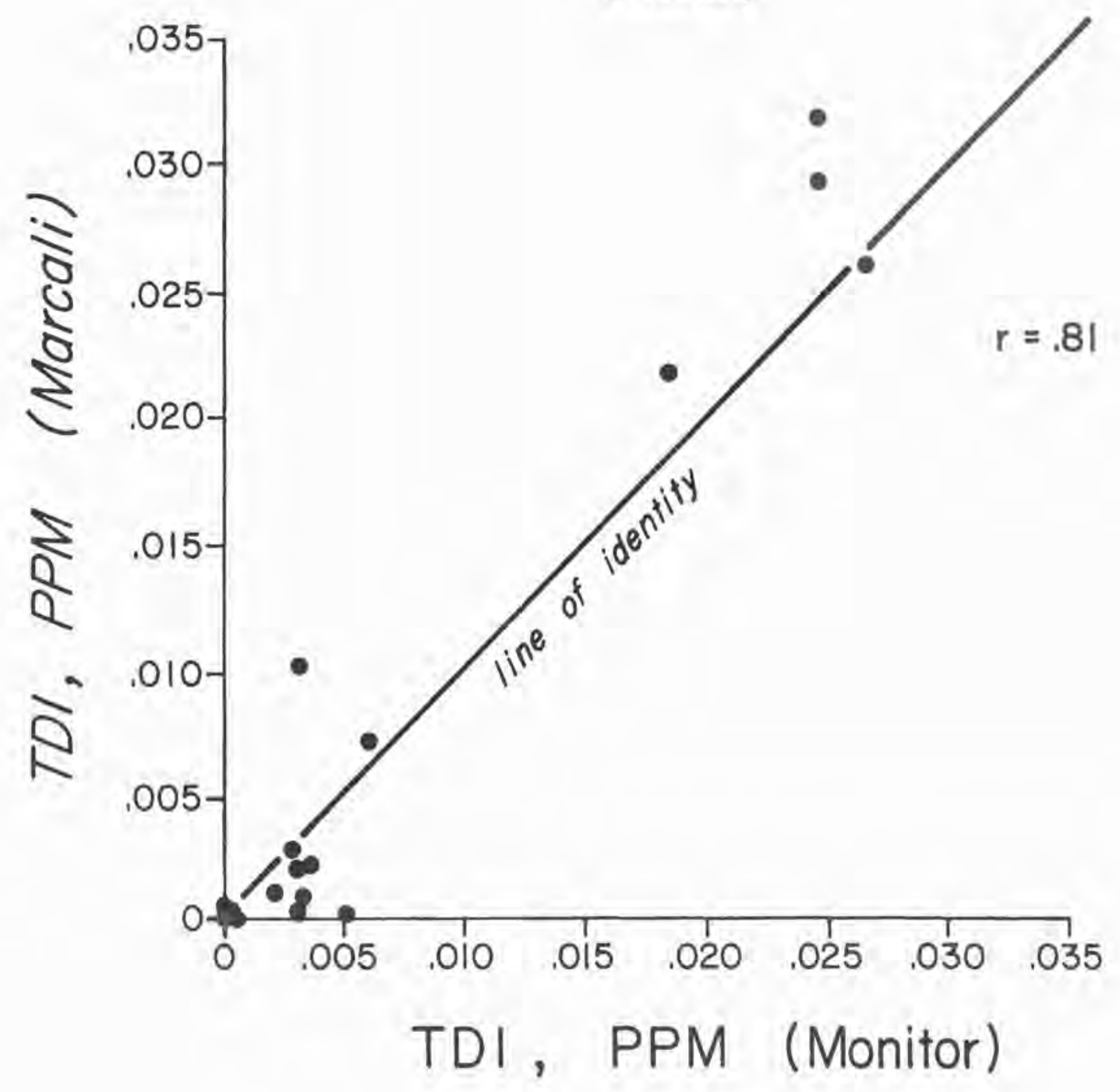

Figure 12 
TDI CONCENTRATION IN PPM

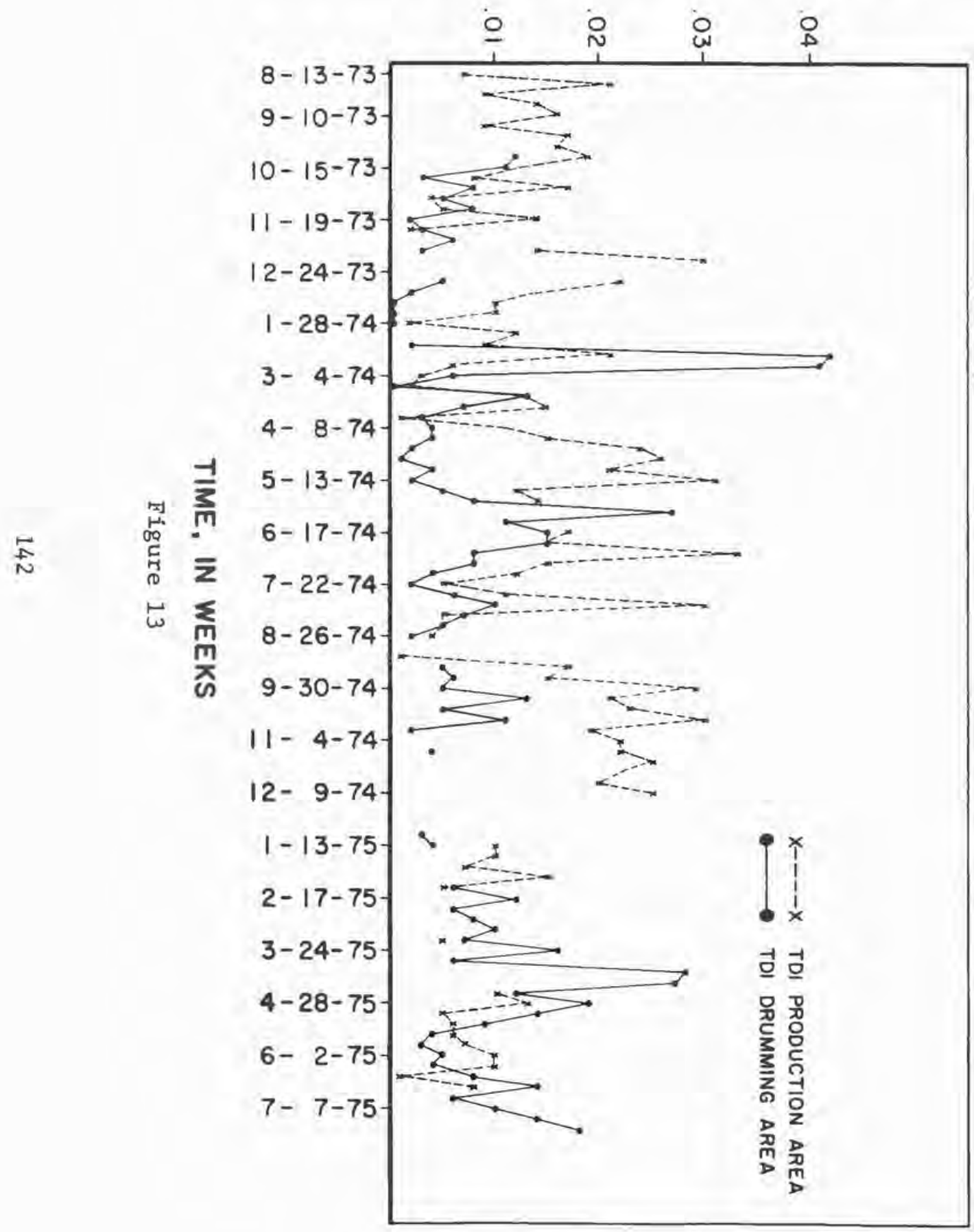


TDI PLANT

HISTOGRAM OF WEEKLY TWA

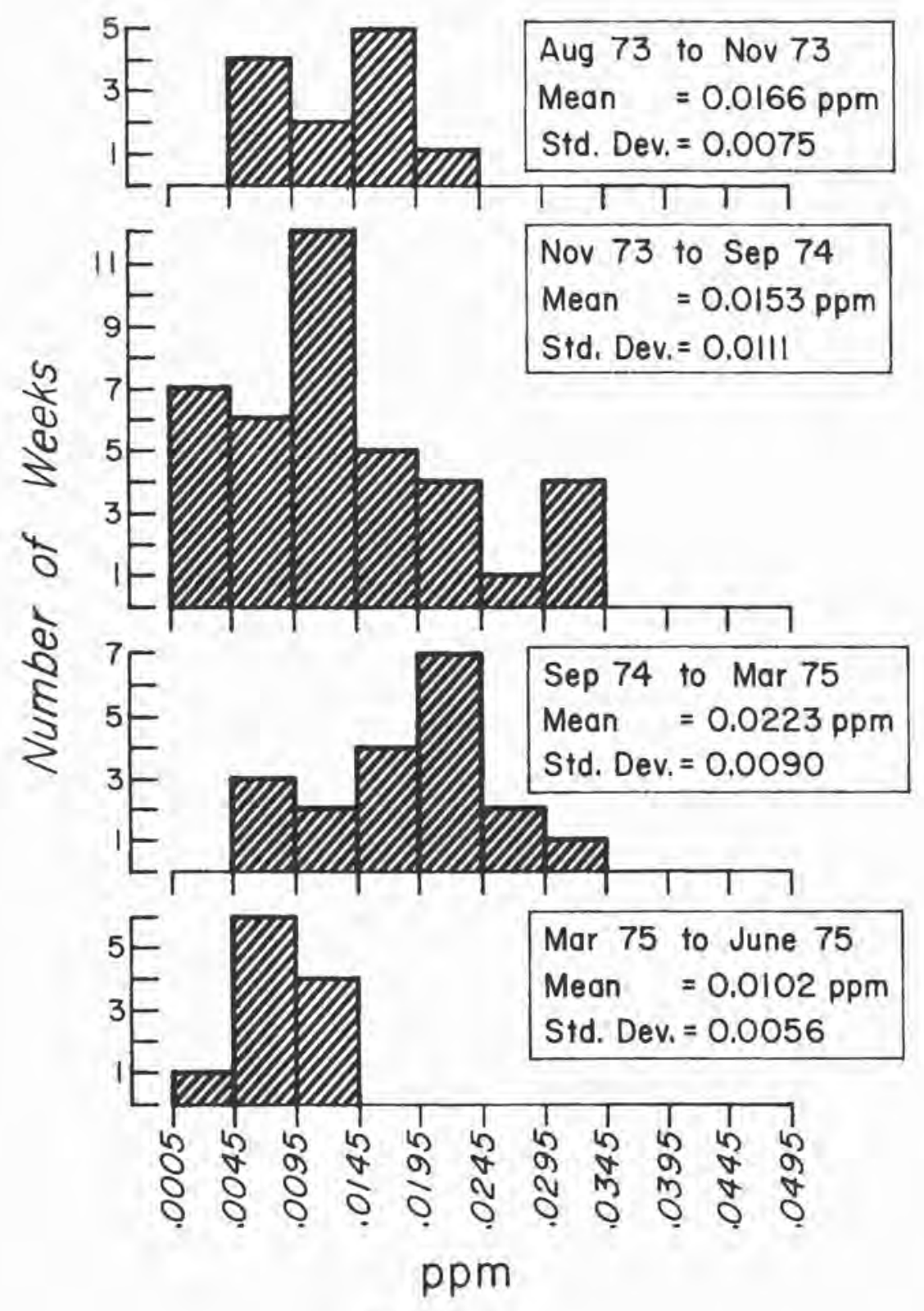

Figure 14 


\section{TDI DRUMMING BUILDING}

\section{HISTOGRAM OF WEEKLY TWA}

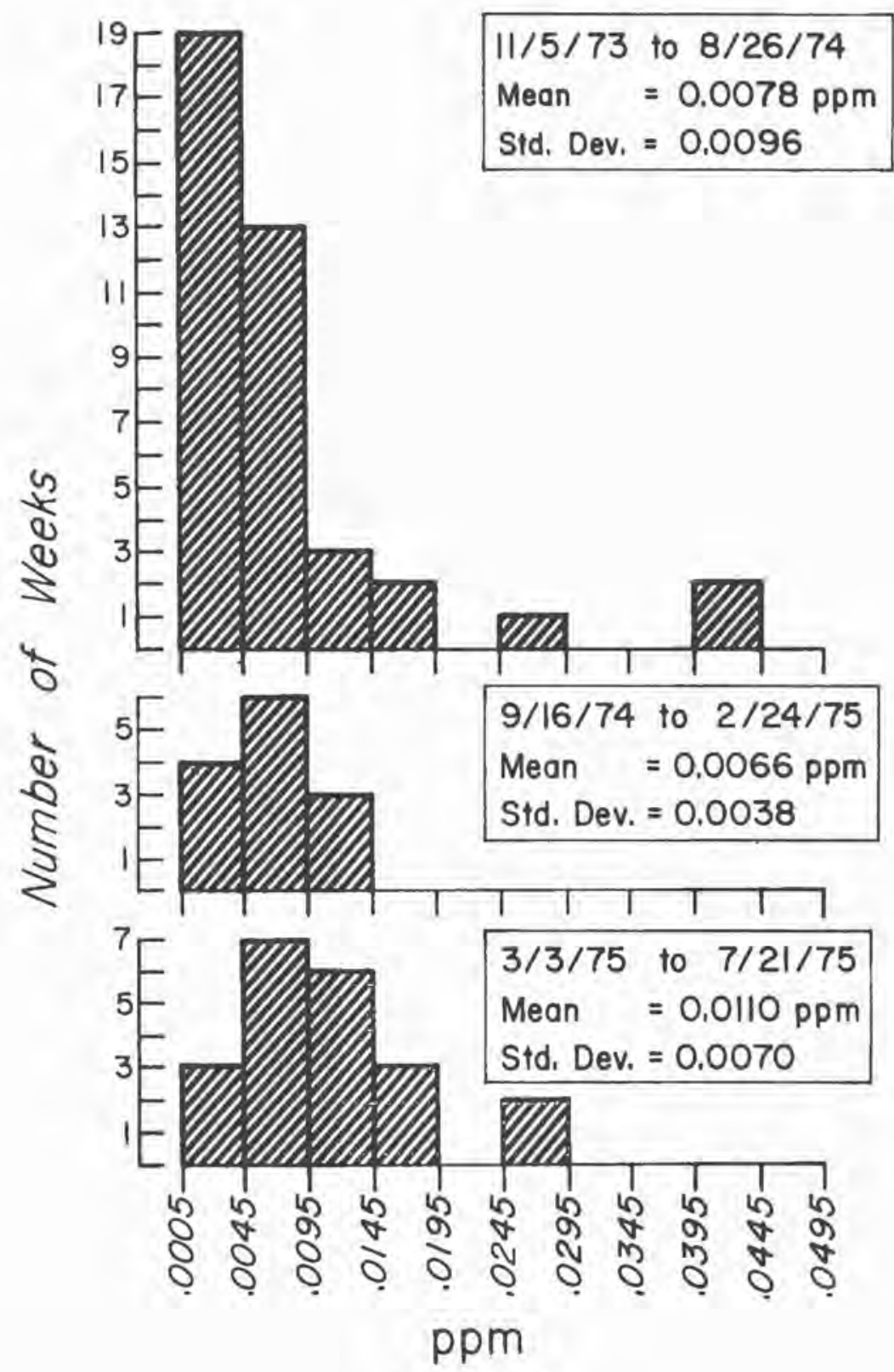

Figure 15 
TYPICAL RECORDER PRINTOUT

FROM TDI PERSONAL MONITOR
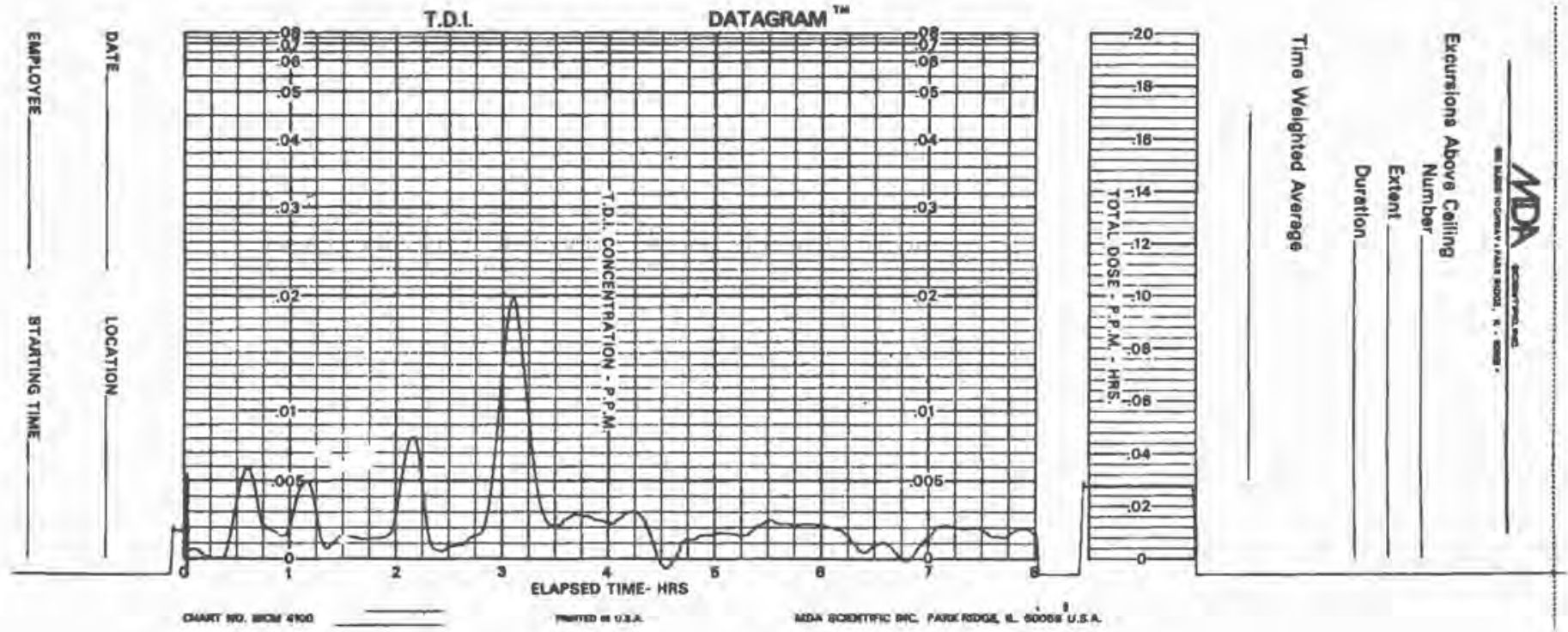

Figure 16 


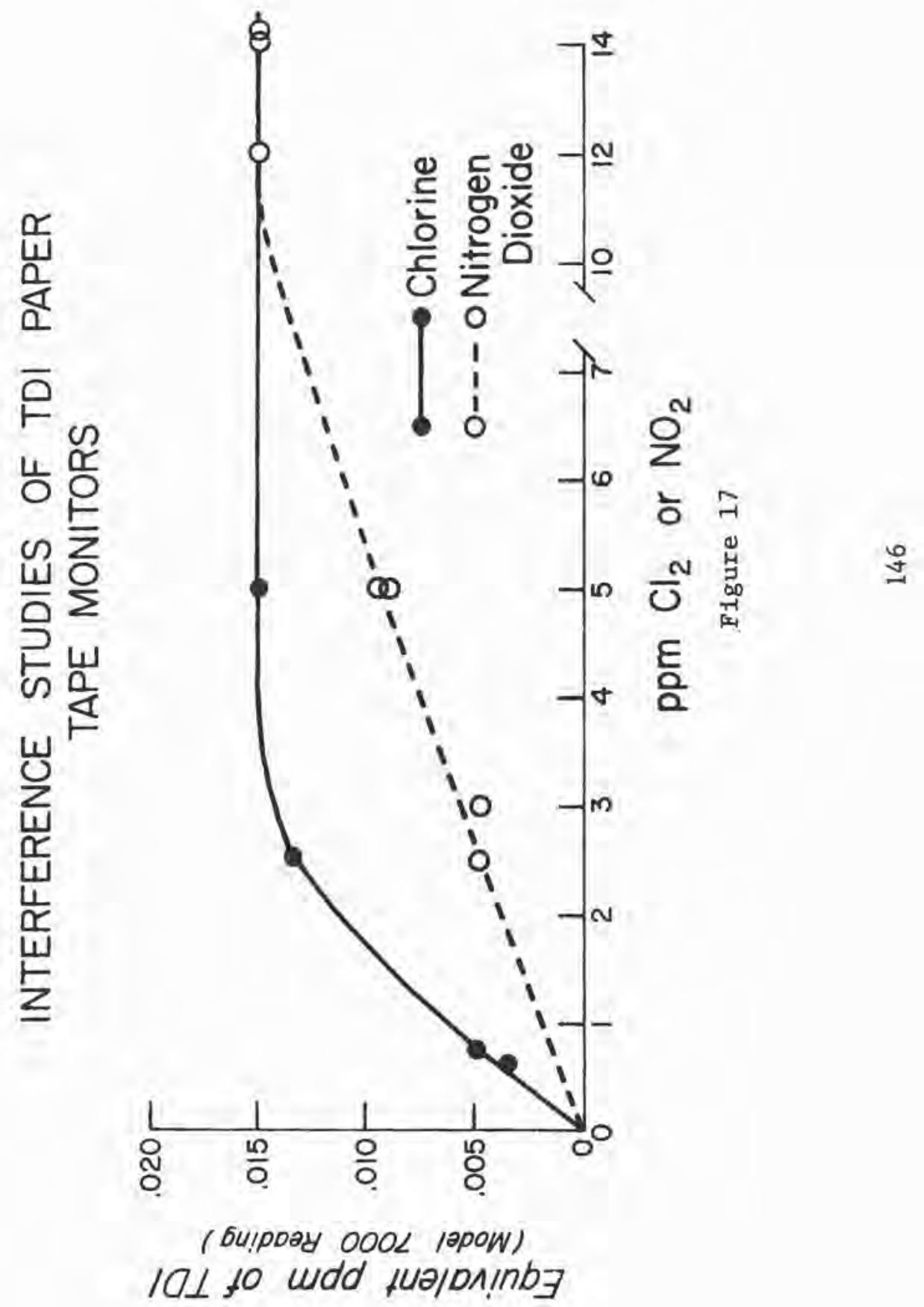




\section{TDI DATAGRAM}

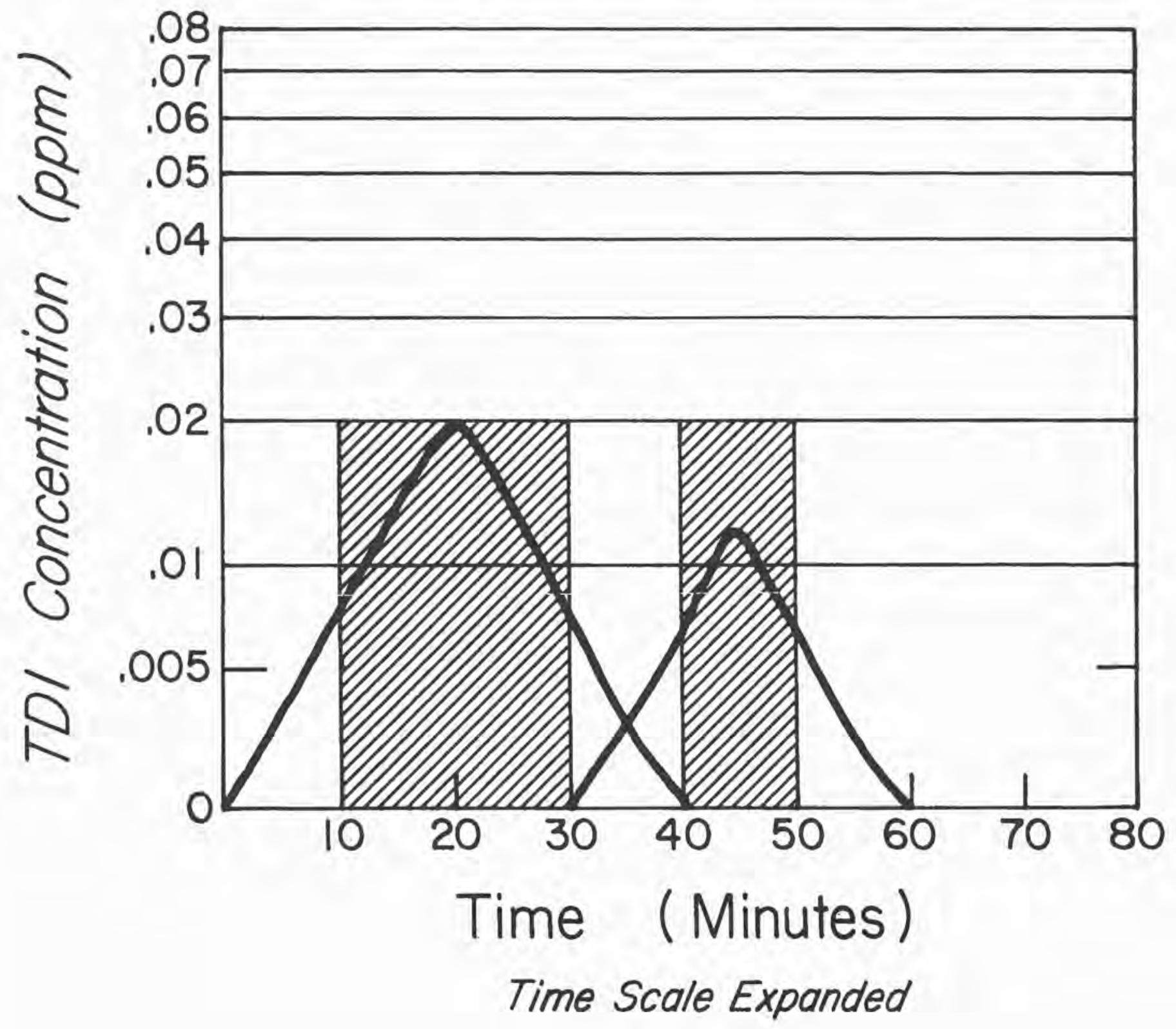

Figure 18 


\section{EFFECT OF TEMPERATURE ON MODEL 7000 TDI MONITOR}

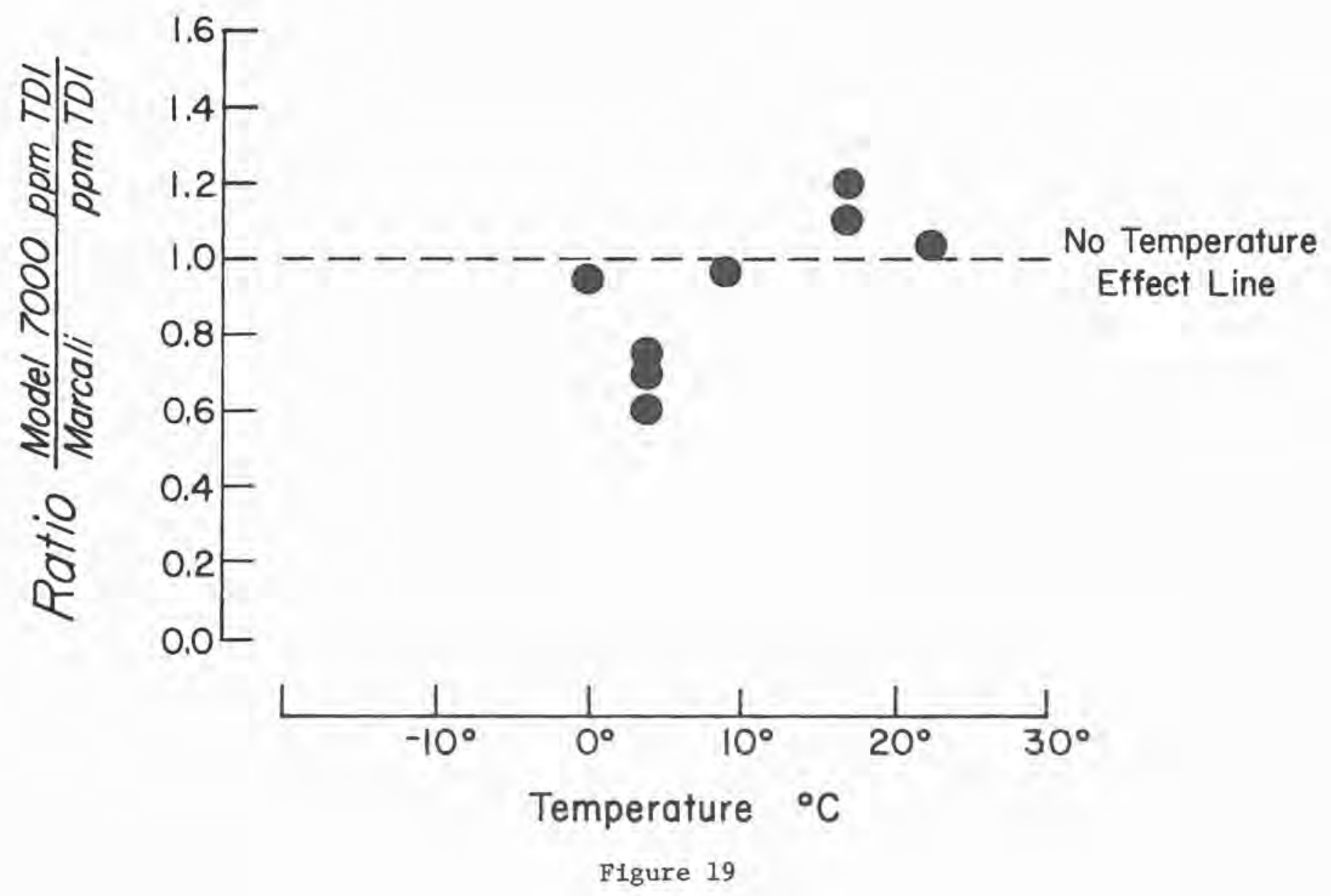




\section{EFFECT OF HUMIDITY ON MODEL 7000 TDI MONITOR}

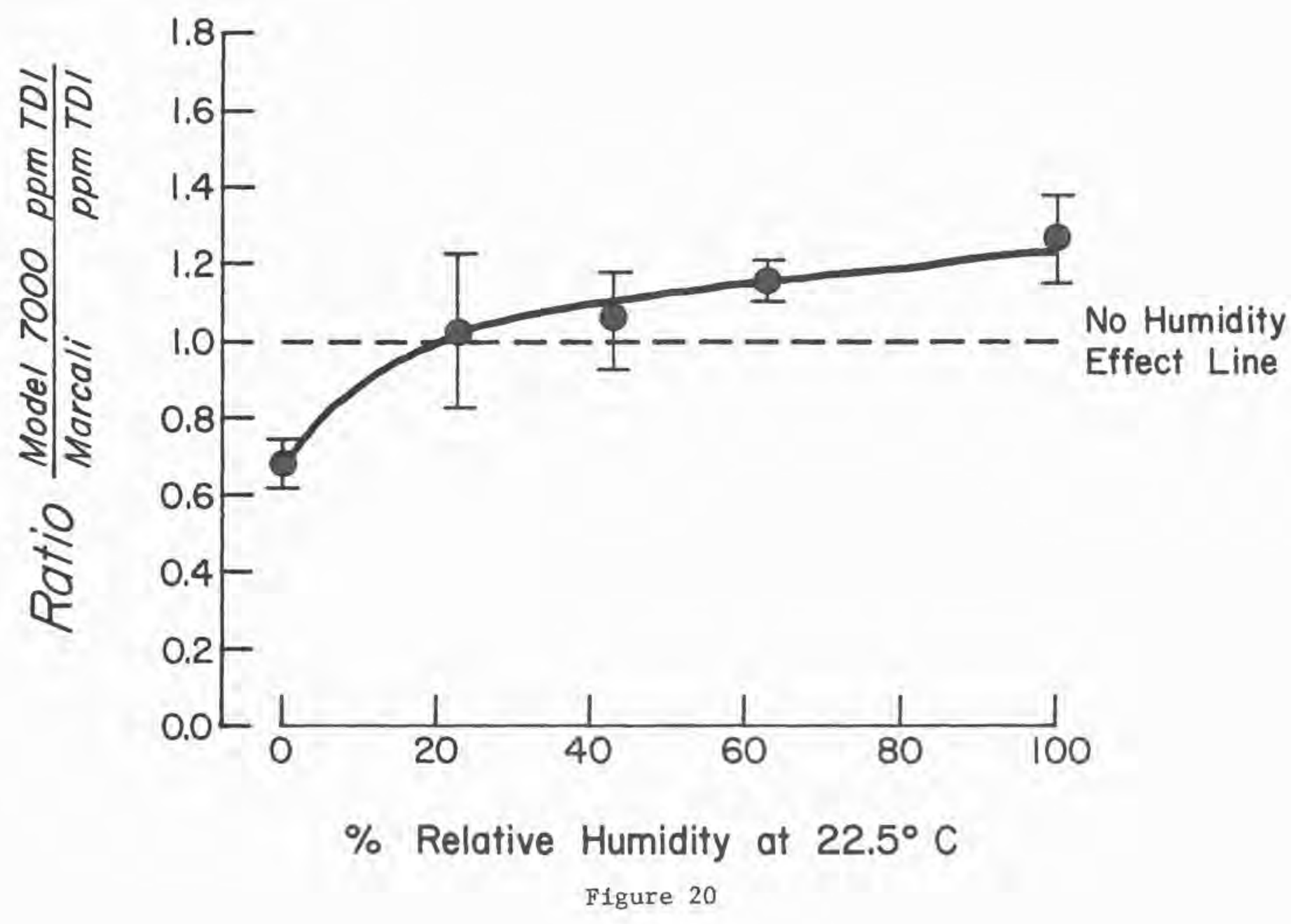




\section{DISTANCE BETWEEN SELECTED JOBS}

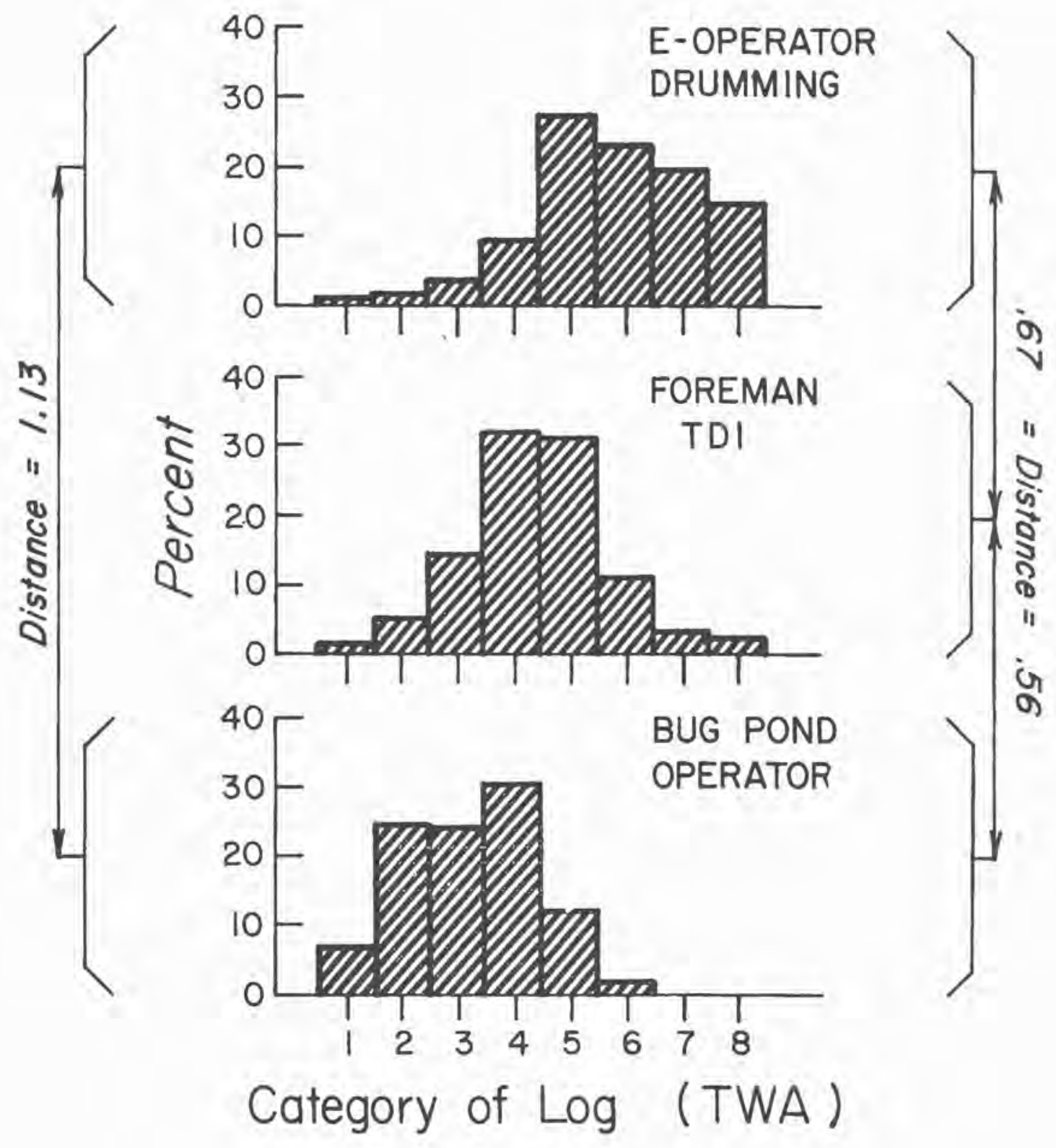

Figure 21 


\section{DISTANCE BETWEEN SELECTED JOBS}

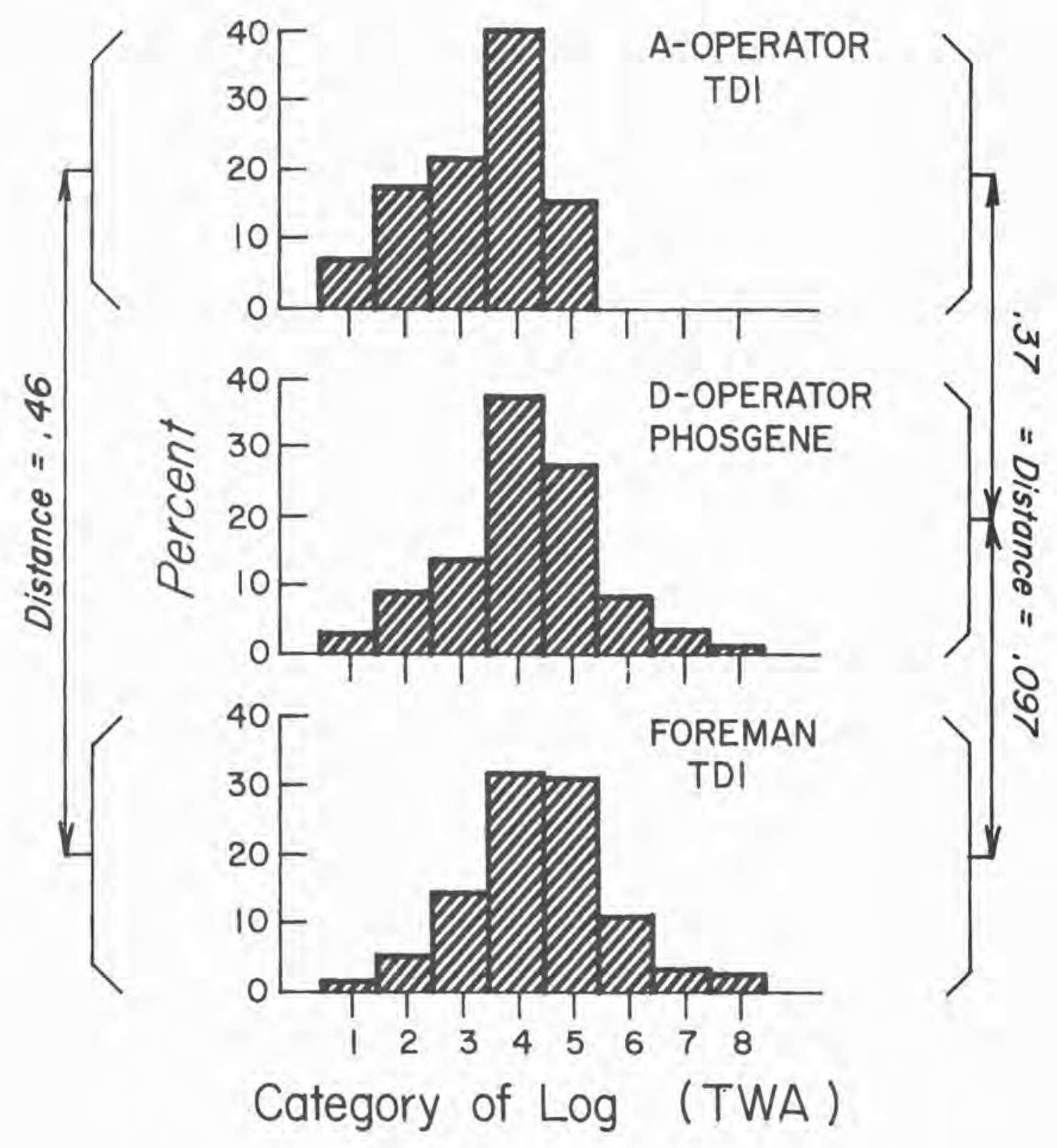

Figure 22 
REPRINTS INCLUDED IN NIOSH FINAL REPORT - 10/12/79

1. Respiratory Effects in Toluene Dilsocyanate Manufacture: A Multidisciplinary Approach - Wei11, Salvaggio, Neilson, Butcher, Ziskind

2. Longitudinal Study of Workers Employed in the Manufacture of TolueneDiisocyanate - Butcher, Jones, 0'Neil, Glindmeyer, Diem, Dharmarajan, Weil1, Salvaggio

3. Environmental characterization of toluene dilsocyanate (TDI) in a manufacturing plant - Dharmarajan, Weill, Self

4. Physical state of airborne $p \cdot p^{\prime}$ diphenylmethane difsocyanate (MDI) and its measurement - Dharmarajan and We111

5. Occupational Exposures to Methylene Bisphenylisocyanate (MDI): Gaseous or Aerosol - Dharmarajan

6. Analysis of Toluene Difsocyanate (TDI) and $p \cdot p^{\prime}-D i p h e n y l m e t h a n e$ Dilsocyanate (MDI) in Air - Dharmarafan

7. The in vitro effect of toluene dilsocyanate on lymphocyte cyclic adenosine monophosphate production by isoproterenol, prostaglandin, and histamine - Davies, Butcher, O'Neil, Salvagglo

8. Occupational asthma caused by low molecular weight chemical agents Davies, Butcher, Salvaggio

9. Occupational Asthma - Karr, Davies, Butcher, Lehrer, Wilson, Dharmarajan, Salvagg10

10. Toluene difsocyanate (TDI) pulmonary disease: Imounologic and Inhalation challenge studies - Butcher, Salvaggio, We111, Ziskind

11. Toluene difsocyanate Pulmonary Disease: Immunopharmacologic and Mecholy1 Challenge Studies - Butcher, Salvaggio, O'Ne11, Weil1, Garg

12. Inhalation challenge and pharmacologic studies of toluene dilsocyanate (TDI) - sensitive workers - Butcher, Karr, 0'Ne11, Wilson, Dharmarajan, Salvaggto, Weill

13. Inhalation challenge testing with toluene difsocyanate (IDI) Butcher

14. Radioallergosorbent Testing (RAST) of TDI Reactive Individuals using p-Tolyl Isocyanate (TMI) Antigen - Butcher, o'Neil, Śalvaggio

15. A new method for the generation of standard atmospheres of organo Isocyanates - Dharmarajan, Rando. 

DEPARTMENT OF HEALTH AND HUMAN SERVICES

PUBLIC HEALTH SERVICE

CENTERS FOR DISEASE CONTROL

NATIONAL INSTITUTE FOR OCCUPATIONAL SAFETY AND HEALTH ROBERT A. TAFT LABORATORIES

4676 COLUMBIA PARKWAY, CINCINNATI, OHIO 45226

OFFICIAL BUSINESS

PENALTY FOR PRIVATE USE. $\$ 300$
Special Fourth Class-Book

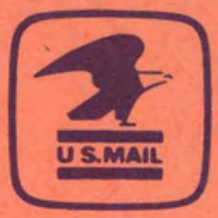

POSTAGE AND FEES PAID U.S. DEPARTMENT OF HHS HHS 396 